
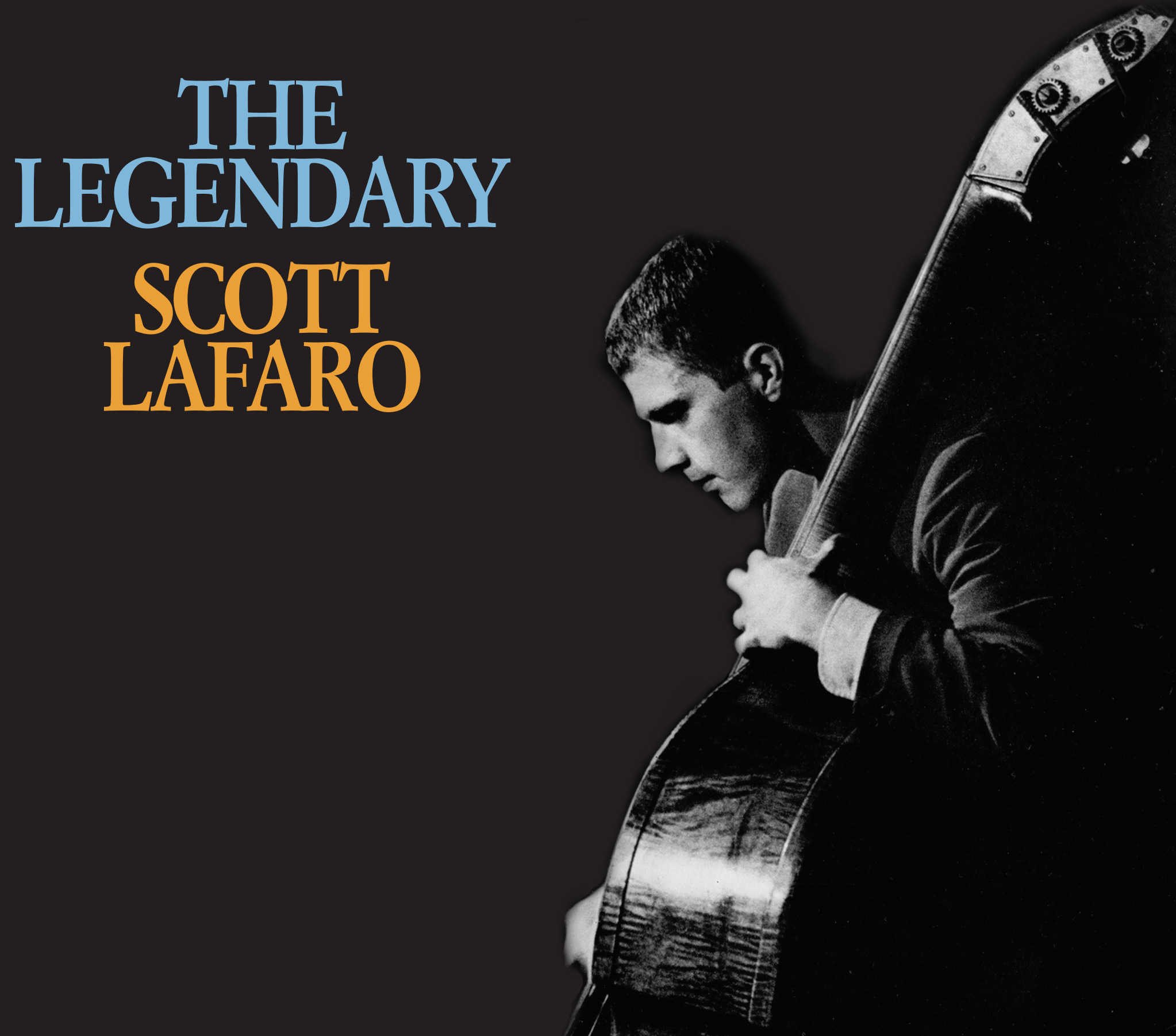


\title{
AN ANALYSIS OF THE BASS PLAYING OF SCOTT LAFARO AS PART OF THE BILL EVANS TRIO $1959-1961$
}

\author{
ROWAN CLARK
}

A thesis submitted to Massey University and Victoria University of Wellington in (partial)* fulfilment of the Master of Music (Performance)

New Zealand School of Music 
First published 2014

(C) Copyright: Rowan Clark, 2014 


\section{ABSTRACT}

Scott LaFaro is widely regarded as a highly interactive bass player, and within the context of the Bill Evans Trio it is commonly believed he was able to cast aside the traditional time keeping role of the jazz bassist.

His considerable reputation seems to rest on this understanding, but as this exegesis aims to show, the general understanding of his legacy within jazz history is open to question

More broadly, this exegesis highlights the fact that any claims about his legacy are supported by very limited analysis of his techniques and approaches, rendering any absolute portrayal of LaFaro misleading.

This exegesis aims to provide a thorough analysis of LaFaro's performances within the Bill Evans Trio. By analysing a representative sample of his work in that context, I hope to discover common techniques and traits that LaFaro employed on a regular basis and which characterise his unique approach to bass playing within a small jazz ensemble.

With the identification of these characteristics, a clearer picture of Scott LaFaro can begin to emerge, as can a more accurate understanding of his legacy. 



\section{ACKNOWLEDGEMENTS:}

I have been fortunate to work with some incredibly talented musicians over the course of this project.

Enormous thanks go to Anita Schwabe and Roger Sellers for their brilliant musicianship, guidance and friendship. And to Chris Buckland and Lex French for expanding the trio's scope!

Thanks also to Jemma Buckland for her eagle eye design and editing skills during the final stages of the thesis.

To Matthew Cave and Tom Warrington I owe a debt of gratitude for their continued friendship and guidance on our shared passion for all things bass. It was - and continues to be - a great adventure.

I have especially enjoyed the guidance, gentle advice and thought provoking dialogue provided by Norman Meehan as my academic supervisor.

I would like to thank my parents, Liz and Brett, and my brother Tristan for their absolute support and encouragement.

And finally the biggest thanks go to my wife Janina for her never failing support and love. 



\section{TABLE OF CONTENTS}

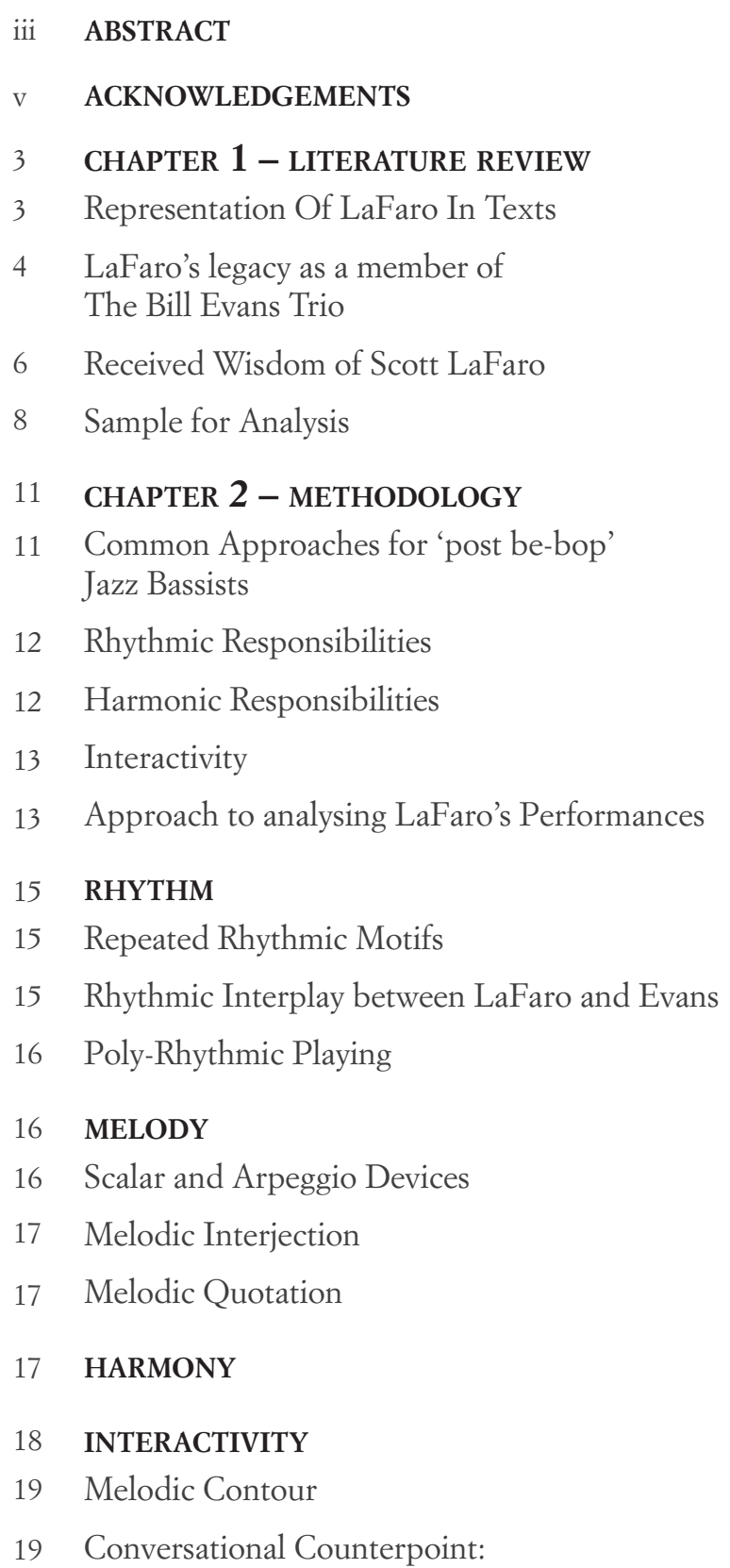

20 CHAPTER 3 - ANALYSIS

20 RHYTHM

20 Rhythmic Interactivity:

25 Repetitive Rhythmic Motifs

26 Similar Rhythmic Patterns used in the same performance

29 Similar Rhythmic Patterns used in multiple performances

31 POLYRHYTHMIC DEVICES

31 Quarter Note Triplet Polyrhythms

34 Eighth Note Triplet Polyrhythms

35 Dotted Quarter Note Polyrhythms

39 INTERACTIVITY

39 Conversational Counterpoint (Yes and...)

40 MELODIC CONTOUR:

45 Mimesis

50 MELODY:

50 Common Scalar and Arpeggio Motifs

55 Melodic Quotation

58 Melodic Interjections

68 HARMONY:

68 Basic Substitution

72 Harmonic Conversation

73 CHAPTER 4 - CONCLUSION

75 CHAPTER 5 - APPENDIX 1: BIBLIOGRAPHY

77 CHAPTER 6 - APPENDIX 2:

FULL TRANSCRIPTIONS

202 CHAPTER 7 - APPENDIX 3: RECORDINGS 



\section{LITERATURE REVIEW}

Received wisdom about Scott LaFaro suggests that he was a pioneer in his approach to jazz bass playing. Even though his professional career was relatively short - six years between 1955 and 1961 - he managed to record and perform with some of the most influential musicians in jazz at that time.

While LaFaro's résumé is impressive and varied, most commentators identify his work within the Bill Evans Trio as being his most influential and innovative. This chapter is an overview of both LaFaro's and the trio's reputation as recorded in numerous historic and academic texts. These texts make claims about the significance of LaFaro's work and his place within jazz history. In my overview I will also include published comments and reflections from musicians who have been influenced by both LaFaro and the trio.

\section{REPRESENTATION OF LAFARO IN JAZZ HISTORY TEXTS}

LaFaro is generally presented as a significant bassist within the continuum of jazz history and the term "virtuoso" is regularly attached to analysis of LaFaro's performances. ${ }^{1}$ His technique "set the pace for a whole school of modern jazz bassists who possessed spectacular instrumental facility like his" and opened the door to more intricate and exciting performances from following generations of bassists. ${ }^{2}$

Numerous jazz bassists echo these comments. Eddie Gomez, who was to play with The Bill Evans Trio in the late 1960's, commented that LaFaro's performances "really showed clearly what the bass was going to be doing for a long time to come." ${ }^{3}$ Bassist Jim Atlas was also in awe of LaFaro's innovative facility, commenting, “[LaFaro] would play Charlie Parker heads... We'd never heard anything like that on a bass." ${ }^{4}$

And shortly after his death, LaFaro was featured in Downbeat magazine with a short eulogy paying tribute to his achievements:

Scott LaFaro's development was beginning to pass belief. With an incredible bass technique, be left musicians open-mouthed. And the general public was beginning to get the message...5

\footnotetext{
1 Keith Shadwick, Bill Evans, Everything Happens To Me: A Musical Biography, (San Francisco: Backbeat Books, 2002), 82; David Hunt, The Contemporary Approach to Jazz Bass Playing, Jazz and Pop, 6/22 (1969), 18; Helene LaFaro-Fernandez, Jade Visions: The Life and Music of Scott LaFaro, (Texas: University of North Texas Press, 2009), 172; Paul Bley and David Lee, Stopping Time, (Quebec: Vehicule Press, 1999), 69; Andrew Gilbert, Bill Evans: Sunday at The Village Vanguard 1961, in 1001 Albums You Must Hear Before You Die, ed. Robert Dimery, (London: Quintet Publishing Ltd., 2006$), 53$.

2 Mark C Gridley, Jazz Styles: History and Analysis, (New Jersey: Prentice-Hall Inc, 1994), 307.

3 Marian McPartland, Bill Evans Genius - All In Good Time, (New York: Oxford University Press, 1987), 124.

4 John Bany, The Legendary Scott LaFaro, Bass World 14/3 (1988), 39.

5 Anon, A Light Gone Out, Downbeat (August 19, 1961), 13. Obituary with remembrances by Marian McPartland and Ray Brown.
} 
In the same issue, bass legend Ray Brown commented that LaFaro's death is "going to set the instrument back ten years. It will be that long before anyone catches up with what he was doing." ${ }^{6}$

One significant observation that has been widely discussed was the technical agility LaFaro possessed. LaFaro's speed and dexterity was, at that time, unique amongst bass players, so much so that listeners observed, "this bass player plays the bass like a guitar." It is claimed that in order to produce these high tempo phrases LaFaro "pioneered using more than one or two fingers to pluck the bass strings." 8 In previous generations, bassists usually played walking bass lines with the use of just the index finger to pluck the string on each quarter note. However, by quickly alternating between two fingers plucking the strings, "LaFaro's new technique lent added speed and allowed greater intricacy and continuity in his lines."

Another significant observation made in regard to LaFaro's advanced technique is his use of the higher register (thumb position) on the double bass. Historian Alyn Shipton comments on LaFaro's performance in Waltz For Debby where "he launches into a clearly articulated solo that marks out new territory in jazz bass playing, both in terms of the high register he uses and the speed of his execution. His accuracy and attack are both spellbinding." 10

These comments about LaFaro's technical prowess on the double bass indicate that he was a pioneer in advancing the role of jazz bassists. His technical facility at the time is presented as being unique and extraordinary within jazz circles, and his arrival on the scene is still considered a watershed moment in the evolution of the jazz bassist.

\section{LAFARO'S LEGACY AS A MEMBER OF THE BILL EVANS TRIO}

As discussed, LaFaro's legacy is usually linked to his work as a member of the Bill Evans Trio. With pianist Evans and drummer Paul Motian, LaFaro produced "music which, more than most in jazz literature, continues to provoke marvel and endless study by listeners and musicians alike." ${ }^{11}$ The trio are credited as the ensemble that "loosened the common practices of the bop style rhythm section which had become standard during the 1940's and 50's... thereby emancipating the piano, bass and drum roles." ${ }^{2}$ LaFaro "broke the chains of how to support" the ensemble and became "an interactive, counterpunctive, melodic contributor throughout the music." 13

\footnotetext{
6 Anon, Downbeat (1961), 13.

Ben Sidran, Paul Motian, in Talking Jazz Unlimited Media Ltd, NMX24 (1995).

Gridley, (1994), 306.

9 Gridley, (1994), 306.

10 Alyn Shipton, A New History of Jazz, (New York: The Continuum International Publishing Group Inc, 2010), 646.

11 Richard Cook and Brian Morton, The Penguin Guide to Jazz Recordings: Eighth Edition, (London: Penguin Books Ltd, 2006), 419.

12 Gridley, (1994), 308.

13 Eddie Gomez in LaFaro-Fernandez, (2009), 164.
} 
Bassist Bob Magnusson comments that:

During his tenure with the Bill Evans Trio, Scott developed his greatest musical innovation. When not soloing, the traditional bass role was walking or playing consecutive quarter notes to accompany the piano. Scott, however, developed the function of playing as if a dialogue or conversation with the piano and drums were taking place. While keeping the integrity of the basic function of the bass, this moved the bass to a completely new level. This revolutionary concept is now a standard approach to jazz bass playing. The concepts that he developed and his virtuosic technique continue to be a great influence and a mainstay of jazz bass playing today. ${ }^{14}$

Other commentators agree with Magnusson's analysis of LaFaro's approach. That LaFaro created dialogue within the trio is the most common claim I have found in reviewing the literature. In an article entitled The contemporary approach to jazz bass (1969), author David Hunt claims that LaFaro pioneered the conversational approach; "a free but organized form of interplay... with the structure of each composition and the combined intuition of all group players serving as guideposts to determine artistic direction."15

Some writers claim that the conversational approach of the trio originally came from Evans, who "consciously tried to develop an interplay among the members of the trio. By developing an improvisational style that utilizes silence much more than the earlier bop pianists, he provided space for the bassist and drummer to interact." ${ }^{16}$ The result of this interactive approach was an evolution for the ensemble whereby "erasing the boundaries between accompanist and soloist, [they] introduced radical new possibilities for small group jazz." ${ }^{17}$

In a number of individual interviews Evans and LaFaro address the approach and goals each had for the ensemble. The most common factor that they discuss regarding their approach is the use of simultaneous improvisation.

In 1959, the year the trio recorded their first album together, Evans is on record expressing his hope that "the trio will grow in the direction of simultaneous improvisation rather than just one guy blowing followed by another guy blowing" ${ }^{18}$ To clarify this comment, Evans is referring to the common approach of bop era ensembles, where musicians - often horn players - take turns soloing while the rhythm section provided a solid platform for the soloist to perform with.

14 Bob Magnusson in LaFaro-Fernandez, (2009), 172.

15 Hunt, (1969), 18.

16 Stephen Widenhofer, Bill Evans: An Analytical Study of his Improvisational Style Through Selected Transcriptions, Doctoral diss., University of Northern

Colorado (1988) 72-73.

17 Gilbert, (2006), 53

18 Nathan Hentoff, Introducing Bill Evans, The Jazz Review, 2/9 (1959), 26. 
By the late 1950's a new approach to time keeping was beginning to gain momentum. LaFaro "had become bored by laying out quarter notes one beat after the next [sic], and had begun inserting other kinds of figures. There was a feeling in the air that if everybody kept time in his head, nobody would have to state it explicitly." 19

An interview from 1960 finds LaFaro reflecting on the approach of the trio:

In the trio we were each contributing something and really improvising together, each playing melodic and rhythmic phrases. ${ }^{20}$

These comments indicate that from their formation as an ensemble, the trio had a common goal, and an ambition to approach their performances in a new and distinctly progressive manner. To perform his part within this new approach, LaFaro intended to explore alternate approaches from the more traditional roles that jazz bassists had played in previous generations of small jazz ensembles.

\section{RECEIVED WISDOM OF SCOTT LAFARO}

As mentioned earlier, the conversational approach the trio had within their performances is discussed at great length throughout the majority of the texts considered for this project. This emphasis suggests that the trio spent a significant amount of their performances musically reacting to each other's playing.

In the Bill Evans biography Everything Happens To Me (2002) author Keith Shadwick describes LaFaro's approach as providing counterpoint underneath Evans's solos. Shadwick goes on to claim that "the major musical reason for this extraordinary level of group intercommunication and creativity was the ability of LaFaro to match and, certainly in rhythmic areas, outpace Evans in terms of the ideas fed in for counterpoint" ${ }^{21}$ This suggests that a common factor in LaFaro's performances was to feed melodic and rhythmic ideas to Evans, ideas to which Evans responded and potentially elaborated in a conversational manner.

Author Mark C Gridley shares this theory:

While Evans was playing a written melody or improvising a fresh line, LaFaro contributed a great diversity of musical ideas. He would throw in melodic figures of his own. He would mimic or answer Evans. Sometimes be would underscore the figures Evans and Motian played.22

These observations suggest my own analysis should consider a number of different interactive or communicative techniques that both LaFaro and Evans may have used.

19 James Collier, The Making Of Jazz: A Comprehensive History, (London: Granada Publishing Ltd, 1978), 395.

20 Martin Williams, Introducing Scott LaFaro, The Jazz Review, 3 (1960), 16.

21 Shadwick, (2002), 89.

22 Gridley (1994), 307. 
LaFaro commented in 1960, "Bill gives the bass harmonic freedom because of the way he voices [his chords.]" ${ }^{23}$ One explanation I have found to help illustrate this approach is an observation of Evans's playing where "he omitted the root tone of the chord, creating a literally bottomless range of improvisatory choices." ${ }^{24}$ It seems LaFaro was free to interpret the harmony of a piece and could influence its direction by substituting other notes underneath Evans's chords.

Pianist Mark Levine concurs with these observations. He explains that while "Art Tatum, Errol Garner and Ahmad Jamal occasionally played non-root position chords in the mid-1950's, Bill Evans [amongst others] developed them further and by the late-1950's were playing [rootless chords] that often included extensions such as ninths and thirteenths. Before that, most bebop pianists followed Bud Powell's lead, playing two or three note root position voicings" that restricted bassists to the chord progression of a song. ${ }^{25}$ Levine goes on to mention, "bass players don't always play the root" of a chord, which allows them to reinterpret the written harmonic structure of a song. ${ }^{26}$

These comments reveal another facet of LaFaro's approach, and could indicate a significant step in the evolution of jazz bass playing. The traditional approach of a bop-era bassist is to continually outline the harmonic progression of a song, regularly stating the root note at the point of a harmonic change. ${ }^{27}$ An abandonment of this principle is an interesting approach, and one that could be confirmed relatively easily with the aid of transcriptions.

In the Bill Evans biography How My Heart Sings author Peter Pettinger gestures towards the sequences that LaFaro regularly performs. "LaFaro created all manner of patterns from note one... he had climbed a ladder to dizzy heights, in sequences that sound roughly like triplets but are actually resolved in a quite independent meter." ${ }^{28}$ This technique is of particular relevance to this project as analysis across a wide sample of data could identify a number of different sequences used repeatedly by LaFaro. Whether these sequences are melodic or rhythmic, it should be possible to identify common motifs that LaFaro may have employed across numerous performances.

\footnotetext{
23 Williams, (1960), 16.

24 Matt Schudel, A Master Fades to Obscurity, Sun-Sentinel, ed. Matt Schudel (Fort Lauderdale: Tribune Co. 1994) 4.

25 Mark Levine, The Jazz Piano Book, (Petaluma California: Sher Music Co. 1989), 41.

26 Levine, (1989), 43.

27 A detailed description of the traditional role a jazz bassist is expected to adhere to is presented in chapter two.

28 Peter Pettinger, Bill Evans: How My Heart Sings, (New Haven: Yale University Press, 1998), 93.
} 
However, even though LaFaro is widely discussed in historic and academic texts, and is continually praised by musicians as a pioneer, there is a distinct lack of analysis of his performances. ${ }^{29}$ Numerous books feature full transcriptions of LaFaro's playing, but don't contain any kind of analysis or explanation of what he specifically performed from song to song. ${ }^{30}$

Where there is analysis of LaFaro's playing, it is frequently brief and underwhelming. For example, the analysis chapter His Music II - included in the Scott LaFaro biography Jade Visions - serves more as an introduction to LaFaro's playing rather than providing a substantial illustration of his musical abilities. ${ }^{31}$ Jeff Campbell gestures towards various approaches used by LaFaro, but only provides singular examples to back up his assertions. There is no evidence that suggests he has taken his findings from a wide sample, nor does he provide notated data to back up his claims. He seems to gesture towards LaFaro's performances as "exemplifying his abilities in the context of the trio's spontaneous improvisational style." 32

I can appreciate that these texts are not designed to offer a comprehensive analysis of LaFaro's playing. Unfortunately, the vague generalisations found within these sources are the most substantial analyses I have found to date. ${ }^{33}$ This reinforces my belief that more research into LaFaro's performances is warranted in order to reveal his unique approach as a jazz bassist, and also to provide substantial evidence to reinforce the claims made about his significance.

\section{SAMPLE FOR ANALYSIS}

I recall hearing Scott LaFaro for the first time when I was teenager at high school. A teacher gave me a copy of the live album Waltz For Debby and told me to listen carefully to what the bassist was playing during the piano solos. I clearly remember being astounded by the performance, and was drawn in by the energy LaFaro was projecting in each track. Over time I became acquainted with further albums produced by the trio, but it was always the live tracks from the Village Vanguard sessions that I kept gravitating towards. The energy and freedom that LaFaro commands had me hooked then, and it remains that way to this day.

This experience is reflected in the choices that make up my sample. Four of the five tracks come from the live recordings made on June $25^{\text {th }}, 1961$, and which continue to resonate with me, and amongst the wider jazz audience. ${ }^{34}$ Publications also present these live albums as being LaFaro's - and the trio's - pinnacle, with which they are forever associated. ${ }^{35}$

29 Robert Hodson's analysis of Autumn Leaves (2007) is an exception to this comment. A more detailed explanation is presented later in this chapter.

30 Hal Leonard, The Bill Evans Trio Volume 1, (Milwaukee, Hal Leonard Corp. 2003); Phil Palombi, Scott LaFaro: 15 Solo Transcriptions, (New York, Palombi Music, 2003)

31 LaFaro-Fernandez, (2009), 155-200.

32 LaFaro-Fernandez, (2009), 197.

33 LaFaro-Fernandez, (2009), 155-200.

34 Gilbert, (2006), 53.

35 Shipton, (2010), 646; Gilbert, (2006), 53. 
The four songs I have included in my sample from these recordings are:

- Solar

- Alice In Wonderland (Take 2)

- Waltz For Debby (Take 2)

- Gloria's Step (Take 2)

Through critical listening I have determined that LaFaro's performances on these tracks are among his most accomplished. His performances are rhythmically intense and also include passages of interaction and counterpoint with Evans. It is also interesting that each of these songs is performed at similar tempi. While both albums recorded during this engagement contain numerous slow tempo ballads, it is during these medium tempo numbers that LaFaro performs with increased activity.

The final song to complete my sample is the trio's performance of Nardis taken from the 1961 album Explorations. The main reason for including a performance taken from outside the live albums is so I can compare the trio's performance and approach from both a studio environment as well as a live concert date. I believe that Nardis sufficiently represents the overall approach LaFaro adopted on the Explorations album. Initial listening has identified that LaFaro performs with a broken rhythmic approach throughout the performance, and also includes some harmonic devices that seem to challenge the written harmony of the song.

While Nardis does make use of some unusual (for the time) harmonic organisation, it does adhere to a 32-measure AABA form and includes a number of conventional cadences.

It should also be noted that the sample does not include any tracks from the trio's 1959 debut album Portrait In Jazz. The primary reason I have avoided performances from this album is because LaFaro's approach on those sessions closely resembles that of a traditional bassist. For most of the album he performs walking bass lines that would be considered a standard approach for any jazz bassist. ${ }^{36}$ For this project I am focussed on discovering the approach LaFaro used to break from these traditions, therefore the performances taken from the live albums are a more appropriate choice.

However, the ensemble's performance on Autumn Leaves from Portrait In Jazz is distinctly different to the approach they employ for the rest of the album. This performance contains the trio's first recorded attempt at a conversational dialogue and allows them to respond at will to each other's musical phrases, improvising freely without being restricted by the traditional roles that they are usually expected to follow.

36 Chapter two contains a detailed description of the role a conventional jazz bassist would be expected to perform as part of a small ensemble. 
While the approach performed in this song is relevant for my project, I have not included it in my sample as a substantial analysis has already been published. ${ }^{37}$ Robert Hodson's review of Autumn Leaves details how the trio:

structure and organize their improvised performance by continually responding to the gestures and motives of both their own improvised solos as well as those of the others in the ensemble. Because... these responses are freed from the constraints of standardized instrumental roles, the musicians are free to respond to one another melodically, using processes of motivic and gestural imitation, transformation, and contrast..$^{38}$

Hodson begins by analysing the musicians' performance in relation to both the individual chord changes of the song, as well as the broader key centres that exist. It seems that LaFaro employs both of these approaches during his performance with Hodson concluding, "at times, he relates the content of his improvisation to the local harmony, at other times he thinks more globally [when] he spins out a melody based on the key centre." 39

Hodson goes on to detail the development of the piano solo, discussing how Evans builds "his improvisation by stringing together transposed and rhythmically transformed motivic echoes" of his opening statement. ${ }^{40}$ Finally he analyses the interaction between the musicians. He focuses especially on the relationship between Evans and LaFaro, describing how "there is a continual give-and-take between them, and [how] their phrases usually dovetail, creating a sense of continual motion and interplay." ${ }^{41}$

In the following chapter I shall discuss the analytical tools I am going to use in my investigations. I shall also present an overview of the musical responsibilities jazz bassists have within a small ensemble, and then question whether LaFaro either followed or abandoned these procedures.

37 Robert Hodson, Interaction, Improvisation and Interplay in Jazz, (New York: Routledge, 2007), 119-144.

38 Hodson, (2007), 135

39 Hodson, (2007), 135

40 Hodson, (2007), 127

41 Hodson, (2007), 128 
Jazz is broad enough to allow for a full range of balance, or lack of balance between the soloist and the other band members. In most jazz groups the soloist's performance has the primacy, and the remainder of the band has the goal of echoing and surrounding this performance with accompaniment. In contrast, a balanced co-creative performance style is demonstrated by a group in which the soloist's performance is less central, and the other band members' improvisational lines are participating in a more democratic dialogue. ${ }^{42}$

As discussed in chapter one, received wisdom about Scott LaFaro indicates that he is considered to have been a pioneer in his approach to jazz bass playing. Numerous musicians and historians have praised his abilities, saying "He proved to be one of the major influences on his instrument" 43 and was a "virtuosic" bassist whose melodic interaction with Bill Evans was unique to the time. ${ }^{44}$ However, there is a significant lack of understanding about exactly what LaFaro performed and how he approached his celebrated role. In this chapter I shall discuss the methods I intend to employ in my attempt to understand LaFaro's methods and approaches within his performances.

\section{COMMON APPROACHES FOR 'POST BE-BOP' JAZZ BASSISTS}

Through critical listening to LaFaro's performances, it is clear that his approach departs from the more traditional role as performed by other noted contemporary bassists including Paul Chambers and Ray Brown. In this next section I discuss the common approaches expected of jazz bassists when performing as part of a small ensemble.

In his book Thinking In Jazz, Paul Berliner describes the role of the rhythm section as "ultimately provid[ing] support for the soloist, whose entrance increases the demands upon their attention and musical sensitivity." 45 This indicates that a bassist - as a member of the rhythm section - is primarily responsible for providing a musical platform for soloists to play over. Effectively, and for most of each performance, the bassist is expected to submit to following and aiding the musical goals of the lead voice in the ensemble. This approach expected from the common bassist affects a number of musical elements within the ensemble.

42 R. Keith Sawyer, Group Creativity, (New Jersey: Lawrence Erlbaum Associates, Inc., 2003), 94.

43 James Collier, The Making Of Jazz: A Comprehensive History, (London: Granada Publishing Ltd, 1978), 395.

44 Helene LaFaro-Fernandez, Jade Visions: The Life and Music of Scott LaFaro, (Texas: University of North Texas Press, 2009), 232-236.

45 Paul Berliner, Thinking In Jazz: The Infinite Art of Improvisation, (Chicago: The University of Chicago Press, 1994 ), 357. 


\section{RHYTHMIC RESPONSIBILITIES:}

The responsibility as rhythmic accompanist is the most important task a bassist must fulfil within a small jazz ensemble. According to Wynton Marsalis "the bass player is the key. He needs to keep a steady pulse, to provide the bottom and to hold the music together." ${ }^{46}$ Specifically, his rhythmic role can be defined as providing "prevalent quarter note motion, four beats to the bar... beats 2 and 4 tend to be played more forcefully than beats 1 and 3, and rhythmic embellishment of the four quarter notes tend not to disturb the basic quarter note pulse for very long. ${ }^{47}$ This is generally referred to as a walking bass line.

These descriptions strongly indicate that there is an expectation that the bassist adheres to a fundamental role as a timekeeper, effectively locking them into a strict accompanist's role. Further to this point, if and when a bassist chooses to stray from this responsibility, it is expected that the excursion not last for long, and that they return to their timekeeping duties promptly.

\section{HARMONIC RESPONSIBILITIES:}

Along with timekeeping responsibilities, bassist's walking lines are to be performed "with some chromatic melodic motion that outlines the harmonic progression clearly." ${ }^{48}$ As described by Jerome Harris, "the bass usually provides the lowest note in a harmonic sonority and consequently is defining the chordal movement." ${ }^{49}$ It seems clear that bassist's walking lines are expected to provide a clear articulation of a song's harmonic structure. However, bassists do not necessarily have to strictly follow a song's written harmonic progression:

Even within the most mainstream setting, musicians make use of chord substitutions, alterations, and chromatic voice leading so frequently that the published chord changes to a tune can be said to serve only as a general framework from which improvisation proceeds. ${ }^{50}$

As a result, bassists may follow another musician's substitutions, or influence the harmonic progression as a song evolves. It is normal for jazz musicians to be sensitive and open to these potential changes, and respond accordingly by following a new harmony suggested by an ensemble member.

\footnotetext{
46 Berliner, (1994), 353.

47 Monson, (1996), 30.

48 Monson, (1996), 30.

49 Monson, (1996), 30.

50 Monson, (1996), 30.
} 


\section{INTERACTIVITY:}

Jazz bassists generally interact with other musicians in performance.

Their "responding figures need not be imitative. In some cases the lines are secondary melodies or riffs." 51 However, if a bass player interjects "too frequently, the rest of the band might turn and stare or otherwise communicate" dissatisfaction. ${ }^{52}$ Clearly there is an underlying expectation that while a bassist can certainly interject ideas from time to time, his or her fundamental role is to retain rhythmic and harmonic forward motion and provide a stable platform for the rest of the ensemble to play with.

As described by Monson and Berliner (and their informants), it seems that a bassist from LaFaro's era would be expected almost exclusively to act as an accompanist within a small ensemble, and musically submit to following the improvisations of the soloist..$^{53}$ This would include all of the rhythmic, harmonic and interactive responsibilities described above. Such an approach would consign the bassist to an almost pre-determined role, performing behind the lead melodic voice of an ensemble with limited room to alter what they play.

\section{APPROACH TO ANALYSING LAFARO'S PERFORMANCES:}

Scott $\mathrm{LaFaro}$ is widely regarded as a pioneer of the modern style of jazz bass playing. In this next section I identify the methods I shall use to analyse his performances, seeking to discover how LaFaro's approach differed from contemporary conventional bassists.

Critical listening at this stage reveals LaFaro makes only limited use of walking bass lines. This observation poses the question: what rhythmic and melodic devices does he use in their place? Does he challenge and change the harmonic construction of the songs he performs? Can I discover evidence of the interactive approach that he and Evans are famous for?

In my attempt to answer these questions, I draw on two kinds of analysis. The first is a formulaic analysis that seeks to uncover any common devices and motifs that LaFaro used across a range of performances. This includes consideration of common melodic shapes and scalar devices, repetitive rhythmic motifs, and any harmonic substitutions that LaFaro may have regularly employed.

Second, I will draw on the theories of R. Keith Sawyer and his work on group creativity to examine interactive aspects of LaFaro's performances. As discussed in chapter one, a large part of LaFaro's reputation rests on claims that his playing was highly communicative and interactive. Discovering these interactive moments within LaFaro's performances forms a large part of my analysis.

51 Monson, (1996), 32.

52 Monson, (1996), 32.

53 Further detailed analysis of the common responsibilities performed by bassists within small jazz ensembles can be found in Saying Something (1996) by Ingrid Monson and Thinking In Jazz (1994) by Paul Berliner. 
Sawyer discusses a number of different interactive theories and identifies various techniques that are used across numerous improvisational art forms. In particular, Sawyer examines musicians' relationships with the emergent in improvised contexts.

The emergent constrains a given performance act on several musical planes simultaneously: tone or timbre, mode and scale permitted, rhythmic patterns, specific motifs, stylistic references, and references to other performances or songs. At any given moment these different planes may be differentially [sic] constrained. Thus as with conversation - where a participant is required to maintain coherence with the linguistic emergent - a musician's creativity is constrained by the musical emergent. ${ }^{54}$

I will analyse LaFaro's performances in relation to the emergent music that the ensemble produces within each performance. ${ }^{55}$ For example, do his performances follow (or lead) the modes and scales played by Bill Evans?

In an interview from 1980, Bill Evans discussed working with bassist Gary Peacock. When Peacock joined the Bill Evans trio in 1964, "he fit right into what we were doing, and yet when his solo time came he went into complete [harmonic and rhythmic] abstraction, and it didn't really fit." ${ }^{56}$ Later in the same interview Evans asserts that "following the form [of a song] gives substance to what's happening. It brings return of idea... in the right places. Whereas if you say, "I'm going to start with nothing and go anywhere," you don't have that kind of fibre in the music." ${ }^{7}$

This suggests that the ensemble's approach under Evans's leadership was to adhere to the formal harmonic and structural landmarks of each composition. The emergent produced from this kind of approach probably substantially constrained LaFaro's own performance and limited his creativity. He would be forced to follow the emergent (which was substantially constrained by Evans's fidelity to the agreed changes) quite strictly, keeping his own performance closely related to Evans's own improvisations.

\footnotetext{
54 Sawyer, (2003), 95.

55 All transcriptions have been checked by the author and appear to be accurate.

56 Jim Aikin, Bill Evans: The Essence of Jazz Piano, Contemporary Keyboard, (1980), 50.

57 Aikin, (1980), 54.
} 


\section{RHYTHM}

\section{REPEATED RHYTHMIC MOTIFS}

LaFaro's rhythmic approach as an accompanist is a big part of what sets him apart from countless other bassists who preceded him in jazz. Through critical listening, I have identified that LaFaro almost completely abandoned performing walking bass lines while accompanying Bill Evans in the sample considered. However, as discussed in chapter one, very little documentation exists detailing what LaFaro did in place of the traditional approaches of jazz bassists of earlier eras.

My first step is to analyse transcriptions of LaFaro's performances for any sort of repetitive rhythmic patterns that he may use. At first, I shall be looking for evidence of the same motif being repeatedly used in the same performance.

Evidence of identical or at least very similar rhythmic patterns in multiple performances of the same song would both identify the motifs that LaFaro used, and may suggest these motifs effectively replaced the traditional walking bass line in LaFaro's performances. By considering both frequency and duration of these motifs (if present) it will be possible to determine if this is reasonable.

The next step in my analysis shall involve comparing these rhythmic patterns across my entire sample. If I can find evidence that LaFaro performed similar rhythmic motifs across numerous songs, it could be deduced that he could perform them on cue, using them as a soloist would use common jazz language in a solo. Paul Berliner describes how "in groups that perform together frequently, players sometimes develop a core of common patterns that they periodically reintroduce in performances to stimulate interplay." 58

In light of this, and given the ensemble enjoyed stable personnel for three years, it is reasonable to assume that I will find common rhythmic motifs within LaFaro's performances. Identification of these common patterns in LaFaro's performances could also identify passages of interplay between the musicians.

\section{RHYTHMIC INTERPLAY BETWEEN LAFARO AND EVANS: 99}

Considering Berliner's comments about interplay in the above section, I am curious to investigate whether LaFaro and Evans used rhythmic patterns to stimulate interaction between one another. Within his accompaniment does LaFaro gesture towards the rhythmic phrases of Evans's piano solos? And if so, how does Evans respond to these gestures?

58 Berliner, (1994), 364.

59 This section is a more liberal category than the Mimesis analysis that is discussed later in this chapter. 
I shall comment on the duration of these passages, seeking to discover whether this approach was reciprocated between the two musicians for long periods of time. Evidence of a long duration would indicate that the two musicians were receptive to this style of interaction and were therefore approaching the performance with a willingness to engage in rhythmic dialogue.

I shall also seek to discover whether LaFaro repeated any of these rhythmic patterns across the rest of my sample. Did some rhythmic motifs stimulate musical interplay more than others? And how often were these phrases used by LaFaro to communicate with Evans?

\section{POLY-RHYTHMIC PLAYING}

I shall also analyse the transcriptions for poly-rhythmic figures in LaFaro's performances. Bassist Chuck Israels - who worked with Evans during the 1960's - explains that polyrhythmic patterns are a common tool used by bassists; "Sometimes, if I were playing a piece in 3/4, I would play two dotted quarter notes, or I would play four quarter notes in a $3 / 4$ measure. And if I laid them in there as an obvious polyrhythm, three against four, that was playing time to me. And that was the way that Bill Evans thought about it, too." ${ }^{60}$ Again, as LaFaro had mostly abandoned the walking bass line accompaniment, he may have employed a poly-rhythmic approach as part of his broken time accompaniment.

Much like the rhythmic motif analysis above, I shall comment on the duration of these figures, and the frequency with which LaFaro used them. I shall also attempt to identify any common polyrhythmic patterns that LaFaro used repeatedly within each song, and also across my sample.

\section{MELODY}

As outlined earlier in this chapter, the traditional role of a jazz bassist is to provide accompaniment support to the lead melodic voice within a small ensemble. There is limited opportunity to alter this approach as a bassist is expected to follow the soloist's cues and respond accordingly to aid their performance. However, upon listening to Scott LaFaro perform as part of the Bill Evans Trio, it is clear that his approach differs from the accepted role of the jazz bass player. In this next section I shall outline the melodic devices I will be searching for within LaFaro's performances that reveal ways in which his approach was unconventional.

\section{SCALAR AND ARPEGGIO DEVICES}

Through critical listening, I have identified that LaFaro often performs long scalar passages within his performances. These runs are often performed at quick tempos, and also encompass a large melodic range, beginning in the bottom register, and finishing towards the top of the bass's range. As well as scalar patterns I shall also be searching for any common arpeggiated motifs LaFaro may use. 
For both the scalar and arpeggio devices, I shall attempt to identify any common patterns that may exist across my sample. For example, what scales does LaFaro use during these passages, and do they correspond to the harmony of the song? Do the arpeggiated patterns occur over similar harmonic changes, and if so, do they comprise repetitive digital patterns?

\section{MELODIC INTERJECTION}

My analysis shall also seek to identify any sections where LaFaro plays counterpoint to Evans's melodic lines. I shall be considering passages where, as Evans finishes a phrase, LaFaro's accompaniment becomes more pronounced and prominent as he fills the gap left by the pianist. In these moments, LaFaro's melodic idea becomes the lead voice of the performance. However, as Evans begins his next phrase, I shall analyse whether LaFaro returns to his original accompanists role, or whether he continues playing in a lead voice capacity, effectively establishing improvised polyphony.

\section{MELODIC QUOTATION}

A common device used by jazz musicians is to quote melodies of songs within their performances. Jazz musicians - often horn players - most commonly do this during their solos as a tool to help stimulate interplay and allow the ensemble to respond to the phrase. ${ }^{61} \mathrm{I}$ am curious to see whether LaFaro used this common technique as part of his accompaniment.

\section{HARMONY}

The extent to which LaFaro's approach was advanced for the time can also be revealed through analysis of his approach to interpreting the harmonic content of a piece of music.

I will start by analysing my sample for common harmonic strategies used by LaFaro in his performances. Specifically I shall be investigating whether LaFaro's performances follow the written harmony of the song. Do his bass lines beneath Evans's improvisations follow the contour of the harmonic progression and clearly indicate each chord change, or is he outlining alternative harmonic progressions and employing substitutions on a regular basis?

I shall comment on the extent to which he is, or is not, performing the written harmony. If any substitutions are being made I shall determine whether there is any sort of pattern in regards to where they occur in the form of the song, or whether he makes substitutions over similar chord types each time.

Sawyer (2002) comments, "Each musician is constrained by the emergent, the set of indexical presuppositions, including the key of the piece, the song's harmonic structure, and the indexical entailments projected by the other players." ${ }^{2}$

61 Sawyer, (2003), 32.

62 Sawyer, (2003), 94. 
This description could be easily applied to the role of a traditional bassist's approach as described above. A traditional bassist would be expected to closely follow the indexical landmarks of a song, acknowledging strongly the written harmonic progressions within his performance, and also playing the role of accompanist by respecting the indexical entailments suggested by the soloists' performances.

With this exegesis, I wish to question whether LaFaro was able to break away from all or part of this particular approach within his playing. When Evans is soloing, is LaFaro acknowledging the written harmony of the song they are performing ala a traditional role, or has he broken free of this approach and is creating new harmonic progressions of his own?

Further to this, Sawyer discusses how "in the presence of these [harmonic] constraints, jazz requires each performer to offer something new at each point, ideally something that is suggestive to the other musicians." ${ }^{3}$

This description of musicians offering something new and suggestive to each other indicates a conversational approach within the emerging performances. I am interested in analysing the level of harmonic "conversation" that may exist between Evans and LaFaro. For example, if Evans performs a harmonic substitution within his solo, does LaFaro acknowledge this and change his own playing to accommodate the new harmony? If there is strong evidence of this practice it would again illustrate the advance LaFaro made as a bassist relative to the traditional approach of a small ensemble bassist.

\section{INTERACTIVITY}

There are a number of different approaches I plan to use to analyse the interactive or conversational elements within my sample. Sawyer asserts that "interaction between performers is immediate, durationally [sic] constrained to the moment of creation, and is mediated by musical or verbal signs. The process of group creativity is coincident with the moment of reception and interpretation by other participants." ${ }^{44}$ By analysing LaFaro's performances from different angles suggested by Sawyer's comments, I hope to discover some common devices he employs across a wide range of songs that reveal interaction between the performers.

The first approach I shall use is analysing the transcriptions for evidence of mimesis between LaFaro and Evans. I shall be looking for passages where either Evans or LaFaro imitates precisely a musical phrase that the other has just performed. I shall also be considering whether these passages are "durationally constrained to the moment of creation" and conclude shortly after they are performed. ${ }^{65}$ If so, this would suggest that the two musicians were open to and responded to each other's improvisations. However, in this case, the response does not develop musically over a long passage of time; instead the responder accurately mimics the original phrase before both musicians continue with the performance.

\footnotetext{
63 Sawyer, (2003), 94.

64 Sawyer, (2003), 86.

65 Sawyer, (2003), 86.
} 


\section{MELODIC CONTOUR:}

Next I shall consider the influence LaFaro and Evans have on the melodic contour of each other's phrases. As described by Berliner:

Contour is also an ongoing feature of interplay, as players anticipate and respond to the nuances within each other's evolving shapes, the distinctive hills and valleys of their creations. ${ }^{66}$

As discussed in chapter one, it has been suggested musical interplay was the primary approach employed by LaFaro and Evans during their performances. It follows that I may well find moments of unison melodic contour whereby one of the musicians emulates the shape and direction of their phrase to match that of the other.

\section{CONVERSATIONAL COUNTERPOINT:}

As discussed in chapter one, LaFaro's playing is believed to have provided a strong rhythmic and melodic counterpoint to the improvisations of Evans. ${ }^{67}$ It has been described as LaFaro "feeding" musical ideas to Evans, and having them acknowledged and reciprocated as if a musical conversation were taking place between the two musicians. ${ }^{68}$

My analysis shall search for moments within Evans' solos where the two musicians trade musical phrases. I shall also attempt to determine any common traits that are employed during these moments. For example, I shall look at the length of each phrase, examining whether LaFaro and Evans prefer to trade shorter melodic lines more regularly, or whether they leave space to allow the other a significant opportunity to make strong independent musical statements.

A way of measuring and analysing this approach is to use a principle known as the 'Yes, and...' ${ }^{9}$ rule. Actors who perform with improvised theatre ensembles often employ this principle, creating and elaborating upon verbal passages in real time with a goal to keep the improvisation progressing towards an ultimate resolution. An actor is trained to accept whatever is proposed by other members of the group, and has the responsibility to respond, all while staying firmly within the context of the performance. Sawyer confirms the value of this approach, describing how the actors "always accept what is offered in the prior turn, and then elaborate on it by offering something new to further develop the drama." ${ }^{70}$

66 Berliner, (1994), 371.

67 This section differs from the earlier category Melodic Interjection where I am looking for brief and sudden interjections from LaFaro that occur during brief gaps in Evans's piano solos. Neither musician elaborates upon these brief phrases following their conclusion.

68 Keith Shadwick, Bill Evans, Everything Happens To Me: A Musical Biography, (San Francisco: Backbeat Books, 2002$), 89$.

69 A detailed example can be found in Sawyer, (2003), 33-37.

70 Sawyer, (2003), 36. 
I believe this principle can be used to interpret conversational passages performed by LaFaro and Evans. First I shall search for passages where LaFaro and Evans leave space within their performance to allow the other to respond with their own melodic phrase. It is during these passages that I shall seek evidence of rhythmic, harmonic and melodic contour relationships that are expanded upon by each musician in every responding phrase. For example, as LaFaro finishes his motif with an ascending melodic contour, does Evans begin his next phrase continuing LaFaro's shape? I believe this type of counterpoint is principally aural and could almost be described as "someone finishing your sentence." 71

In the next chapter I shall offer analysis of my sample using these aspirations and tools as my guide.

71 An example of this approach is featured in Monson, (1994), 77. Drummer Ralph Peterson discusses trading melodic ideas with pianist Geri Allen, including quoting the melody from Salt Peanuts, a well-known bebop standard written by Dizzy Gillespie. 
In this chapter I discuss the results of my findings as laid out in chapter two. I have presented the results in four primary categories: Rhythm, Interactivity, Melody and Harmony. Each of these sections contains a number of sub-headings where I present my examples.

\section{RHYTHM}

\section{RHYTHMIC INTERACTIVITY:}

As described in chapter two (p.26), these examples of rhythmic gesturing illustrate either LaFaro or Evans loosely imitating each other's rhythmic phrases. These gestures - or imitations - occur either immediately following the original phrase, or within a few bars. ${ }^{72}$

\section{Gloria's Step:}

In this first example Evans plays a descending melody that features a row of quarter note triplets. LaFaro appears to pick up on this rhythmic idea and in the second bar he uses the same quarter note triplet figure as the primary rhythm of his phrase.

Chorus C Bars 4-6

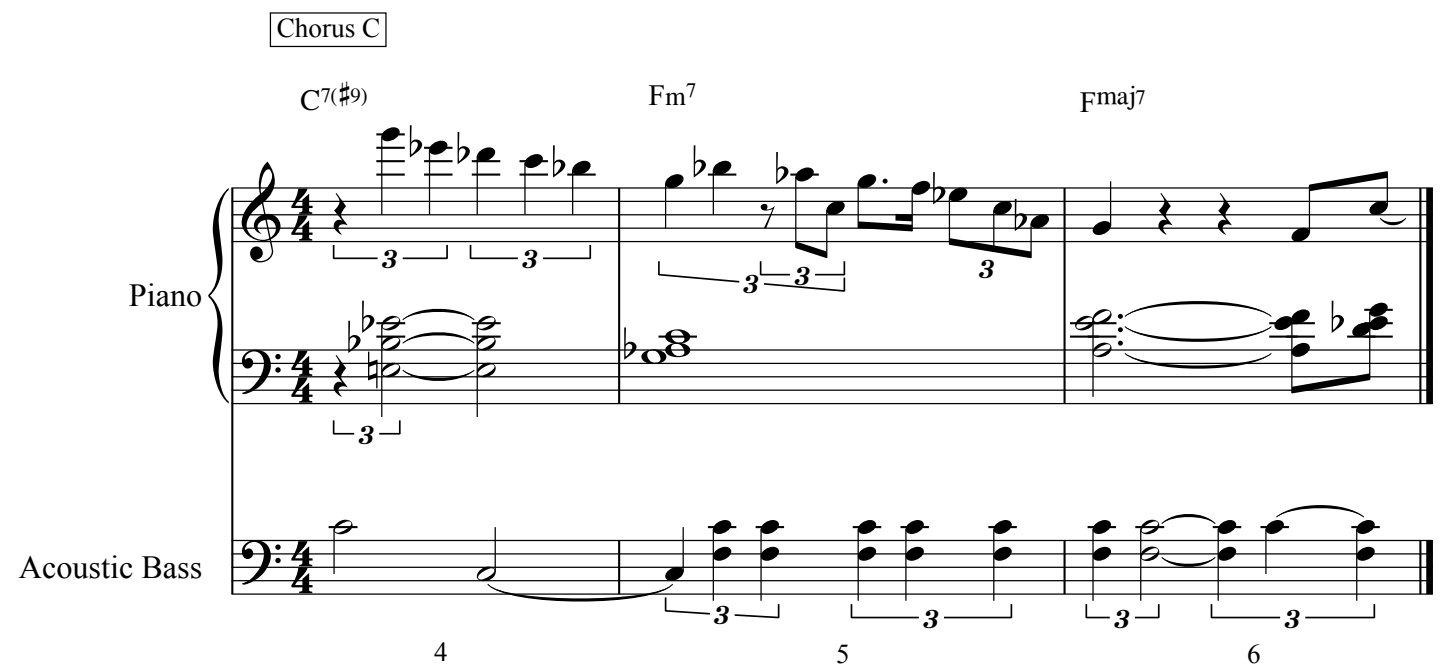

72 These examples do not take into consideration the imitation of melodic contour or complete copies of a melodic statement. The Mimesis section later in this chapter outlines these kinds of approaches. 
This next example is very similar. This time LaFaro leads, playing three quarter note triplets at the end of bar 13. Evans responds immediately with his own rhythmic phrase using quarternote triplets. This gesturing continues over a total of four bars where Evans concludes the passage with a descending line that resolves after bar 17 .

Chorus C Bars 13-16
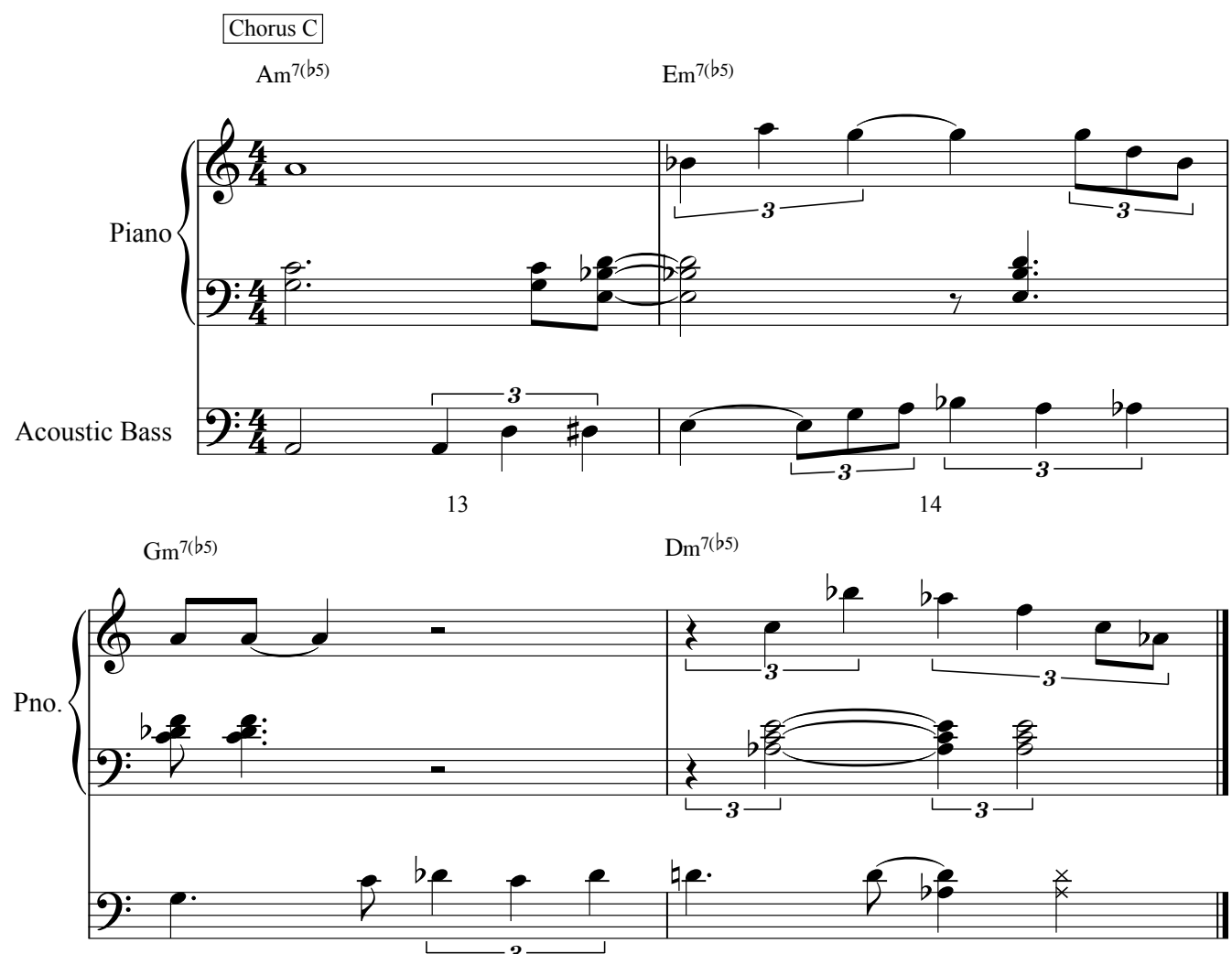

15

16 


\section{Solar:}

In the first four bars of this example, Evans's melodic phrase almost continuously features quarter note triplets as the primary rhythmic element. At bar six, Evans changes the rhythm of his phrase to eighth notes, but shortly after LaFaro changes his own rhythmic phrase to consist of quarter note triplets before concluding at bar seven.

Chorus F Bars 2-7
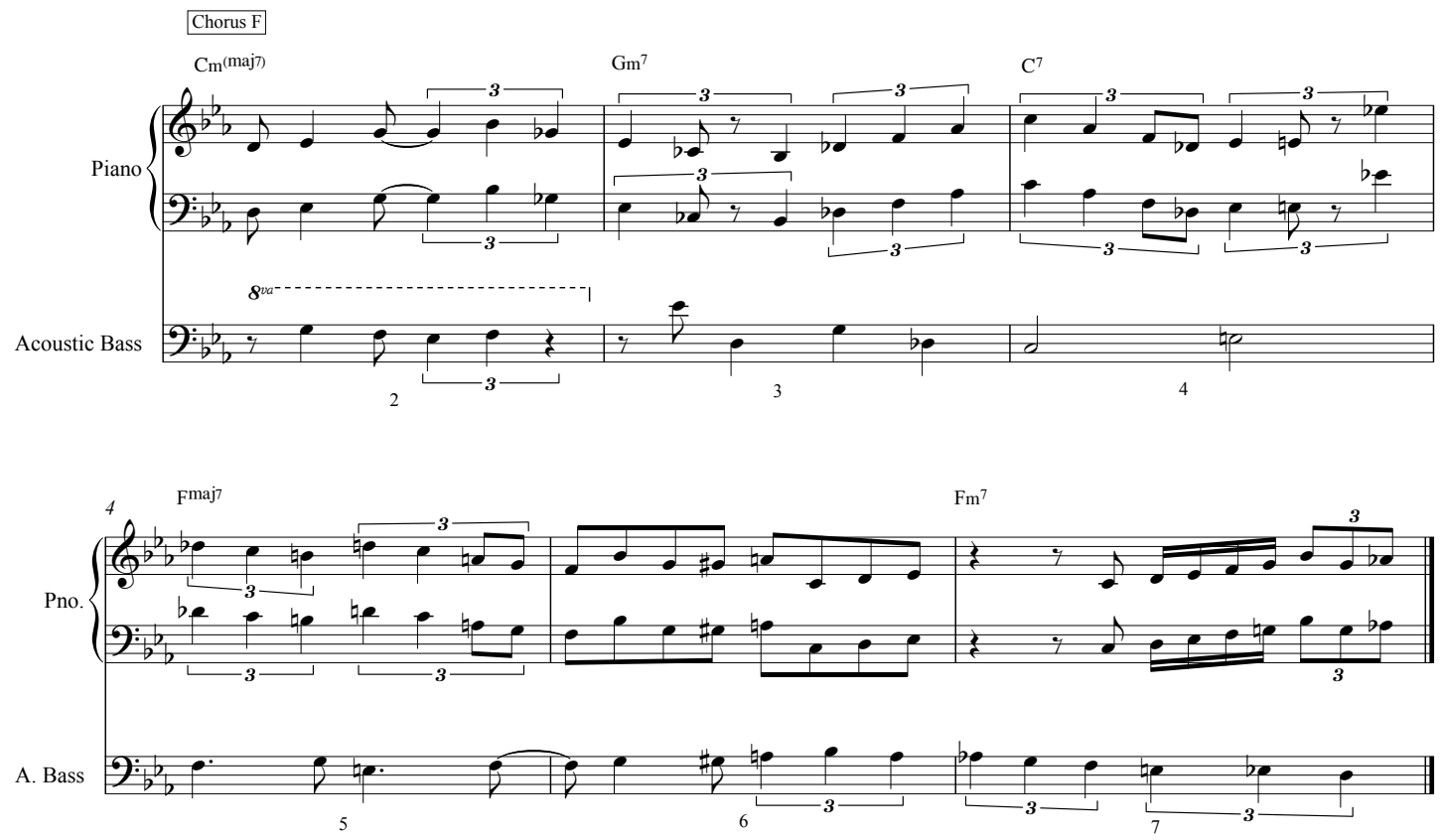
In the final bar of Chorus $\mathrm{G}, \mathrm{LaFaro}$ begins to play in continuous quarter note triplets and, apart from the inclusion of a minim at the top of Chorus $\mathrm{H}$, continues this pattern consistently for a total of five bars. Again as above, Evans acknowledges this rhythmic motif, and only two bars after LaFaro begins the pattern, Evans changes his own rhythmic pattern to conform to LaFaro's. For nearly three bars the two musicians are linked together through the quarter note triplets until they both resolve their phrases on beat one of bar five of chorus $\mathrm{H}$.

Chorus G Bar 12 leading into Chorus H Bars 1-5

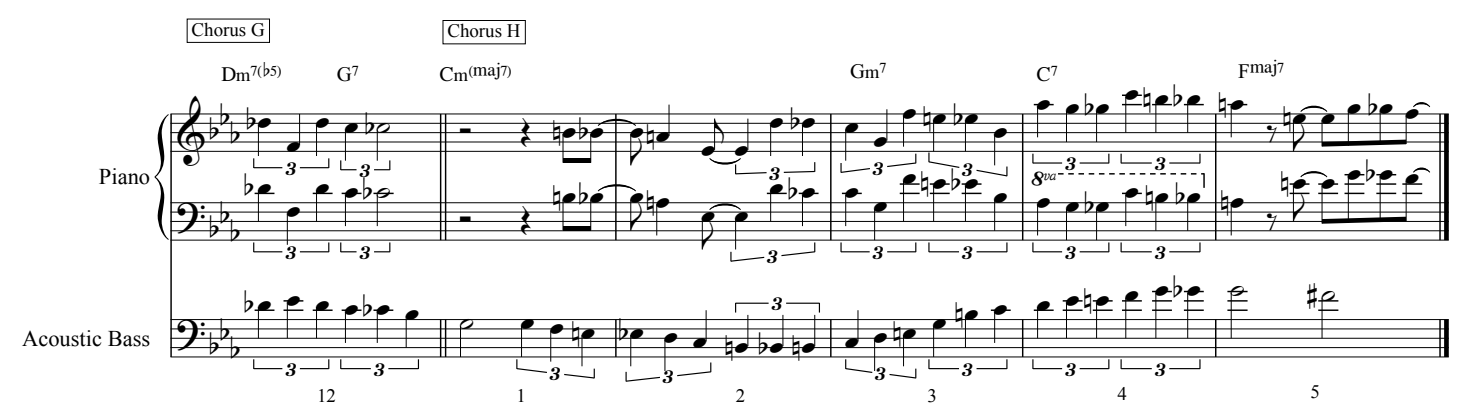

\section{Waltz For Debby:}

In bar 23 of this example, LaFaro plays a brief set of quarter note triplets before changing to a broken two feel in bar 24. However, in bar 23, Evans seems to immediately respond to LaFaro's rhythmic pattern by starting his own ascending triplet motif that resolves with silence two bars later.

Chorus C Bars 23-25

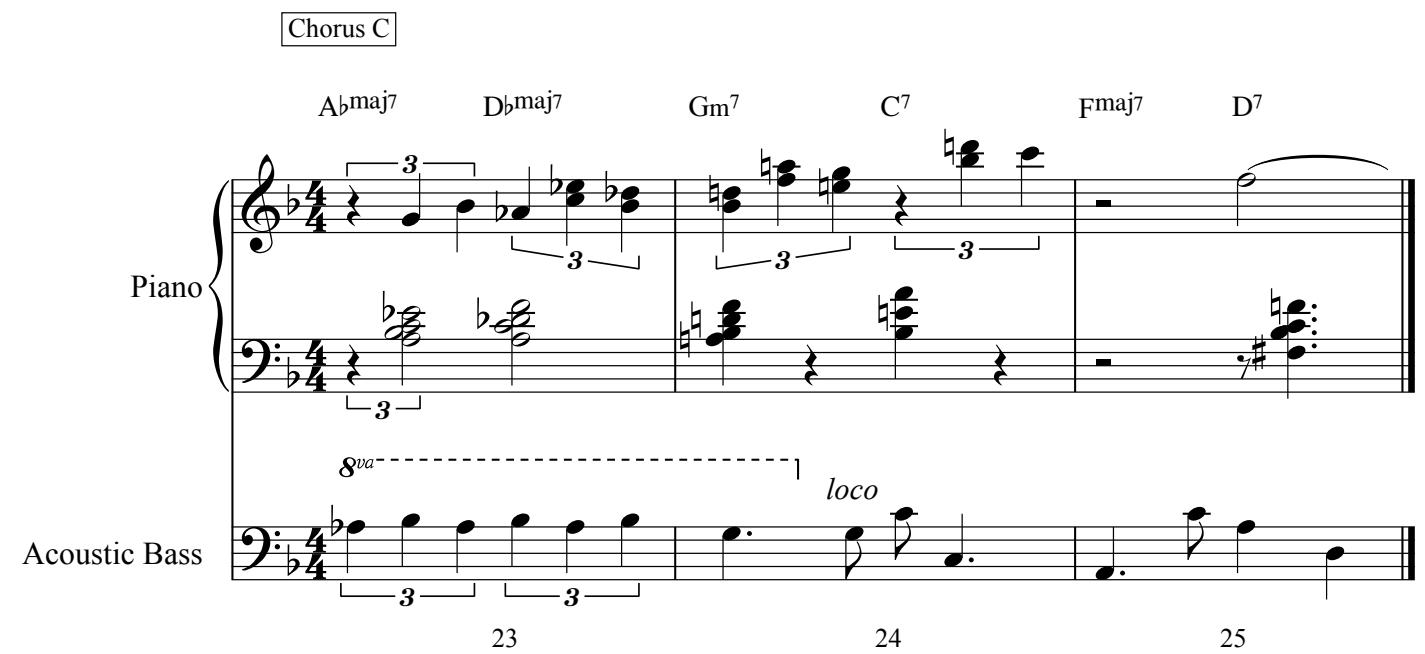




\section{Alice In Wonderland:}

In this example, Evans plays a short three bar phrase made up of primarily eighth notes. During bar 31 LaFaro abandons his previous accompanying rhythms and changes his own line to match the eighth notes that Evans is playing. It would appear that at first, LaFaro was receptive and chose to react to the eighth note rhythmic phrase that Evans was leading. I believe it is also possible to conclude that Evans heard LaFaro change his rhythmic accompaniment and resolved his line at bar 31 to leave space for LaFaro's phrase to become the primary melodic phrase at that moment.

Chorus B Bars 29-32

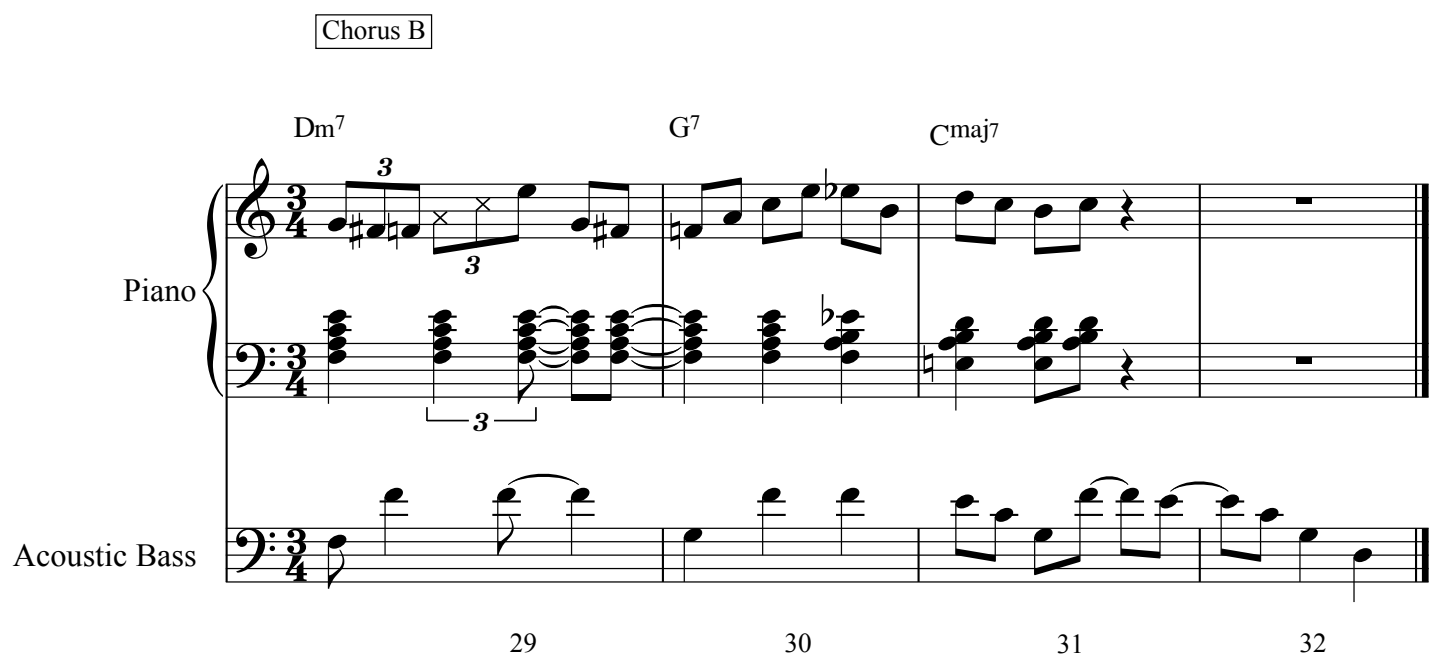

\section{REPETITIVE RHYTHMIC MOTIFS}

Throughout the performances I have analysed, LaFaro regularly plays repetitive rhythmic phrases while accompanying Evans' piano solos. He also uses these motifs as part of his counterpoint approach, providing new textures and melodic figures that feature underneath Evans's own lines

All of the following examples have a duration of at least two bars. This indicates that LaFaro was attempting to keep his rhythmic motifs active over a number of bars, sometimes playing against the rhythms of Evans and Motian. My sample discounts a large number of very brief rhythmic patterns that LaFaro did not develop over any significant period of time.

While most of the rhythmic patterns LaFaro used are unique to each performance, a few have similarities that appear multiple times in either one song, or across a number of songs. 


\section{SIMILAR RHYTHMIC PATTERNS USED IN THE SAME PERFORMANCE:}

\section{Gloria's Step:}

While these examples are not quite identical, they are built around the same fundamental shape where

LaFaro opens the motif with a longer note, followed by three quarter note triplets. The most interesting part about these two examples is that both of them occur at the same point in the harmonic sequence - two bars into the second half of the song.

Chorus B Bars 13-15

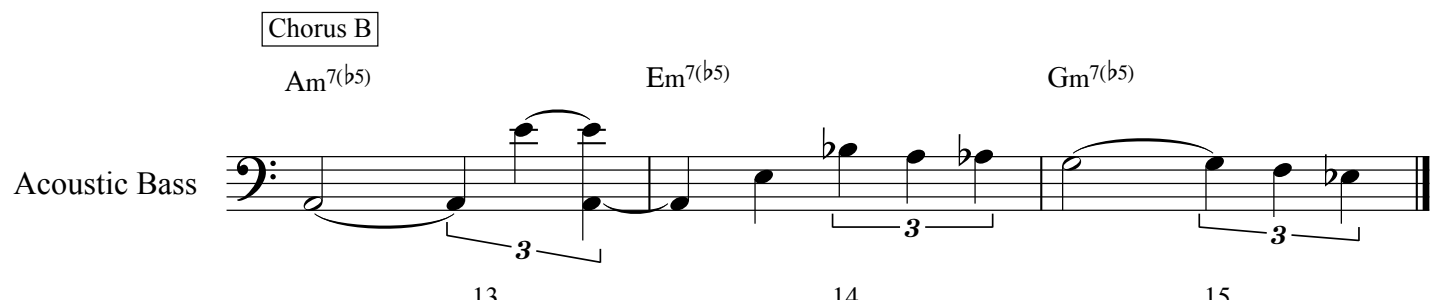

$13-14$

15

Chorus C Bars 13-15

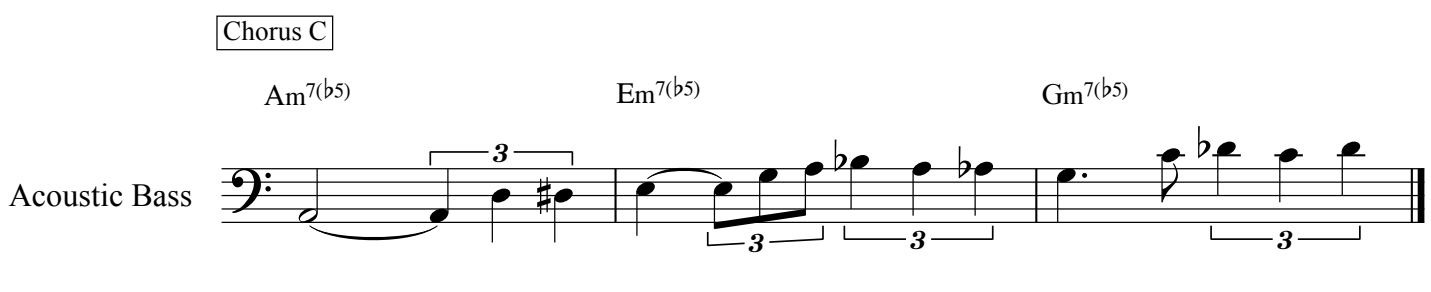

13

14

15

A similar approach happens in Solar.

Again while each motif is not identical, they share a number of common elements. The first example shows LaFaro performing a repetitive three beat rhythmic pattern that continues for more than six bars. Similar patterns are found later in his performance during Choruses $\mathrm{E}$ and $\mathrm{K}$ as shown in the following two examples. In both of these examples LaFaro has added an extra crotchet to the pattern, lengthening the phrase by one beat. 
Chorus C Bars 5-11
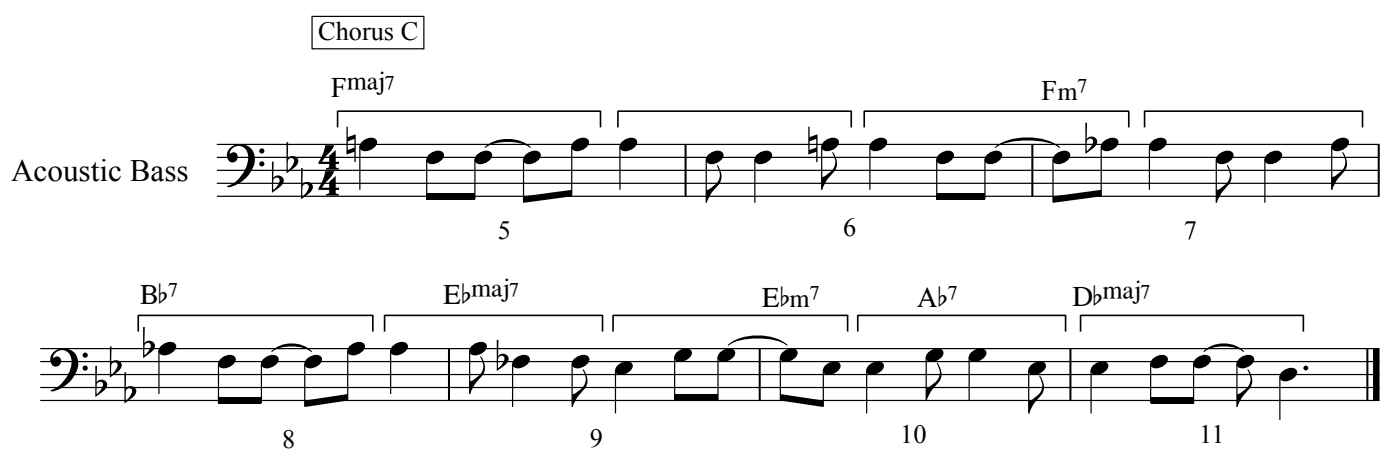

Chorus E Bars 2-6

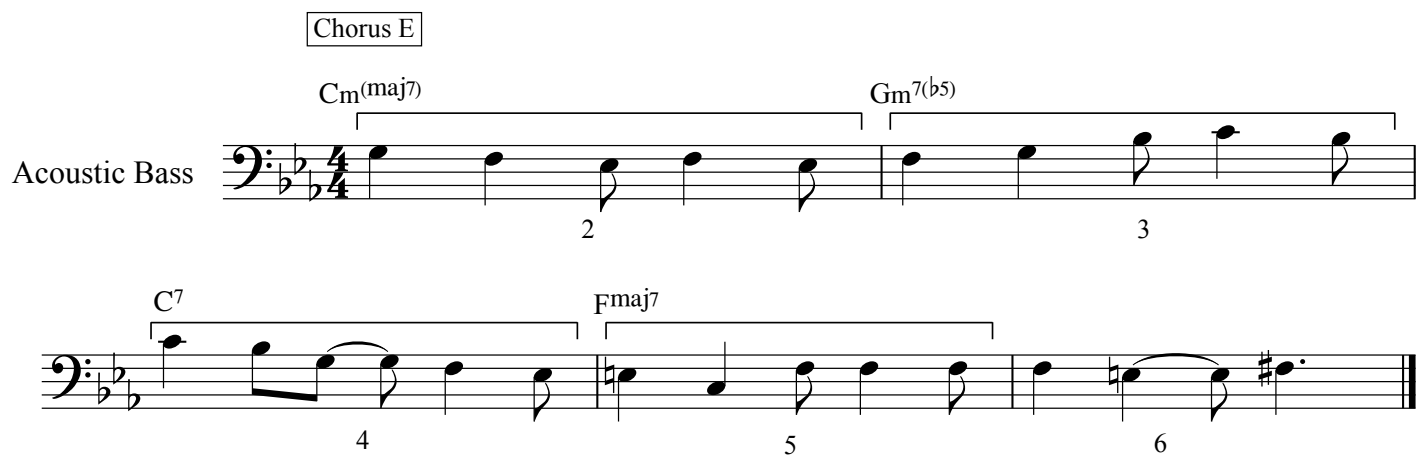

Chorus K Bars 5-7

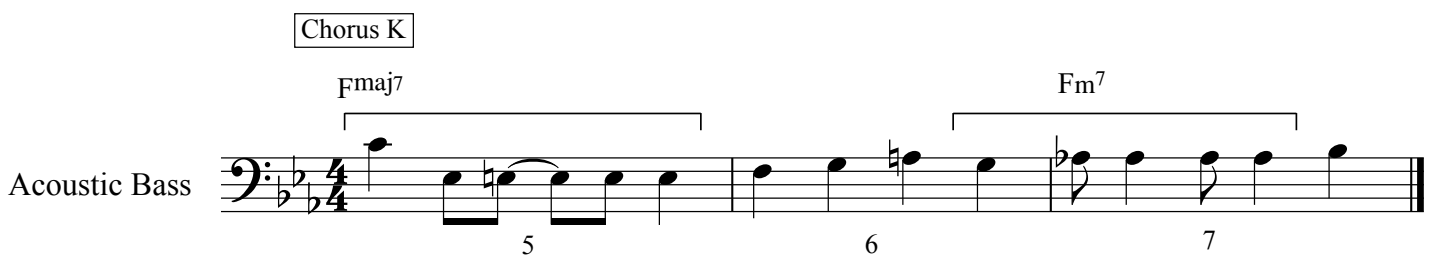

LaFaro also uses a similar rhythmic phrase in Waltz For Debby:

The first example shows that LaFaro begins the rhythmic phrase in bar 24, before slightly refining the line to include two crotchets at the end of each subsequent bar. The second example is nearly identical except that instead of a longer dotted crotchet beginning each motif, LaFaro plays two quavers before continuing with the same ending to each bar. 
Chorus C Bars 24-28

Chorus C

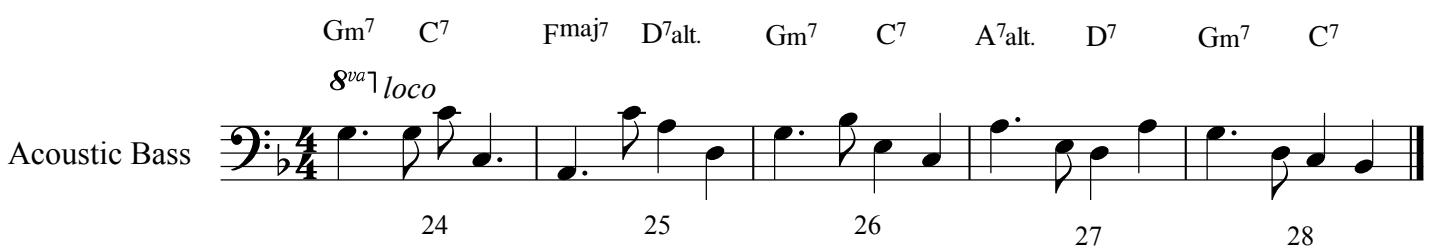

Chorus F Bars 13-16

Chorus F

$\begin{array}{lllll}\mathrm{A}^{7} & \mathrm{Dm}^{7} & \mathrm{Bm}^{7} & \mathrm{E}^{7} & \mathrm{~A}^{\text {maj7 }}\end{array}$

Acoustic Bass

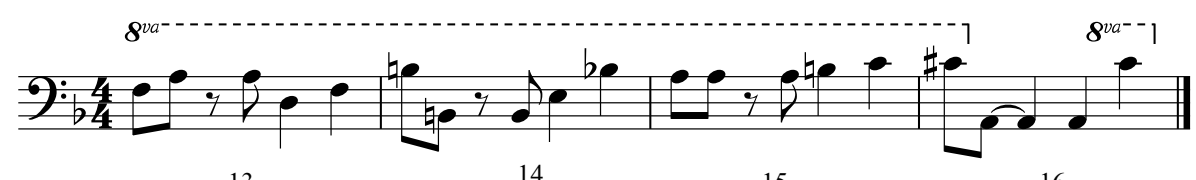

14

15

16

\section{Alice In Wonderland:}

Alice In Wonderland contains a number of repetitive rhythmic patterns. This performance also contains the longest pattern played by LaFaro within my sample. Beginning in bar two of Chorus B, this rhythmically simple pattern lasts for a staggering 25 bars. This pattern is the closest example of LaFaro nearly playing a traditional walking bass line, but for the dotted crotchet followed by a quaver in every second bar.

Chorus B Bars 2-26

Chorus B

$\mathrm{G}^{7} \quad \mathrm{C}^{\text {maj7 }} \quad \mathrm{F}^{\text {maj7 }} \quad \mathrm{Bm}^{7(b 5)} \quad \mathrm{E}^{7}$ alt. $\quad \mathrm{A}^{7(b 9)} \quad \mathrm{Eb}^{7}$

Acoustic Bass

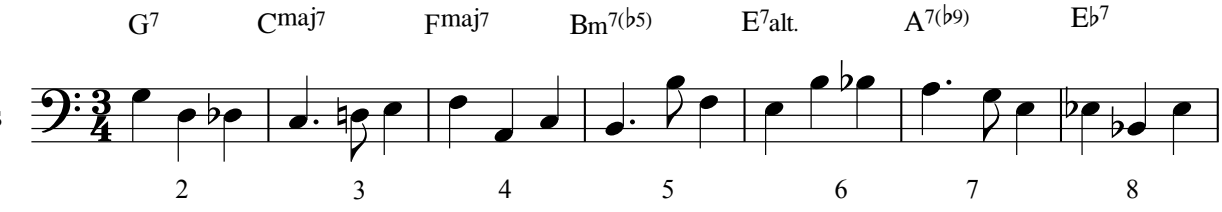

A. Bass

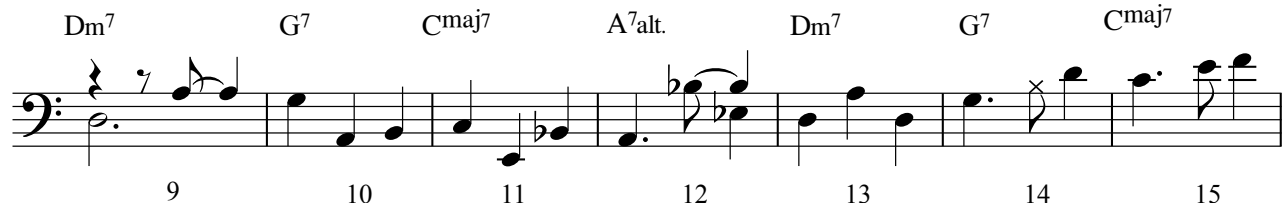

A. Bass

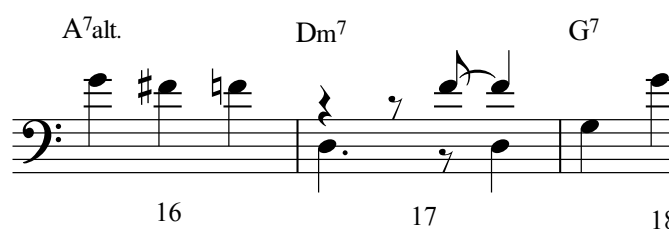

Cmaj7

Fmaj7

16

17

18

20

$\mathrm{Bm}^{7(b 5)}$

$\mathrm{E}^{7}$ alt.

$\mathrm{A}^{7}$

$E b^{7}$

$\mathrm{Dm}^{7}$

$\mathrm{G}^{7}$

A. Bass

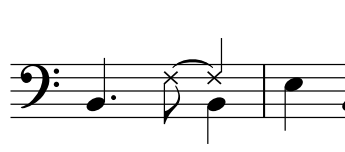

21 
Towards the end of the song LaFaro replicates this rhythmic pattern for a shorter length of time.

Chorus E Bars 19-25

$$
\begin{gathered}
\text { Chorus E } \\
\text { C }^{\text {maj7 }}
\end{gathered}
$$

Fmaj7

$\mathrm{Bm}^{7(b 5)}$

Acoustic Bass

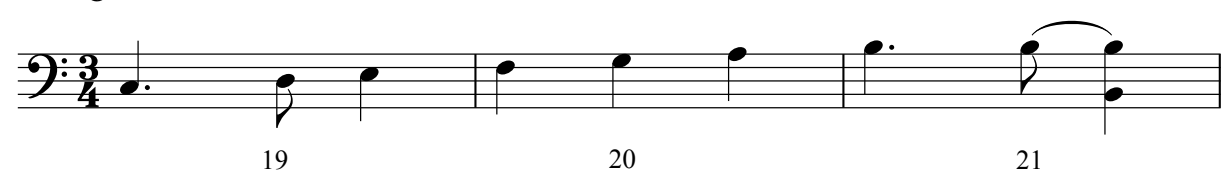

19

$\mathrm{E} b^{7}$

$\mathrm{Dm}^{7}$

A. Bass

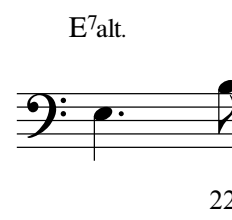

$\mathrm{Am}^{7}$

$\mathrm{E} b^{7}$

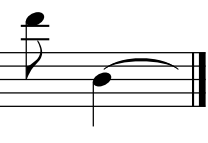

23

24

25

\section{SIMILAR RHYTHMIC PATTERNS USED IN MULTIPLE PERFORMANCES:}

\section{Alice In Wonderland:}

LaFaro sometimes avoids playing beat one while playing a repetitive rhythmic pattern. In Alice In Wonderland he plays a six bar phrase where he completely avoids landing on beat one of each bar.

Chorus A Bars 4-9

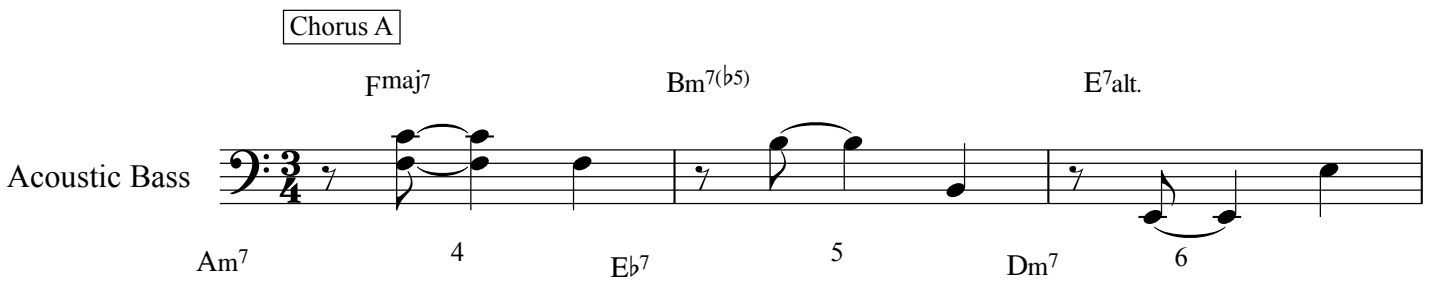

A. Bass

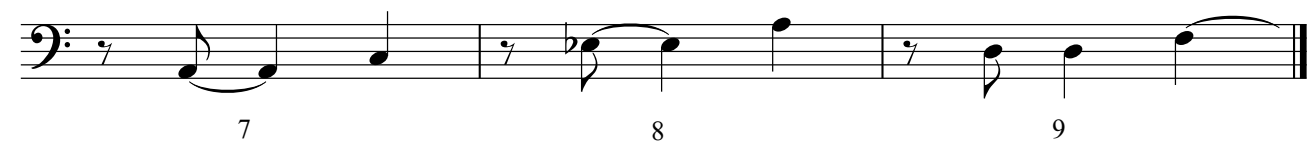


In the next example LaFaro plays a rhythmic pattern similar to the one above, except that this time he fills in beat one of each bar.

Chorus B Bars 46-52

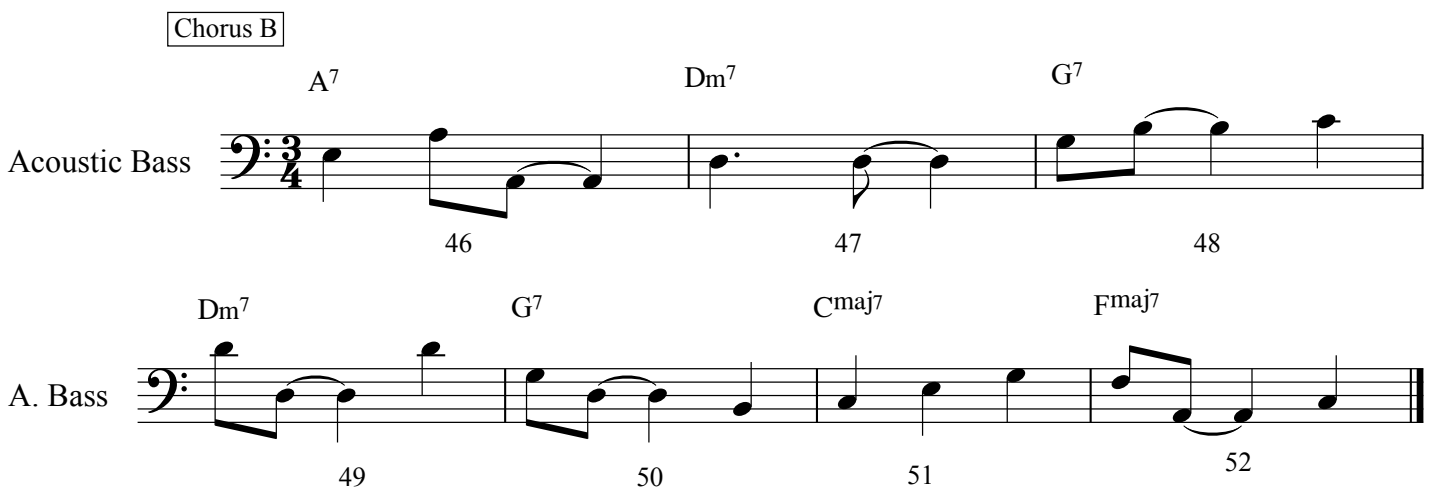

\section{Gloria's Step:}

The same approach is used in a repetitive rhythmic motif in Gloria's Step. Again LaFaro avoids playing the downbeat at the top of the bar but puts emphasis on the up beat followed by a rhythmic resolution with crotchets on beats three and four. Also in the first bar of this example LaFaro begins the line on the and of one but a note is still being held over from the previous bar.

Chorus B Bar 17-19 - Chorus C Bar 1

\section{Chorus B}

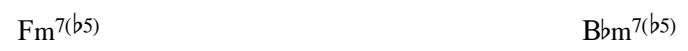

Acoustic Bass

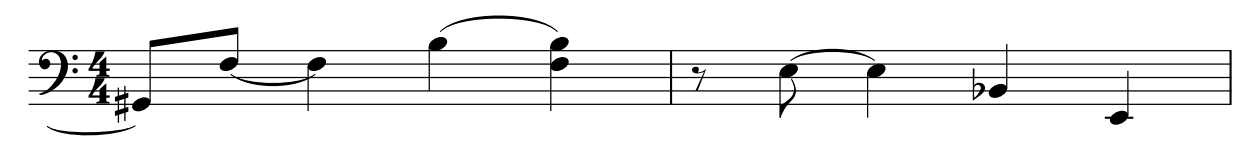

17

18

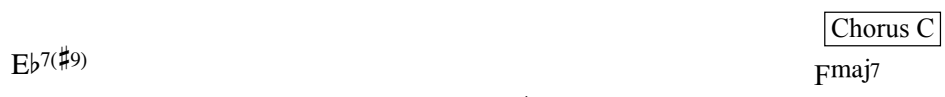

A. Bass

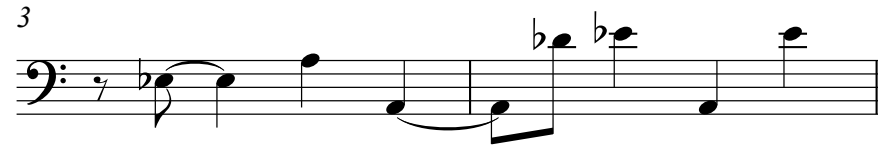

19 


\section{POLYRHYTHMIC DEVICES}

\section{QUARTER NOTE TRIPLET POLYRHYTHM'S:}

The following are examples of LaFaro's use of quarter note and eighth note triplet motifs. All of the examples come from passages where LaFaro seems to play a polyrhythmic phrase that has no relationship to anything that either Evans or Motian are performing at that time. This indicates that LaFaro was comfortable in his role to quickly play a rhythmic device that implied a different meter to the principal groove of a song. When listening to these examples, LaFaro's approach creates tension as he plays against Motian's regular rhythmic pattern. This tension is only released as LaFaro resolves the polyrhythm and returns to the regular groove as stated by the other musicians in the ensemble.

As some of these examples show, shortly after LaFaro begins his polyrhythmic motif, Evans begins to mimic the pattern. This approach is discussed in greater depth in the Mimesis and Rhythmic Interplay sections later in this chapter.

\section{Waltz for Debby:}

This two bar phrase is an interesting example in the context of this study as it relates strongly to the basic role expected from jazz bassists. LaFaro manages to acknowledge the harmonic progression of the song by outlining each chord change while also keeping the melodic contour of the bass line smooth without any large intervallic leaps. This diatonic approach within the harmony is then offset by the tension created as LaFaro performs the polyrhythm against Motian's standard drum pattern. ${ }^{73}$

Chorus C Bars 7-8

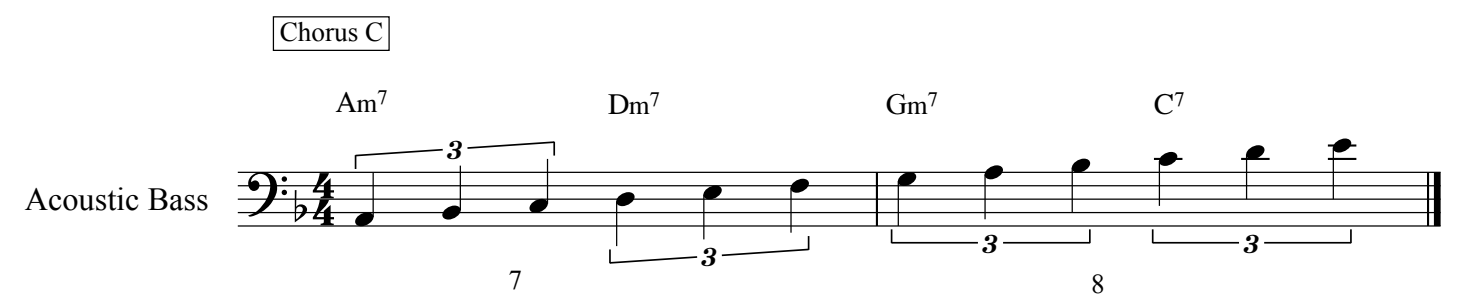

73 See Appendix II for the full transcription of Motian's performance. 


\section{Solar:}

In this example, LaFaro uses a quarter note triplet polyrhythm to set up a harmonic pedal, outlining a basic $\mathrm{C}$ tonality against the song's harmonic progression. In the final two bars he changes the harmonic pedal to loosely outline $\mathrm{a} \mathrm{B} b$ tonality to match the change in the song's key centre. Both the harmonic and rhythmic aspects of this motif give the phrase a floating feeling as he again creates tension as he performs against the standard drum pattern.
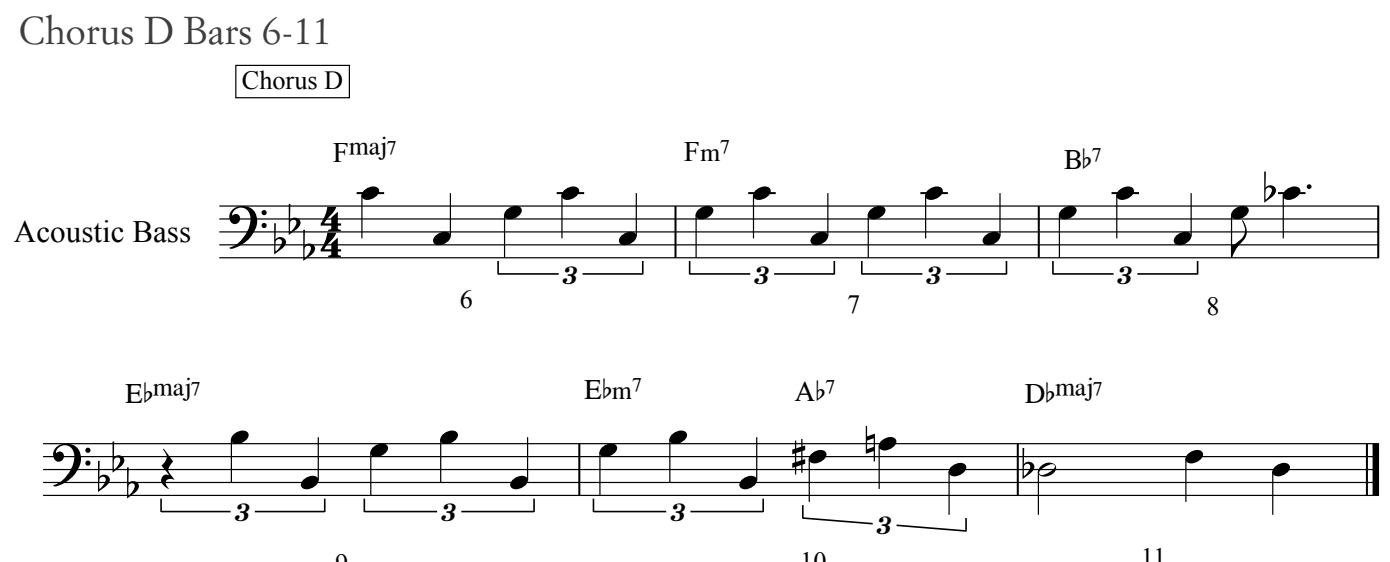

10

This example is similar to the one from Waltz For Debby discussed above. LaFaro's line is smooth as it slowly descends to its lowest point at $\mathrm{B} b$ in the third bar, before then ascending over the following two bars to it's conclusion in a high $\mathrm{G}$ in the bass's upper register.

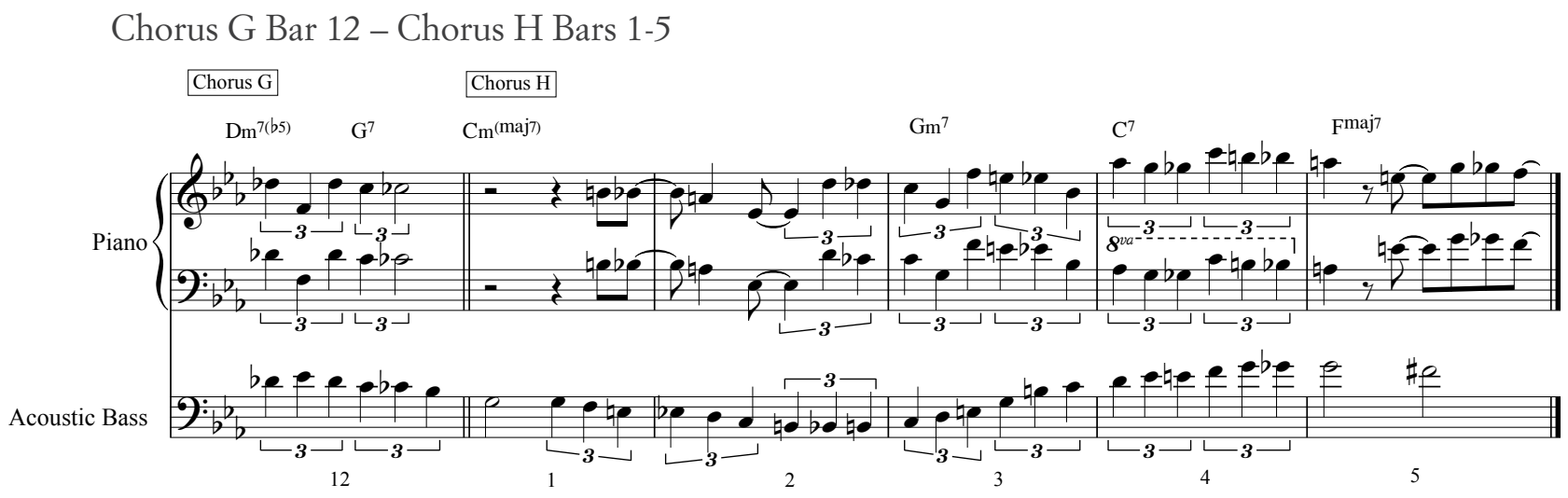

The following two examples occur during the out head and coda of the performance. It is interesting that both phrases are of similar length, and also begin on beat three at the start of each chorus. Not only does LaFaro repeat the polyrhythm in the same part of the chorus, but in both examples the melodic and intervallic construction is almost identical, where the first example has a range of a minor third, and the second a range of a major second. 
Chorus MM Bars 1-4

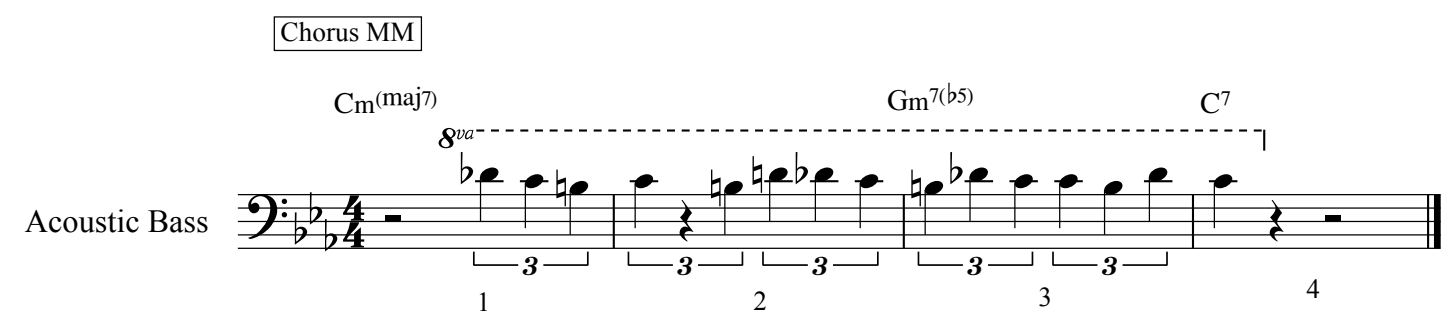

Chorus NN Bars 1-3

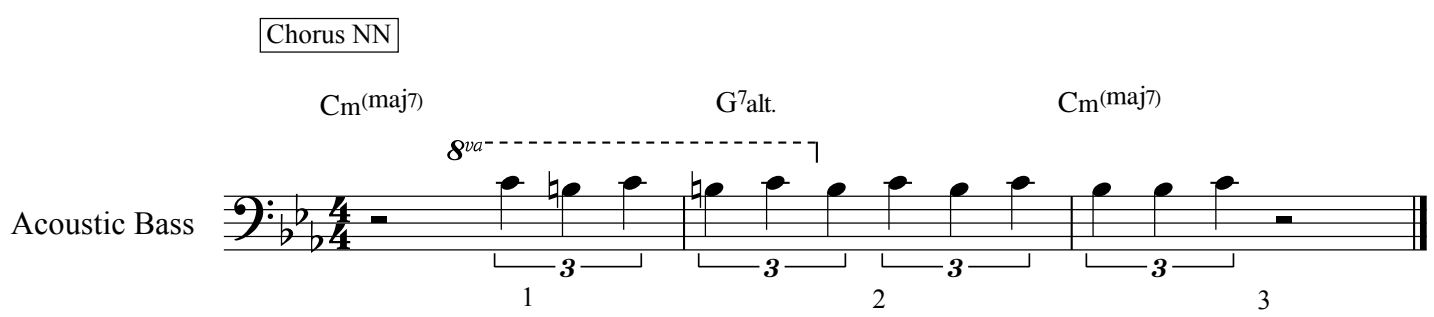

\section{Gloria's Step:}

In this example LaFaro again uses a harmonic pedal point with the polyrhythm to create tension with his motif. The double stop of $\mathrm{F}$ and $\mathrm{C}$ dynamically creates a denser musical texture against the $\mathrm{F}$ minor and $\mathrm{F}$ major chords. This contrasting effect is enhanced greatly by the polyrhythm once again being played against the regular drum pattern by Motian.

Chorus C Bars 5-6

Chorus C

$\mathrm{Fm}^{7} \quad \mathrm{Fmaj}^{\mathrm{m}}$

Acoustic Bass

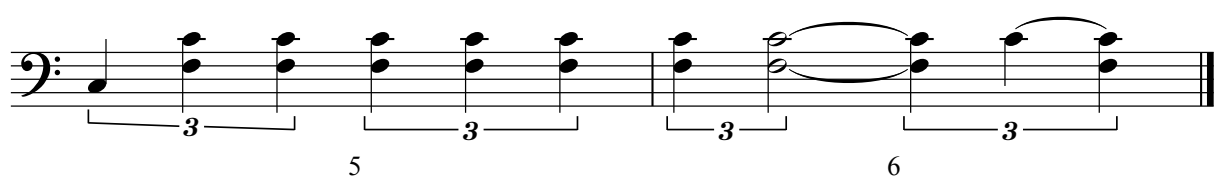




\section{EIGHTH NOTE TRIPLET POLYRHYTHMS:}

\section{Gloria's Step:}

Like the earlier polyrhythm example discussed above in Gloria's Step, in both of the following examples LaFaro uses an eighth note triplet pattern to accentuate a harmonic pedal point. In Gloria's Step LaFaro executes some very quick hammer-ons between two notes that are a semi-tone apart. In the first bar, after holding an $\mathrm{A} b$ for two beats, he begins his quick motif alternating between a $\mathrm{G}$ and the $\mathrm{A}$ b. LaFaro continues the fast motif during the next bar, but moves the pattern down a semi-tone to outline the E minor chord.

Chorus C Bars 10-11

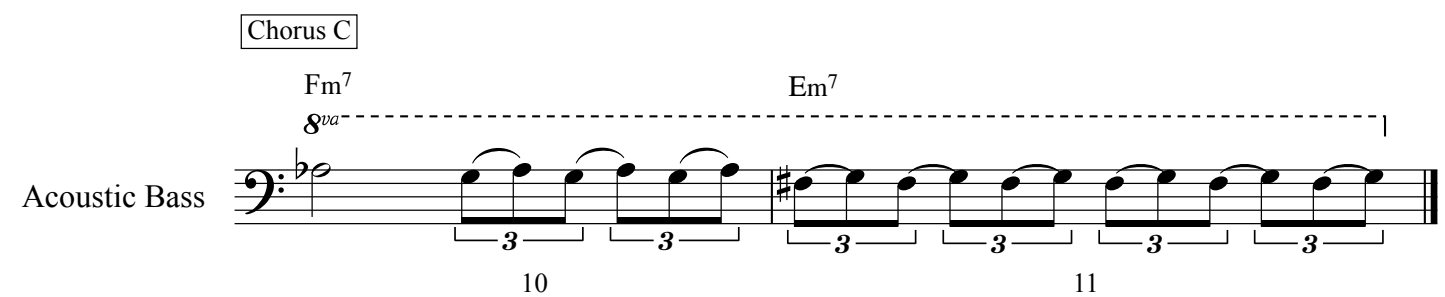

\section{Alice In Wonderland:}

During the performance of Alice In Wonderland LaFaro performs an eighth note polyrhythm, accentuating the tonic and dominant notes of the corresponding harmony. Like the above example he moves the pattern down a semitone to match the chord change before concluding the polyrhythm and returning to his usual accompaniment approach.

Chorus B Bars 43-44

Chorus B

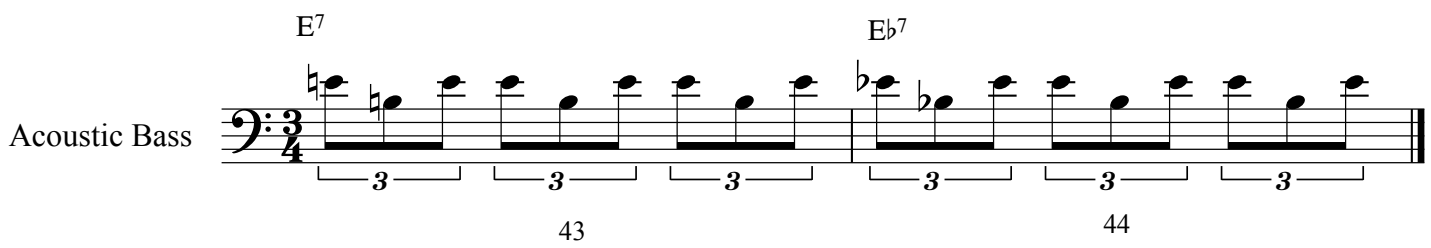




\section{DOTTED QUARTER NOTE POLYRHYTHMS}

\section{Alice In Wonderland:}

During Alice In Wonderland LaFaro only sparingly employs the dotted quarter polyrhythm within his performance. All of the examples shown are brief. During both, LaFaro continues to clearly outline the harmonic progression - especially in the second example where he exclusively plays the tonic of each chord. And like the triplet polyrhythms discussed earlier, there does not appear to be any kind of musical communication between the musicians in the preceding measures that would set-up or influence LaFaro to perform in this manner.

Chorus A Bars 60-62

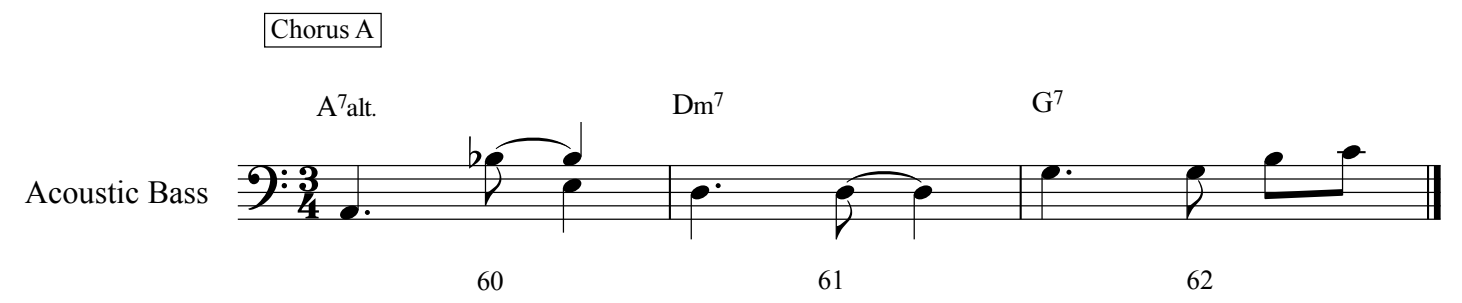

Chorus B Bars 33-35

Chorus B

$\begin{array}{lll}\mathrm{D}^{7} & \mathrm{G}^{7} & \mathrm{C}^{7}\end{array}$

Acoustic Bass

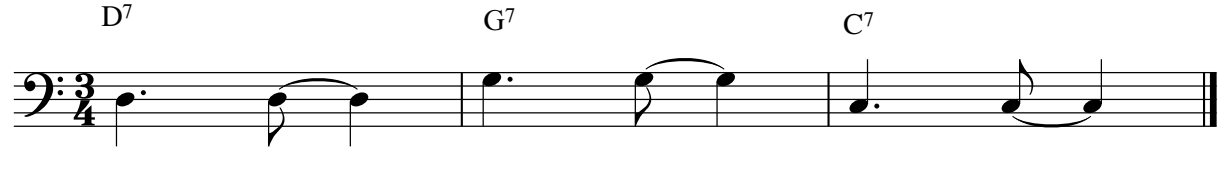

33

34 
These next examples are also similar to those above. Again LaFaro almost exclusively performs the tonic notes of the corresponding harmony, but this time his performance may have been influenced by Evans's left hand. In the first example Evans has already been playing the polyrhythm for four bars before LaFaro begins his own, and continues to play it as LaFaro joins him.

Chorus E Bars 41-48
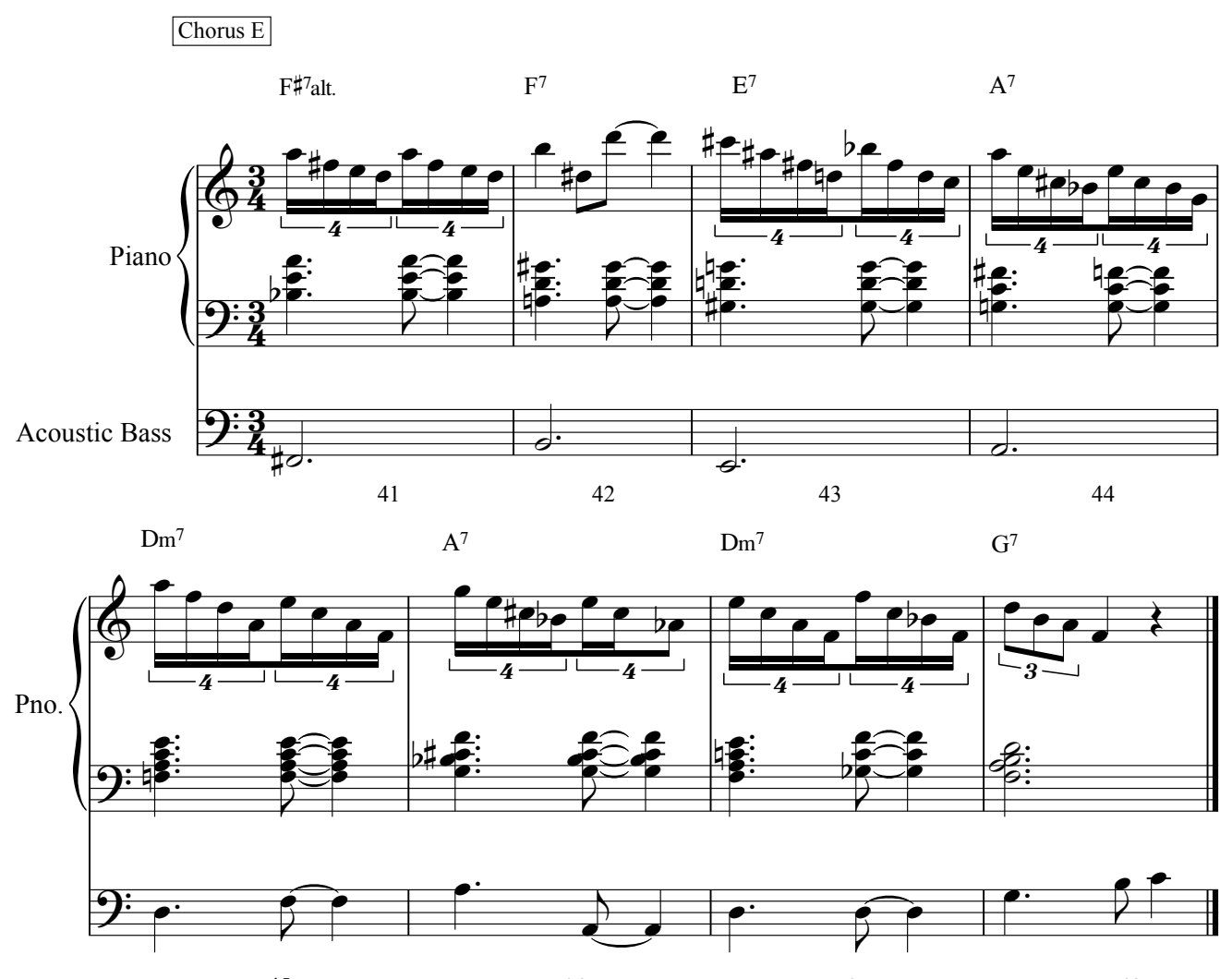

46

47

48

In this final example LaFaro and Evans once again perform the polyrhythm in unison.

Chorus F Bars 24-28

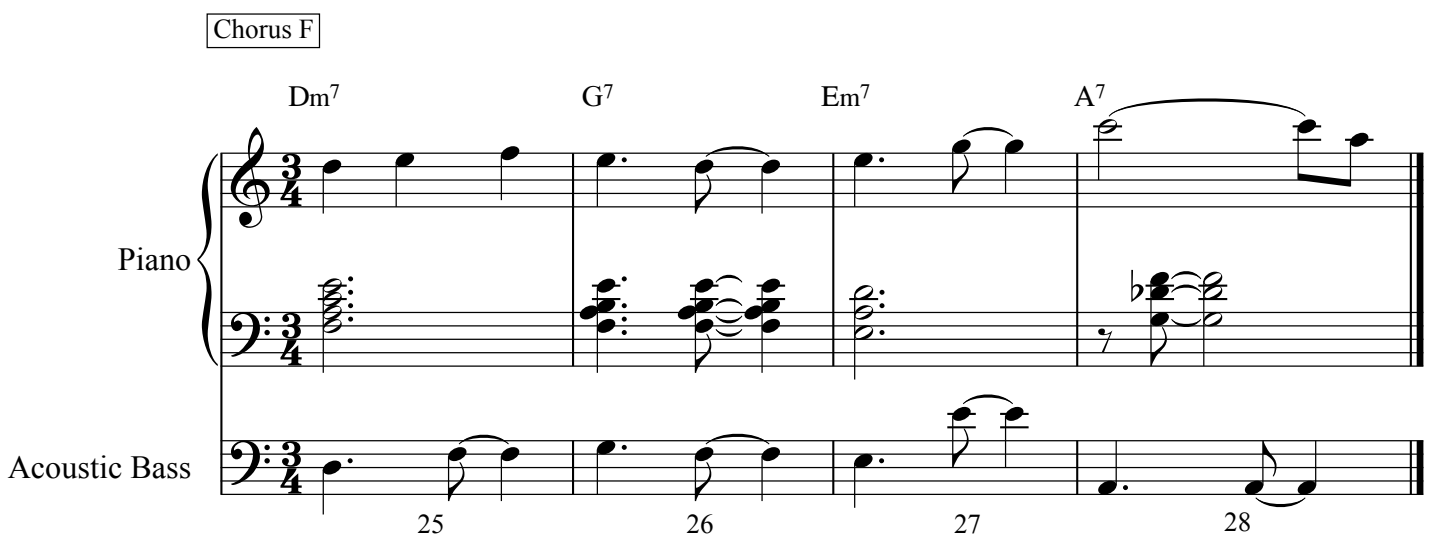




\section{Solar:}

These first two examples taken from Solar occur towards the beginning of the piano solo. Both examples are of short duration - three and five bars respectively - and it seems that LaFaro tailors his use of the polyrhythm to accommodate the harmony. For instance, in bar four of the second example LaFaro starts the bar by playing a dotted quarter, but then finishes the bar with two descending quarter notes that lead to the D bmaj7 chord change in the fifth bar.

\section{Chorus D Bars 1-3}

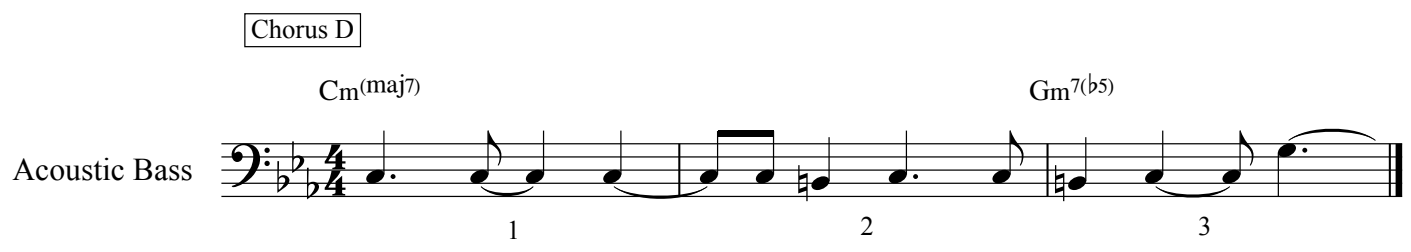

Chorus G Bars 7-11

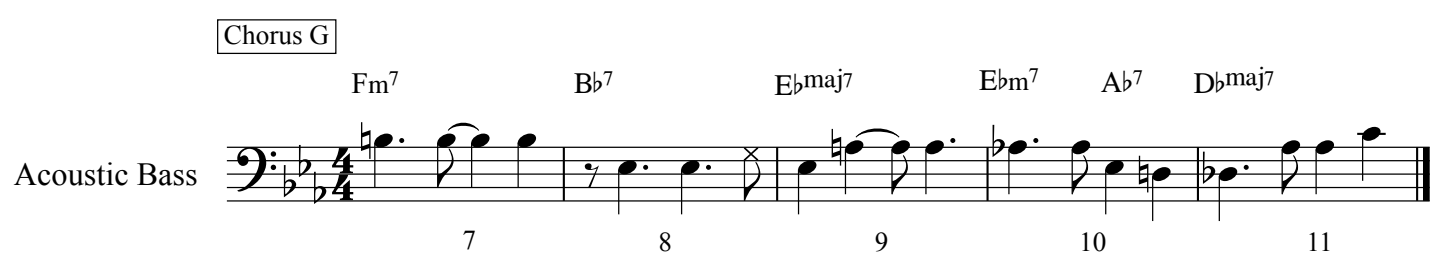

As the piano solo progresses, LaFaro begins to stretch the duration of the polyrhythmic phrases. The most extreme of these occurs during Chorus I where LaFaro performs a broken version of the polyrhythm for the entire chorus. This is quite a contrast to the uniformly short patterns he played in Alice In Wonderland.

Chorus I Bars 1-12

Chorus I

$\mathrm{Cm}^{(\text {maj7) }}$

$\mathrm{Gm}^{7(b 5)}$

$\mathrm{C}^{7}$

Acoustic Bass
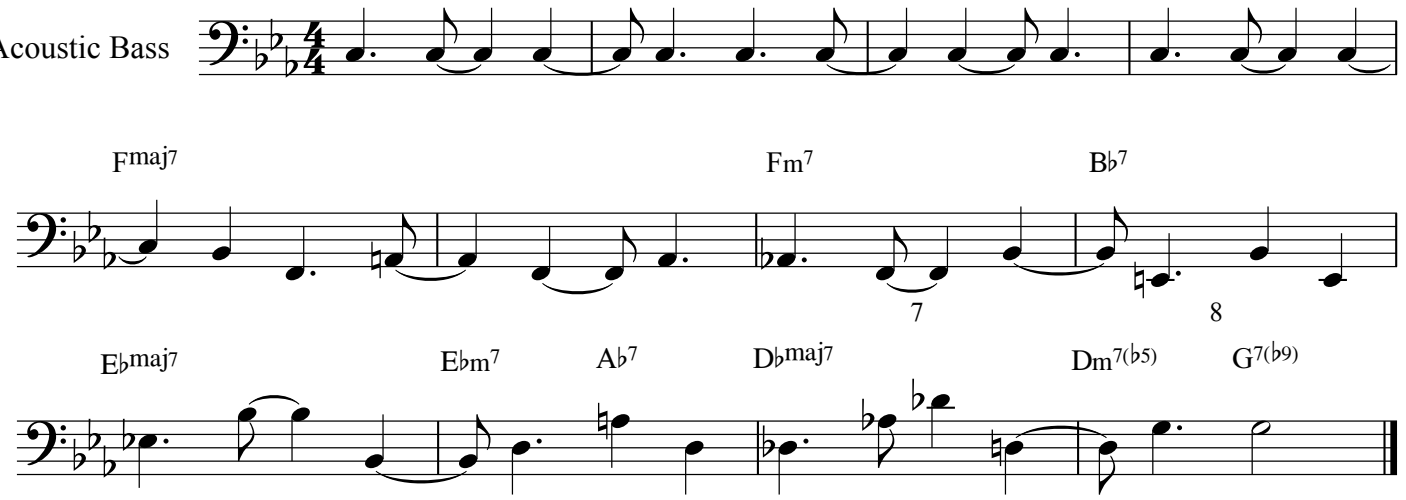

9

10

11 
In the very next chorus LaFaro also strongly gestures towards the polyrhythmic motif. Throughout bars 6-8 he breaks up the rhythmic pattern by playing in octaves, and further breaks the pattern by playing separate eighth and quarter notes in the top octave of the motif.

Chorus J Bars 5-9

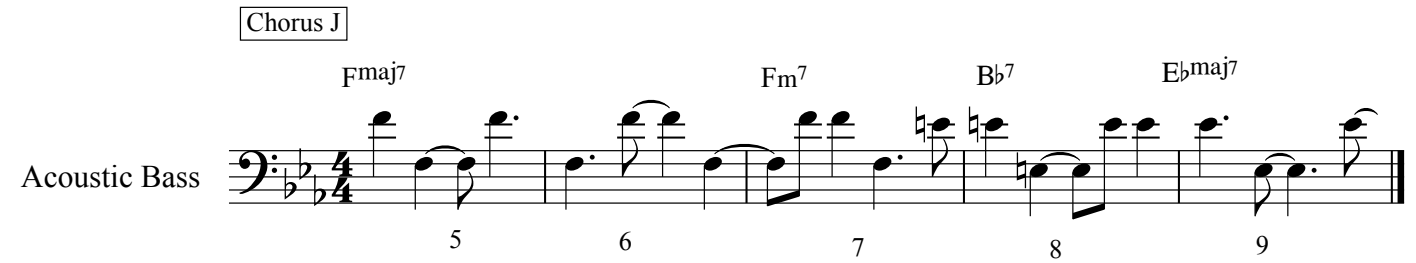

The final example also illustrates LaFaro performing the polyrhythm over nearly the entire chorus. And for most of the duration of this example, LaFaro strictly plays the polyrhythmic pattern, only deviating from it in the second to last bar. This example indicates that LaFaro, while strongly gesturing towards the dotted quarter polyrhythm, was more concerned about accurately spelling each chord change as it occurred during the song's harmonic structure.

Chorus L Bars 1-10

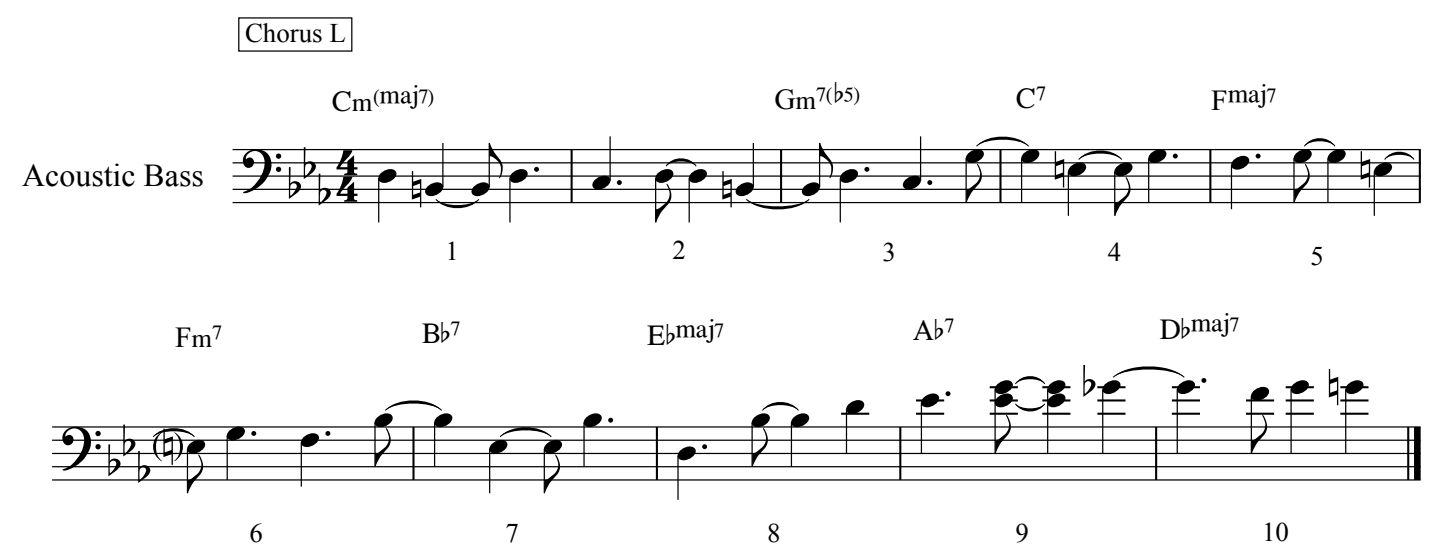




\section{INTERACTIVITY}

\section{CONVERSATIONAL COUNTERPOINT (YES AND...)}

As described in chapter two (p.19) a passage of Conversational Counterpoint occurs when either LaFaro or Evans leaves space within their solo for the other to fill. The responding musician may continue the melodic phrase as if it had never stopped. He might continue the melodic contour of the original phrase, or the responding musician may even start his line on the same note that resolved the original motif.

I could find no evidence of Conversational Counterpoint (Yes, and...) in Solar, Gloria's Step, Waltz For Debby or Nardis. However there is a clear example within Alice In Wonderland.

\section{Alice In Wonderland:}

After performing a repetitive rhythmic pattern, LaFaro's playing becomes rhythmically varied as he begins an ascending line to pedal on a high $\mathrm{E}$ for two bars. It seems that Evans notices this rhythmic activity as two bars later he leaves a gap in his playing, one that allows LaFaro to fill the gap with an ascending eighth note run resolving on a high $\mathrm{G}$ in thumb position.

The interesting part of this counterpoint passage is the note choices that the two musicians make. Evans resolves his melodic phrase on a mid range $G$ and lets it ring for the duration of the bar. LaFaro would have heard this note clearly, and he chooses to acknowledge it by finishing his ascending eighth note phrase by repeating the same tone in bar 17 .

In response, Evans begins his new phrase on the same $\mathrm{G}$ and also continues the melodic contour of LaFaro's original phrase. When listening to this passage, it seems that as LaFaro concludes his melodic idea, Evans immediately responds and continues the musical discussion.

Chorus A Bars 15-18

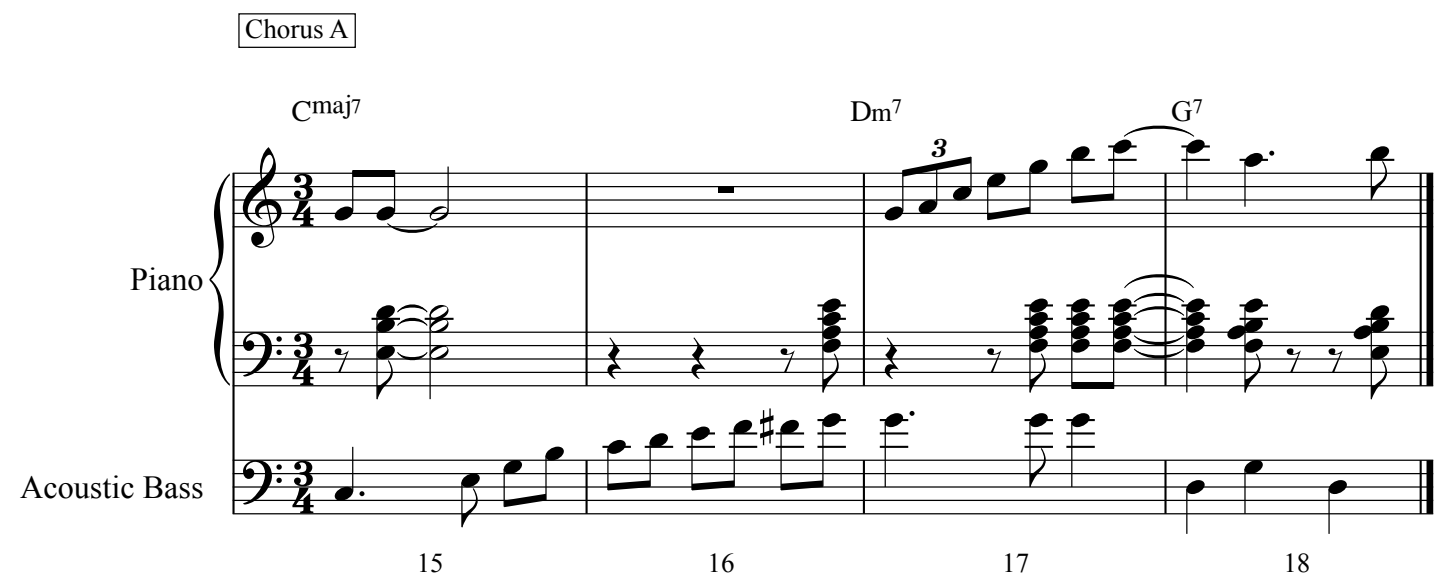




\section{MELODIC CONTOUR:}

This section illustrates passages where it appears that either LaFaro or Evans perform a phrase that the other then responds to by imitating the melodic contour. These responsorial phrases can occur while the original phrase is still being played, or they can follows shortly after the initial line has concluded.

\section{Solar:}

As Evans finishes his repetitive rhythmic pattern at the end of Chorus B, LaFaro plays an ascending eighth-note leading into the top of Chorus $\mathrm{C}$. This ascending pattern continues for the following two bars of the new chorus, but LaFaro has stretched the rhythmic pattern to now consist of a dotted crotchet followed by a quaver. Evans at first leaves space for LaFaro to perform the melodic line, and then starts his own phrase that imitates the melodic contour that LaFaro continues to play.

Chorus B Bars 10-12 \& Chorus C Bars 1-3
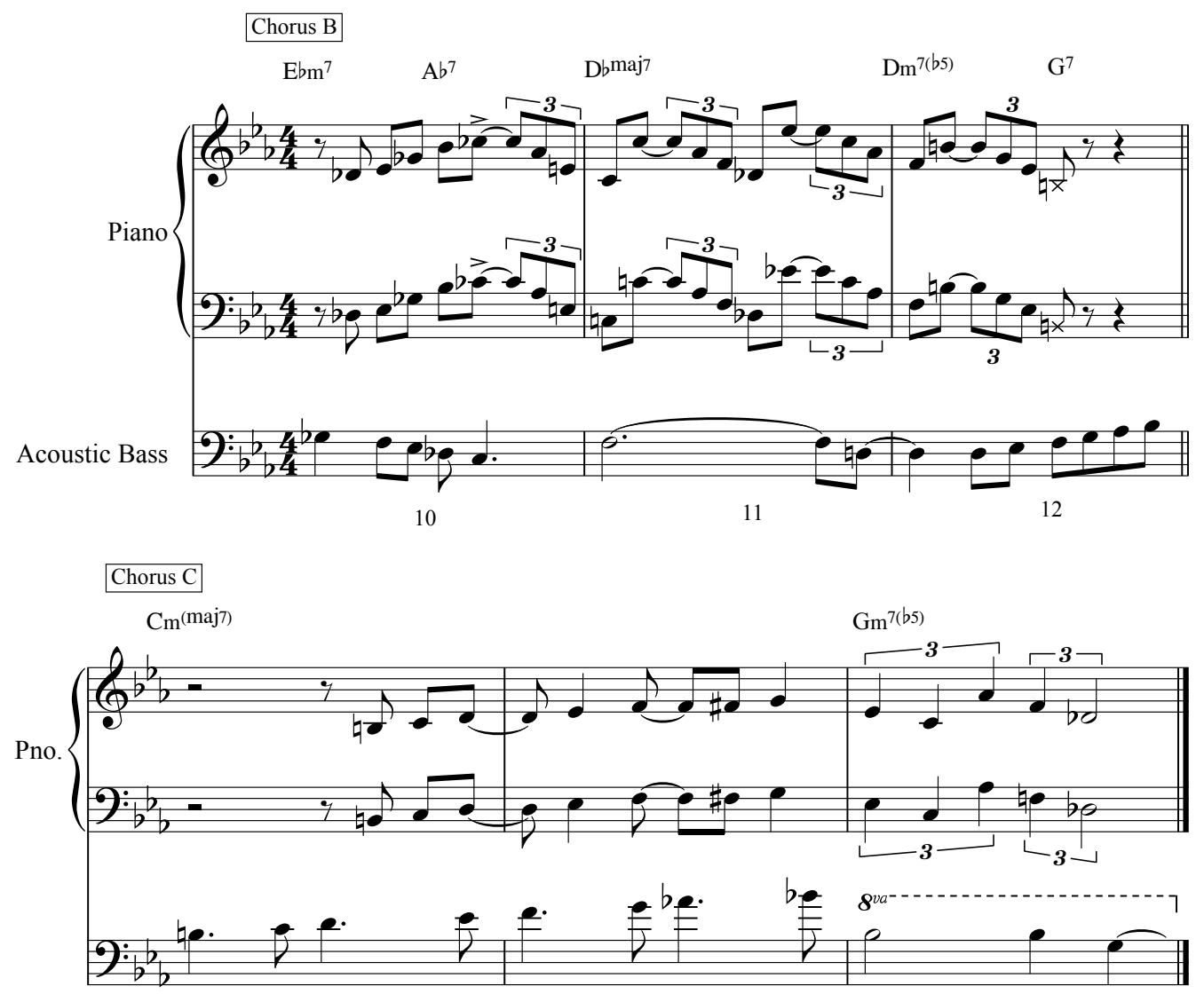

1

2

3 
Starting in the second bar of Chorus E, LaFaro plays a melodic line that mostly moves in intervals of seconds. He continues this pattern for another eight bars as he outlines the written harmony, employing tritone substitutions relative to the accepted harmony apparently to avoid making larger intervallic leaps. During the first five bars of this example, Evans includes a mixture of large and small intervals as part of his solo. However, after a small gap in his piano solo at bar seven, Evans begins his next phrase immediately using smaller intervals as the basis of his melodic idea. Perhaps Evans picked up on LaFaro's pattern and responded to it by changing his own melodic phrase to acknowledge LaFaro's melodic contour?

Chorus E Bars 2-9

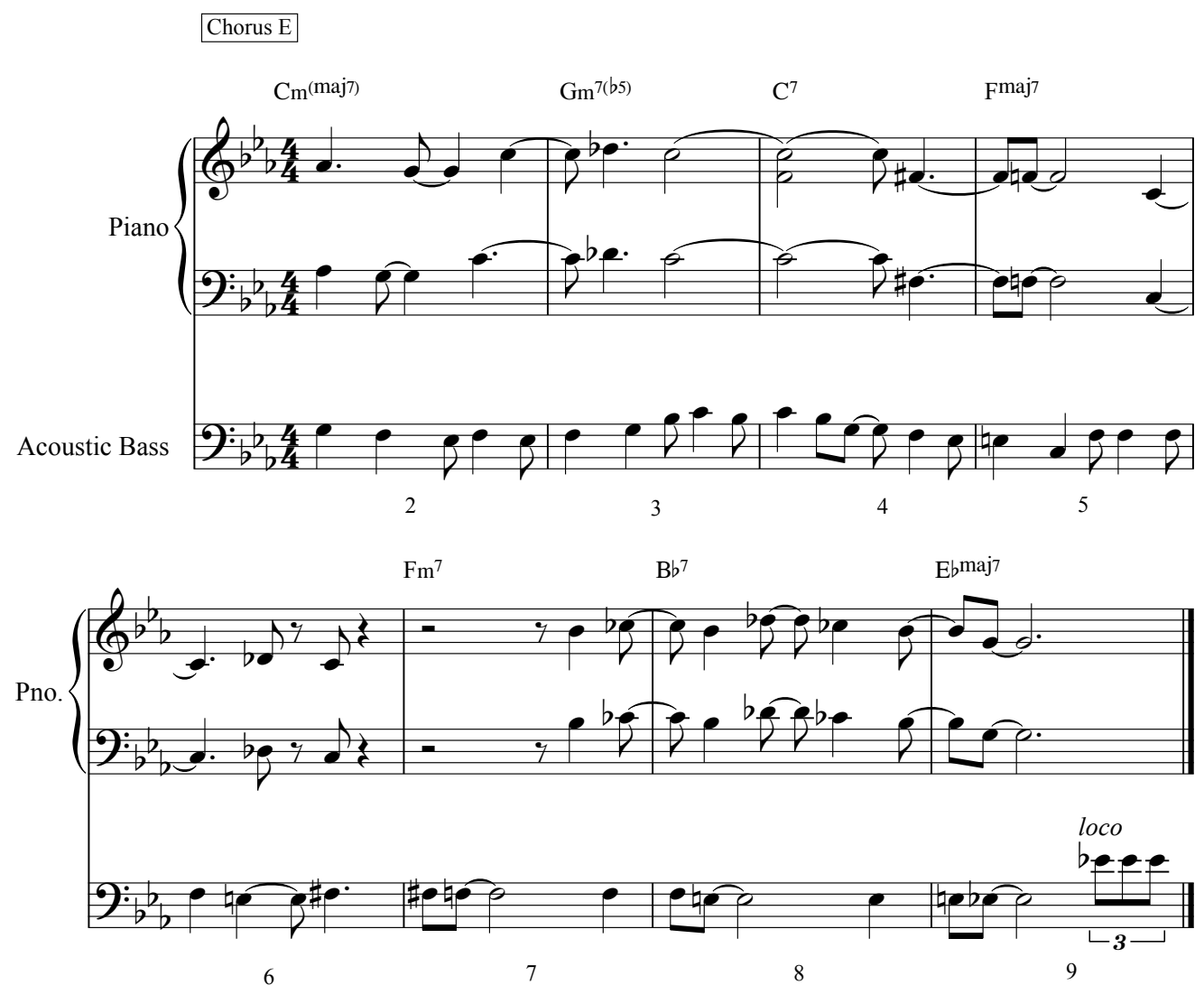




\section{Waltz For Debby:}

Over the course of bars 28-30, Evans plays a repetitive one bar ascending and descending phrase that clearly outlines the harmonic progression. At the same time LaFaro's playing is rhythmically conservative as he uses only minims while spelling the chord changes. This suddenly changes in bar 30 when LaFaro plays a short eighth-note run ascending to a high F. This short phrase clearly matches the melodic contour that Evans has repeated three times before LaFaro matched it. It seems that LaFaro may have heard Evans's repetitive pattern and decided to break his strict rhythmic accompaniment to join Evans as the melodic line ascended to its peak.

Chorus B Bars 28-31

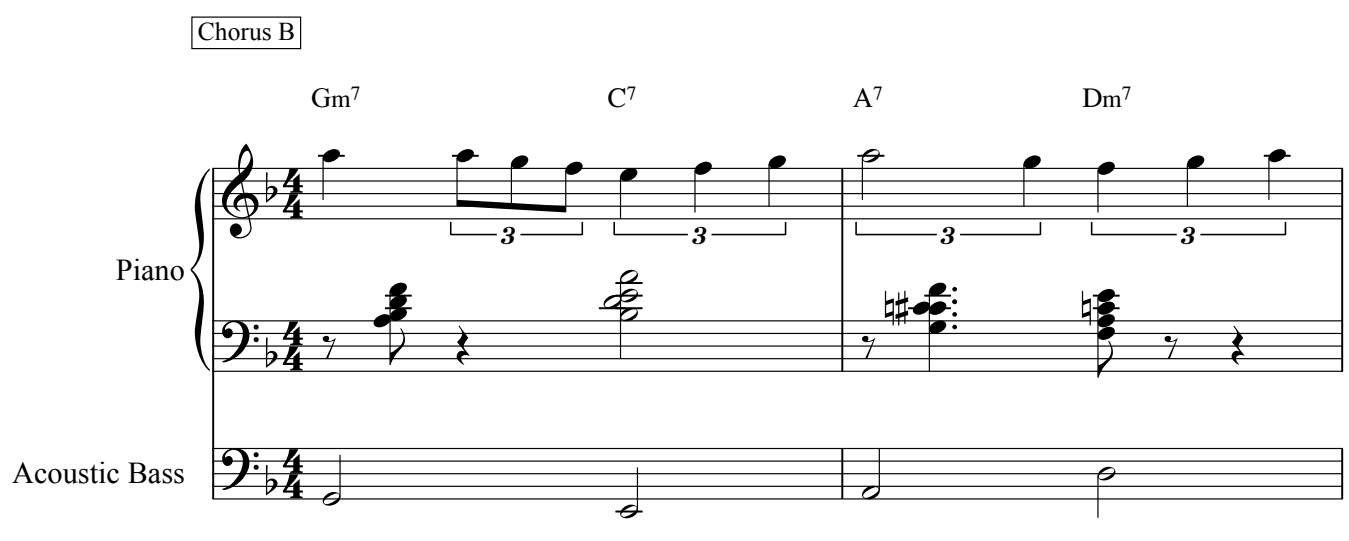

28

29

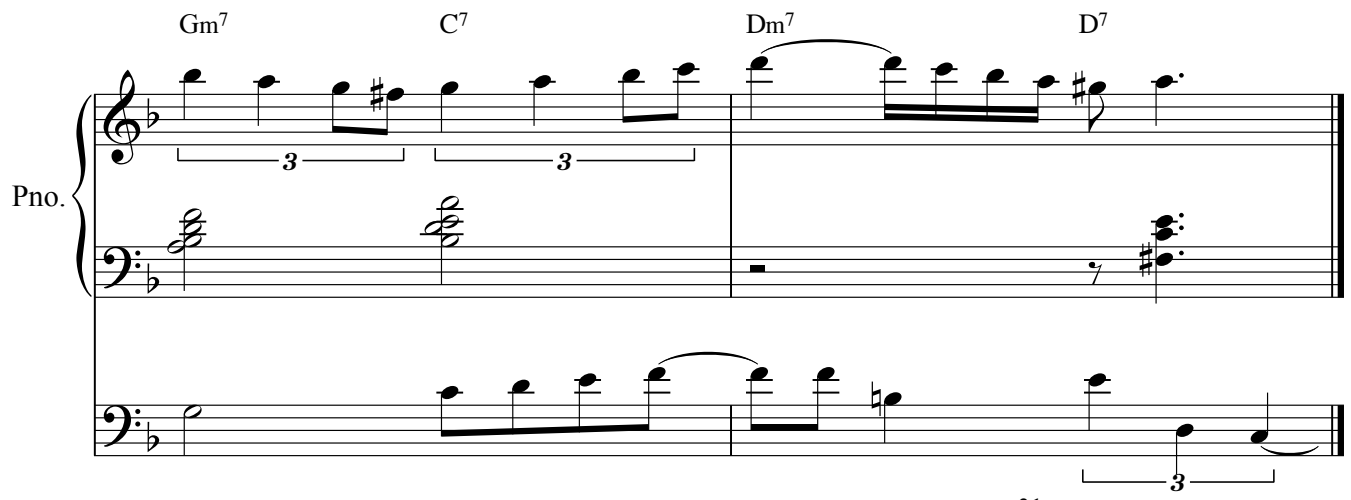

30

31 
In bar six of this example, Evans plays a descending melodic phrase that resolves as he holds the $\mathrm{C}$ for approximately two and a half beats. Immediately LaFaro begins to play a long ascending line, scaling over two octaves that peaks at a high $\mathrm{B} b$ in thumb position. As LaFaro's melodic line climbs ever higher, Evans seems to follow suit, making large intervallic jumps to keep up with his bassist. As Evans's line peaks at a high $\mathrm{G}$ he begins to descend towards a resolution in bar eleven. It seems that LaFaro follows Evans, reversing the contour of his own line only three beats after Evans had reached his peak, indicating that both musicians were open to interacting and following each others' phrases.

Chorus C Bars 6-11

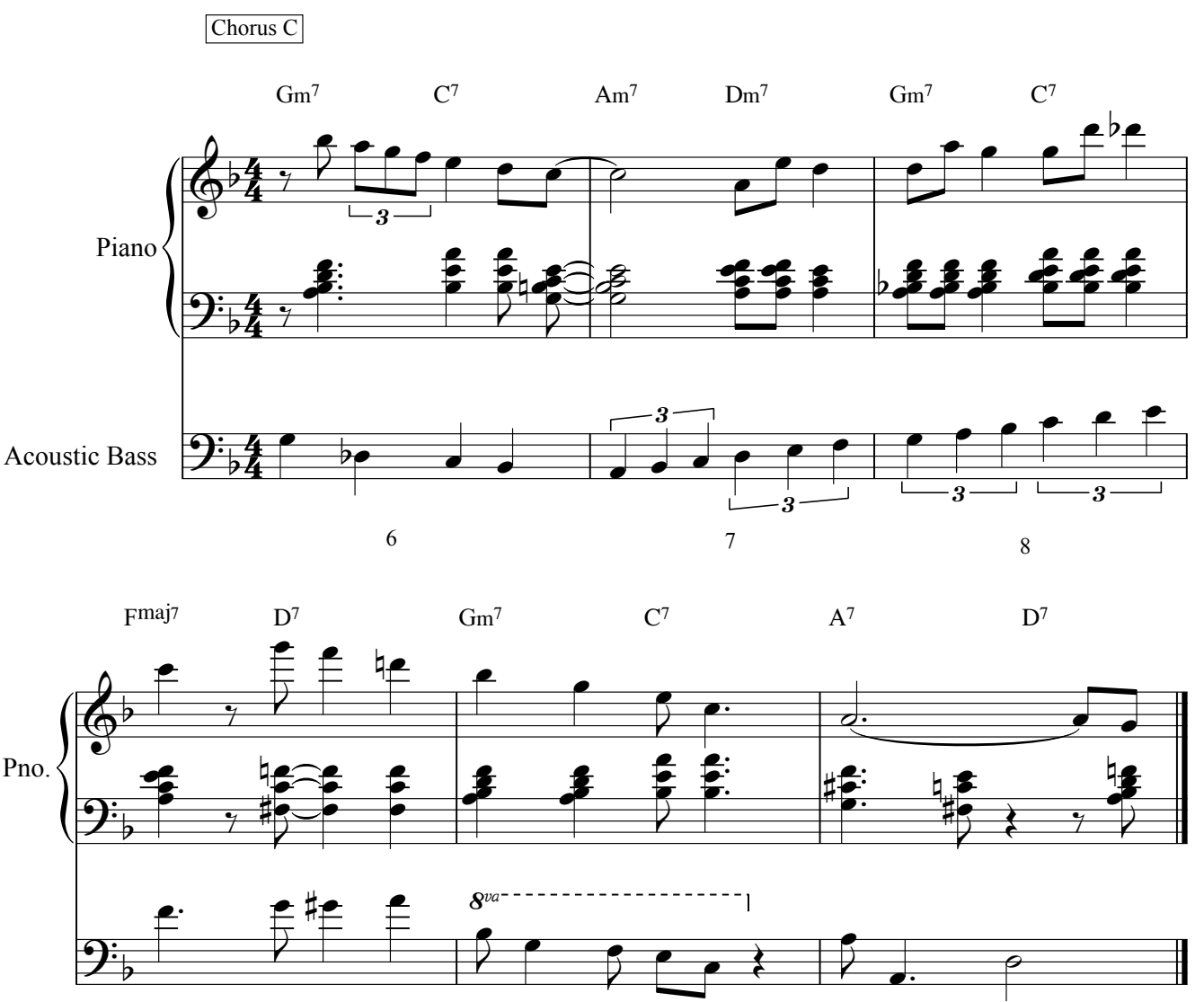

9 


\section{Alice In Wonderland:}

In this example, Evans plays a short ascending phrase made up of eighth notes that concludes with a crotchet at the melodic peak of the line. LaFaro complements this brief phrase by also playing an ascending phrase, starting with eighth notes and then playing a polyrhythm that eventually resolves on beat one of bar 47. It seems to me that LaFaro chose to respond to Evans's line as at bar 45 his approach dramatically changed. During the previous few bars, LaFaro had played conservatively in the lowest register of his bass, playing either quarter or half notes in his accompaniment. During this time Evans was soloing using large groupings of sixteenth notes that were the dominant feature of the performance at that point. However, as soon as Evans uses a different subdivision within his solo - the eighth note run at bar 45 - LaFaro immediately changes his approach, and his playing becomes more active as he imitates Evans's melodic contour.

\section{Chorus A Bars 45-47}

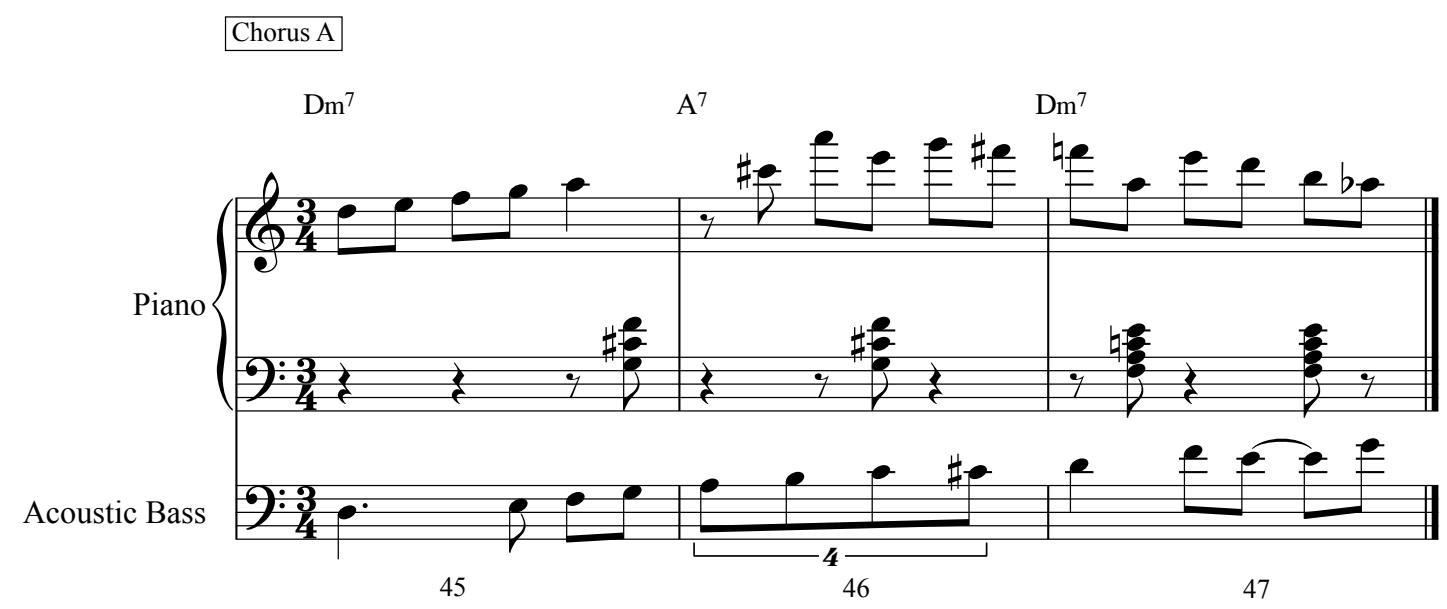

I could find no evidence of melodic contour interactivity in Nardis or Gloria's Step. 


\section{MIMESIS:}

I consider Mimesis occurs when one of the musicians attempts to precisely follow the melodic contour and rhythm of the original idea of another musician. They may not play the exact same note(s), as they may be moving through different harmonic changes at the time they play their mimetic phrase.

\section{Alice In Wonderland:}

This example contains two points of mimesis as played by LaFaro. During bar 37 Evans plays some eighth notes before descending in bar 38 using eighth note triplets. At this point LaFaro breaks from the long notes he had been playing for some time, and mimics the rhythmic phrase that Evans just played. What makes this more extraordinary is that as LaFaro is doing this, Evans repeats the same phrase, meaning that both musicians play the same rhythmic line at the same time. Also, the melodic contour of this phrase is identical with each musician's line ascending and descending in unison.

The second point of mimicry occurs in bar 39. As Evans descends and ultimately resolves his phrase, one beat later LaFaro seems to mimic the pianist's movements and uses the same rhythmic and melodic shape to resolve his own line before returning to a simpler accompanist's approach.

Chorus A Bars 37-39

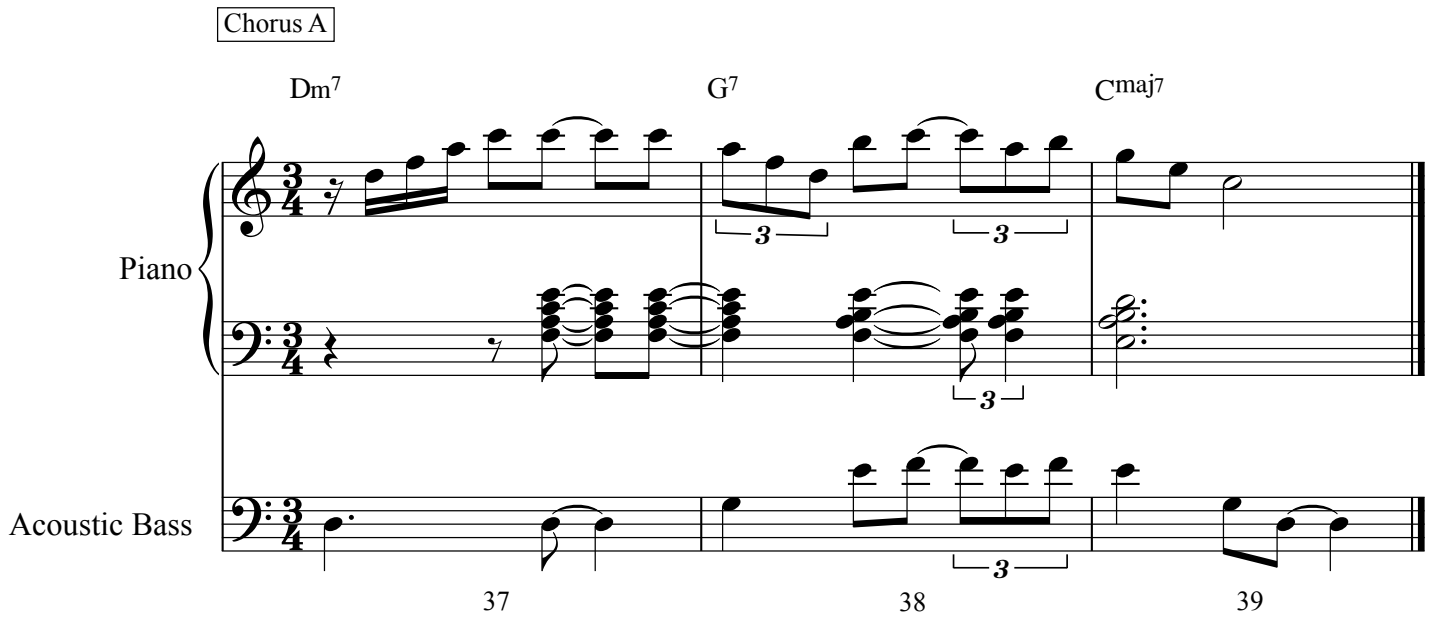




\section{Nardis:}

Two examples of mimesis are also evident in Nardis and occur in quick succession. As seen in the transcription, up until the final two bars of Chorus D LaFaro had been playing a selection of long tones, strictly outlining the harmonic progression in the lowest register of the bass. ${ }^{74}$ However, a space appears in bar 31 as Evans concludes his phrase.

LaFaro hears a gap in the piano solo and takes the opportunity to perform his own phrase. He quickly ascends to eventually pedal on a high $\mathrm{E}$ that he resolves on beat one of the following chorus. It is fair to assume that during the gap in the piano solo, Evans clearly hears LaFaro perform this ascending line, and quickly mimics LaFaro's rhythmic and contour shape exactly.

This example is immediately followed by another passage of mimesis beginning with LaFaro in bar one of Chorus E. After resolving his previous phrase on beat one, LaFaro performs another melodic statement involving a set of triplets and eighth notes that is resolved on the minim in bar two. One beat after LaFaro concludes his phrase, Evans mimics the rhythmic pattern resolving on beat four of bar two. LaFaro then continues this pattern, and one beat after Evans finishes copying LaFaro's first phrase, LaFaro repeats the rhythmic motif identically.

Chorus D Bars $31 \& 32$ - Chorus E Bars 1-3

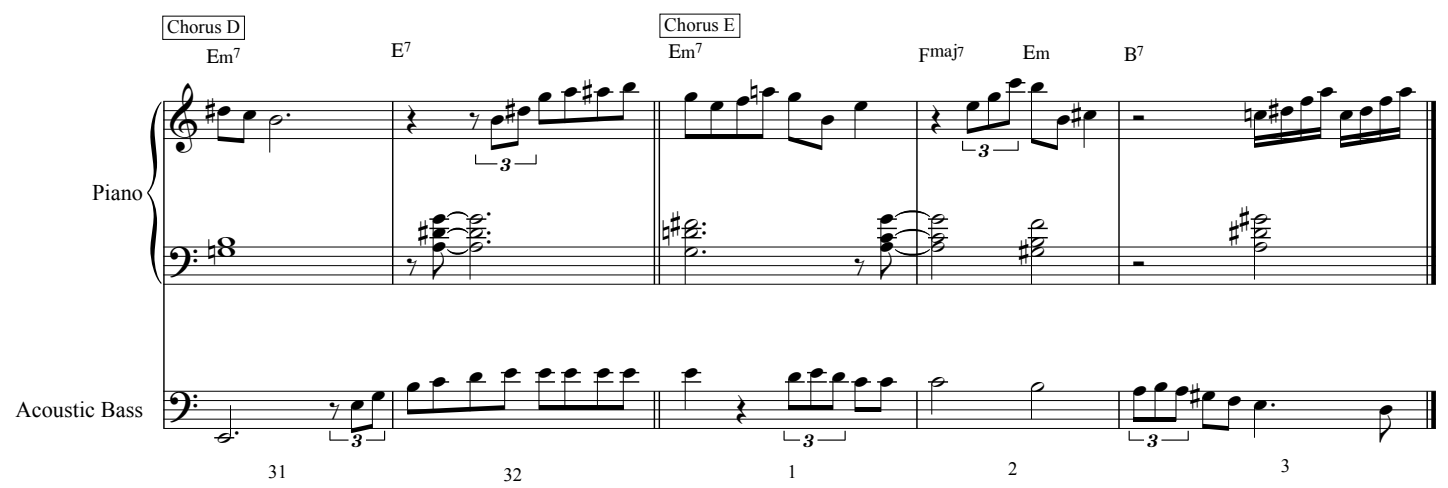




\section{Solar:}

In bar six of this example, LaFaro sets up an ascending quarter note triplet motif. This motif pedals between $\mathrm{C}$ and $\mathrm{G}$ to create a floating feeling to the harmony, as the $\mathrm{G}$ in the phrase does not strongly relate to the written harmony. LaFaro abruptly stops the motif after he plays a $\mathrm{Cb}$ in bar eight - the b9 in relation to the B 67 chord [possibly a mistake]. Shortly after this brief pause LaFaro begins playing the same rhythmic device again, this time primarily pedaling over a $\mathrm{B} b$ - the fifth of the written harmony - before concluding the phrase by outlining the harmony leading to $\mathrm{D} b$ in bar 11 .

Evans begins mimicking the motif during bar nine as LaFaro begins playing it again. Evans uses the motif to clearly outline the harmony at bar nine before resolving the line at bar eleven on $\mathrm{D} b$, just two beats after LaFaro had concluded his motif.

Chorus D Bars 6-11
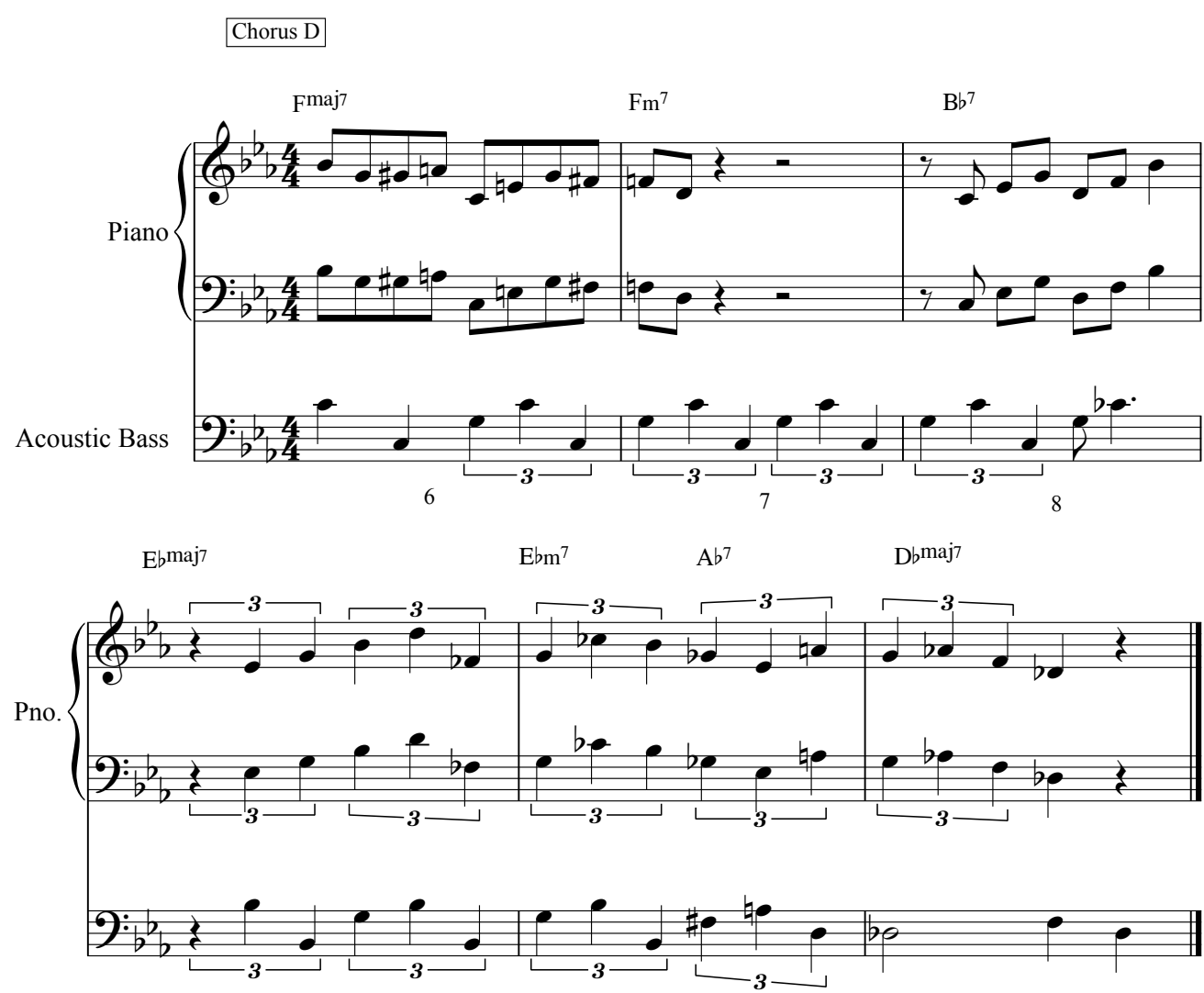

9

10 
In this example it is LaFaro who mimics and extends a phrase originally played by Evans. At the top of Chorus $\mathrm{N}$ Evans begins a new melodic phrase where he ascends an inverted $\mathrm{C}$ minor arpeggio. The basic rhythmic pattern of eighth notes clearly spells the chord, and the final held note helps accentuate the peak of the melodic phrase.

Immediately LaFaro mimics this idea by taking the same melodic contour and rhythmic structure and plays his version of the phrase in the same position in the next bar. While LaFaro begins his phrase on the same note that Evans did in bar one, he changes the note choice to clearly outline the Gmin7(b5) chord change at bar three.

LaFaro continues with this melodic idea by playing the same phrase in bar four. This time his note choice clearly outlines the new $\mathrm{C} 769$ chord change that occurs in that bar. And again two bars later, he plays the same rhythmic motif except this time he changes the melodic contour of the phrase and descends to ultimately resolve the line on the $\mathrm{F}$ tonic note of the key centre.

Chorus N Bars 1-6
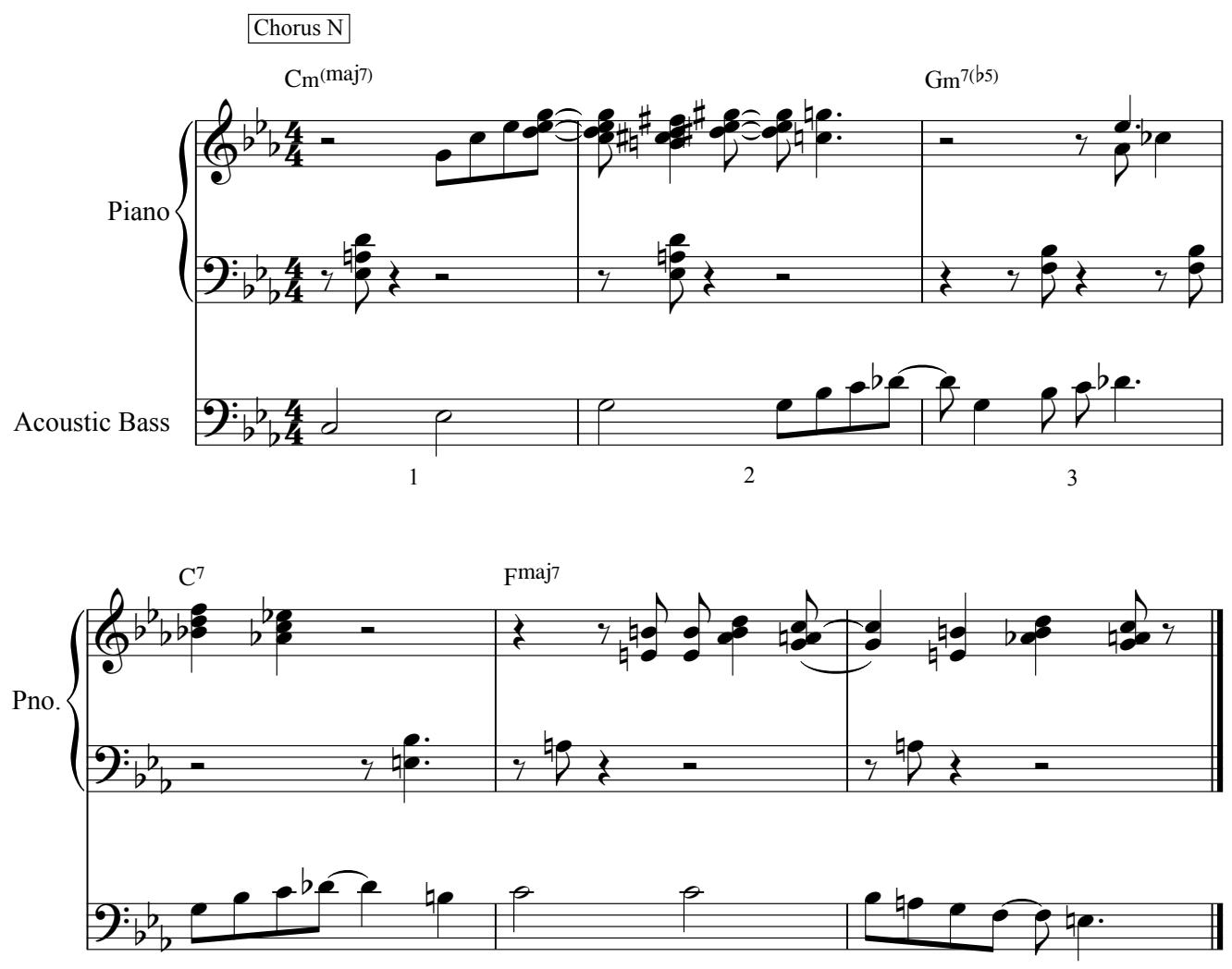


\section{Gloria's Step:}

During the first bar of this example, Evans plays a rhythmic figure that repeats using an eighth and a quarter note in sequence. The motif has the range of a tone, cycling between the $\# 9$ and b9 of the C7alt chord that is part of the written harmony. The very next bar LaFaro repeats the rhythm of Evans's phrase and also matches the melodic contour, playing between $\mathrm{F}$ and $\mathrm{E} b$, complementing the chord change in the second bar.

Chorus F Bars 4-5

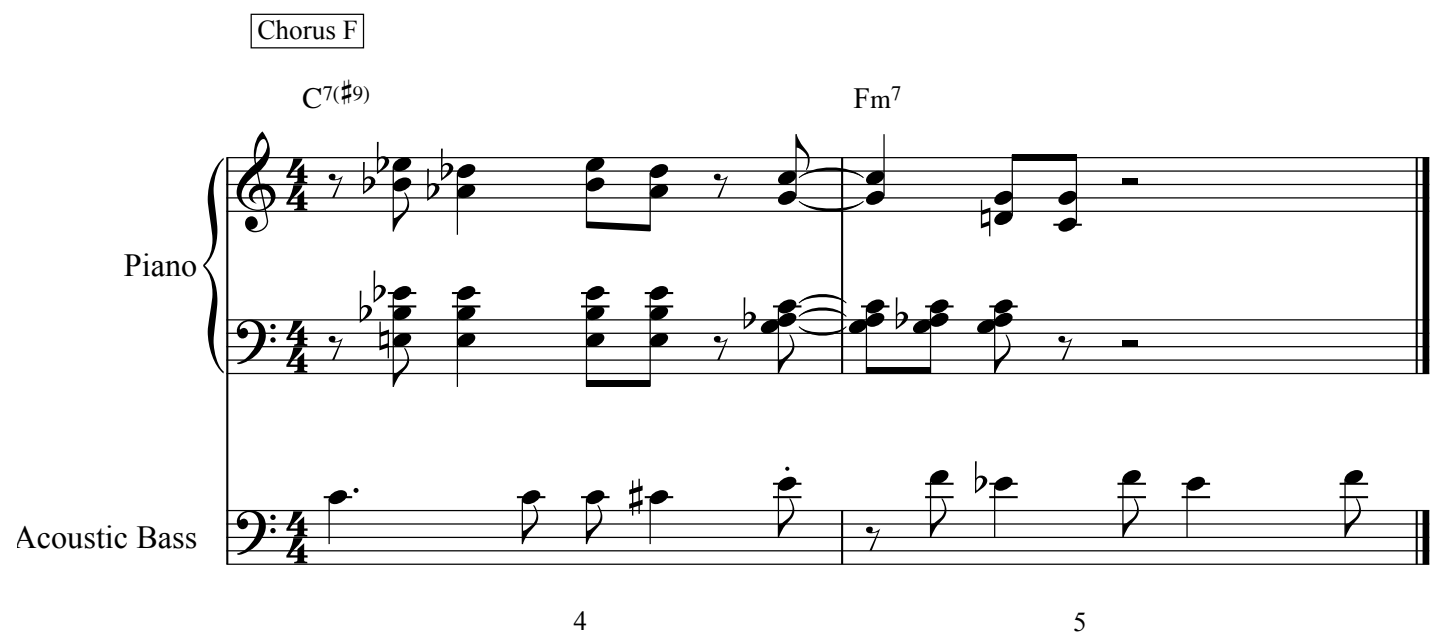

I could find no evidence of this kind of mimesis in Waltz For Debby. 


\section{MELODY:}

\section{COMMON SCALAR AND ARPEGGIO MOTIFS}

In this section I have examined my sample for any scalar or arpeggiated patterns that LaFaro uses sometimes repetitively - as part of his accompanying approach. When searching for scalar phrases I looked for a passage where LaFaro consistently continued playing the same contour, playing semitones or tones, outlining some sort of scale. The contour would not be affected by a song's chord changes - for example LaFaro may employ substitutions within his lines so as to keep the contour of the scalar device continuing through the harmonic progression of the song.

The arpeggiated motifs I isolate are phrases where LaFaro exclusively uses chord tones as part of his accompaniment. These arpeggios are sometimes repetitive motifs that LaFaro alters to conform to a song's harmonic progression, or sometimes simply form part of his accompaniment to outline the written harmony of a song.

\section{Solar:}

\section{Scalar Runs:}

This scalar passage is a good example of the melodic range LaFaro used across the bass. In the final measure of Chorus B LaFaro begins an eighth note phrase ascending up a D Locrian scale before changing the rhythm at the start of Chorus C. At this point the stated harmony of the song changes to a Cmin(maj7) chord, and LaFaro alters his ascending pattern accordingly. Starting on a $\mathrm{B}$ ң LaFaro outlines the $\mathrm{C}$ minor-major scale over the following two bars. He concludes the passage with a $\mathrm{B} b$, anticipating (the minor $3 \mathrm{rd}$ of) the next chord change - Gmin7 b5.

Chorus B Bar 12 - Chorus C Bars 1-3

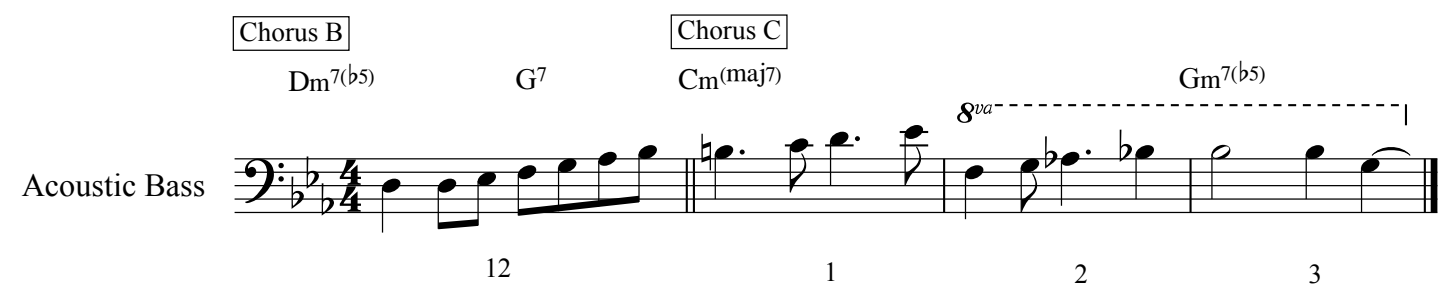


During Chorus H, LaFaro also performs a scalar run at the start of the form. Halfway through bar one, LaFaro begins a descending passage that begins on the fifth $(\mathrm{G})$ of the Cmin(maj7) chord. This continues until bar three where LaFaro changes the melodic direction and begins to ascend. Also at bar three LaFaro seems to change the harmonic structure of the scalar device to match that of the new key centre. Whilst the written harmony in bar three is Gmin7 b5, it appears that LaFaro's scale is outlining the following C7 chord, effectively omitting the iimin7 chord and taking two bars on the V7 chord before completing the phrase in bar five.

Chorus H Bars 1-5

$$
\begin{array}{r|}
\text { Chorus } \mathrm{H} \\
\mathrm{Cm}^{\text {(maj7) }}
\end{array}
$$

Acoustic Bass
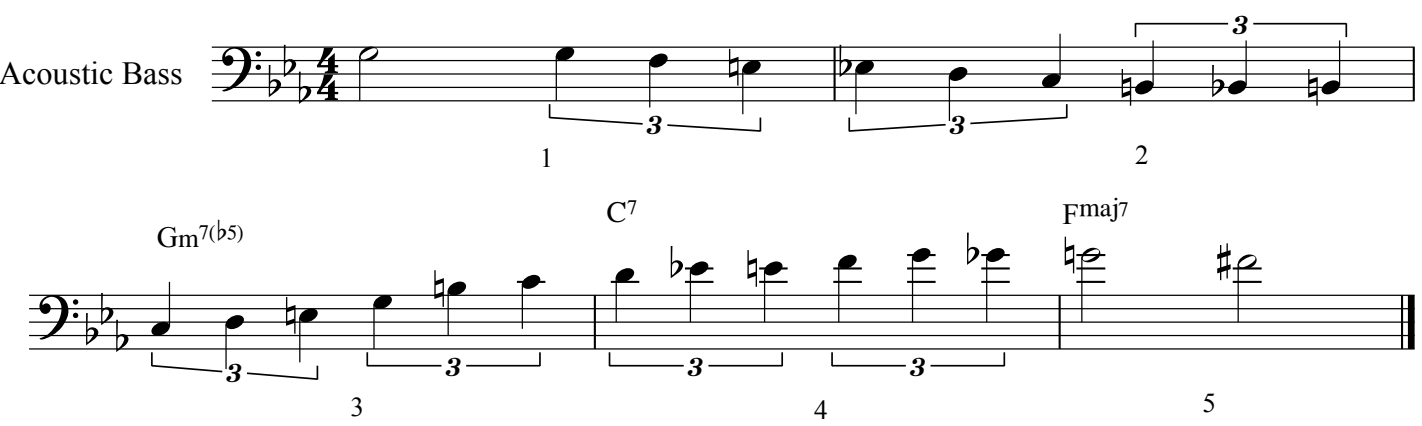

\section{Arpeggios:}

In this example, LaFaro seems to imitate Evans's original arpeggiated phrase at the beginning of chorus $\mathrm{N}$. LaFaro uses the same melodic contour to outline the Cmin7 chord as written in the harmony before concluding the motif by resolving on a $\mathrm{D} b$ - the flattened fifth of the following $\mathrm{Gm} 7 \mathrm{~b} 5$ chord in bar three. ${ }^{75}$ LaFaro then plays the same arpeggiated motif at the start of bar four, but as the written harmony has changed to a $\mathrm{C} 7$ chord, his phrase resolves on the b9, superimposing an altered type of harmony on the dominant chord.

Chorus N Bars 1-9

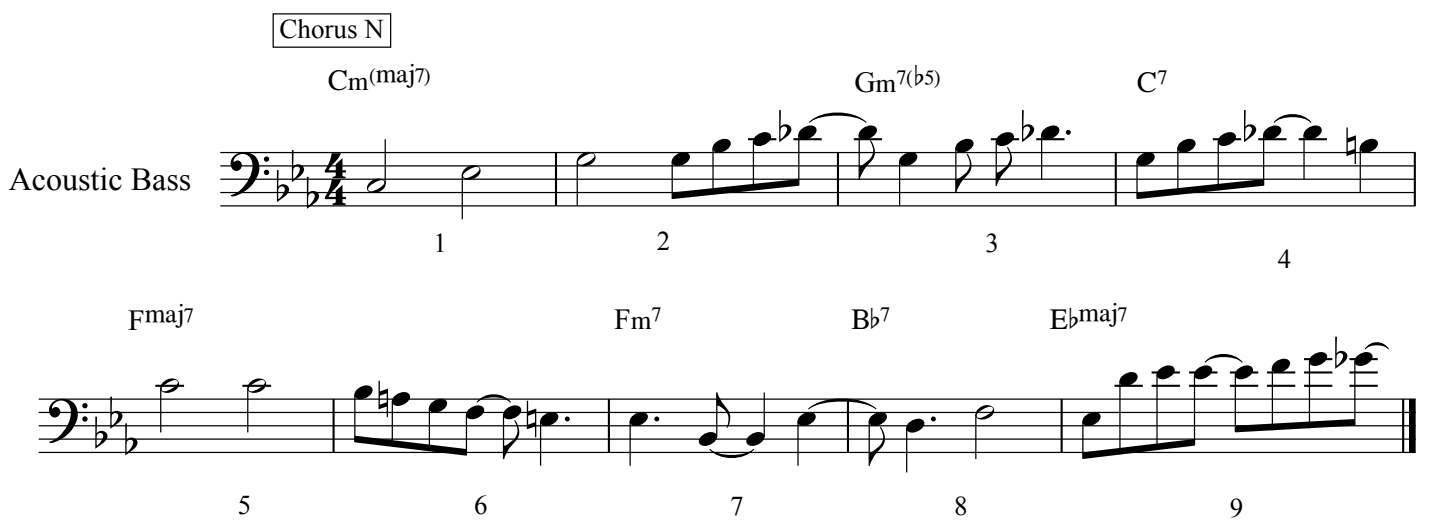

75 More information about this passage in terms of interactivity can be found in the Mimesis discussion on p.65 of this chapter. 


\section{Gloria's Step:}

\section{Arpeggios:}

In this example, LaFaro spells the two chord changes by exclusively playing chord tones within his bass line. After starting on a high E, LaFaro descends quickly, outlining the rest of the chord before playing a double stop made up of the minor $3^{\text {rd }}(G)$ and minor $7^{\text {th }}(D)$ of the Emin7 harmony. He then goes on to outline the Fmaj7 chord change in bar two by first playing the fifth (C) before descending down the triad and resolving on a low $\mathrm{F}$ in the bottom register of the bass.

Chorus B Bars 11-12

Chorus B

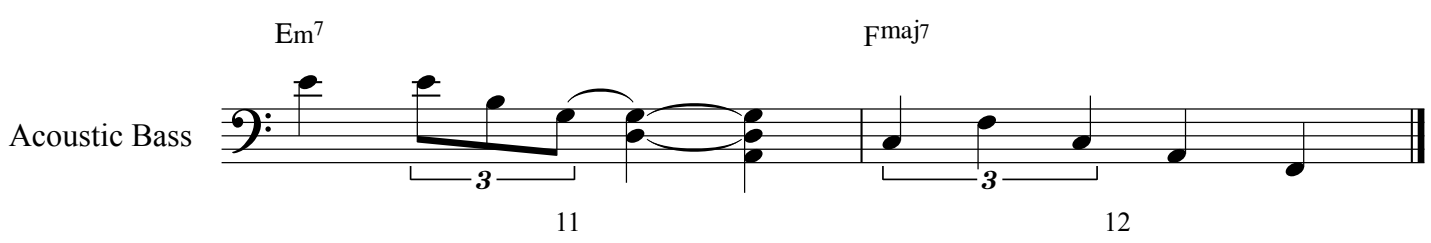

\section{Nardis:}

\section{Scalar Runs:}

The following two examples show LaFaro clearly outlining an E natural minor scale at the very end of both Chorus $\mathrm{D}$ and $\mathrm{E}$. The first example shows LaFaro ascending an $\mathrm{E}$ minor triad, including the flattened sixth and seventh to outline the song's E natural minor (Aeolian) harmony. He finishes the phrase by pedaling on a high E, resolving the line at the beginning of the following chorus.

Chorus D Bars 31-32 - E Natural Minor scale

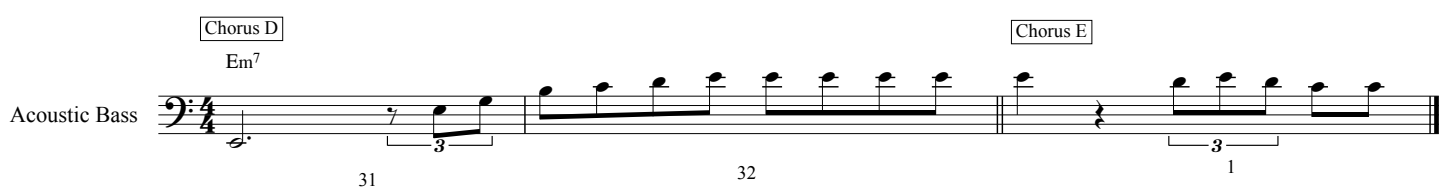

Chorus E Bars 31-32 - E Natural Minor Scale

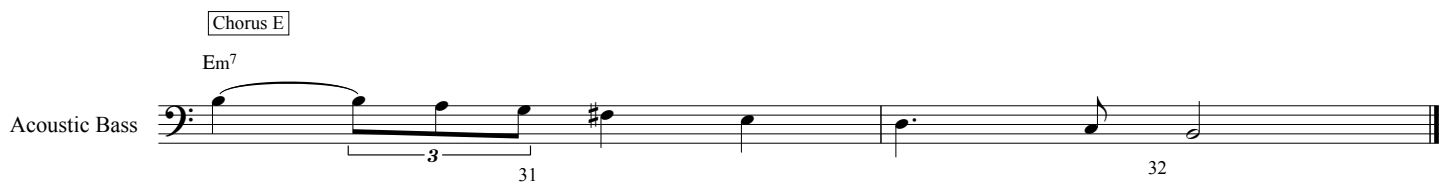




\section{Waltz For Debby:}

\section{Scalar Runs:}

This brief example shows LaFaro beginning a scalar phrase on the root note of the written D7 chord. He continues ascending up a scale that then incorporates the Gmin7 chord change in the following bar. At the peak of the scalar line LaFaro plays a $\mathrm{B} b$ - the $b 7$ of the written $\mathrm{C} 7$ chord - before dropping to an $\mathrm{E}$ a to conclude the phrase.

Chorus B Bars 3-4

Chorus B

$\begin{array}{llll}\text { Fmaj7 } & \mathrm{Dm}^{7} & \mathrm{C}^{7}\end{array}$

Acoustic Bass

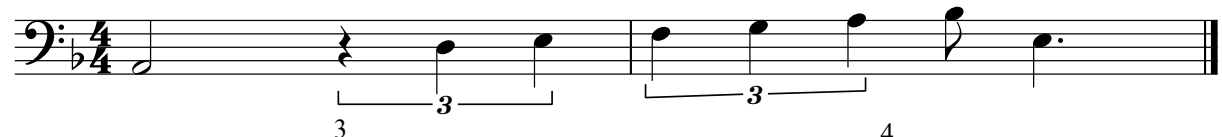

Later in the same chorus LaFaro performs another scalar phrase that climbs into the higher register of the bass. After holding a $G$ during the first bar of the example, LaFaro begins a quick ascent of a G Dorian scale using mostly eighth notes. At the end of bar 17 he anticipates the subsequent Amin7 chord change by holding the minor $3^{\text {rd }}-\mathrm{C}$ - before continuing with the scale. After breaking up the rhythm he eventually resolves the phrase at the start of bar 19 on a high B b - the minor third of the written Gmin7 chord change, after which his line starts to descend back down the bass.

Chorus B Bars 17-19

Chorus B

$\begin{array}{llllll}\mathrm{Gm}^{7} & \mathrm{C}^{7} & \mathrm{Am}^{7} & \mathrm{D}^{7} & \mathrm{Gm}^{7} & \mathrm{~A}^{7}\end{array}$

Acoustic Bass

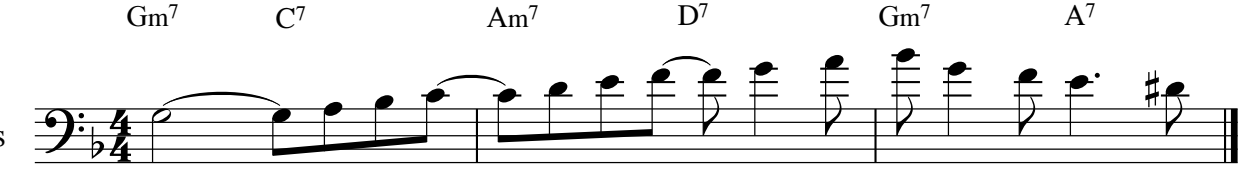

17

18

19 
Using quarter note triplets, LaFaro begins a two-bar ascent that manages to outline four different chord changes without having to break the contour of the phrase. LaFaro's scalar device incorporates the root note and $3^{\text {rd }}$ of every chord change as it ascends ever higher, finally resolving on beat one of bar three. By its conclusion, LaFaro's phrase has covered nearly two octaves in the space of two bars.

Chorus C Bars 7-9

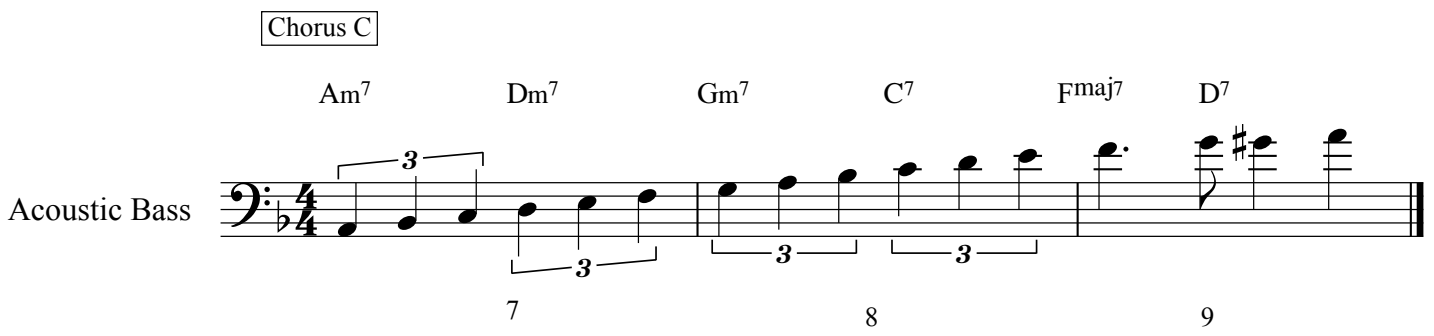

\section{Alice In Wonderland:}

\section{Scalar Runs:}

This example shows LaFaro playing a brief scalar passage across one octave in the lower register of the bass. After holding a D at the start of bar one, he begins to ascend a D Dorian scale. LaFaro constructs the scalar phrase to play an A at the start of the second bar, outlining the A7 chord change before finally resolving the phrase on the Dmin7 chord change in bar three.

Chorus A Bars 45-47

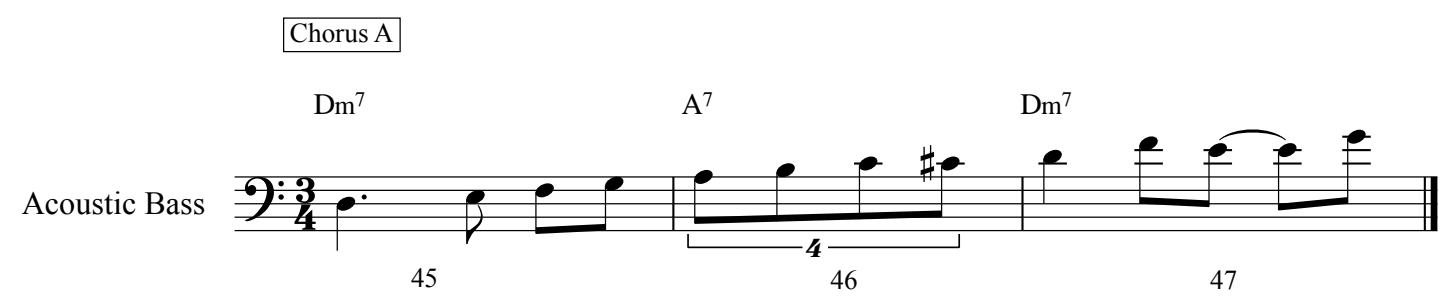

\section{Arpeggios:}

During the melody (in head) of Alice In Wonderland, LaFaro briefly abandons his traditional accompanist approach behind Evans and performs an arpeggiated motif consisting of two $\mathrm{C}$ major triads. Starting on a low $\mathrm{C}$ in the bottom register of the bass, LaFaro quickly ascends one and a half octaves to peak at a high $\mathrm{G}$ in thumb position before he resolves the motif by moving down a semitone to $\mathrm{F} \#$ in the third bar and returning to a traditional accompanying role. 
In Head Chorus: 33-34

In Head Chorus

$\mathrm{C}^{\mathrm{maj} 7}$

Acoustic Bass

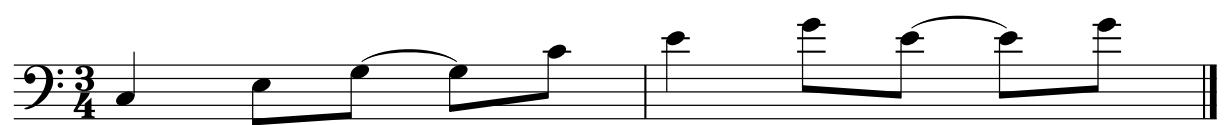

33

34

Over this three bar example, LaFaro plays a repetitive rhythmic motif and outlines the triadic notes of each chord change.

Chorus B Bars 57-59

Chorus B

$\mathrm{Dm}^{7} \quad \mathrm{G}^{7} \quad \mathrm{C}^{\text {maj7 }}$

Acoustic Bass

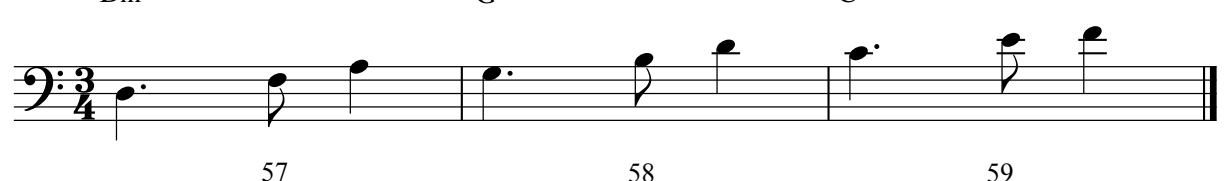

58

\section{MELODIC QUOTATION:}

As discussed earlier in chapter two, I have examined LaFaro's playing for examples of passages of melodic quotation. These phrases consist of recognizable melodies from either another song, or fragments of the melody from the song that he was playing at the time.

\section{Solar:}

Amongst my sample, the most substantial example of this approach comes from LaFaro's performance in Solar. LaFaro's entrance into the song quotes the melody with Evans at bar nine in the opening chorus.

Chorus 1 Bars 9-12

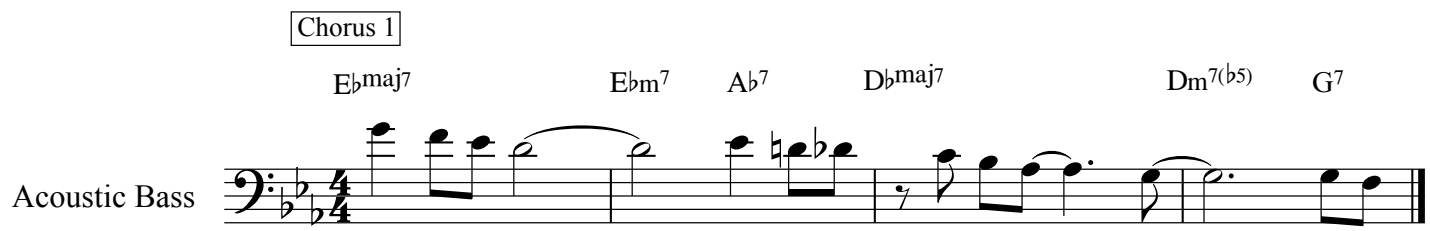

9

10

11

12 
As shown in this example, he continues to strongly hint at the melody in the following chorus, usually echoing the same melodic statement that Evans has just played.

At the very end of Chorus two, LaFaro loosely quotes the last phrase of the written melody to lead his bass line into the piano solo. At this point, as is common in small ensemble performances, Evans abandons the song's written melody after playing it for two choruses and begins his solo. However, underneath the first two choruses of piano solo, LaFaro's accompaniment is almost exclusively made up of quoting the song's melody.

Chorus 2 Bars 1-12

Chorus 2

$\mathrm{Cm}^{\text {(maj7) }} \quad \mathrm{Gm}^{7(\mathrm{~b} 5)} \quad \mathrm{C}^{7}$

Acoustic Bass
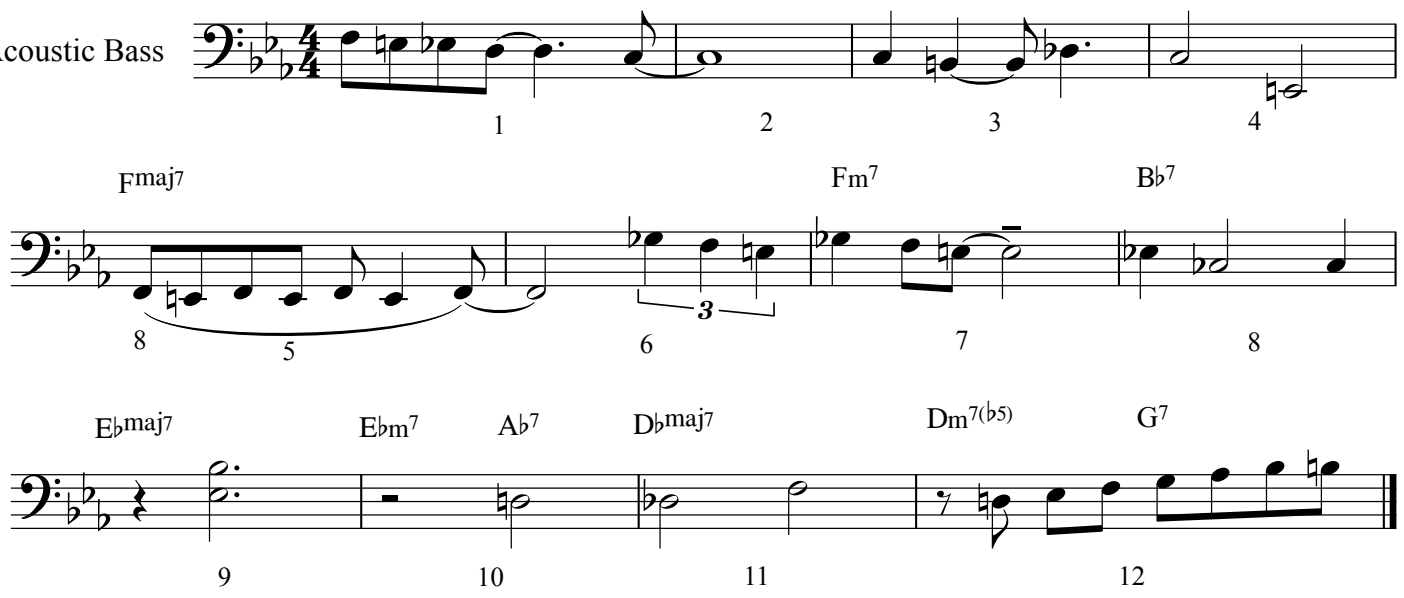
Chorus 2 Bar 12 \& Chorus A + B

Chorus 2

$\operatorname{Dm}^{7(b 5)} \quad \mathrm{G}^{7} \quad \mathrm{Cm}^{\text {(maj7) }}$

Chorus A

Acoustic Bass

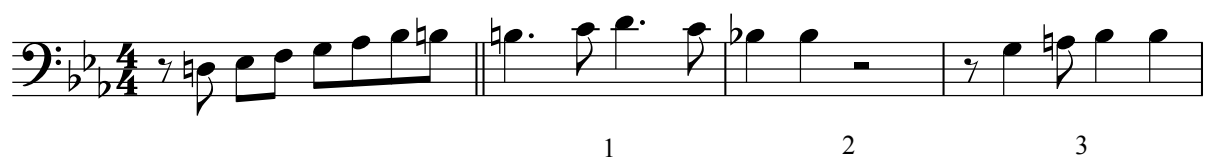

$\mathrm{C}^{7}$

Fmaj7

$\mathrm{Fm}^{7}$

$\mathrm{Bb}^{7}$

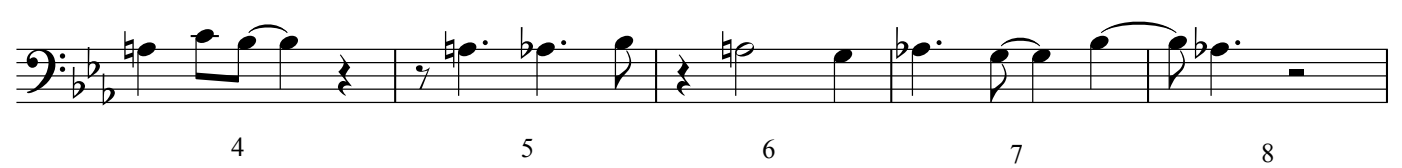

Ebmaj7

$\mathrm{Ebm}^{7}$

$\mathrm{A} b^{7}$

$\mathrm{D} b$ maj7

$\mathrm{Dm}^{7(b 5)}$

$\mathrm{G}^{7}$

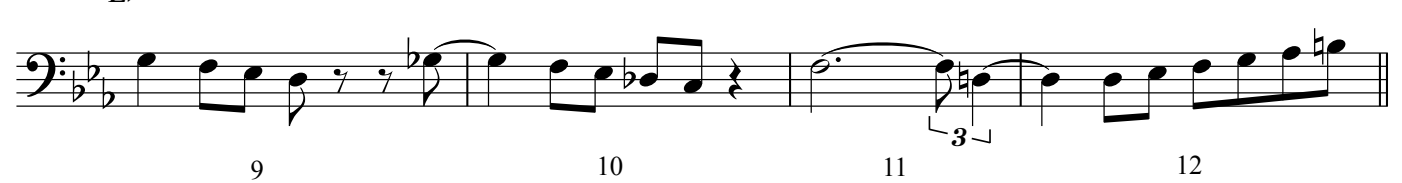

10

12

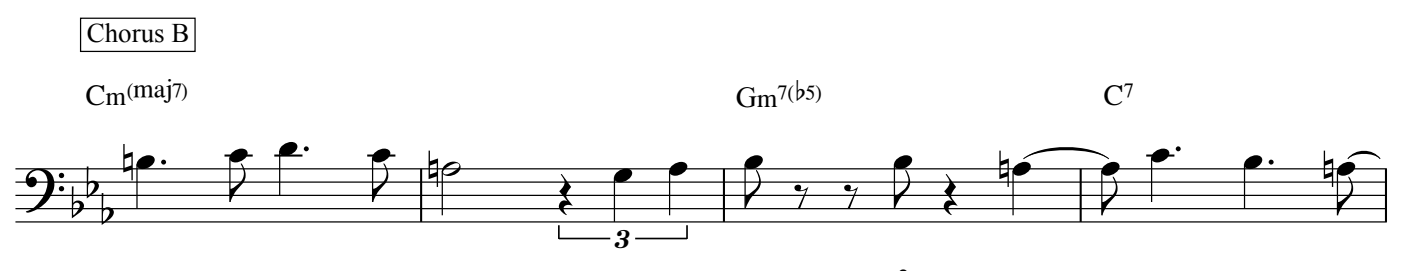

1

4

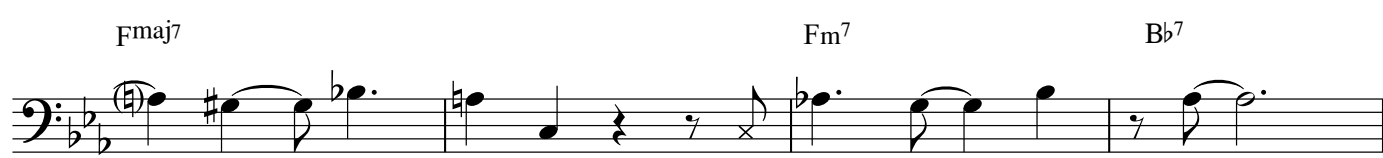

5

6

7

8

$\mathrm{E} b$ maj7

$\begin{array}{lll}{\mathrm{E} b \mathrm{~m}^{7}}^{7} & \mathrm{~A} b^{7} & \mathrm{D} b^{\text {maj7 }}\end{array}$

$\mathrm{Dm}^{7(b 5)}$

$\mathrm{G}^{7}$

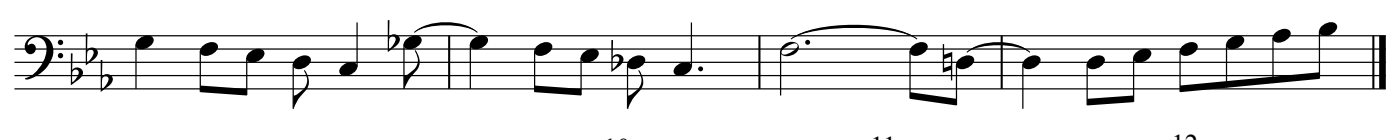

9

10

11

12 


\section{Waltz For Debby:}

During the in head of Waltz For Debby, LaFaro takes an opportunity to quote part of the melody. During the second chorus of the in head, LaFaro plays a part of the melody in unison with Evans.

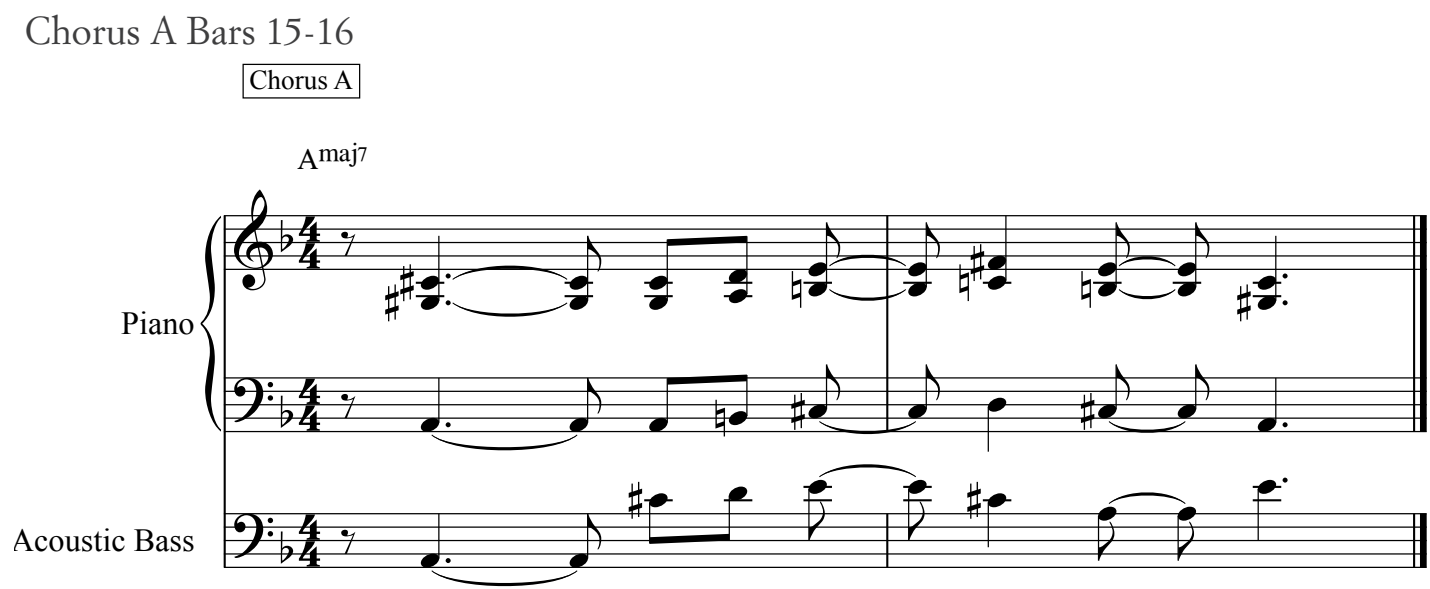

15

16

\section{MELODIC INTERJECTIONS:}

Throughout my sample, there are numerous examples of LaFaro melodically interjecting phrases during Evans's piano solo. These phrases occur whenever Evans leaves a brief gap in between his own melodic statements. As the following examples show, while Evans is performing a phrase, LaFaro is accompanying in a more conservative and traditional manner, usually playing in the lowest register of the bass and rhythmically using longer tones underneath the piano solo. However, as soon as Evans leaves a space in his solo, LaFaro immediately changes his approach, changing his own phrases to include eighth note runs and often quickly ascending the bass to play in the higher registers. It would appear that LaFaro would sense a brief gap in Evans's solo, in which he would take the opportunity to make his own melodic statement. LaFaro's phrase would generally conclude almost as soon as Evans played a new melodic idea, at which point LaFaro would relinquish the lead voice to Evans and would once again return to a more traditional role. 


\section{Alice In Wonderland:}

During the piano solo in Alice In Wonderland, LaFaro takes a number of opportunities to fill the gaps left by Evans. The first example shows Evans completing his melodic phrase by descending in eighth notes before resolving the line in bar 15 . As soon as this resolution has occurred LaFaro breaks from his rhythmically simple accompaniment, and using eighth notes quickly ascends into the higher register of the bass. As Evans begins his new phrase at bar 17, LaFaro changes back to playing longer rhythms before dropping back down into the lower register of the bass.

Chorus A Bars 13-18
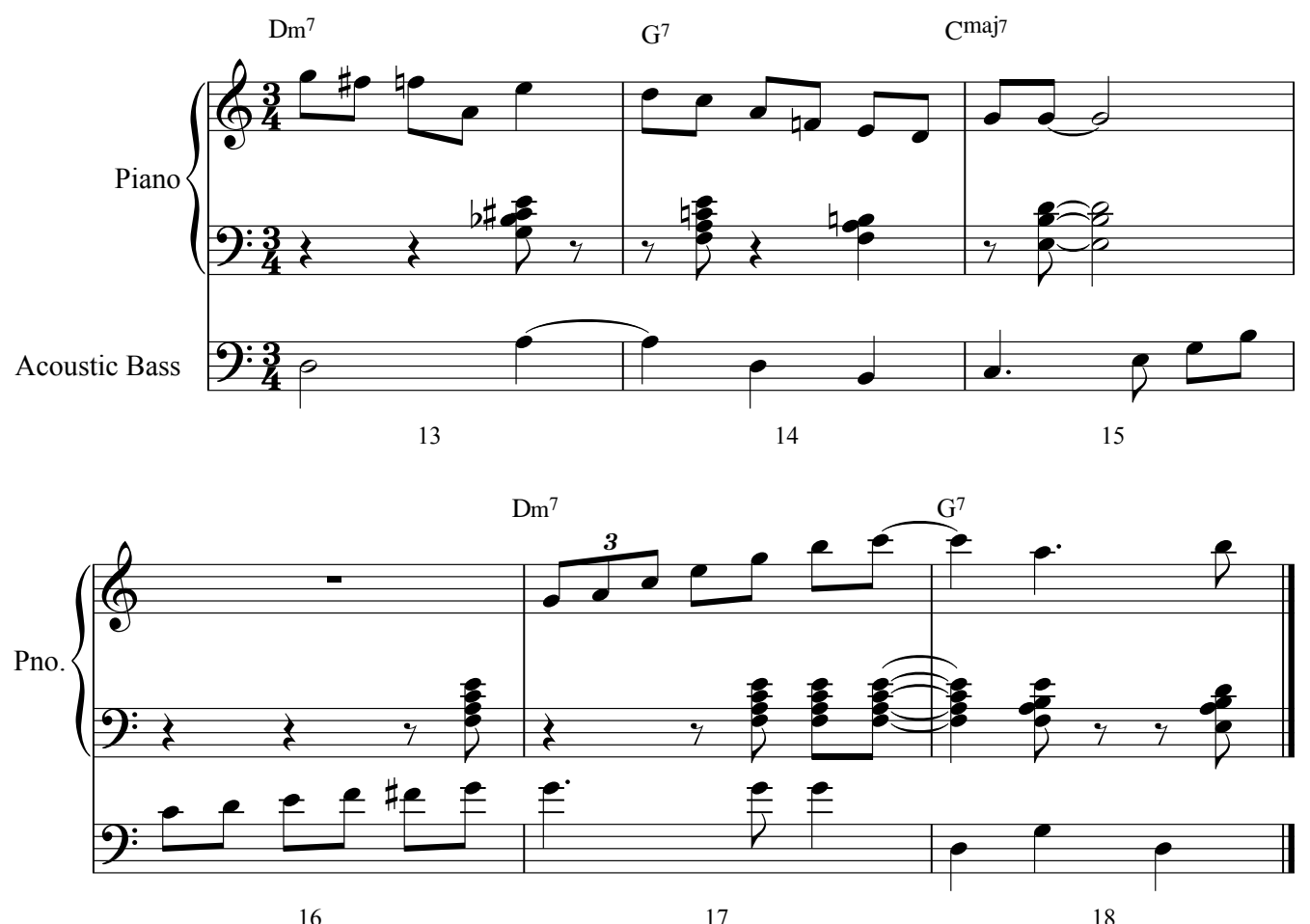

16

17

18

The next example shows LaFaro playing a repetitive rhythmic pattern under Evans's piano solo until at the end of the third bar he begins a long ascending line using mostly eighth notes. Unlike the above example this phrase begins while Evans is also playing an eighth note line. It appears that during the fourth bar Evans had heard LaFaro starting to play a busier phrase, and he resolves his own melodic line to let LaFaro's phrase stand out. However, as soon as the following chorus begins, LaFaro immediately reverts back to playing longer tones underneath another busy rhythmic line from Evans. 
Chorus A Bars 60-64 \& Chorus B Bars 1-2

Chorus A

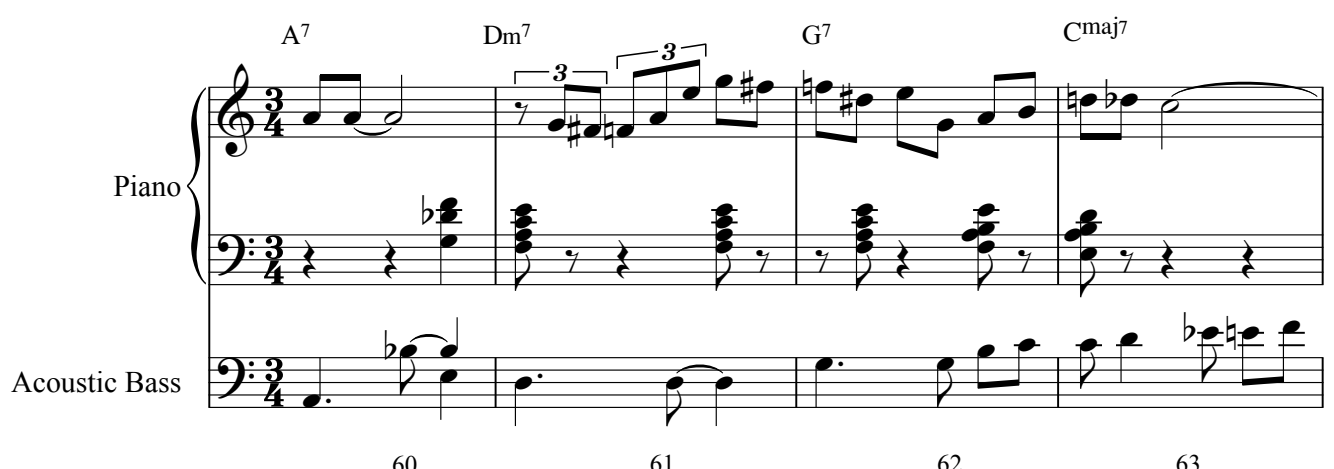

60

61

62

63

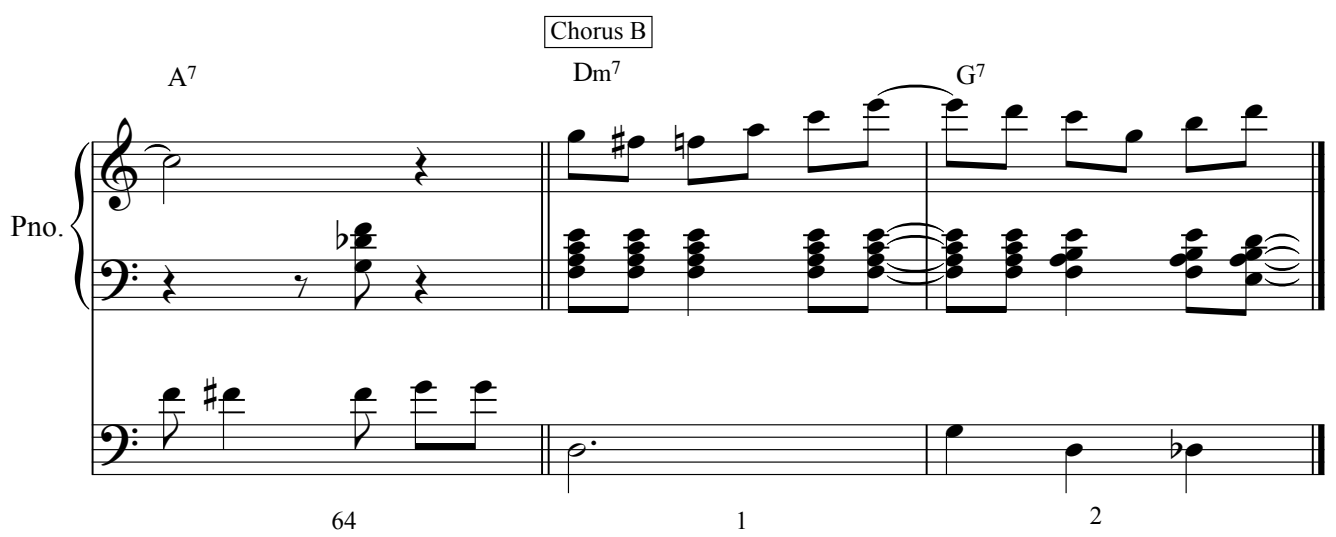


The following two examples are taken from the out head of the performance. In both cases they clearly illustrate LaFaro playing simple long notes behind Evans's melody, until suddenly LaFaro jumps into the higher register of the bass to play his own melodic phrase. In both of these cases the brief phrase from LaFaro occurs at the very end of the A sections, and I believe it is reasonable to conclude that LaFaro had pre-determined these figures as Evans was most likely going to leave a gap as the melody had resolved at the end of each section.

Chorus F (Out head) Bars 15-16

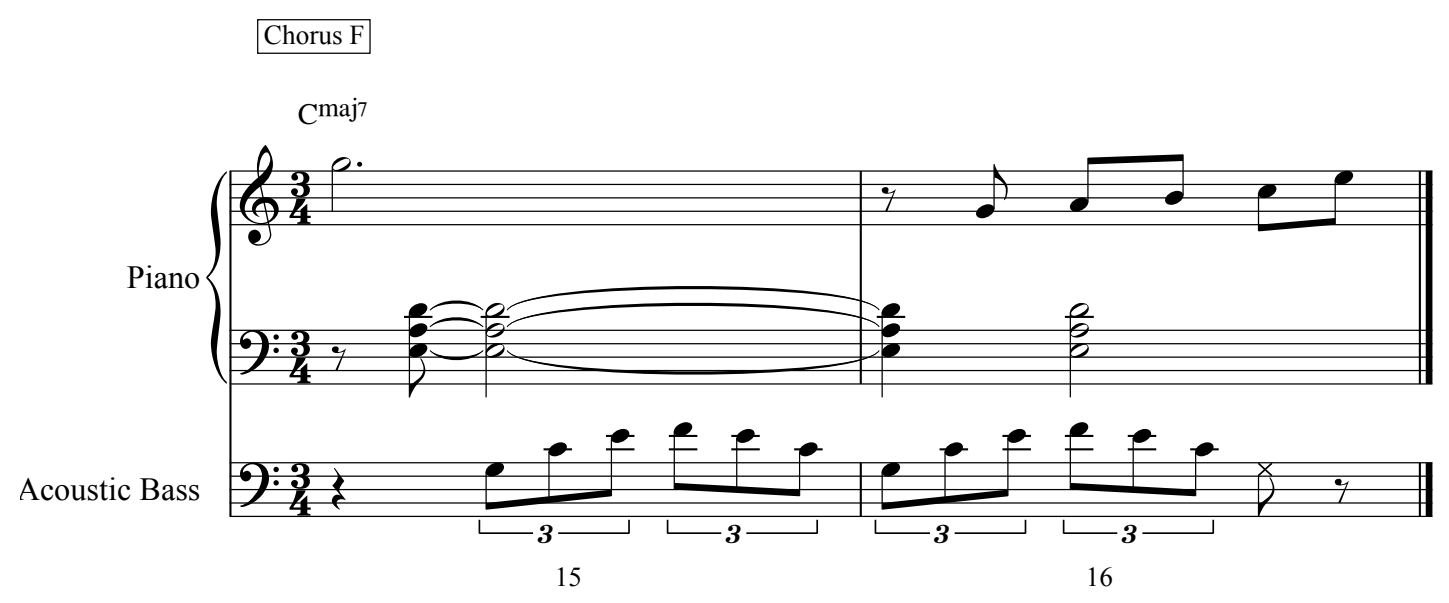

Chorus F (Out head) Bars 31-32

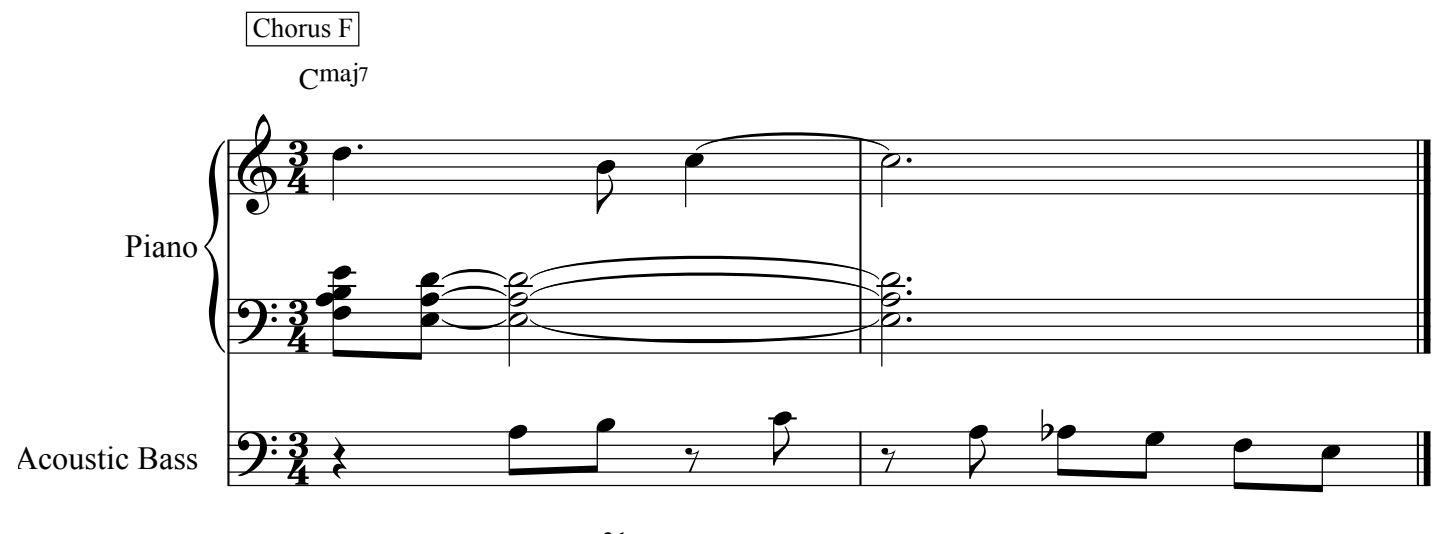

31 


\section{Waltz For Debby:}

This example shows LaFaro changing his approach from clearly outlining the root notes of the written harmony to performing a rhythmic motif in the higher register of the bass. This rhythmic phrase occurs at bar 25 as Evans begins to outline the chord changes using just minims. By the end of bar 26 as Evans begins to again include eighth notes in his playing LaFaro simplifies his own rhythmic accompaniment and changes register, moving back down the bass to outline the tonic of each chord change.

Chorus A Bars 23-27

Chorus A
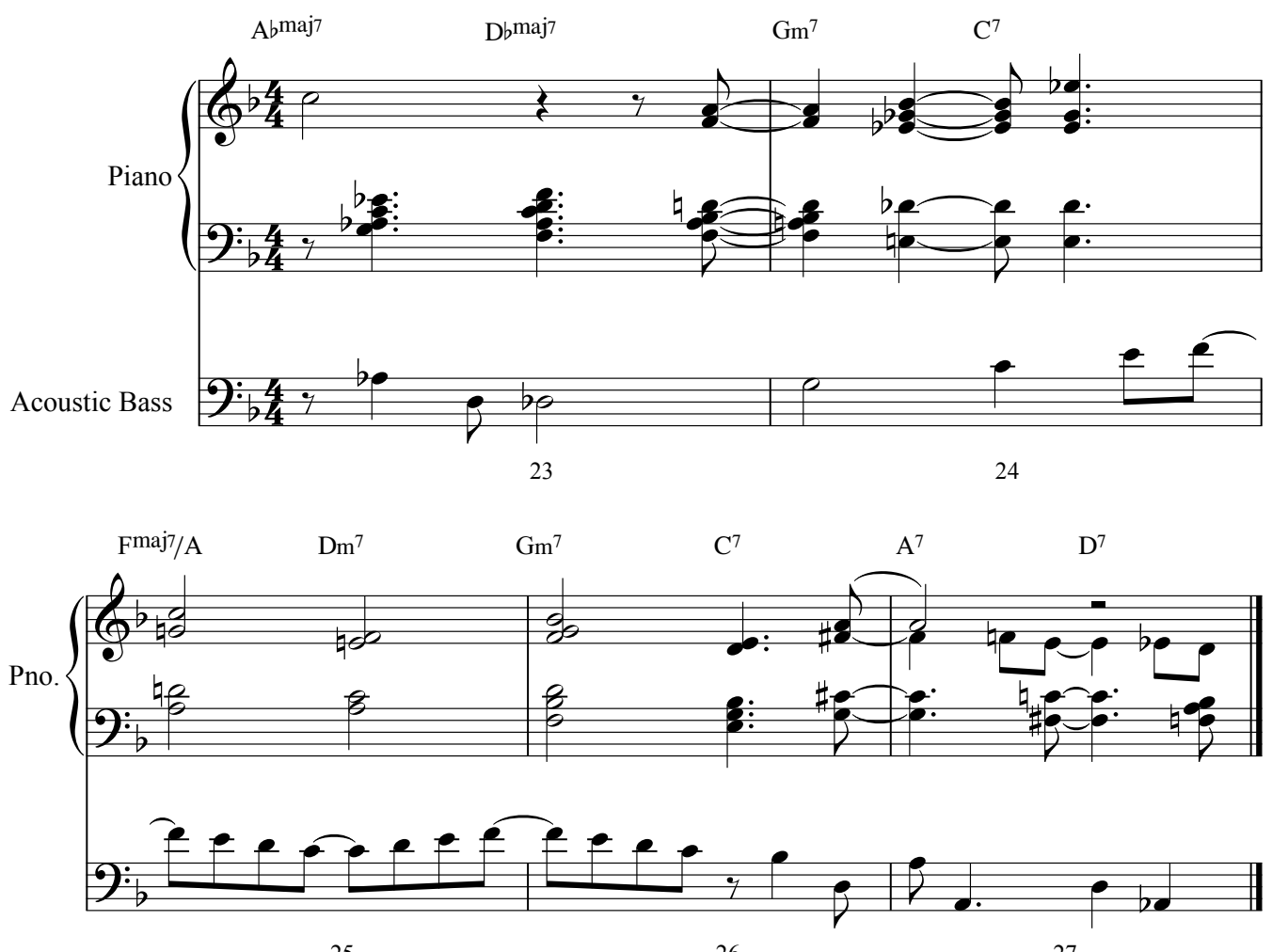
Another example from Waltz For Debby occurs in Chorus B. Here LaFaro begins a fast ascending eighth note line that ultimately reaches a high $\mathrm{B} b$ in thumb position. By the third bar Evans has begun a new eighth note line and LaFaro simplifies his rhythm and begins to descend back to the lower register of the bass. By the fourth bar LaFaro has reverted back to quarter notes.

Chorus B Bars 17-20

Chorus B

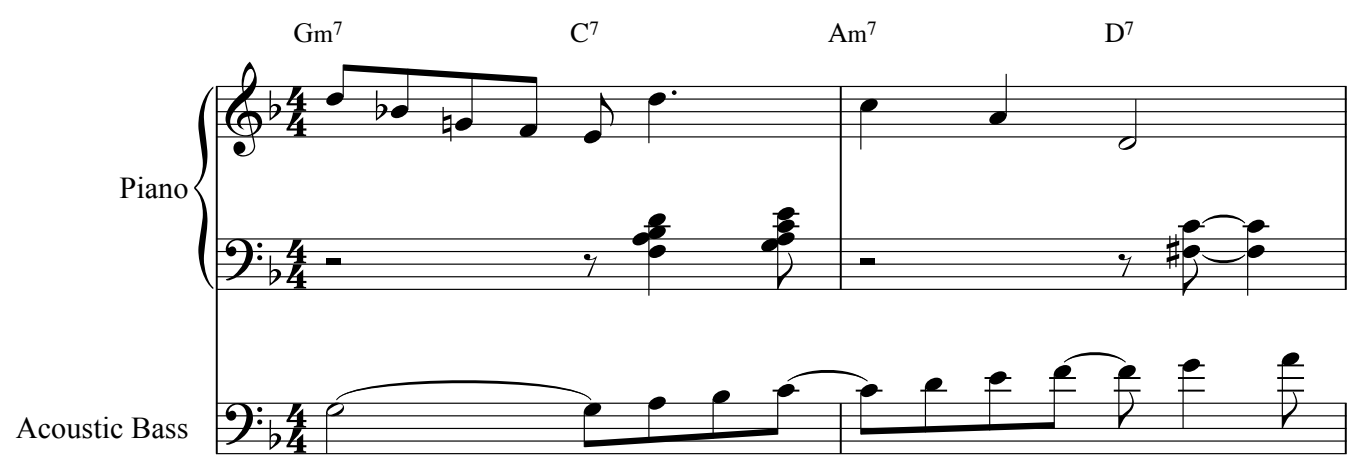

17

18

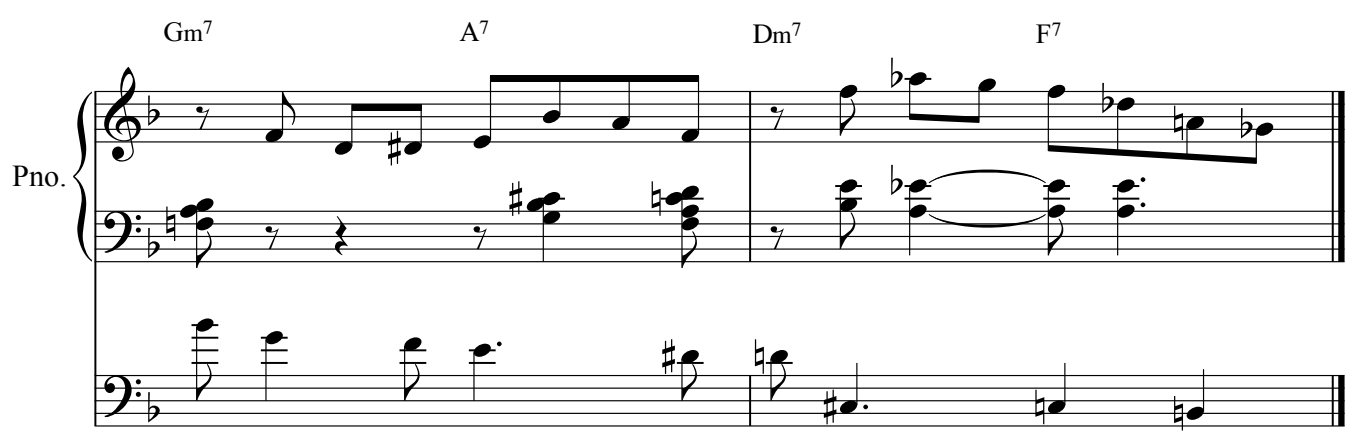

19

20 
Solar:

As this example illustrates, Evans finishes a melodic passage at the end of the first bar. LaFaro seems to be aware of this resolution, and in turn plays a very brief eighth note motif before changing his line to include longer rhythmic tones underneath Evans's next melodic phrase. Immediately following the conclusion of this new phrase LaFaro jumps to a higher register and plays another brief eighth note motif as Evans leaves another gap in the piano solo.

Chorus H Bars 6-10
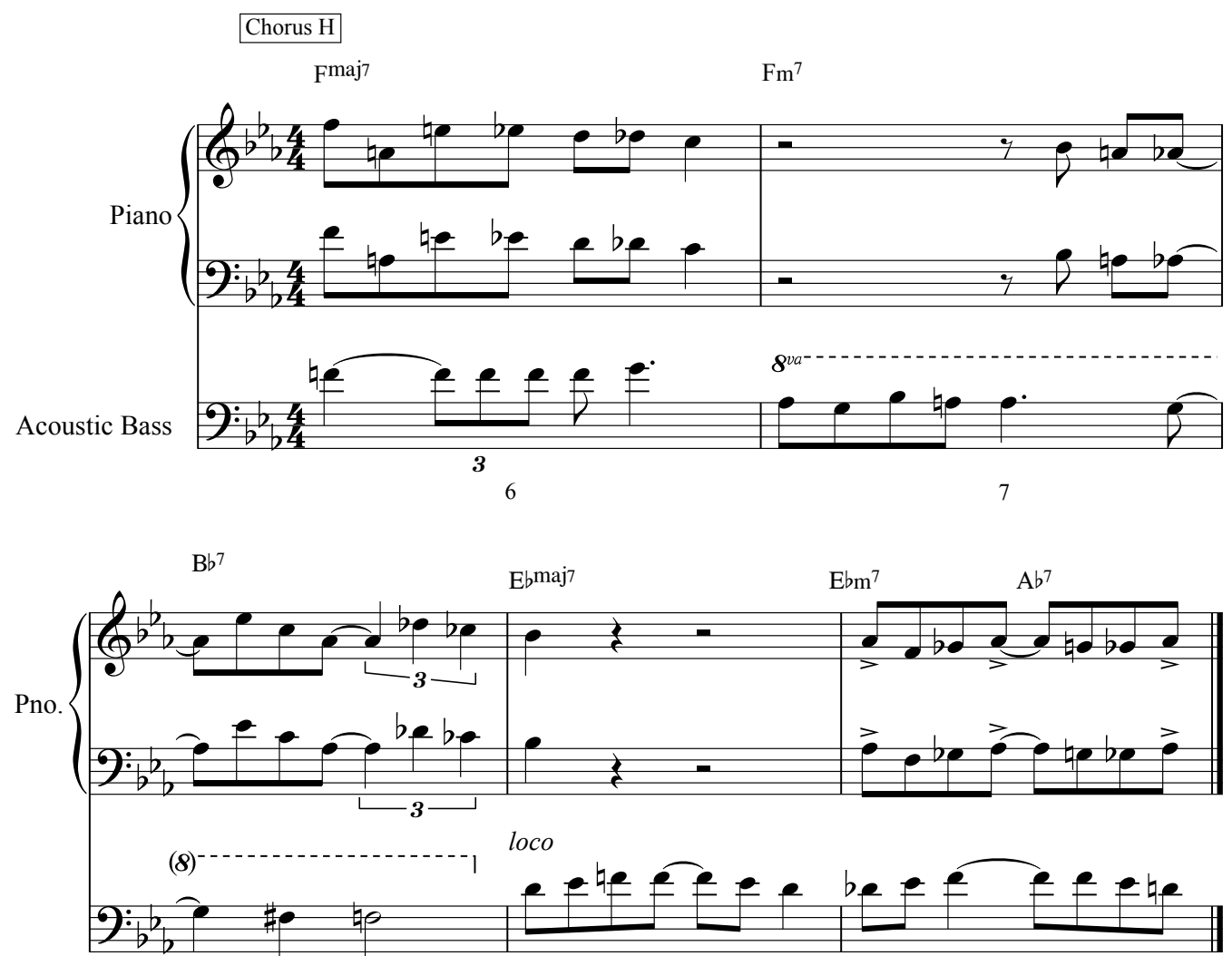

10 


\section{Gloria's Step:}

In the following examples, LaFaro uses triplet motifs to fill gaps left by Evans during the in and out heads of the performance. These motifs occur at the same place in the form each time, and I believe it is reasonable to conclude that LaFaro had pre-determined these passages as he knew that in these moments there was no melodic content expected from the piano.

Chorus A Bars 4-6

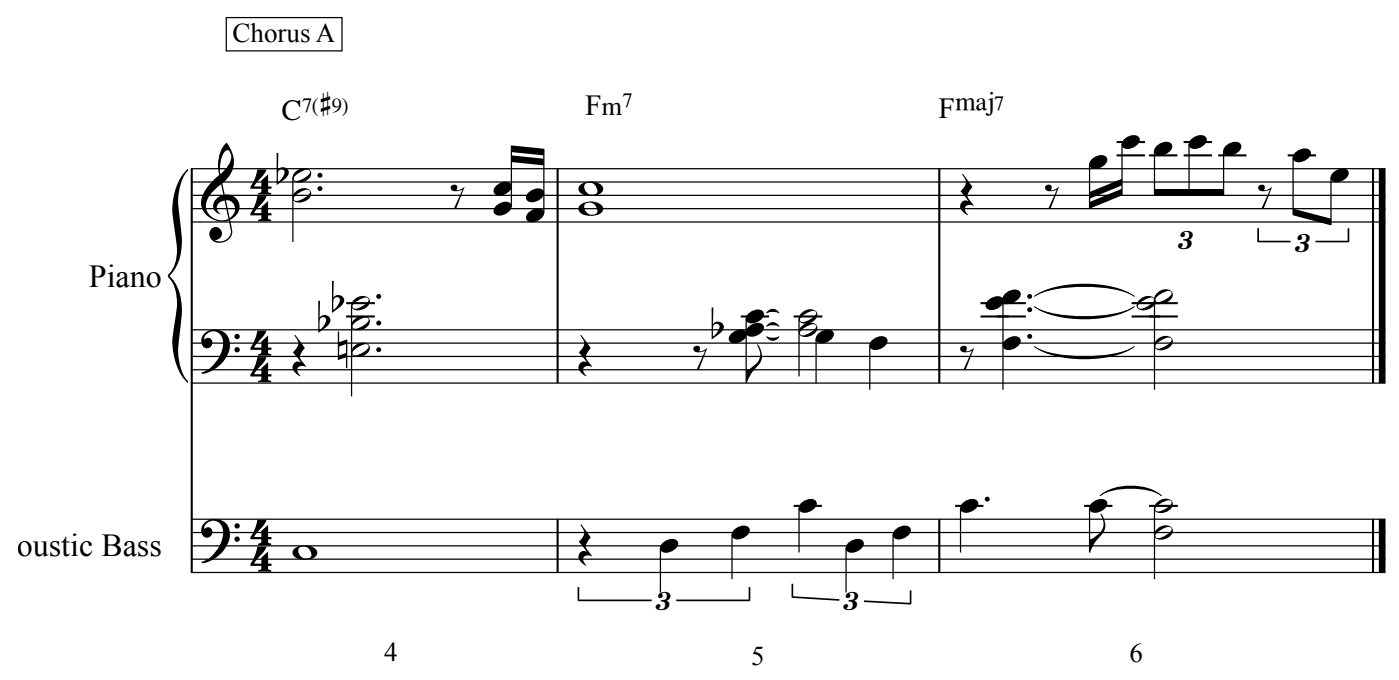

Chorus A Bars 9-11

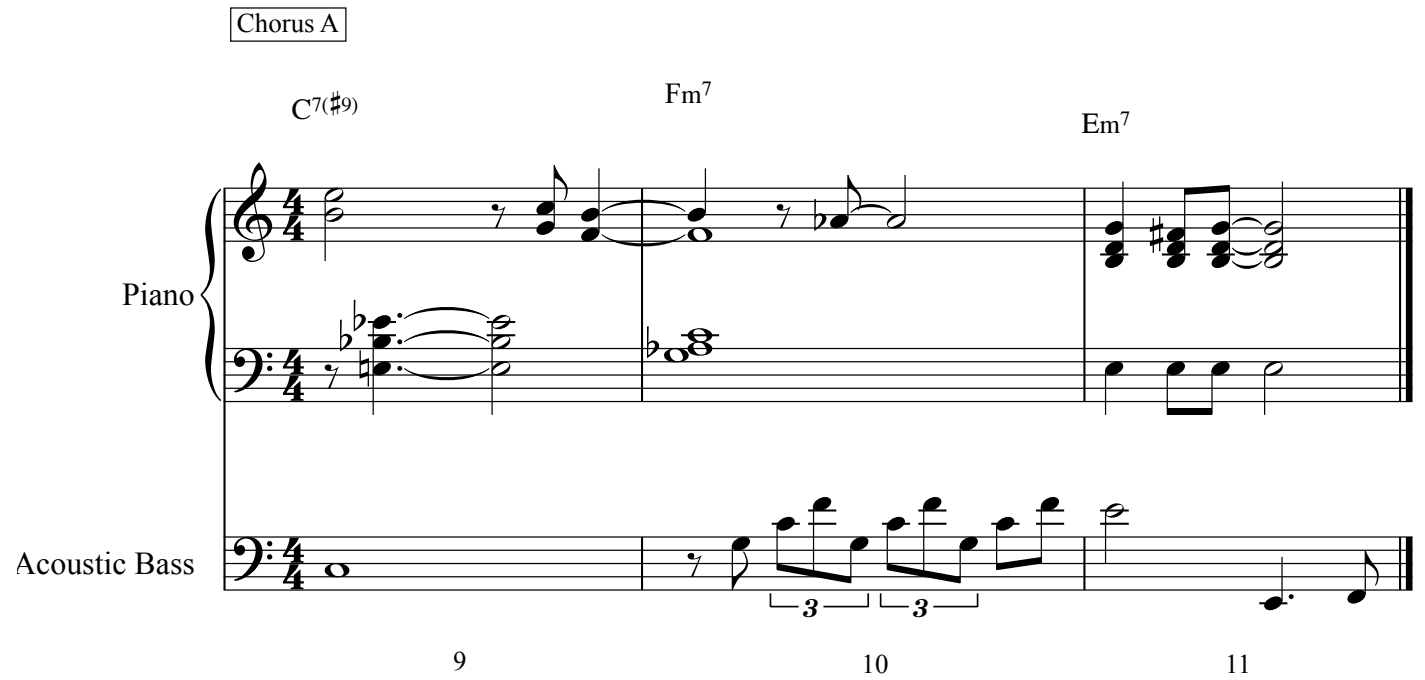


Chorus B Bars 4-7
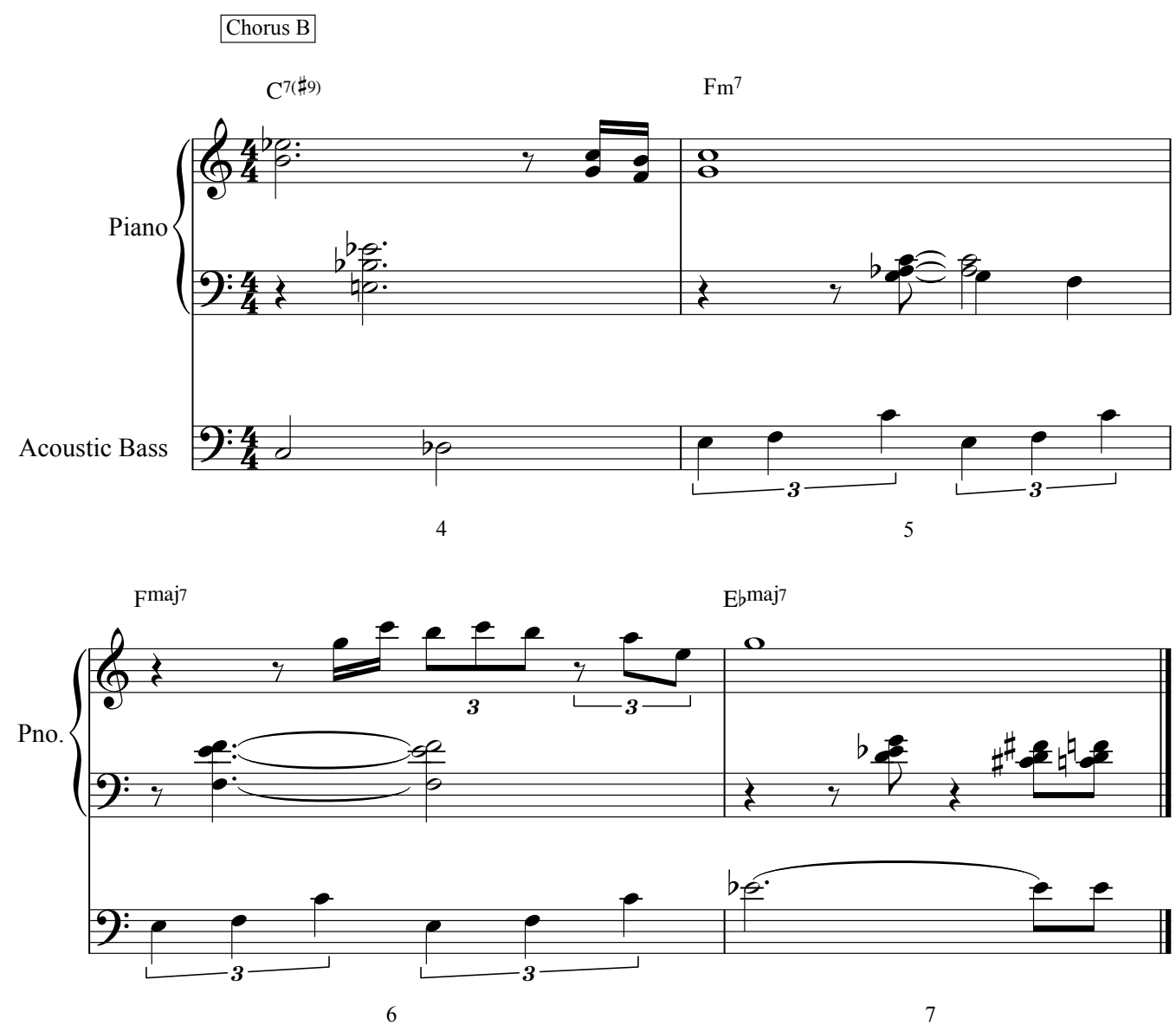

Chorus B Bars 9-11

Chorus B

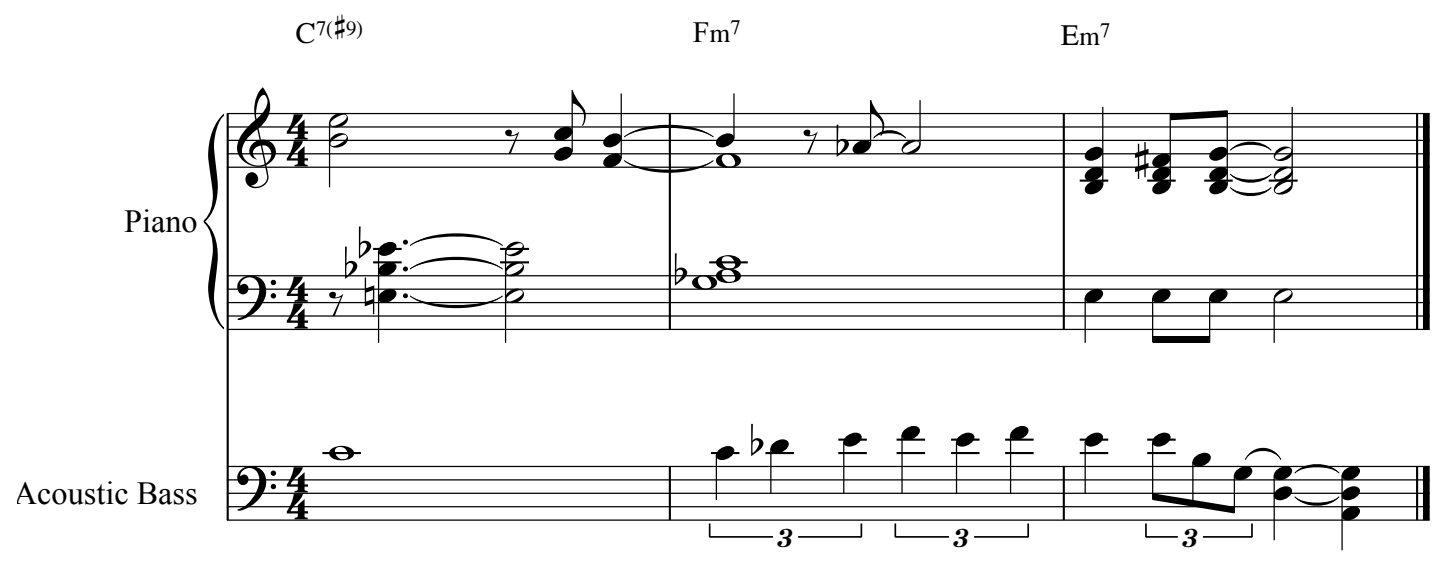

9

10

11 
Chorus K Bars 4-7

Chorus K
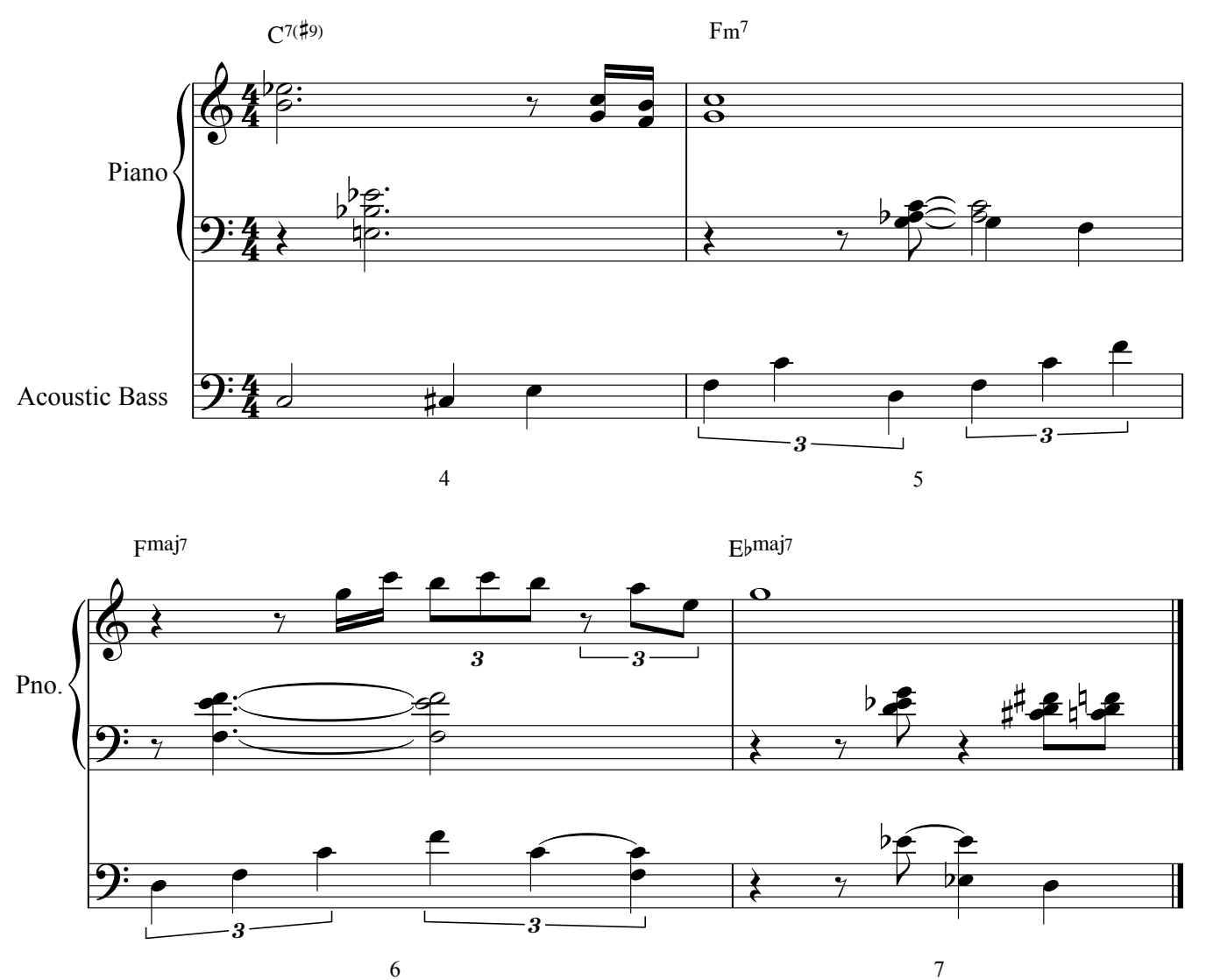

Chorus K Bars 9-11

Chorus K
$\mathrm{C}^{7(\# 9)}$
$\mathrm{Fm}^{7}$
$\mathrm{Em}^{7}$

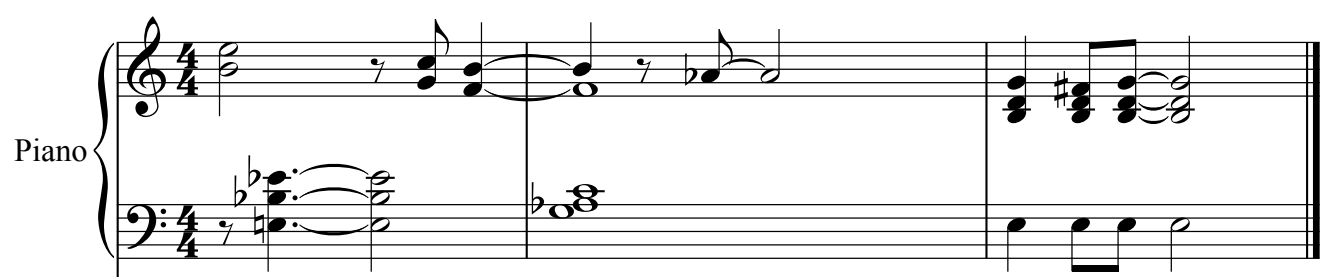

Acoustic Bass

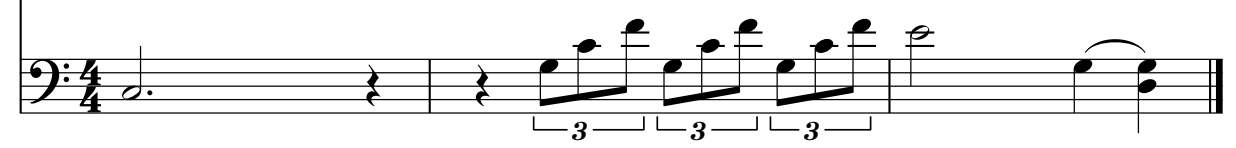

9

10

11 


\section{HARMONY:}

\section{BASIC SUBSTITUTION}

\section{RELATIVE MAJOR/MINOR SUBSTITUTION:}

The following examples show LaFaro substituting chords in the written harmonic progression for the relative major or minor of the prescribed chord. For example, where an F major chord is written, LaFaro may play a D underneath the chord, effectively changing the chord into a Dmin7 chord, the relative minor of F major.

This approach also applies when LaFaro emphasizes the minor $3^{\text {rd }}$ of a min7 chord. For example LaFaro may play an $\mathrm{F}$ as the fundamental bass note underneath a Dmin7 chord that is written in a song's harmony. This has the effect of substituting the relative major chord in place of a minor chord.

\section{Gloria's Step:}

At the top of chorus D, LaFaro holds a D from the previous bar as the harmony changes to Fmaj7 - the relative major of the $\mathrm{D}$ minor LaFaro is implying.

Chorus C Bar 20 - Chorus D Bar 1

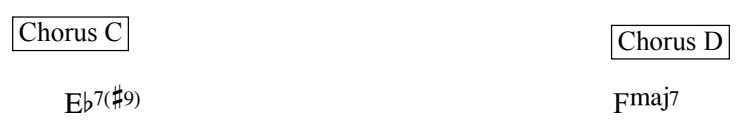

Acoustic Bass

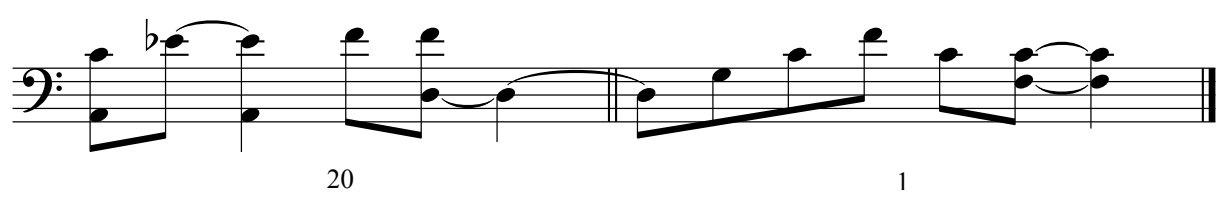

\section{Nardis:}

In this example, LaFaro plays an A on the off beat of beat one against the written Cmaj7 chord change, implying A minor in its place.

Chorus D Bar 12

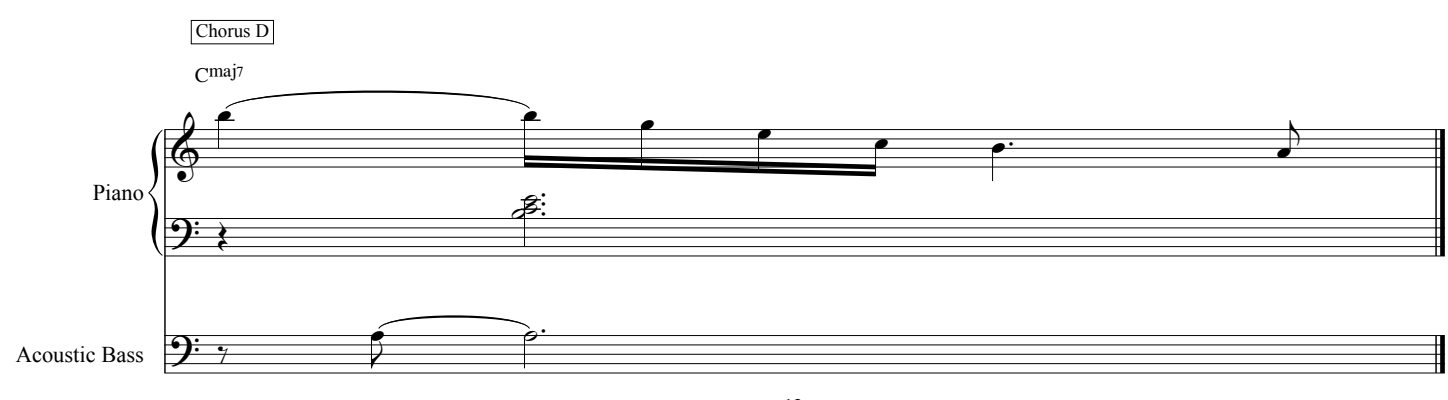




\section{Waltz For Debby:}

The following three examples show LaFaro playing the same substitute in the same place during Choruses A, B and C. In all cases the written harmony is an Amin7 chord but LaFaro consistently plays the major $3^{\text {rd }}-\mathrm{C}$ - against it. ${ }^{76}$

\section{Chorus A/B/C Bar 33}

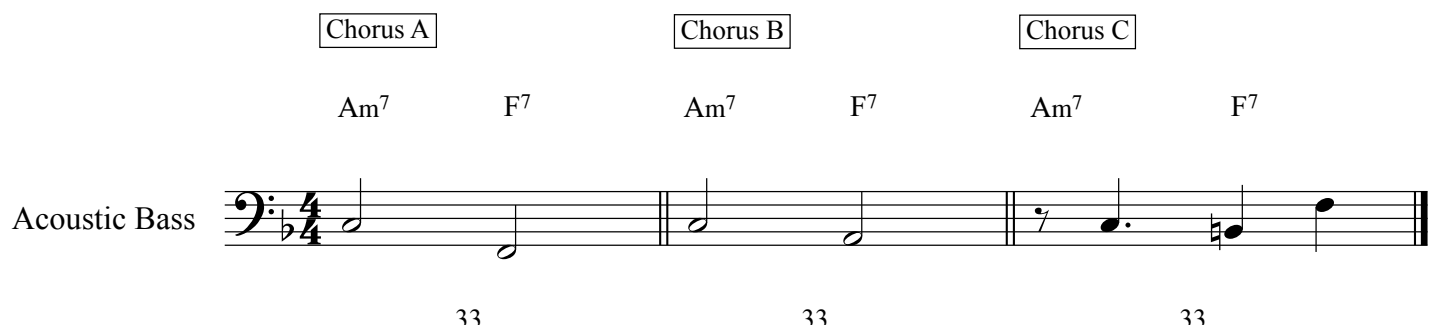

\section{SUBSTITUTIONS THAT CREATE A MELODIC CONTOUR:}

This section illustrates passages of LaFaro's accompaniment where he used numerous harmonic substitutions that allowed his bass lines to follow a smooth melodic contour. For example, instead of playing each stated tonic note of the written harmonic structure, by playing other chord tones LaFaro may have been able to keep playing a descending bass line that could continue over numerous chord changes.

\section{Nardis:}

During this next example, LaFaro uses chord substitutions to allow his bass line to continue ascending through the song's harmonic progression. In the first bar LaFaro plays a $\mathrm{D} \#$, the major $3^{\text {rd }}$ of the B7 chord of the harmony. His line ascends and briefly rests on a B , the fifth of the written Emin7 chord. This is swiftly replaced when LaFaro moves up a semitone, playing and holding a $\mathrm{C}$ that eventually resolves against the Fmaj7 chord change in the third bar. He continues this pattern the following bar by playing another long $\mathrm{D} \#$ note against the new $\mathrm{B} 7$ chord before finishing the phrase on a high $\mathrm{E}$ against a Cmaj7 chord in the final bar.

Chorus D Bars 24-29

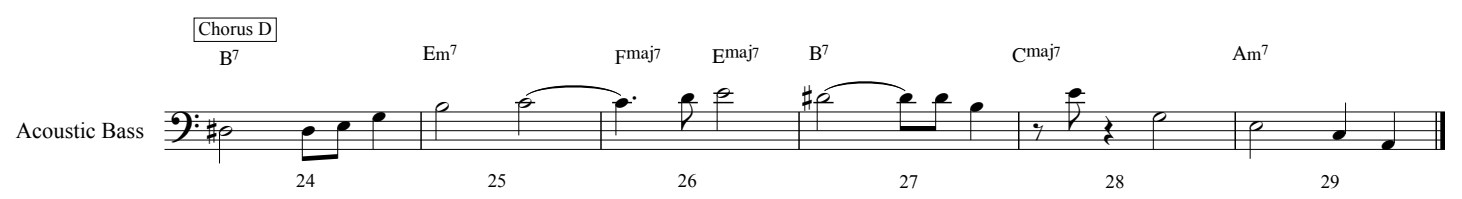




\section{Waltz For Debby:}

This example shows LaFaro using numerous harmonic substitutes to perform a descending bass line. In bar one, after playing a $\mathrm{G}$ on the $\mathrm{Gmin} 7$ chord, LaFaro plays a $\mathrm{B} b$ against the $\mathrm{C} 7$ chord change. From here he begins to descend playing an A over the A7 chord, and then an Ab - a tri-tone substitution - against the D7 chord change. This contour continues into the next bar as he plays a $\mathrm{G}$ on the Gmin7 chord, followed by a low $\mathrm{E}$ against the written $\mathrm{C} 7$ chord.

Chorus B Bars 26-28

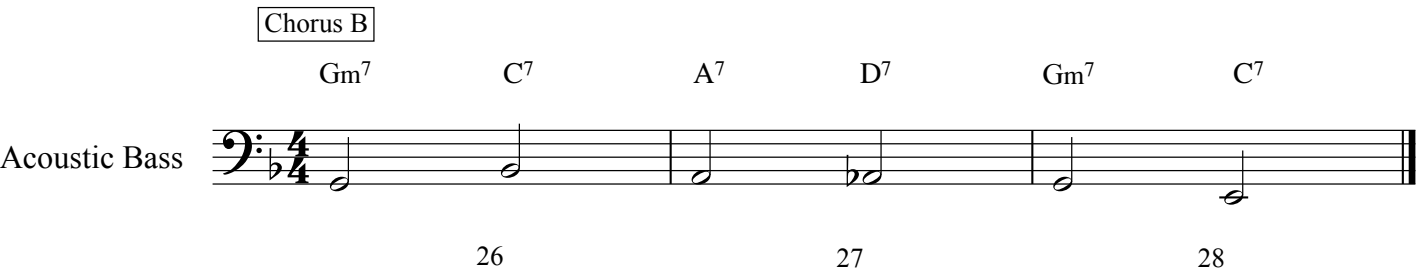

\section{Solar:}

This example from Chorus I of Solar shows LaFaro using numerous substitutions to enable a melodic pattern to keep its intervallic shape. In bar one LaFaro begins by playing the Major $3^{\text {rd }}(\mathrm{A})$ over the written harmony - Fmaj7. This changes slightly in bar three where LaFaro flattens the A to an Ab, acknowledging the chord change to F minor7. During the final bar, LaFaro then widens the intervallic space between the two-note motif by first playing a $\mathrm{B} b$ underneath the $\mathrm{B} b 7$ chord change, but then playing a tri-tone substitute - E natural - as the lower note.

Chorus I Bars 5-8

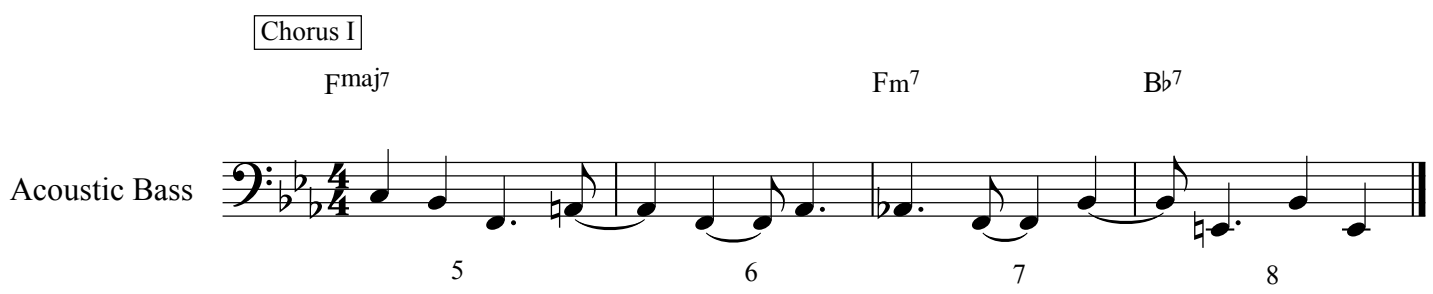


The next example shows LaFaro playing another descending melodic motif using substitutions to keep its contour. During the first three bars LaFaro plays the written tonic - F - in octaves. At the B b7 chord change, LaFaro moves his octave pattern down a semitone, playing the tri-tone substitution - Eq. At the next bar he again moves the octave pattern down another semitone to play an $\mathrm{E} b$ underneath the written Ebmaj7 chord change.

Chorus J - Bars 5-9

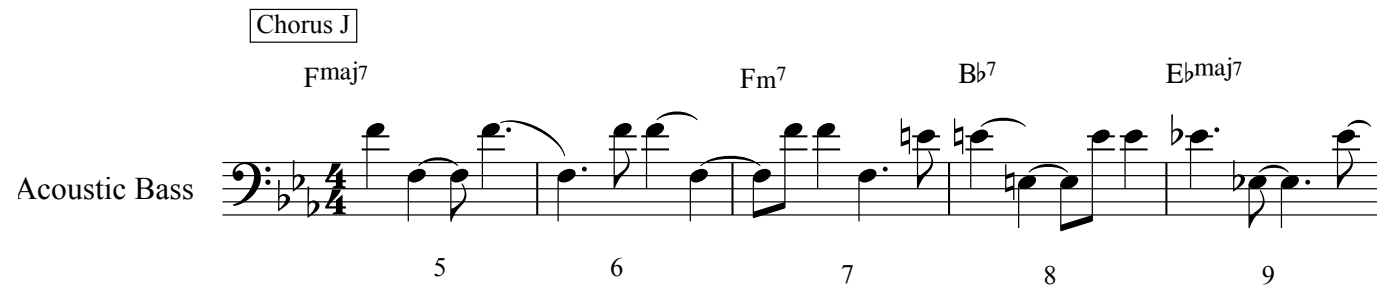

\section{CHORD TONE AND TRI-TONE SUBSTITUTIONS:}

Throughout my sample there are numerous examples of LaFaro performing basic chord tone and tri-tone substitutions. Jazz bassists use these substitutions widely within their performances, and I believe it is fair to comment that LaFaro was well versed in this approach. ${ }^{77}$ The tri-tone substitution in this example is possibly the most common used by jazz bassists. ${ }^{78}$ Over the II-V-I progression, LaFaro plays the root note of both the iimin7 and Imaj7 chord. However, over the V7 chord, LaFaro executes the substitution, allowing his bass line to descend in semitones. These examples are almost too numerous to mention, but briefly, here is an example of LaFaro playing a tri-tone substitution on the V7 during Solar: ${ }^{79}$

Chorus E Bars 7-9

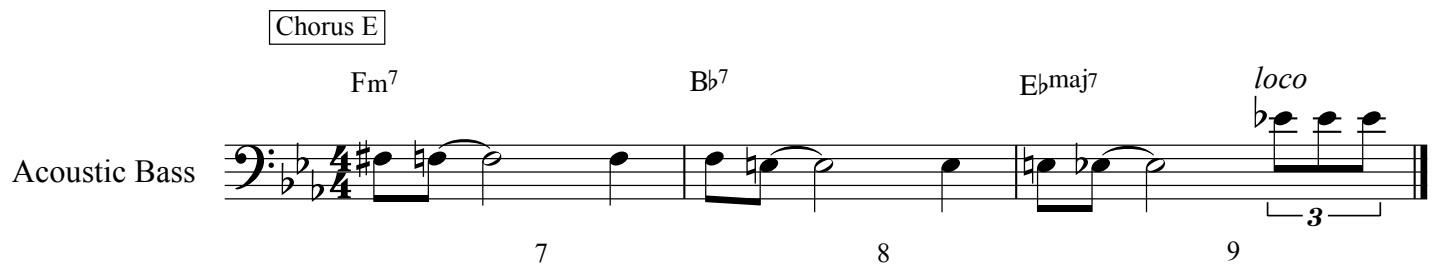

7 See Monson (1996) 31-32 for a full description of common substitutions made by bassists.

78 Mark Levine, The Jazz Piano Book, (Petaluma California: Sher Music Co. 1989), 34.

79 Numerous examples can be found within the appendices 
The following is an example of LaFaro using basic chord tone substitution. Instead of playing the root note of the new chord change - Fmaj7 - on beat one, LaFaro plays an A, the major $3^{\text {rd }}$ of the key centre. This substitution creates tension within the performance as it implies a new harmony - Amin b6 - instead of the written Fmaj7 chord change.

Chord tone substitution: Solar Chorus C Bar 5

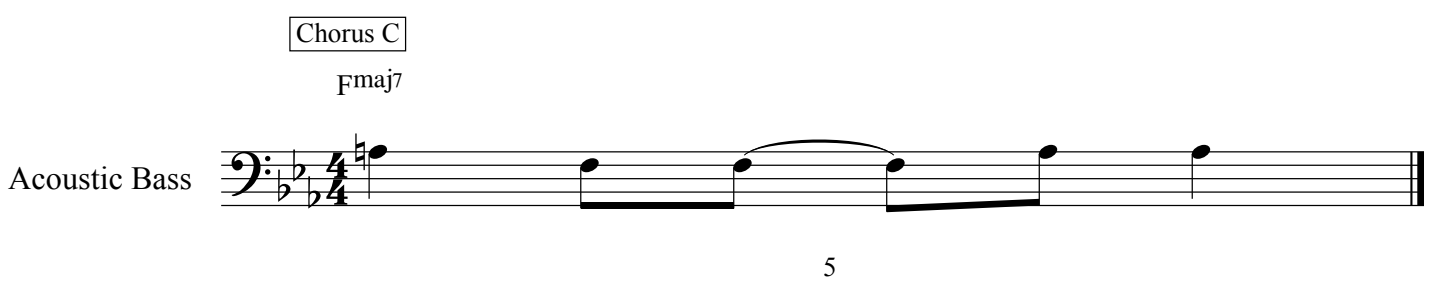

\section{HARMONIC CONVERSATION}

As discussed in chapter two (p.17) this section seeks to outline examples of LaFaro and Evans in harmonic conversation with each other. Specifically I am seeking passages where one musician may abandon the written harmonic progression of the song, and the other follows this new vein of harmony before they both return to the original chord structure.

Across my sample I have found no evidence to suggest that Evans and LaFaro used this approach. As described earlier in this chapter, there are numerous examples of LaFaro using basic substitutions within his performances, as well as passages of harmonic substitutions that create melodic phrases. However, it appears that LaFaro and Evans remain committed to outlining the written harmonic progression of each song, and as such do not deviate from this approach. The result is that there is no opportunity for either musician to lead or follow each other into new areas of harmony. 
From my results above it is evident that Scott LaFaro generally refrains from playing walking bass lines within the Bill Evans Trio. Further, and contrary to the claims of a number of commentators, neither is he engaged in a spontaneous musical dialogue with Evans. Rather, it seems that he plays with a different approach to that usually expected from small ensemble jazz bassists of the era.

As discussed earlier in chapter two (p.15-17) it seems the trio attempted to create a three way spontaneous improvised counterpoint in their performance of Autumn Leaves from Portrait In Jazz (1959). ${ }^{80}$ However, this approach is unique to that recording and, on the basis of recorded evidence, it was not attempted again at any stage of their association together. Nonetheless, this spontaneous counterpoint forms a large part of what is presented to the world when discussing Scott LaFaro's legacy. ${ }^{81}$

My findings also support the conclusion that LaFaro - as part of the Bill Evans Trio - did not engage in a comprehensive two-way musical discussion with Evans. In fact any musical interactivity is limited relative to the claims made by a number of scholars who have commented on LaFaro's playing with Evans. My findings suggest that Scott LaFaro was a bassist who established a unique vocabulary that would be useful in the context of spontaneous improvised counterpoint, but that kind of interaction was not a priority for the Bill Evans trio. ${ }^{82}$ As discussed in chapter one, Evans describes Gary Peacock's approach (which appears to be closer to providing a spontaneously improvised counterpoint) as abstraction and which, in Evans's opinion didn't fit within the ensemble's approach. ${ }^{83}$

My results indicate that LaFaro used a number of techniques and approaches in his performances to create this new sound as a bassist. His use of repetitive rhythmic motifs and polyrhythmic devices played a significant part in allowing LaFaro to abandon the common walking bass line as the predominant component of his accompaniment to Bill Evans's piano solos. By discarding the traditional walking approach (which LaFaro may have considered restrictive) LaFaro filled his performances with scalar and arpeggiated patterns that would simultaneously outline the harmonic progression of a song whilst also creating melodic phrases.

80 Also see Hodson, (2007) for his analysis of Autumn Leaves.

81 See chapter two, p.7-9.

82 It should be noted that in some other settings - such as Ornette Coleman's recordings Free Jazz (1960) and Ornette (1961) - LaFaro's performances probably functioned as improvised counterpoint, although some commentators such as Paul Bley dispute this. See Meehan, (2003), 45.

83 See earlier comments by Aikin (1980) in chapter two, p.23. 
Further, by abandoning the walking bass line and adopting the more fragmented approach discussed in this thesis, LaFaro created the opportunity to frequently interject with his own melodic statements during moments of respite in Evans's solos.

Whilst there is only one brief example of LaFaro and Evans performing with a Conversational Counterpoint approach in the sample examined, LaFaro does interact with Evans using other devices such as: imitating the melodic contour of Evans's phrases; and mimicking phrases immediately after Evans performs them.

On the basis of the sample examined in this study, LaFaro reveals himself to be a bass player using a different harmonic and rhythmic vocabulary to other bassists of the time. In doing so he contributed to - and is frequently given credit for - creating a new role for bassists within small jazz ensembles.

There is no question that Scott LaFaro was an outstanding jazz bass player. However, claims that he was largely responsible for freeing jazz bassists to engage in improvised counterpoint liberated from the constraints of walking bass lines appear - on the basis of the sample considered here - to be exaggerated.

Further research and analysis of other bassists, such as Gary Peacock, Steve Swallow and Charlie Haden may reveal more information regarding the development and evolution of the role a jazz bassist plays as part of a small ensemble. 
Aikin, Jim. Bill Evans: The Essence of Jazz Piano.

Contemporary Keyboard (June 1980), 50.

Anon, A Light Gone Out, Downbeat 28/17 (1961), 13.

Bany, John. The Legendary Scott LaFaro.

Bass World 14/3 (1988), 39.

Berendt, Joachim-Ernst \& Heusmann, Gunther.

The Jazz Book. Chicago: Chicago Review Press, 2009.

Berliner, Paul. Thinking In Jazz.

Chicago: The University of Chicago Press, 1994.

Bley, Paul and Lee, David. Stopping Time.

Quebec: Vehicule Press, 1999.

Brownell, John. Analytical Models of Jazz Improvisation. Jazzforschung 26 (1994), 9-29.

Carr, Ian; Fairweather, Digby \& Priestley, Brian. Jazz The Rough Guide. New York: R.R. Donnelly \& Sons, 2000.

Carr, Roy. A Century of Jazz.

New York: Da Capo Press, 1997.

Collier, James. The Making Of Jazz: A Comprehensive History. London: Granada Publishing Ltd, 1978.

Cook, Richard and Morton, Brian.

The Penguin Guide to Jazz Recordings: Eighth Edition. London: Penguin Books Ltd, 2006.

DeVeaux, Scott. Constructing the Jazz Tradition. Black American Literature Forum, 1991.

Doerschuk, Robert L. 88: The Giants of Jazz Piano.

San Francisco: Backbeat Books, 2001.

Franklin, Benjamin. Commentaries on Jazz

Musicians and Jazz Songs.

New York: The Edwin Mellen Press, Ltd., 2011.
Gilbert, Andrew. Bill Evans: Sunday at The Village Vanguard 1961. In 1001 Albums You Must Hear Before You Die, ed. Robert Dimery. London: Quintet Publishing Ltd., 2006.

Gioia, Ted. The History of Jazz. Oxford University Press, 2011.

Goldsby, J. Game Changer: How Scott LaFaro rewrote the rules of Jazz Bass. Bass Player (2010)

www.bassplayer.com/article/Game-Changer--HowScott-LaFaro-Rewrote-The-Rules-Of-Jazz-Bass/4747, 1 January 2010.

Gridley, Mark C. Jazz Styles: History and Analysis. New Jersey: Prentice-Hall Inc, 1994.

Gushee, Lawrence. Lester Young's "Shoe Shine Boy". In A Lester Young Reader, ed. Lewis Porter. Washington: Smithsonian Institution Press, 1991. 224-254.

Hentoff, Nathan. Introducing Bill Evans.

The Jazz Review 2/9 (1959), 26.

Hodson, Robert. Interaction, Improvisation and Interplay in Jazz. Routledge, 2007.

Hunt, David. The Contemporary Approach to Jazz Bass Playing. Jazz and Pop 6/22 (1969), 18

Kernfeld, Barry. The New Grove Dictionary of Jazz. London: Macmillan Press Ltd, 1988.

Kirchner, B. The Oxford Companion to Jazz. New York: Oxford University Press, 2000.

LaFaro - Fernandez, Helene. Jade Visions: The Life and Music of Scott LaFaro. Texas: University of North Texas Press, 2009.

Leonard, Hal. The Bill Evans Trio Volume 1. Milwaukee: Hal Leonard Corporation, 2003. 
Levine, Mark. The Jazz Piano Book.

Petaluma California: Sher Music Co. 1989, 41.

Litweiler, John. Ornette Coleman: A Harmolodic Life.

New York: Quartet Books Ltd., 1992.

Lyons, Len. The Great Jazz Pianists.

Da Capo Press, New York, 1983.

McPartland, Marian.

Bill Evans Genius - All In Good Time.

New York: Oxford University Press, 1987.

Meehan, Norman.

Time Will Tell-Conversations with Paul Bley.

Albany: Berkeley Hill Books, 2003.

Monson, Ingrid. Saying Something.

The University of Chicago Press, 1996.

Morgenstern, Dan. Living with Jazz.

New York: Pantheon Books, 2004.

Palombi, Phil.

Scott LaFaro; 15 Transcriptions from The Bill Evans

Trio Recordings Sunday at the Village Vanguard and

Waltz for Debby.

Palombi Music, 2003.

Pettinger, Peter. Bill Evans, How My Heart Sings.

Yale University Press, London.

Potter, Gary. Analysing Improvised Jazz.

Jazz Studies. College Music Symposium.

Prouty, Ken. Knowing Jazz: Community, Pedagogy

and Canon in the Information Age.

Mississippi: The University of Mississippi, 2012.

Ramsey, Doug. Jazz Matters.

Fayetteville: The University of Arkansas Press, 1989.

Rumsey, H. Scott is the most important

bass player since Iimmy Blanton.

Downbeat. 28/5 (1958), 49.

Sawyer, R. Keith. Group Creativity.

New Jersey: Lawrence Erlbaum Associates, Inc., 2003.

Shadduck, Anthony.

Charlie Haden, Scott LaFaro and Harmolodics: Bass styles

in Ornette Coleman's "Free Jazz".

California State University, 2006.

Shadwick, Keith. Bill Evans, Everything

Happens To Me, a musical biography.

San Francisco: Backbeat Books, 2002.
Shipton, Alyn. A New History of Jazz. New York: The Continuum International Publishing Group Inc, 2010.

Schudel, Matt. A Master Fades to Obscurity.

Sun-Sentinel, ed. Matt Schudel. Fort Lauderdale:

Tribune Co. 1994.

Sidran, Ben. Talking Jazz, an oral history.

California: First Da Capo Press, 1995.

Smith, Gregory E. Notions of Improvisation - Homer,

Gregory, and Bill Evans: The Theory of Formulaic

Composition in the Context of Jazz Piano Improvisation. PhD Diss., Harvard University, 1983.

Tanner, Paul O.W; Megill, Gerow, David W \& Maurice. Jazz. Dubuque: Wm. C. Brown Publishers, 1992.

Tynan, J. Stan the Man. Downbeat 28/7 (1958), 45.

Ward, Geoffrey C. \& Burns, Ken. Jazz.

Alfred A. Knopf, New York, 2000.

White, H. The Question of Narrative

in Contemporary Historical Theory.

History and Theory. 23/1 (1984), 1-33.

Widenhofer, Stephen. Bill Evans: An Analytical Study of his Improvisational Style Through Selected Transcriptions. Doctoral diss., University of Northern Colorado 1988.

Williams, Martin. Introducing Scott LaFaro.

The Jazz Review 3 (1960), 16.

Williams, Martin. Jazz Changes.

New York: Oxford University Press, 1992.

Wilson, Peter Niklas.

Ornette Coleman, His life and Music.

California: Berkeley Hill Books, 1999. 


\section{APPENDIX 2: INDEX \& FULL TRANSCRIPTIONS}

1: Solar - Transcription taken From Leonard, Hal. The Bill Evans Trio Volume 1. 2003.

2: Alice In Wonderland - Transcription taken from Leonard, Hal. The Bill Evans Trio Volume 1. 2003.

3: Waltz For Debby - Transcription taken from Leonard, Hal. The Bill Evans Trio Volume 1. 2003.

4: NARdis - Transcription taken from Leonard, Hal. The Bill Evans Trio Volume 1. 2003.

5: Gloria's Step - Transcriptions taKen from Orpheum Music. GLORIA's STEP IMPROVISATION. 1961. $\&$

Laird, Adrian. Gloria’s Step(Take 2). 2012. 
1: Solar - Transcription taken from Leonard, Hal. The Bill Evans Trio Volume 1. 2003. 


\section{Solar}

By Miles Davis
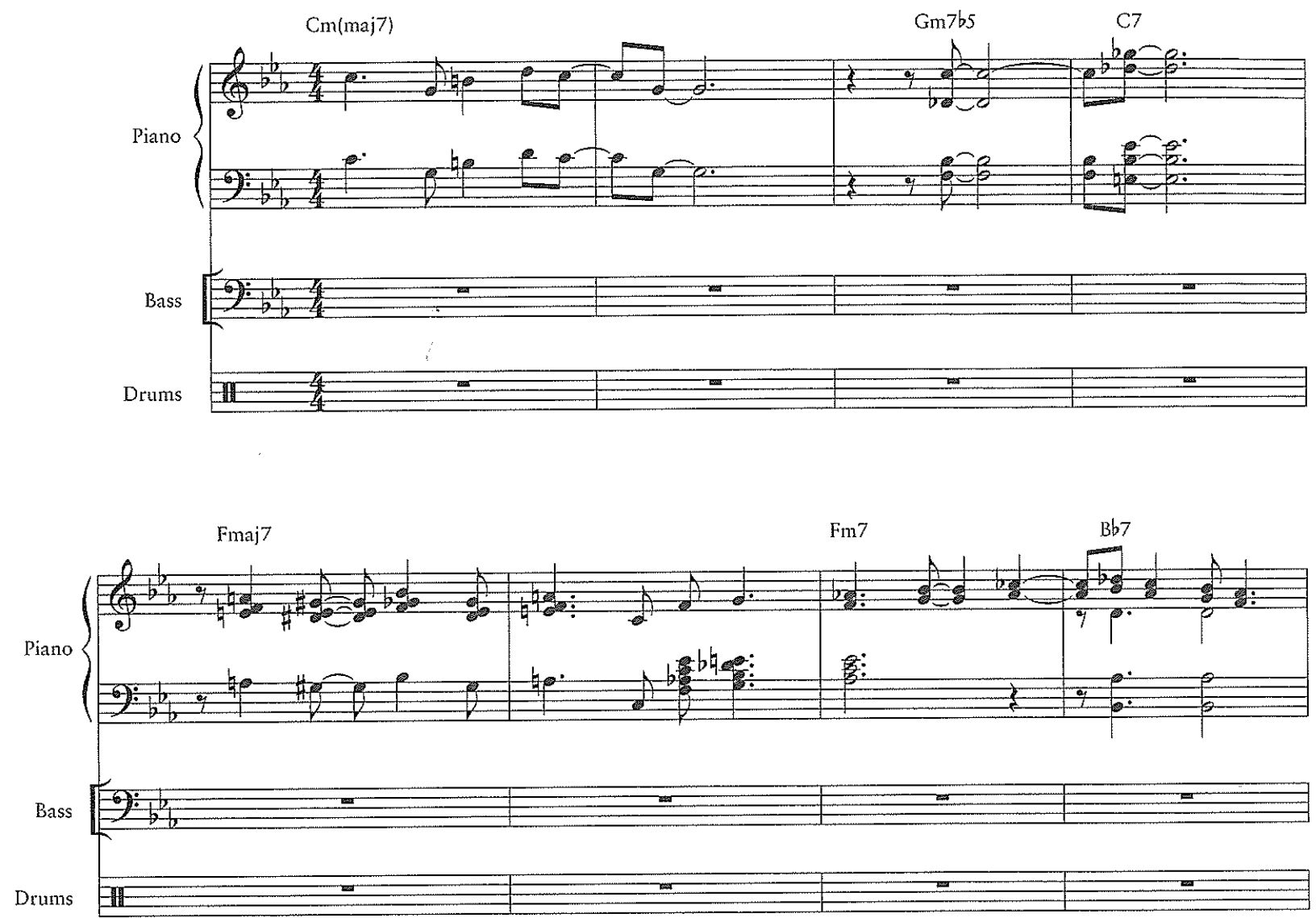

Ebmaj

Ebm7

Ab7

Dbmaj7

Din7b5

G7

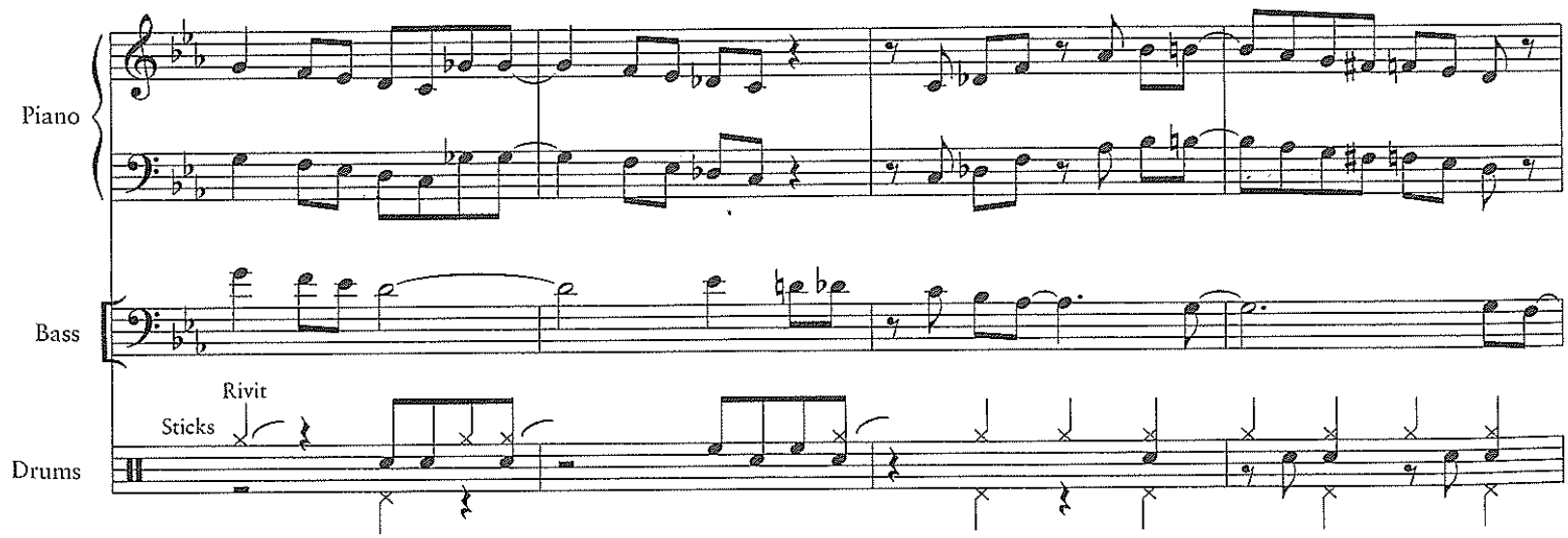

Copyright (c) 1963 Prestige Music 

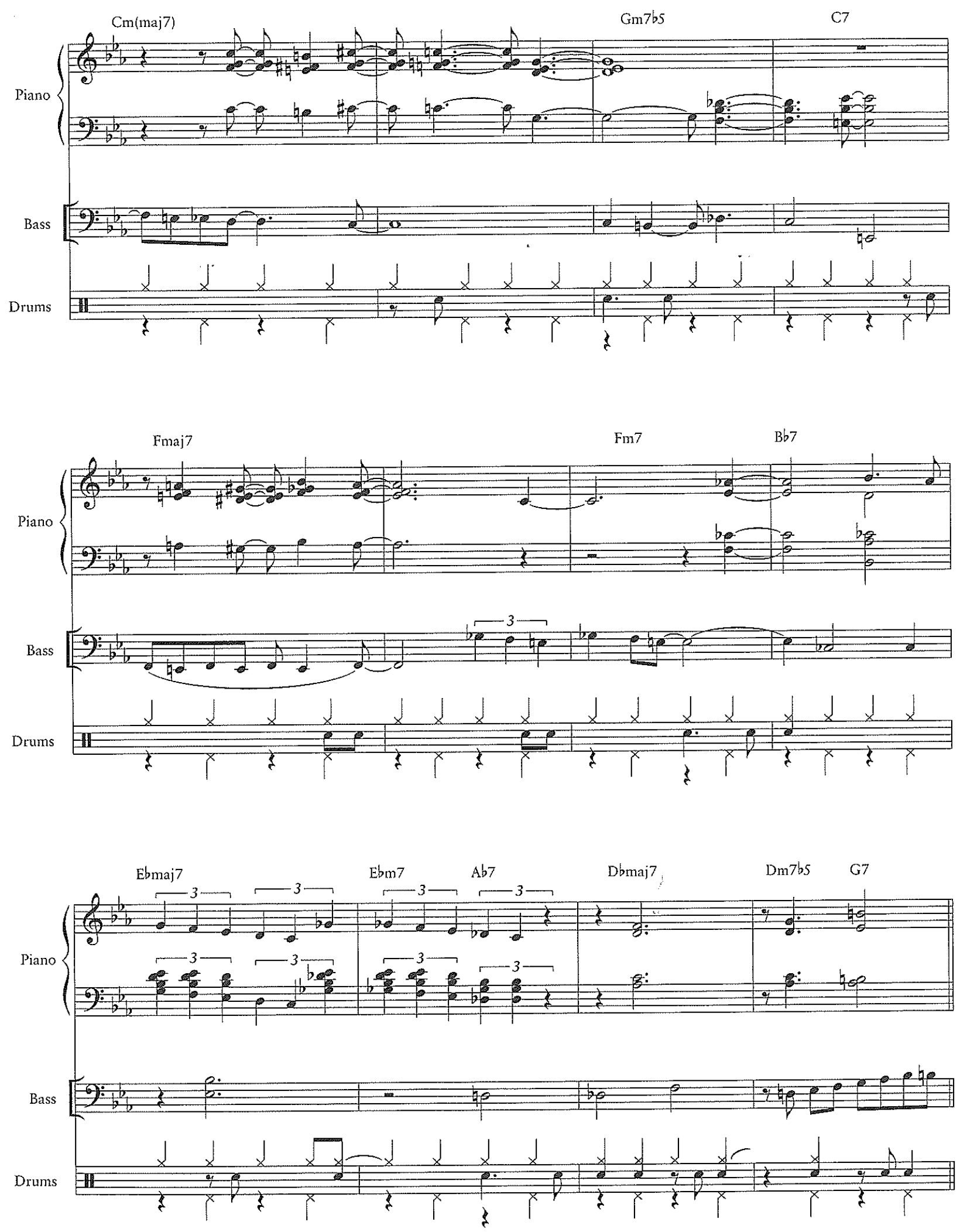


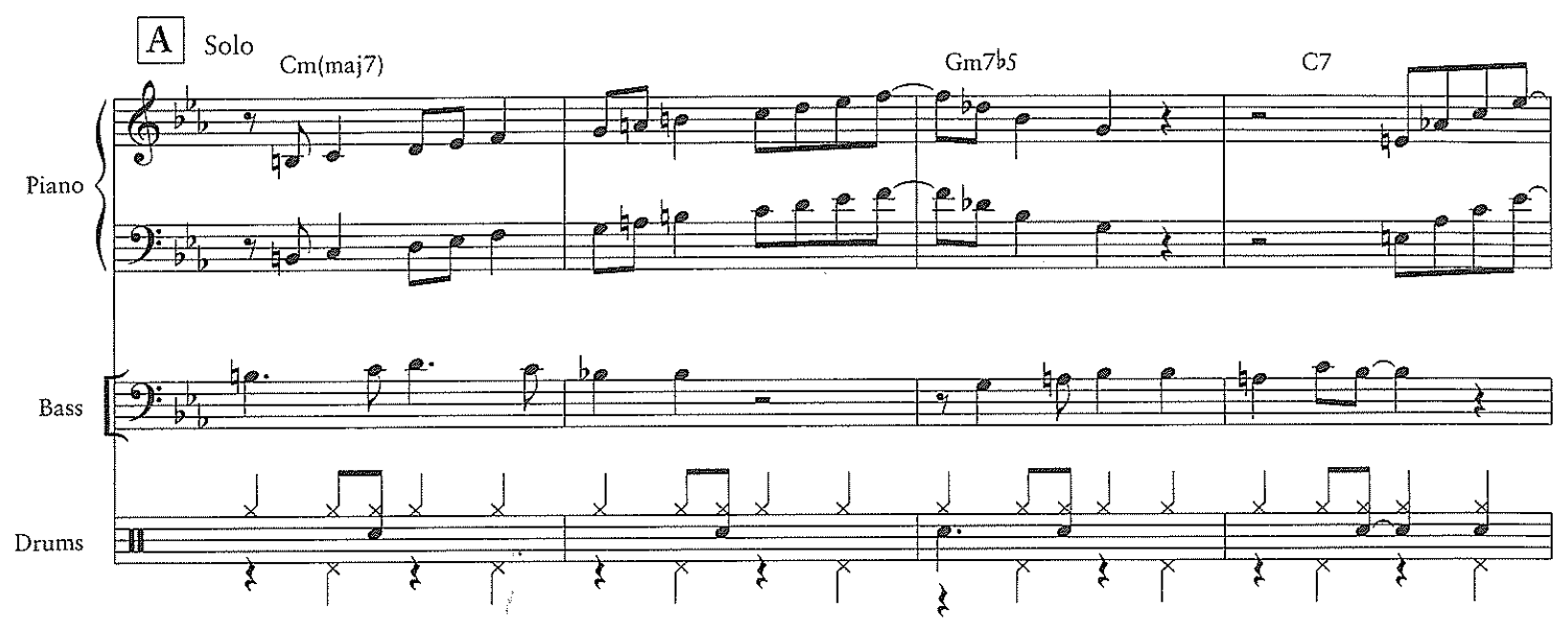

$\begin{array}{lll}\text { Fmaj7 } & \text { Fm7 } & \text { Bb7 }\end{array}$
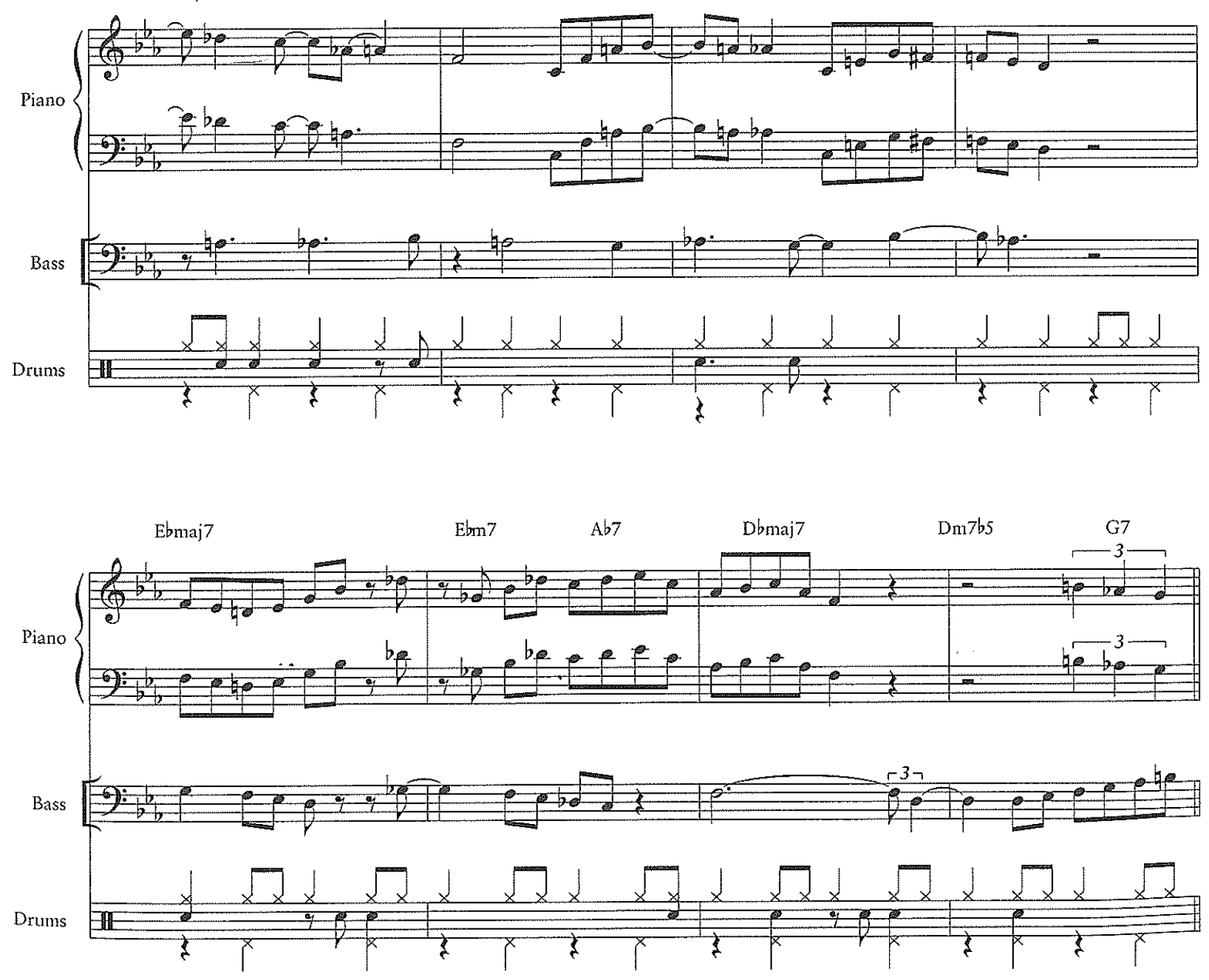

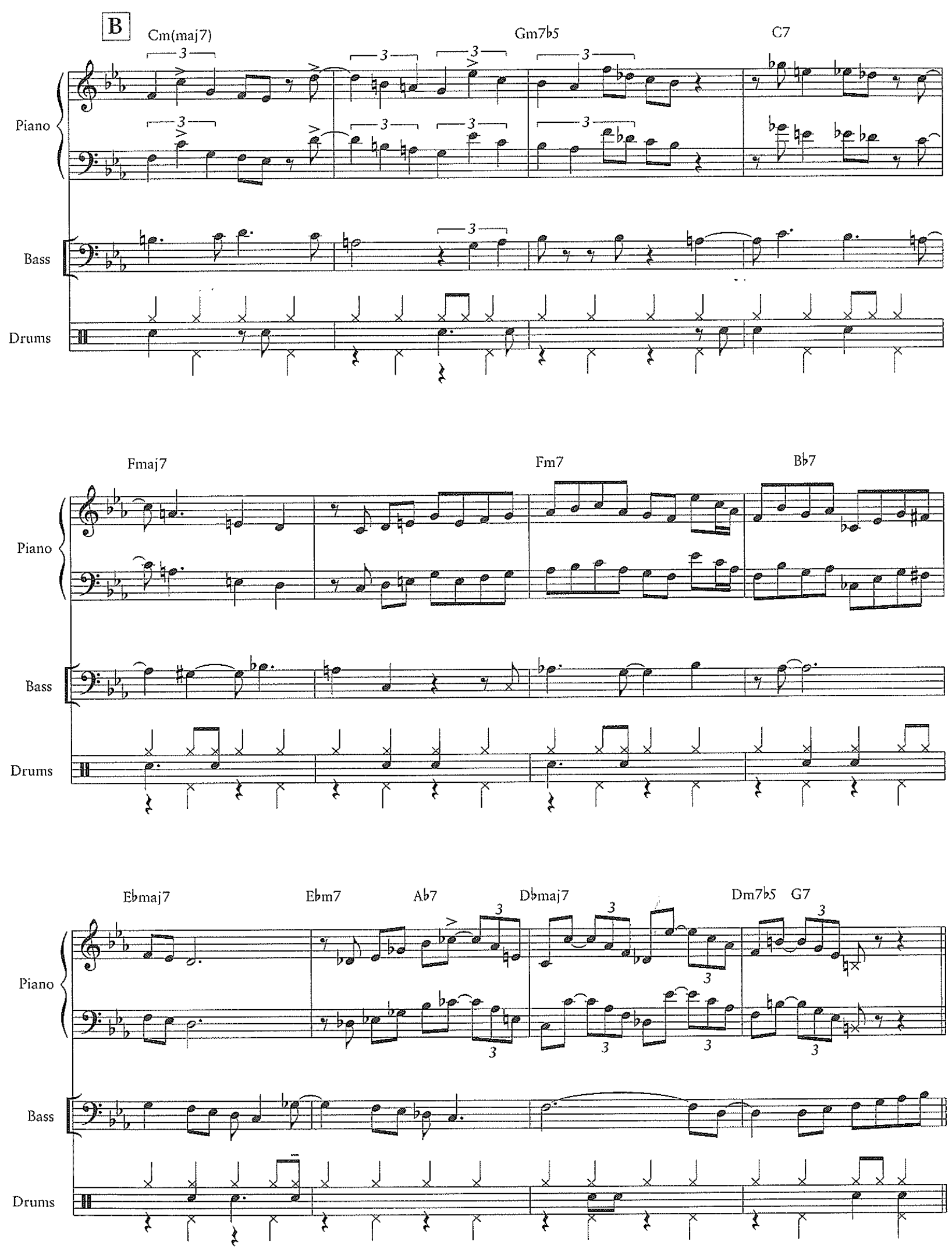

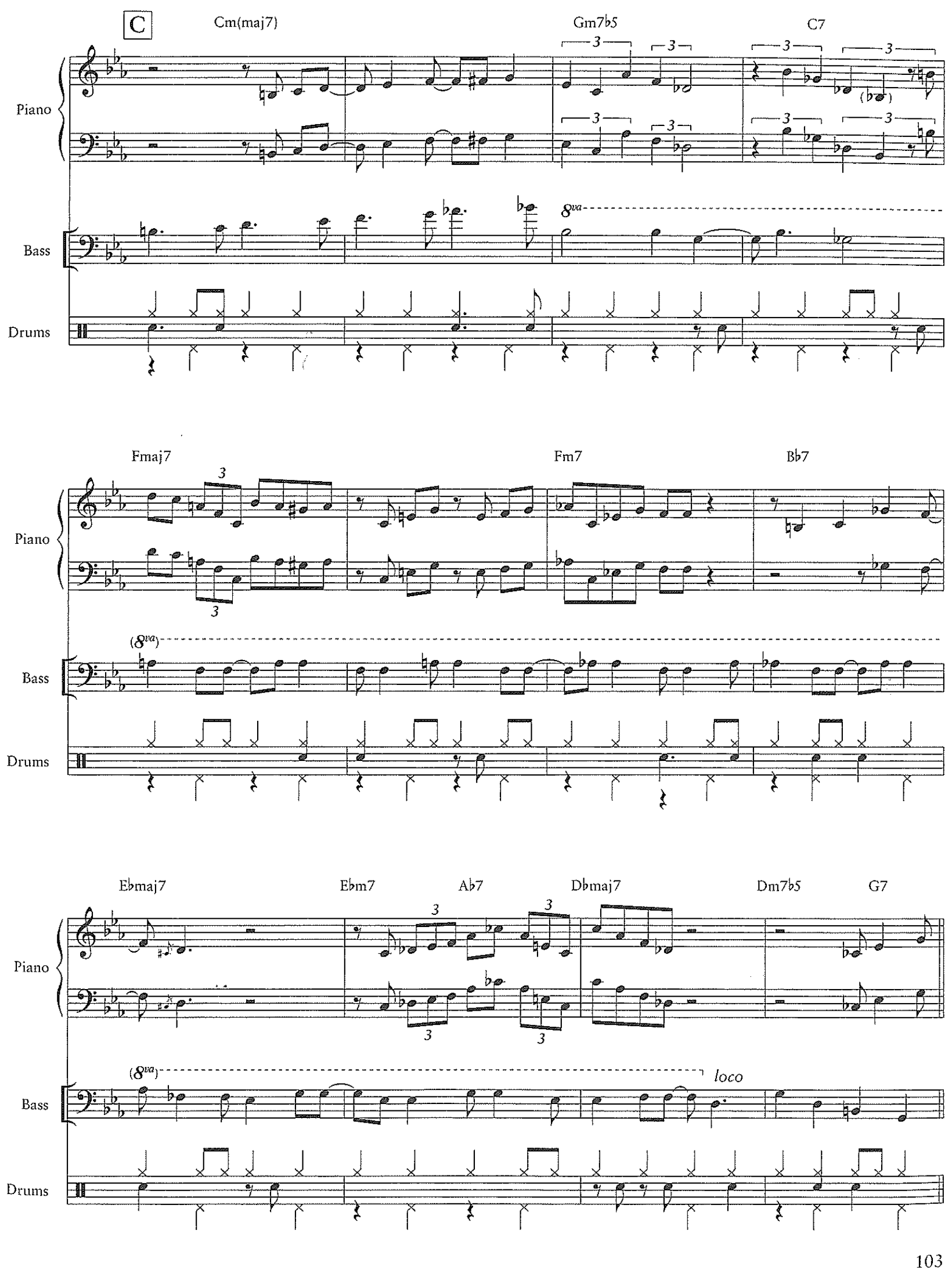

84 

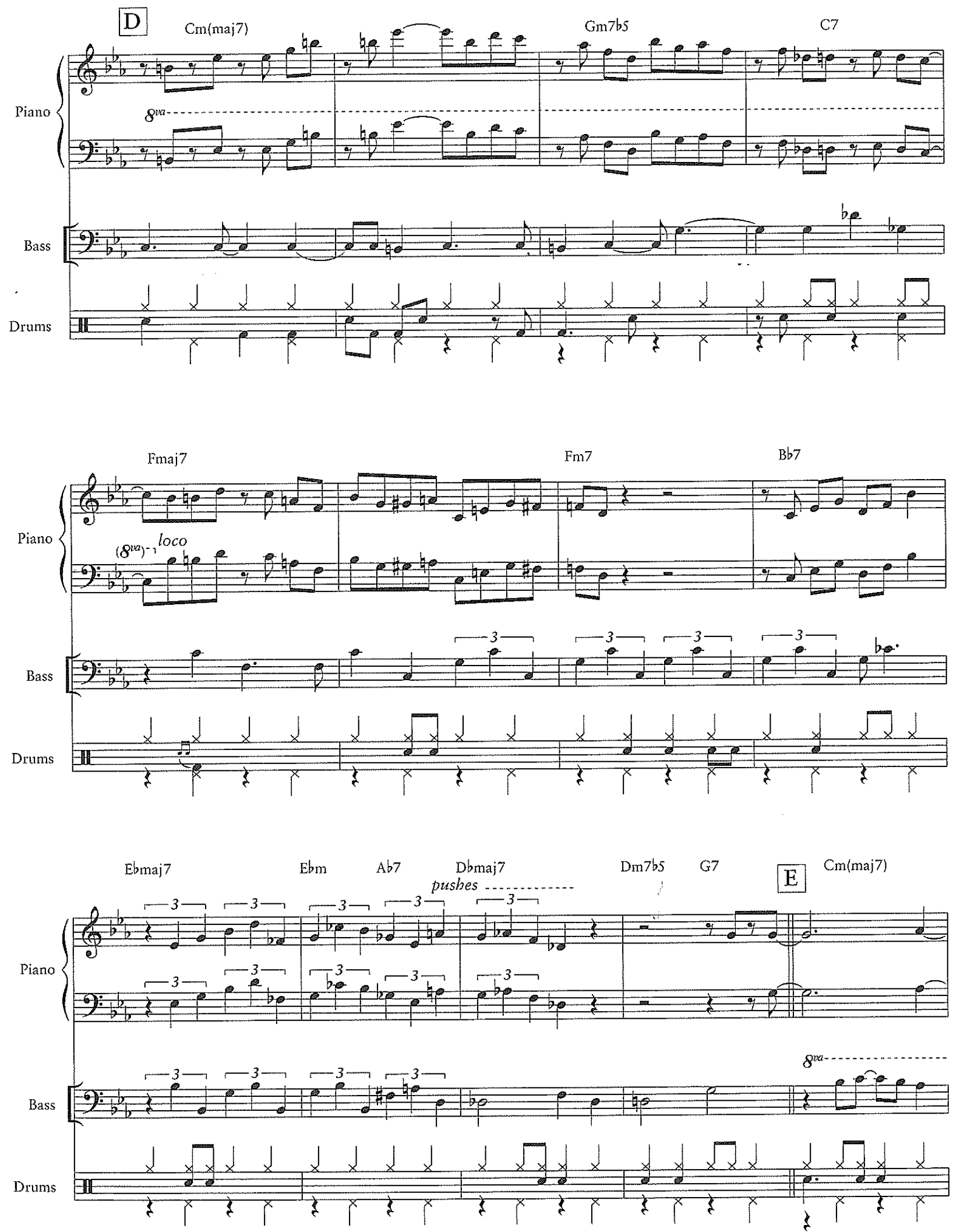

104

85 

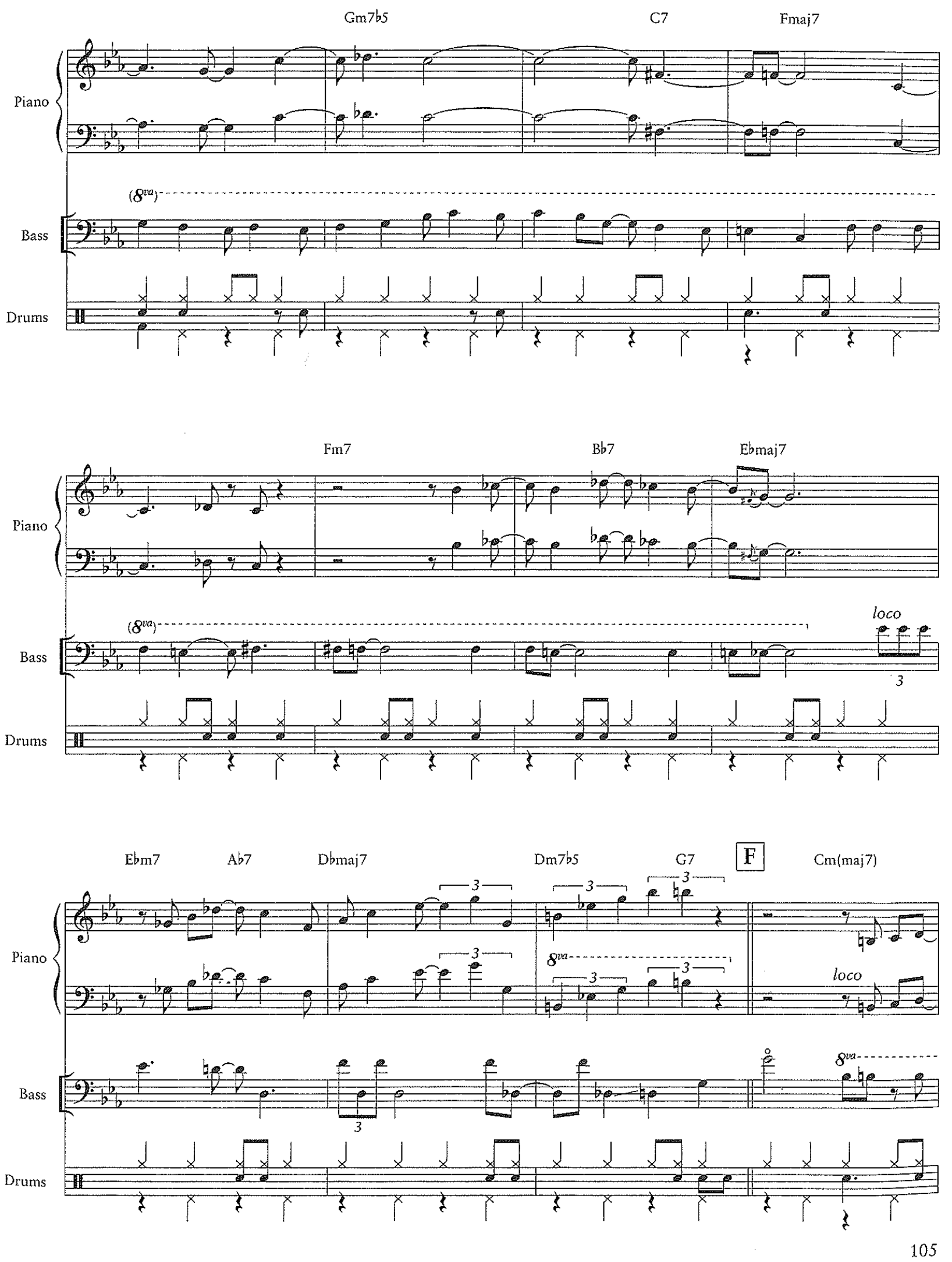

86 

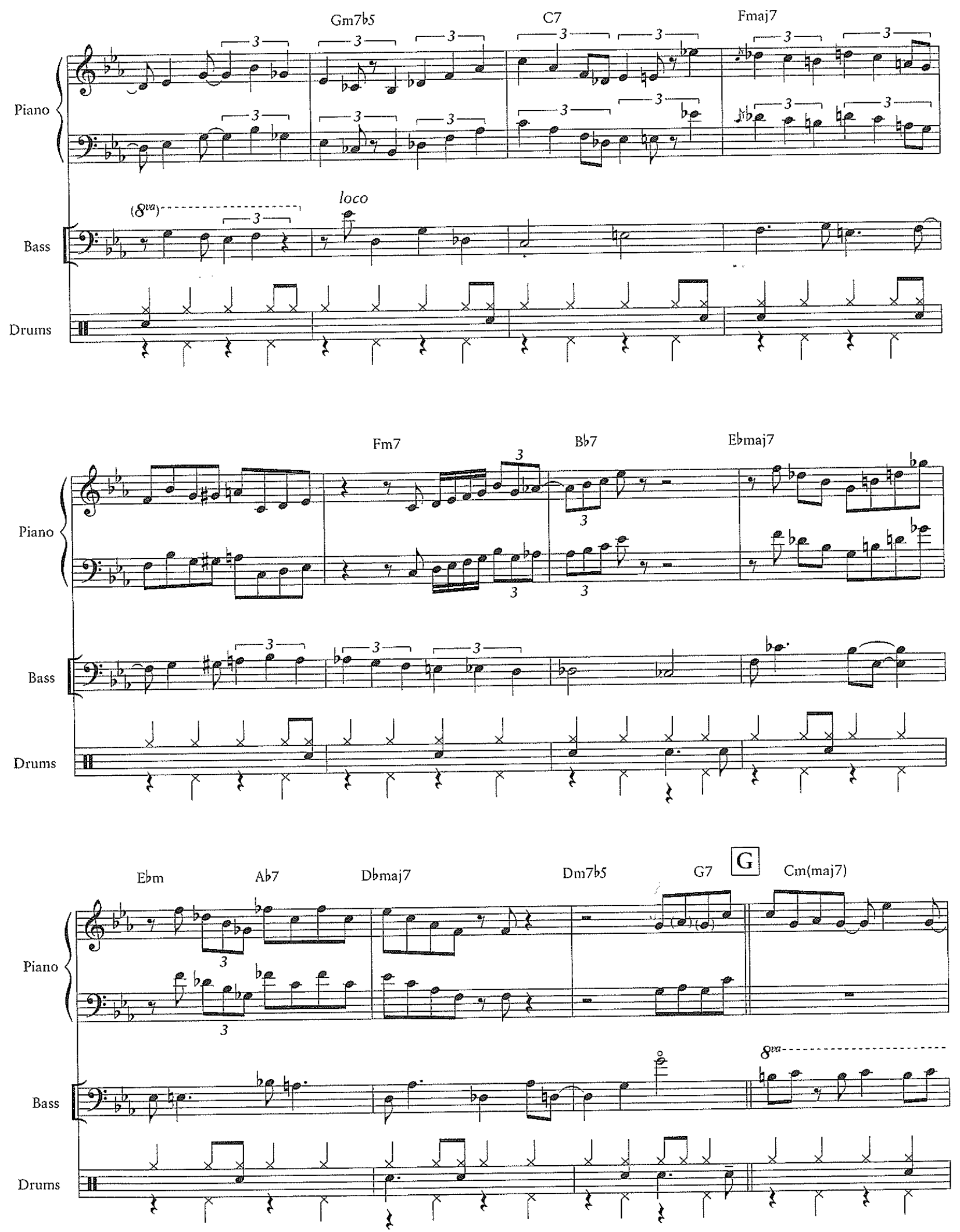

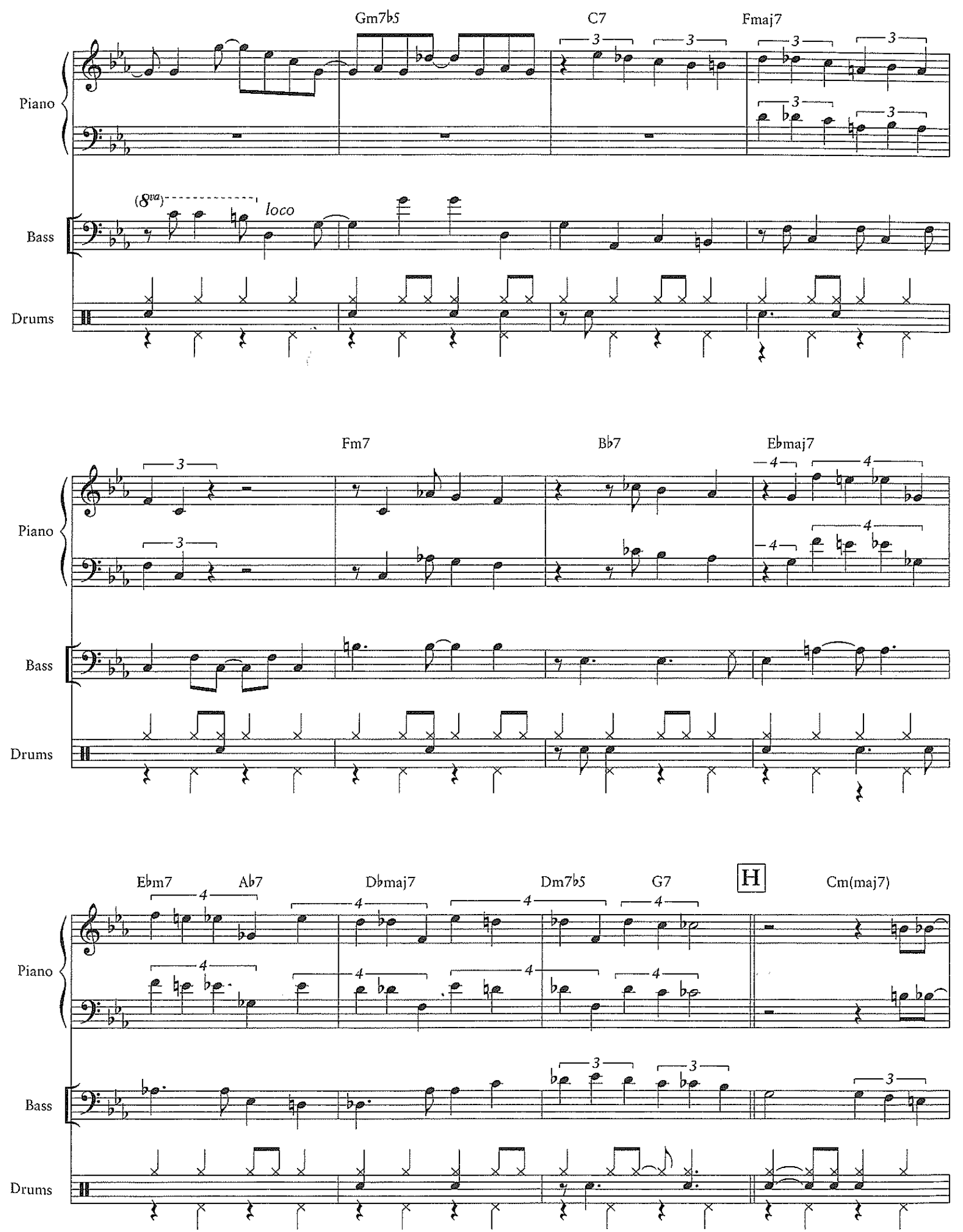

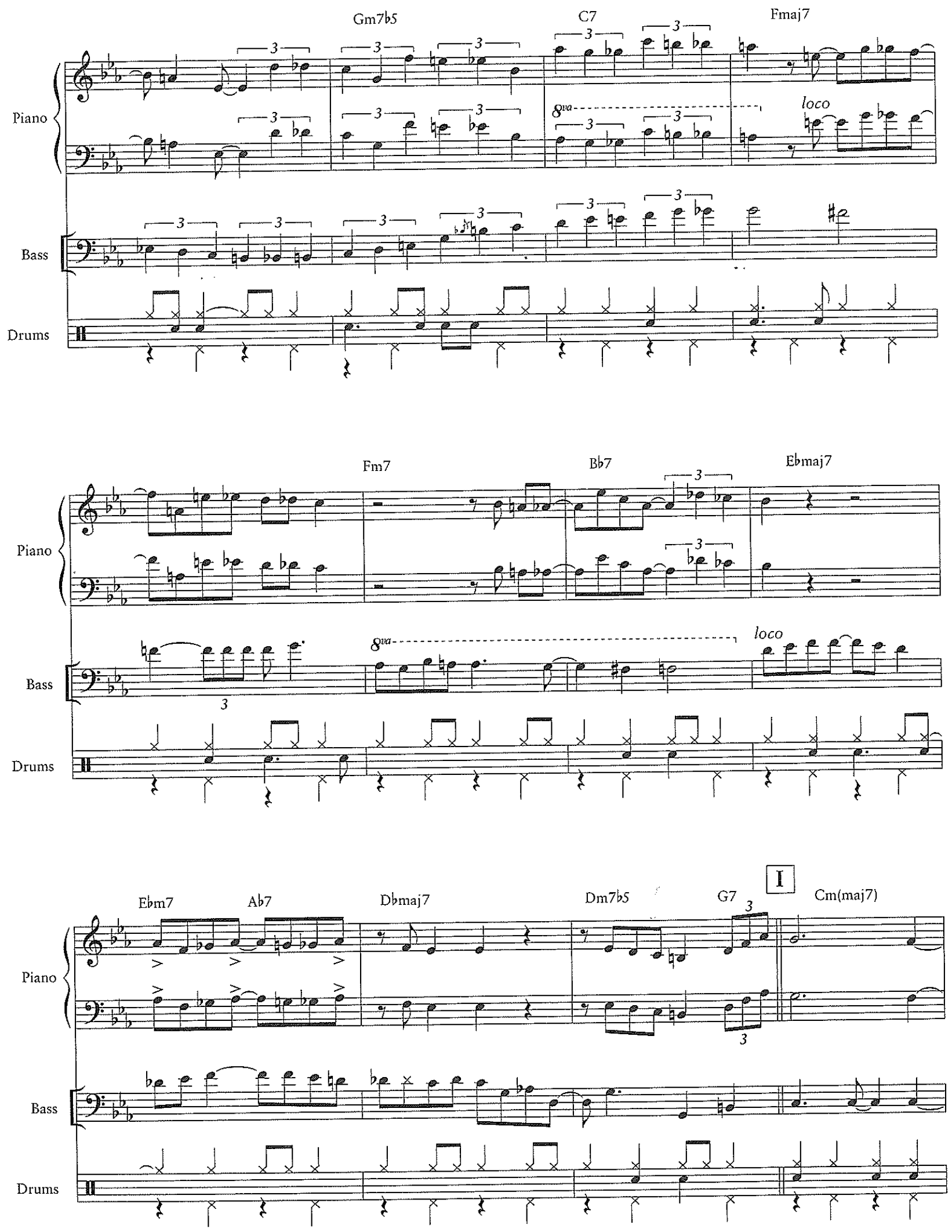

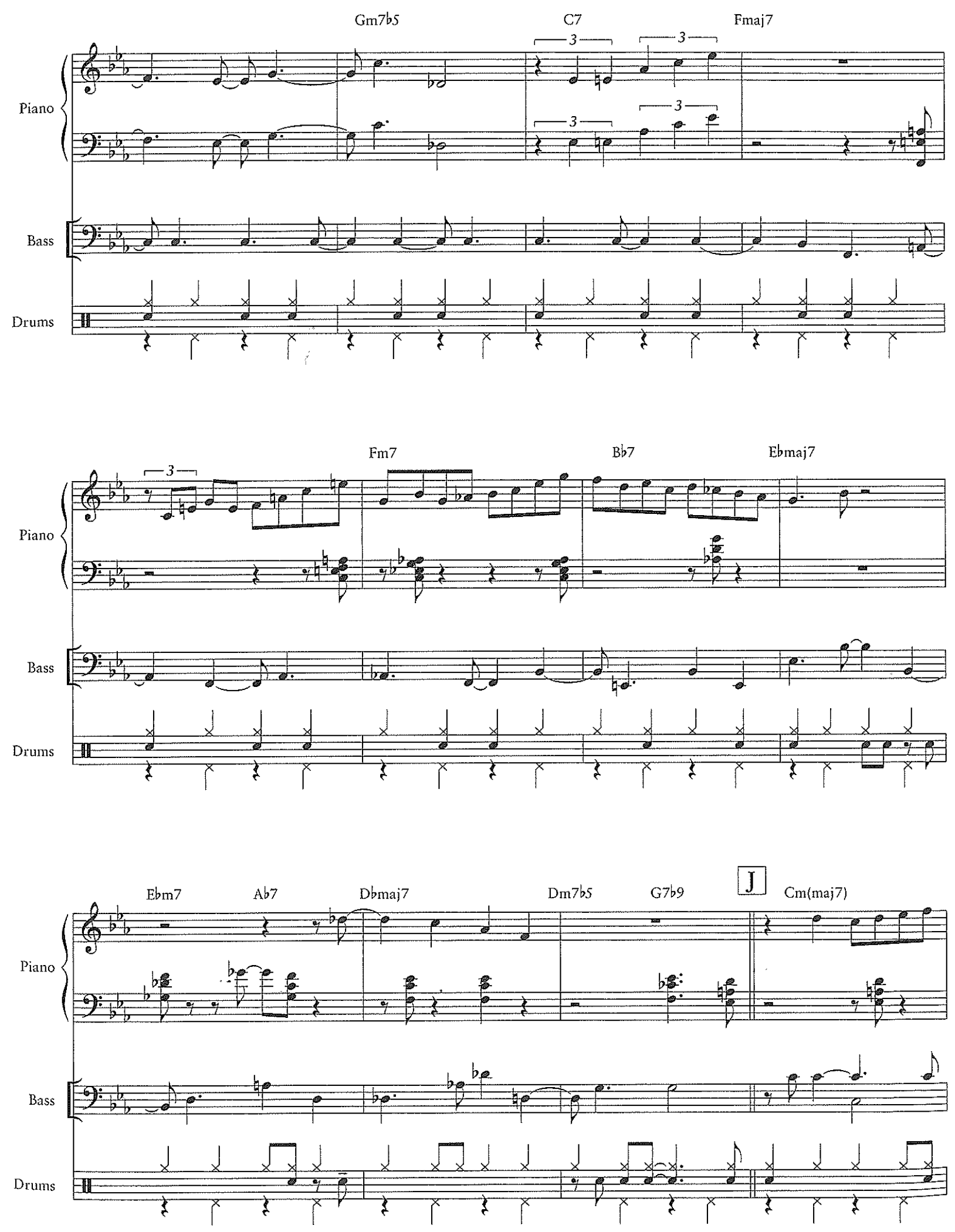

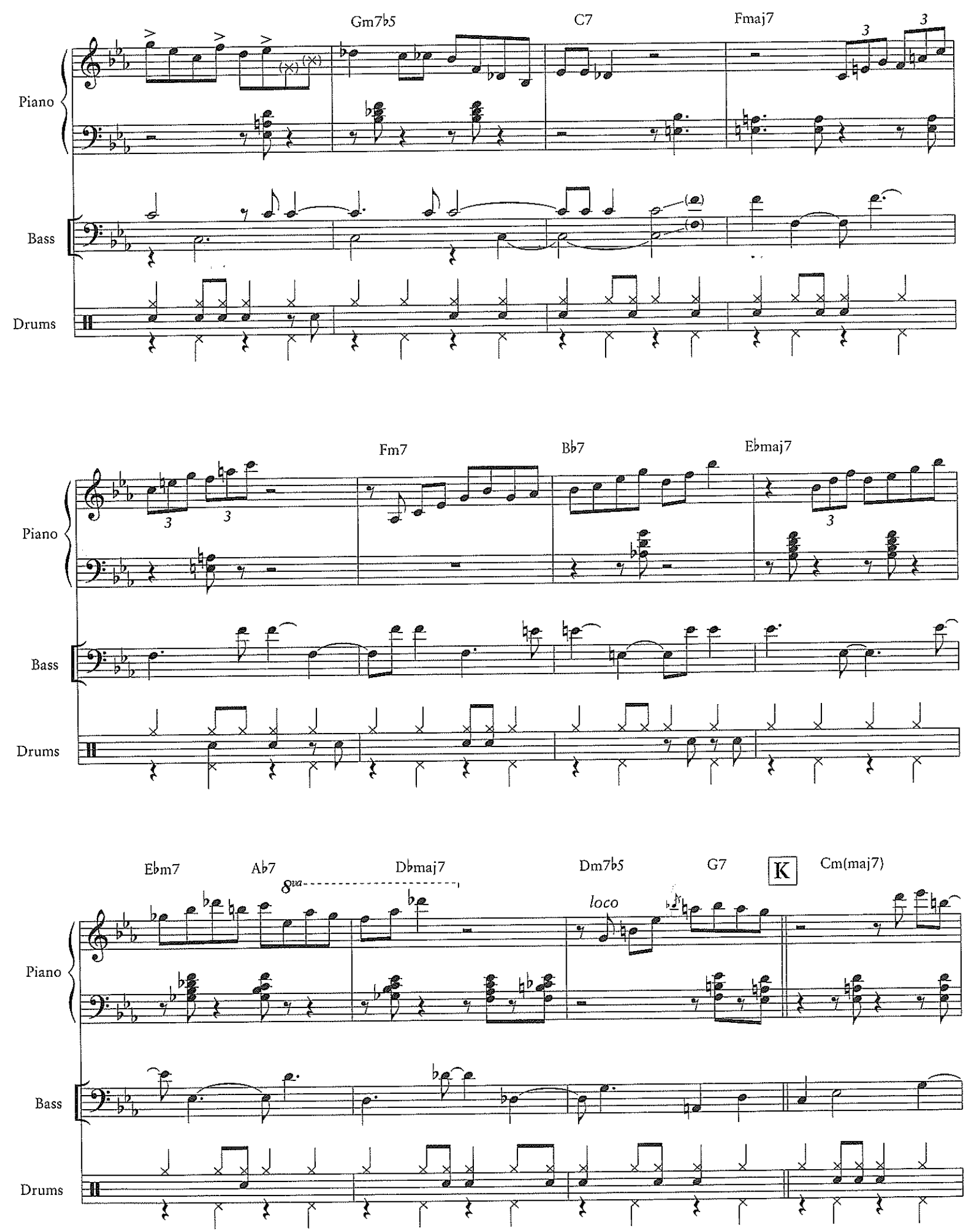

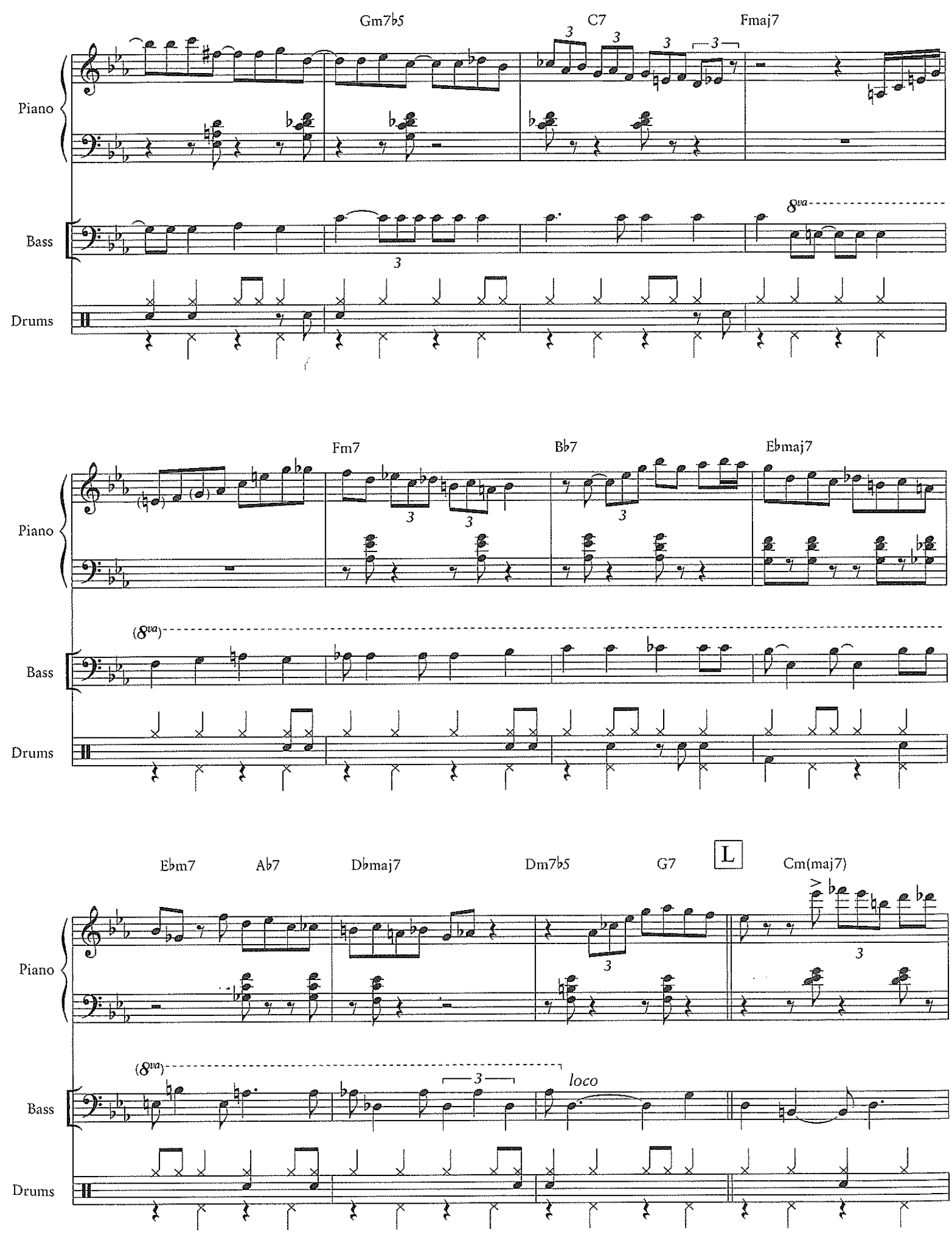

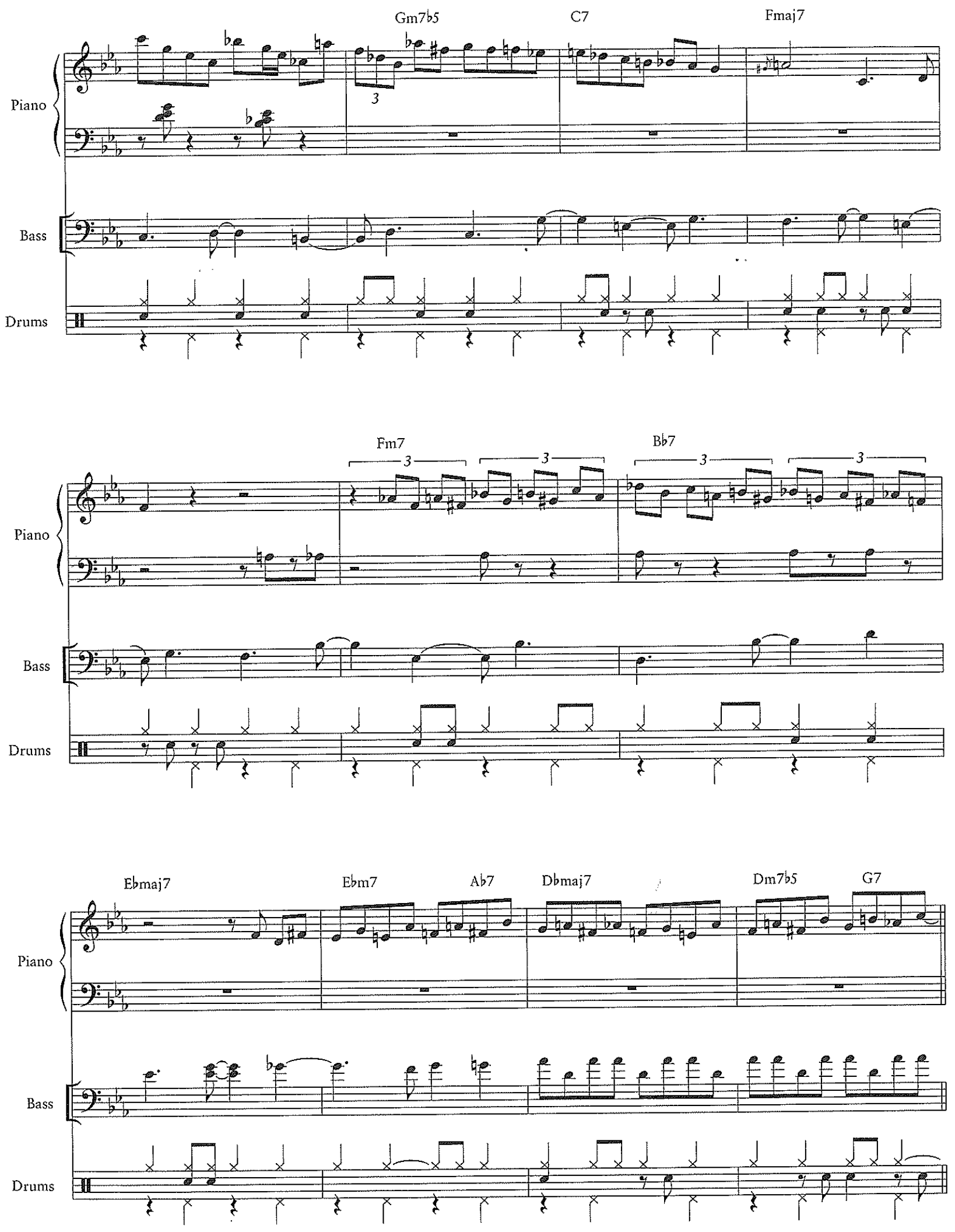

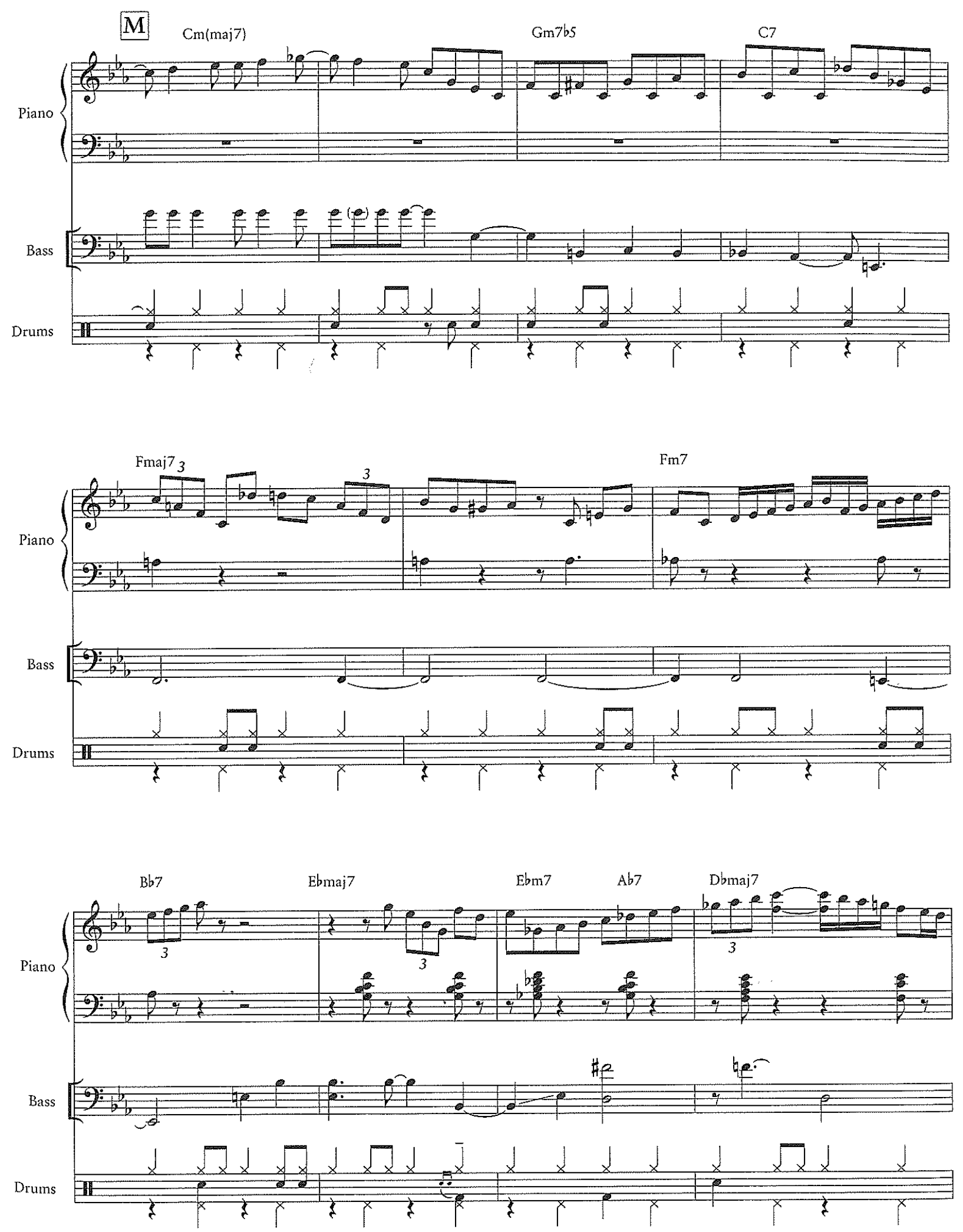

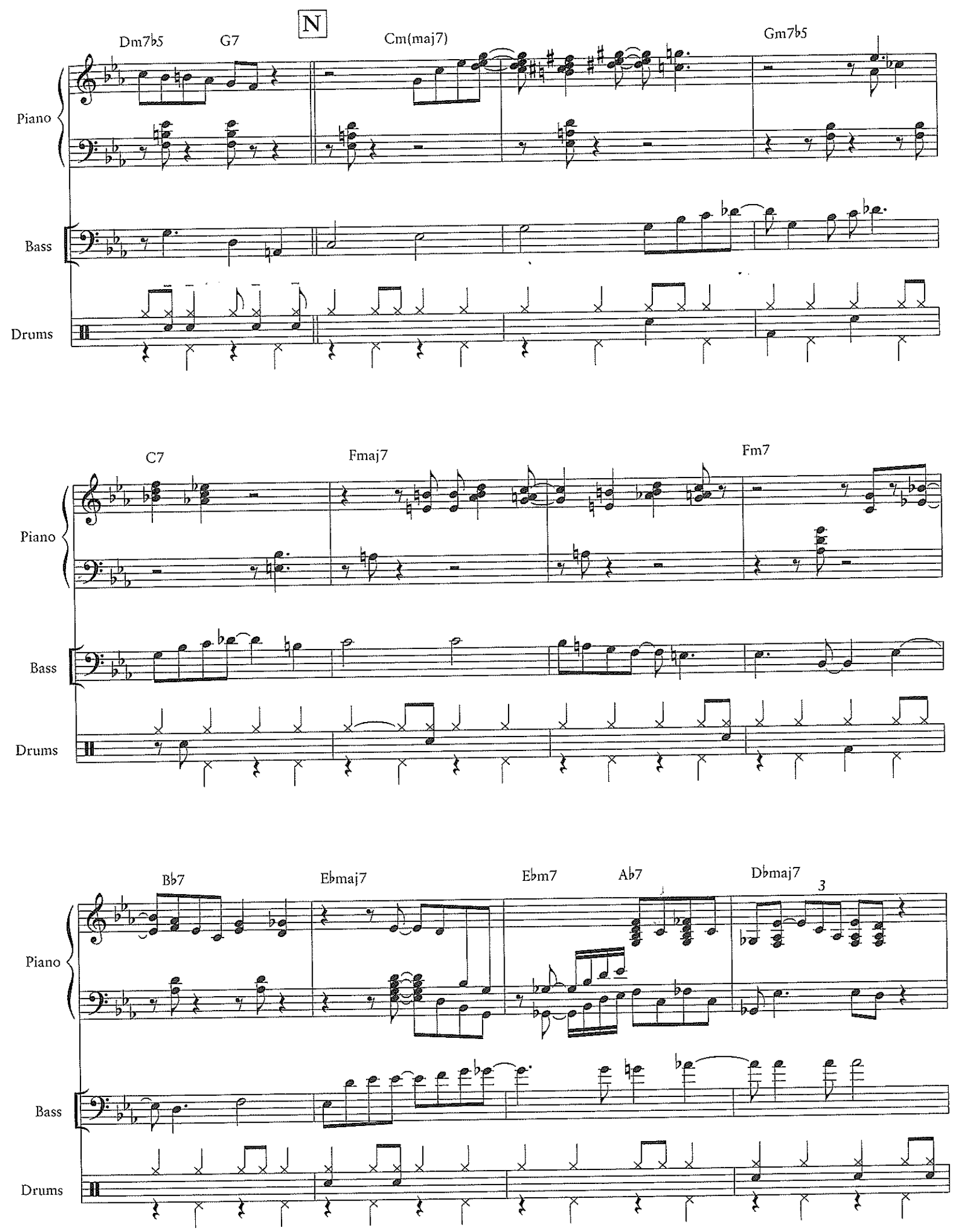
O
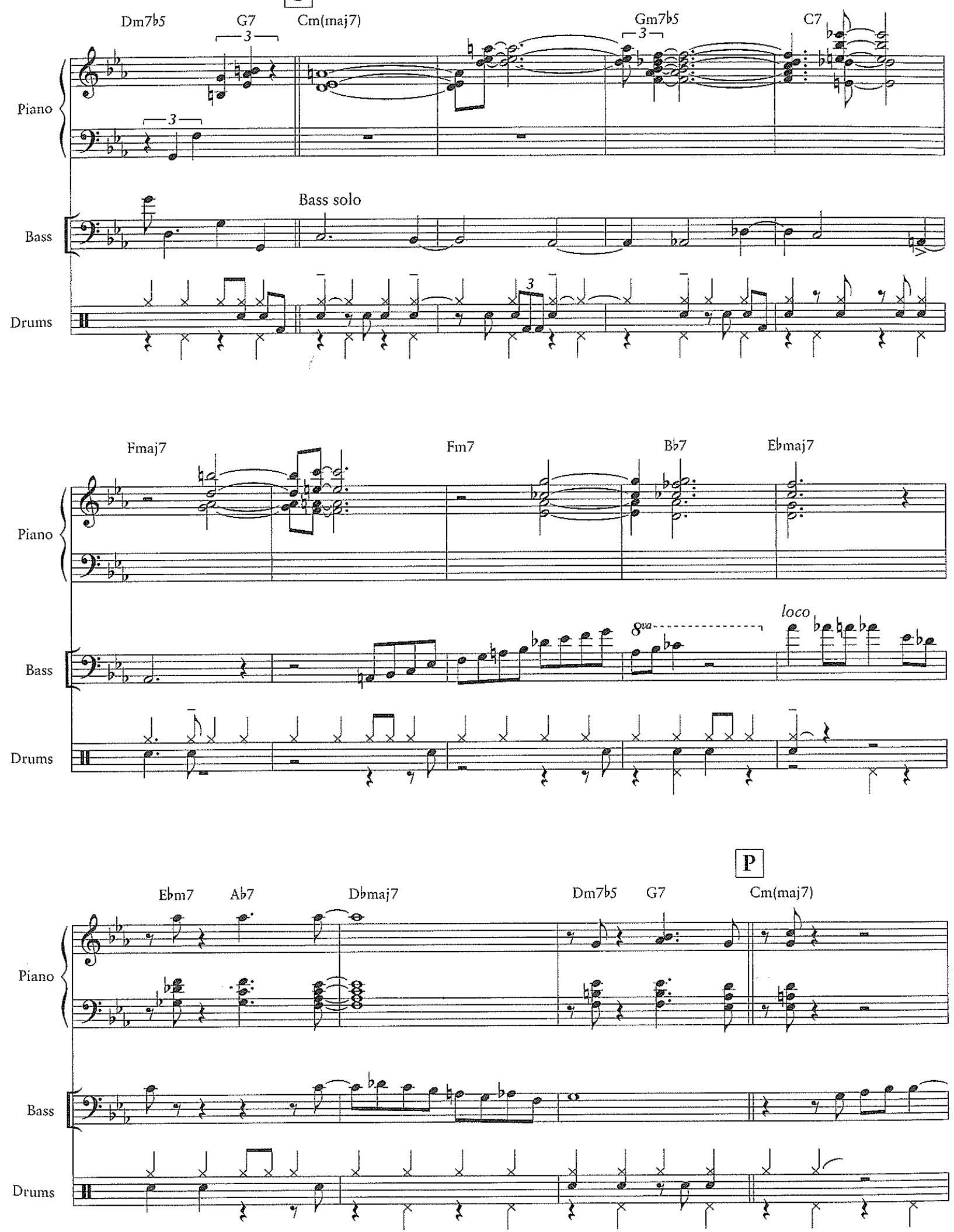


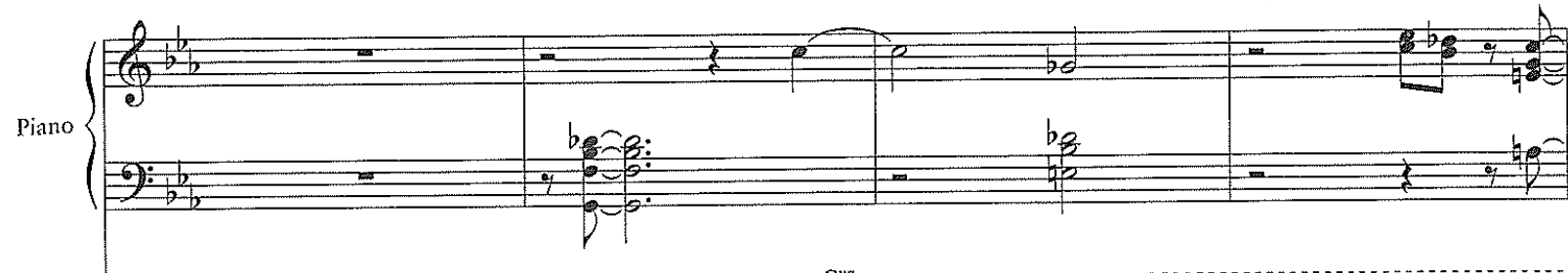

Bass

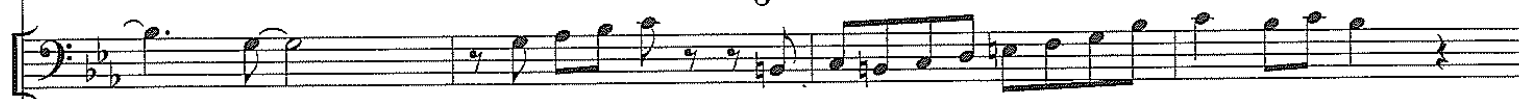

Drums

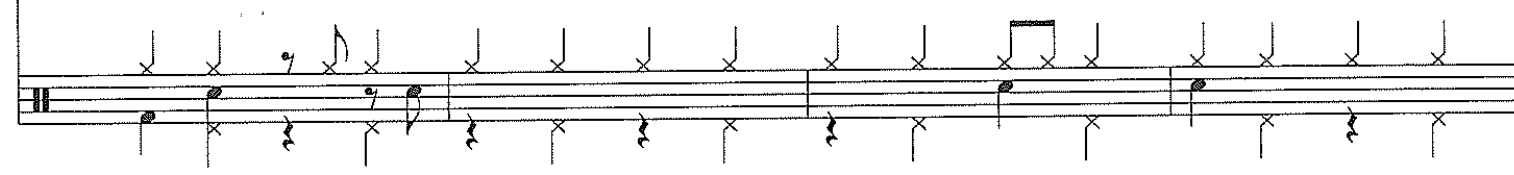

Fm7

Bb7

Ebmaj7

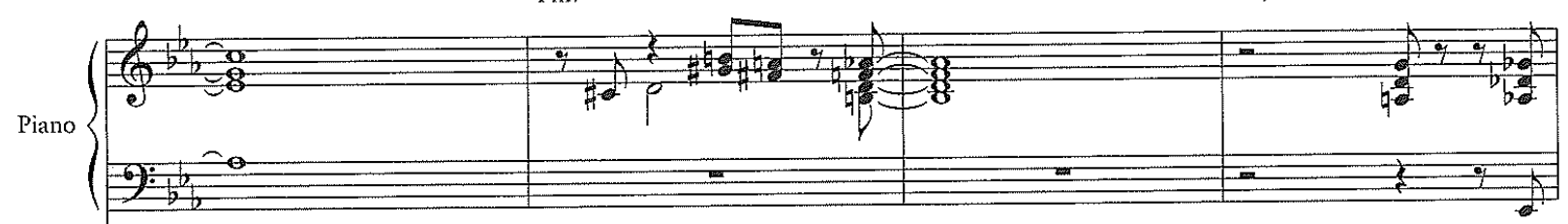

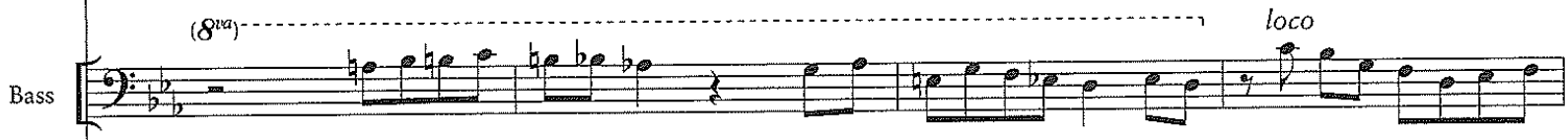

Drums
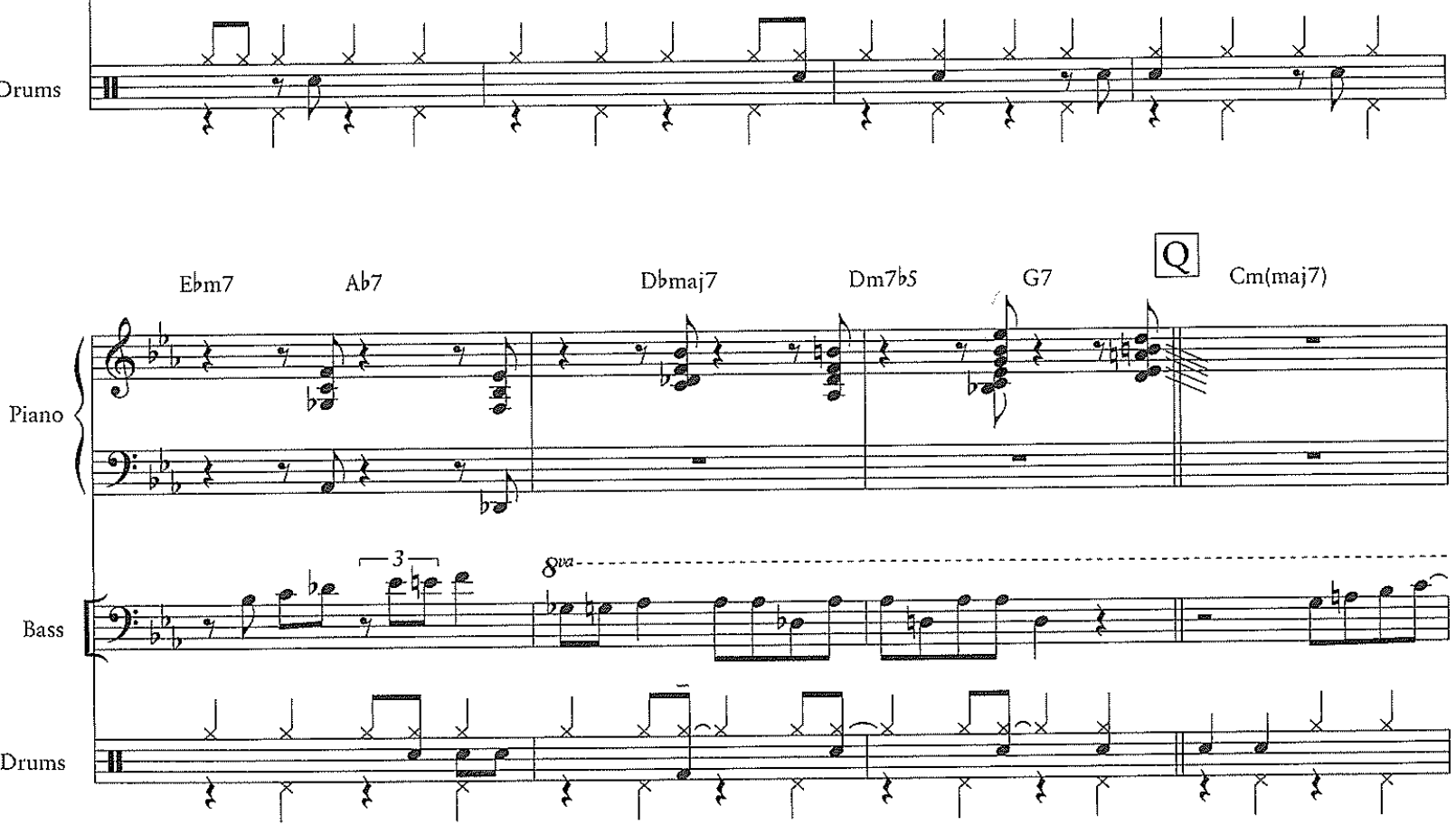

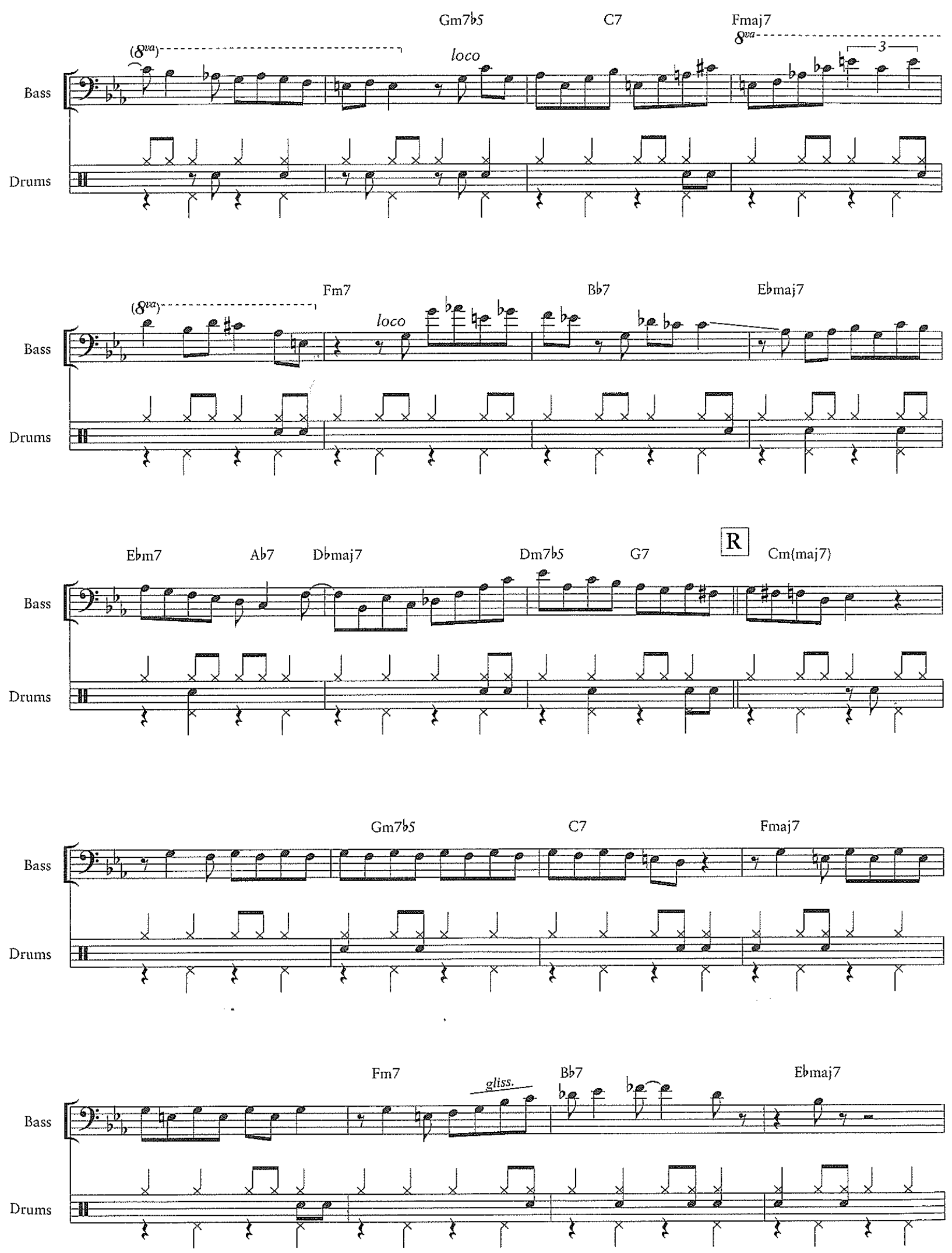

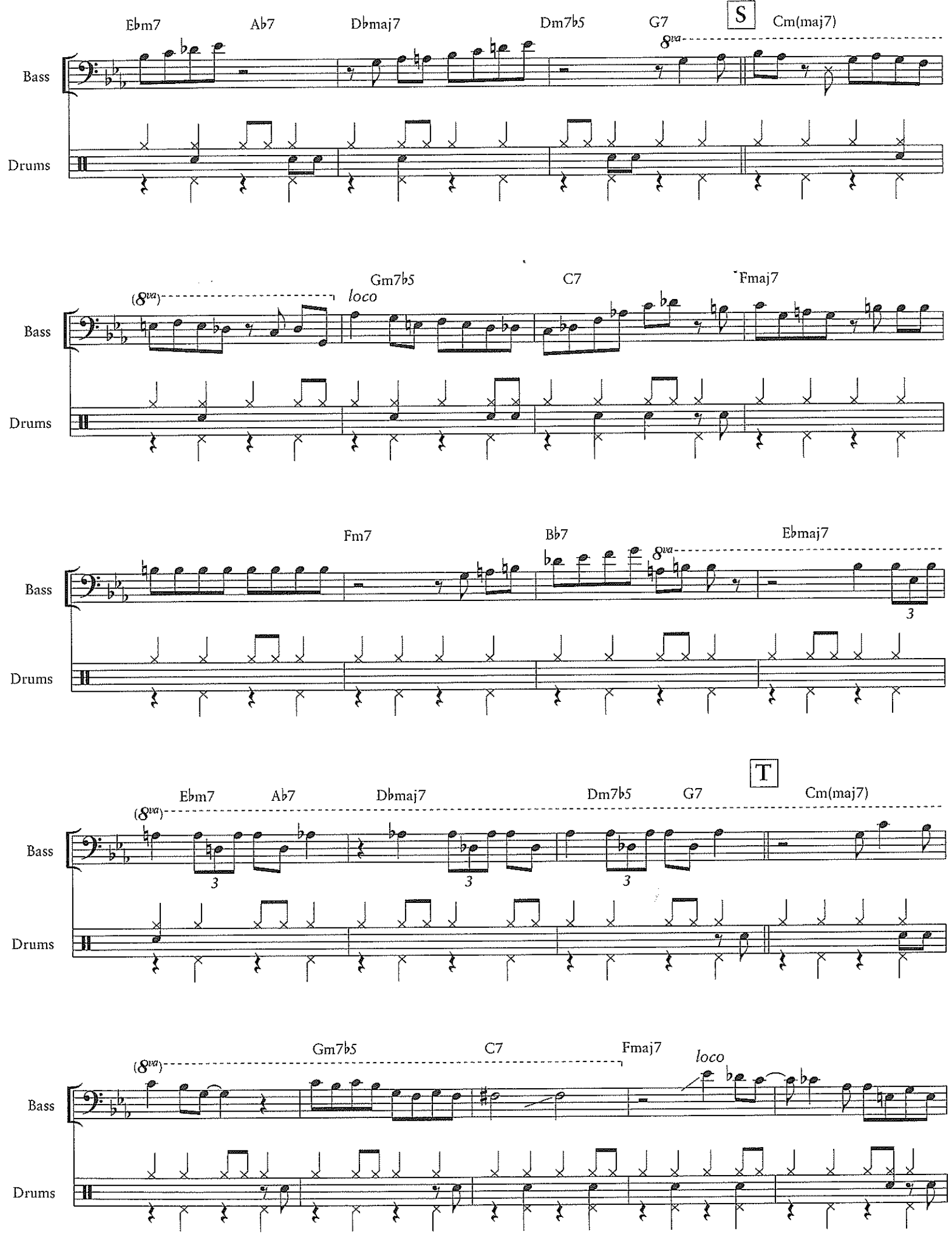

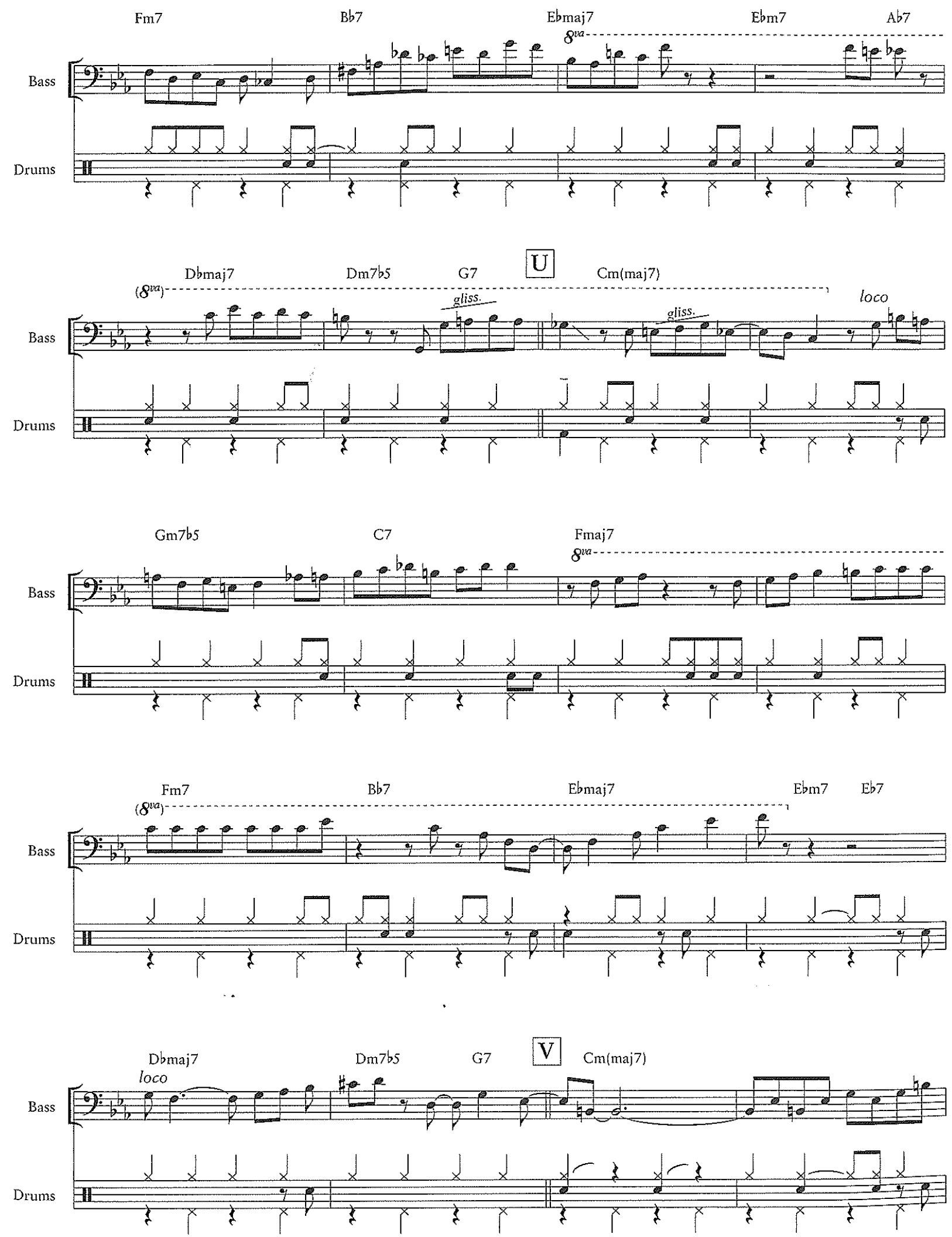

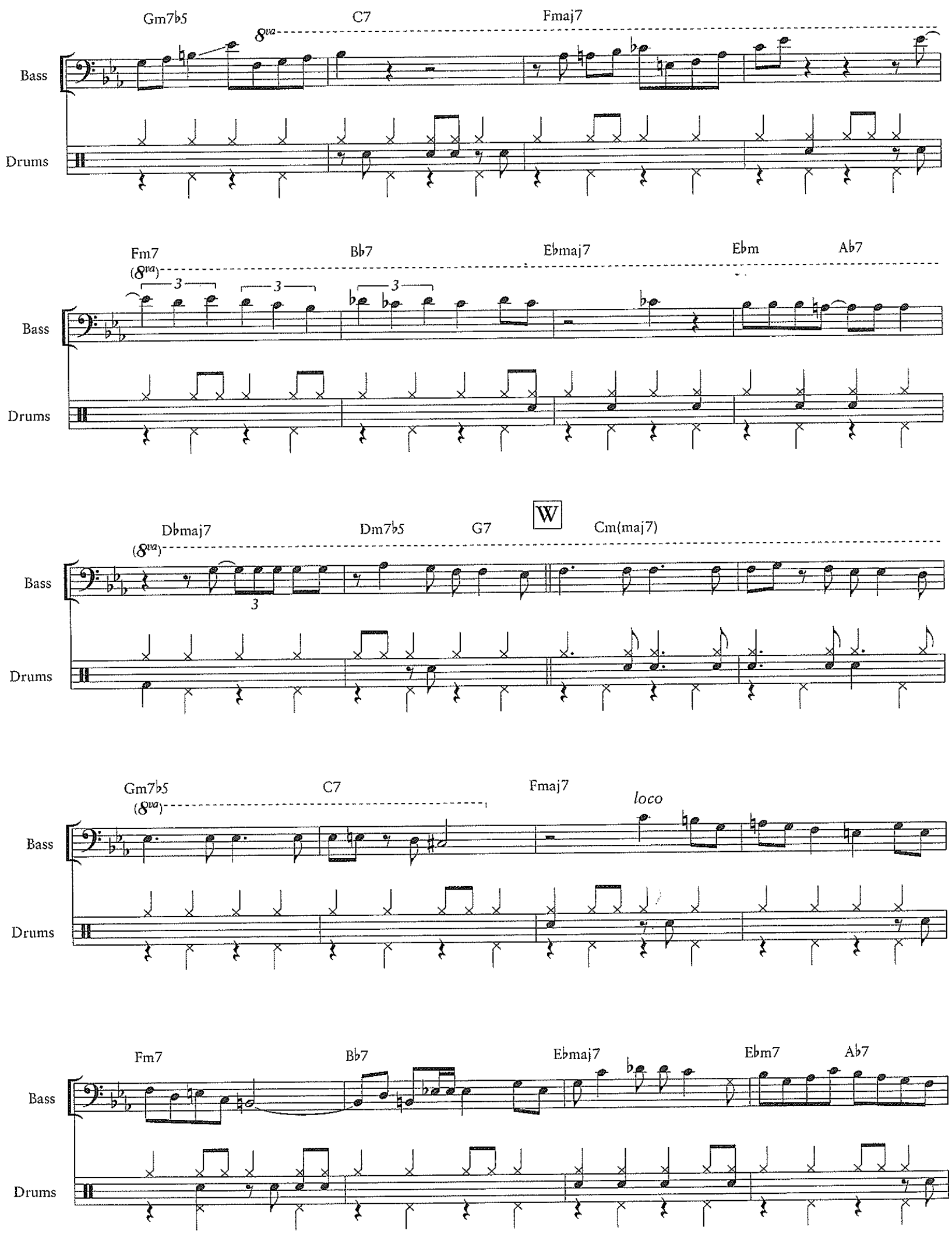

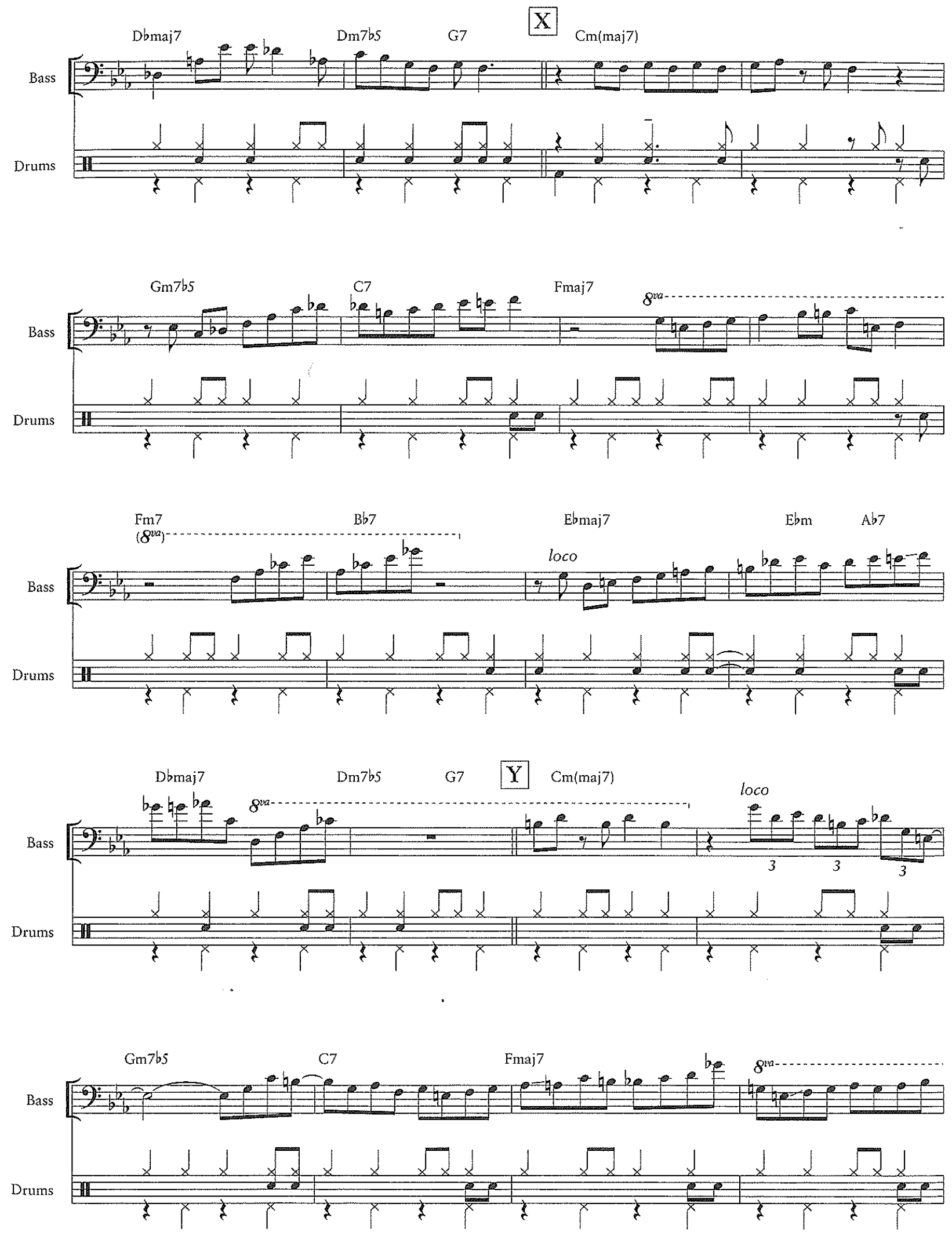


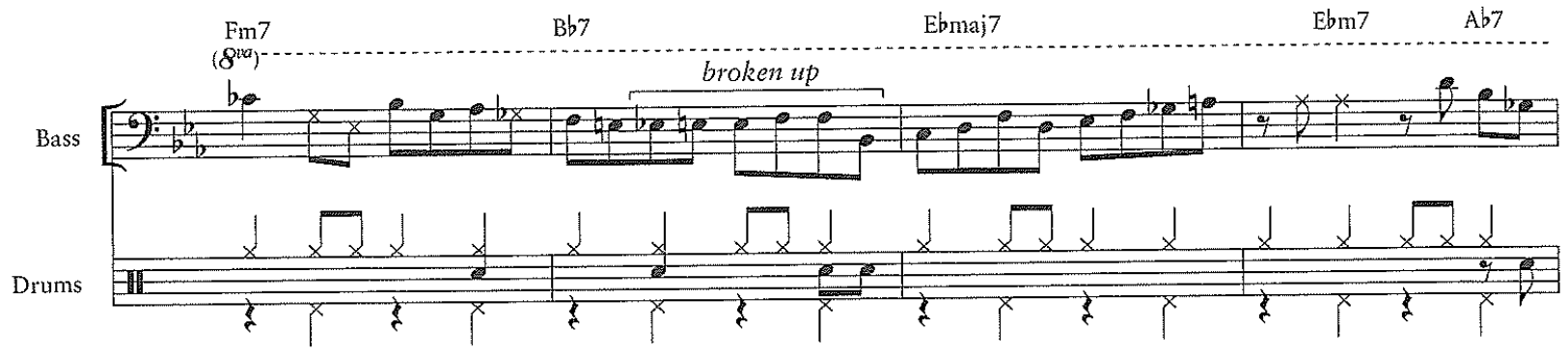

Z
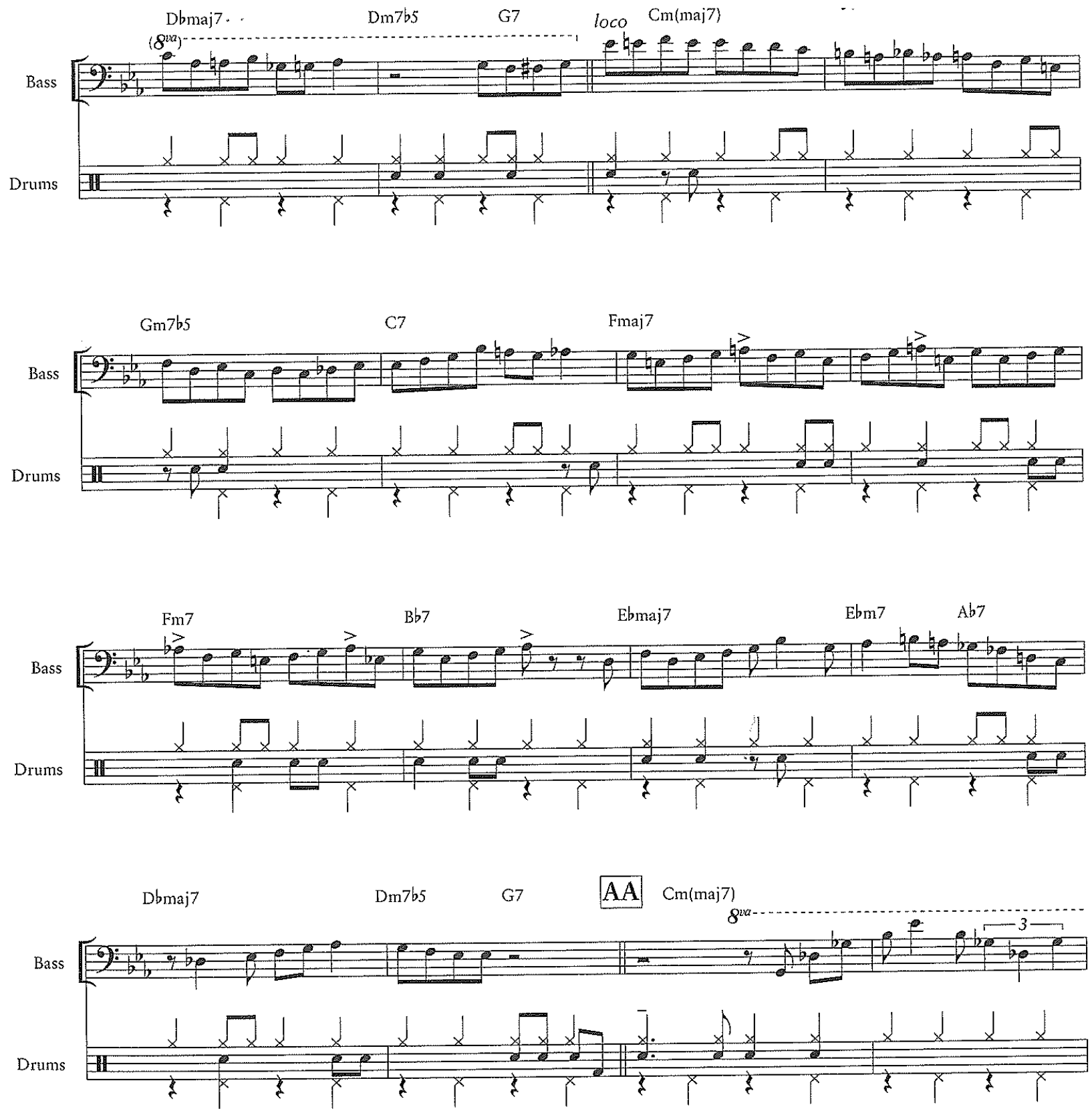

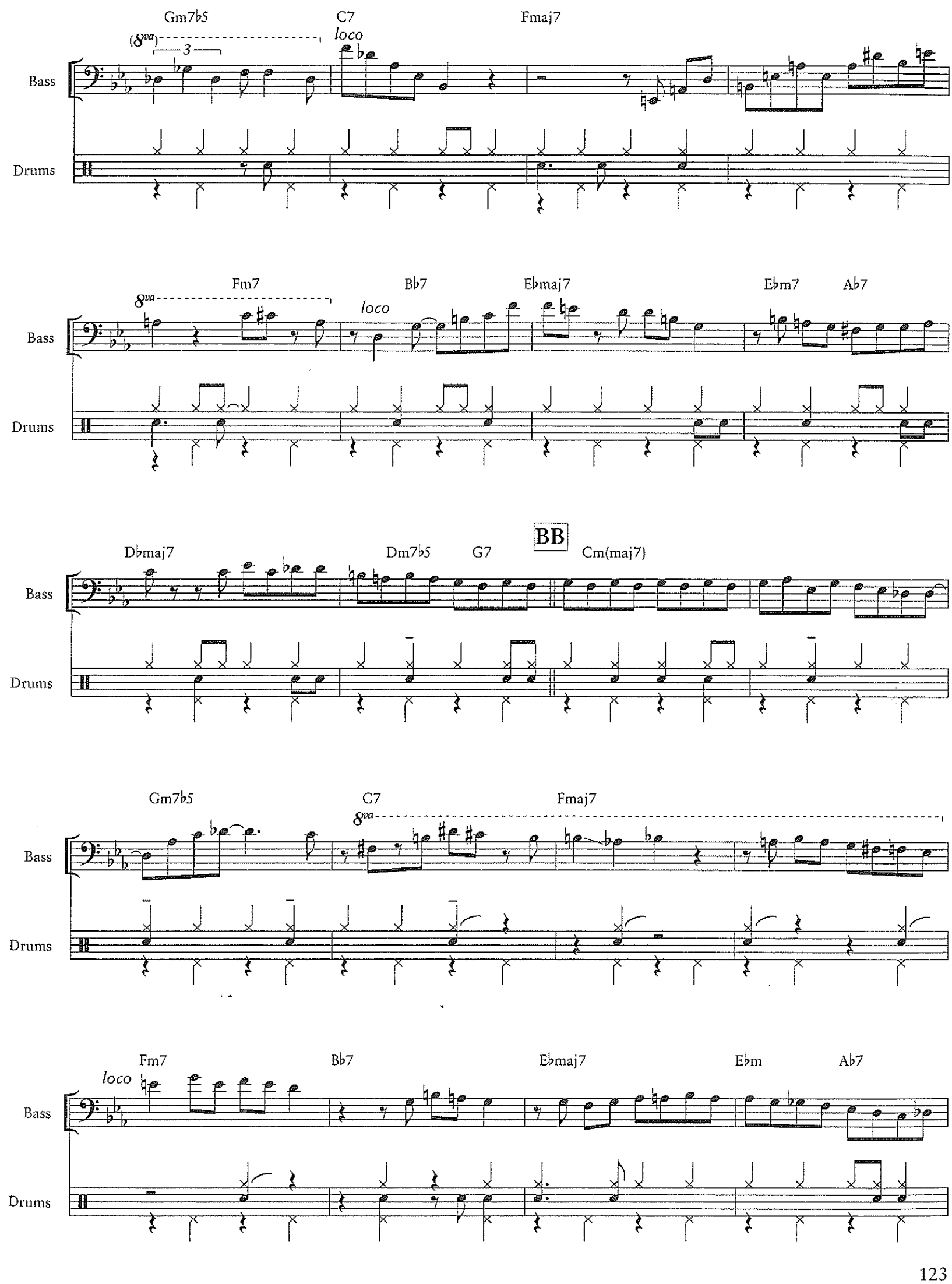

104 

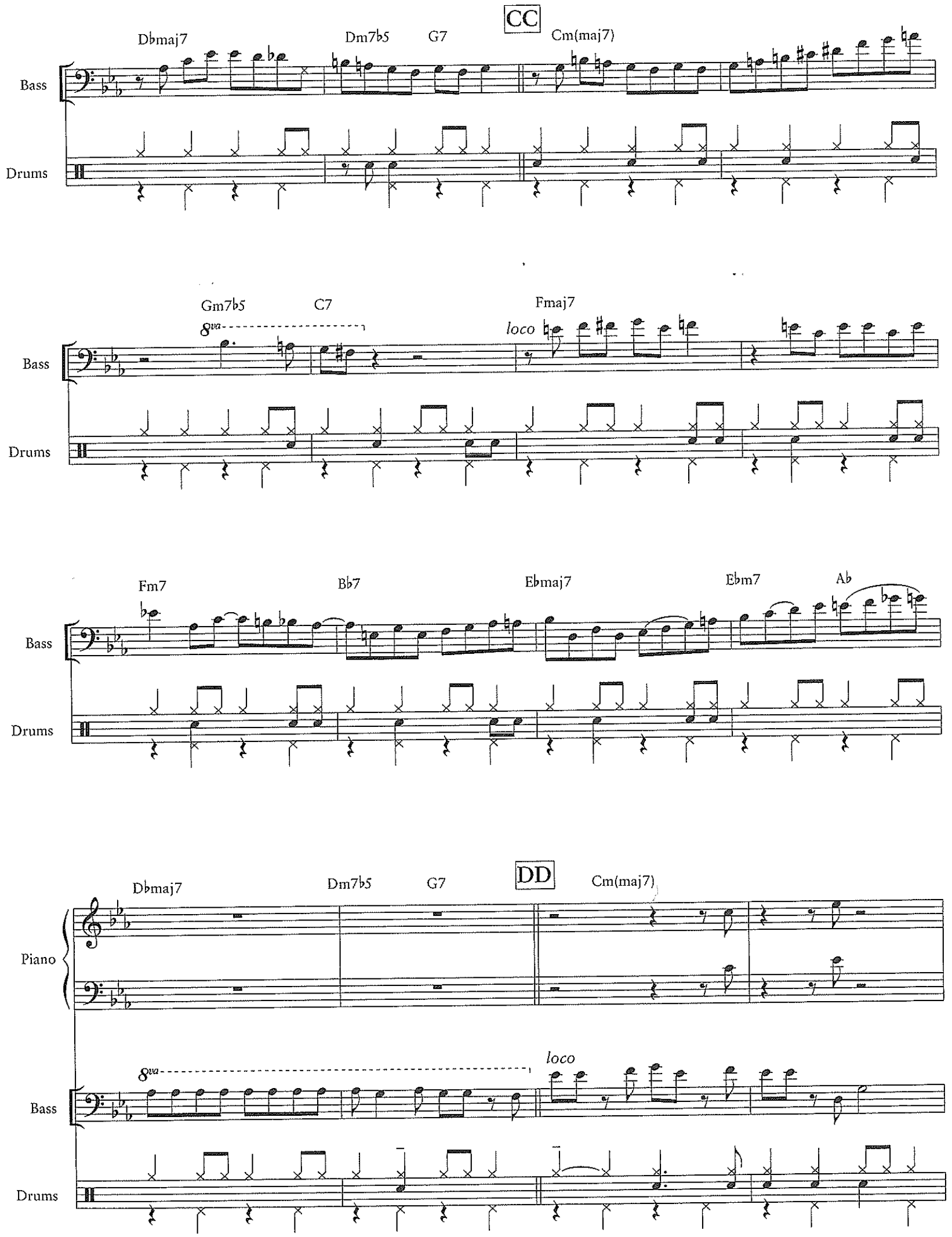

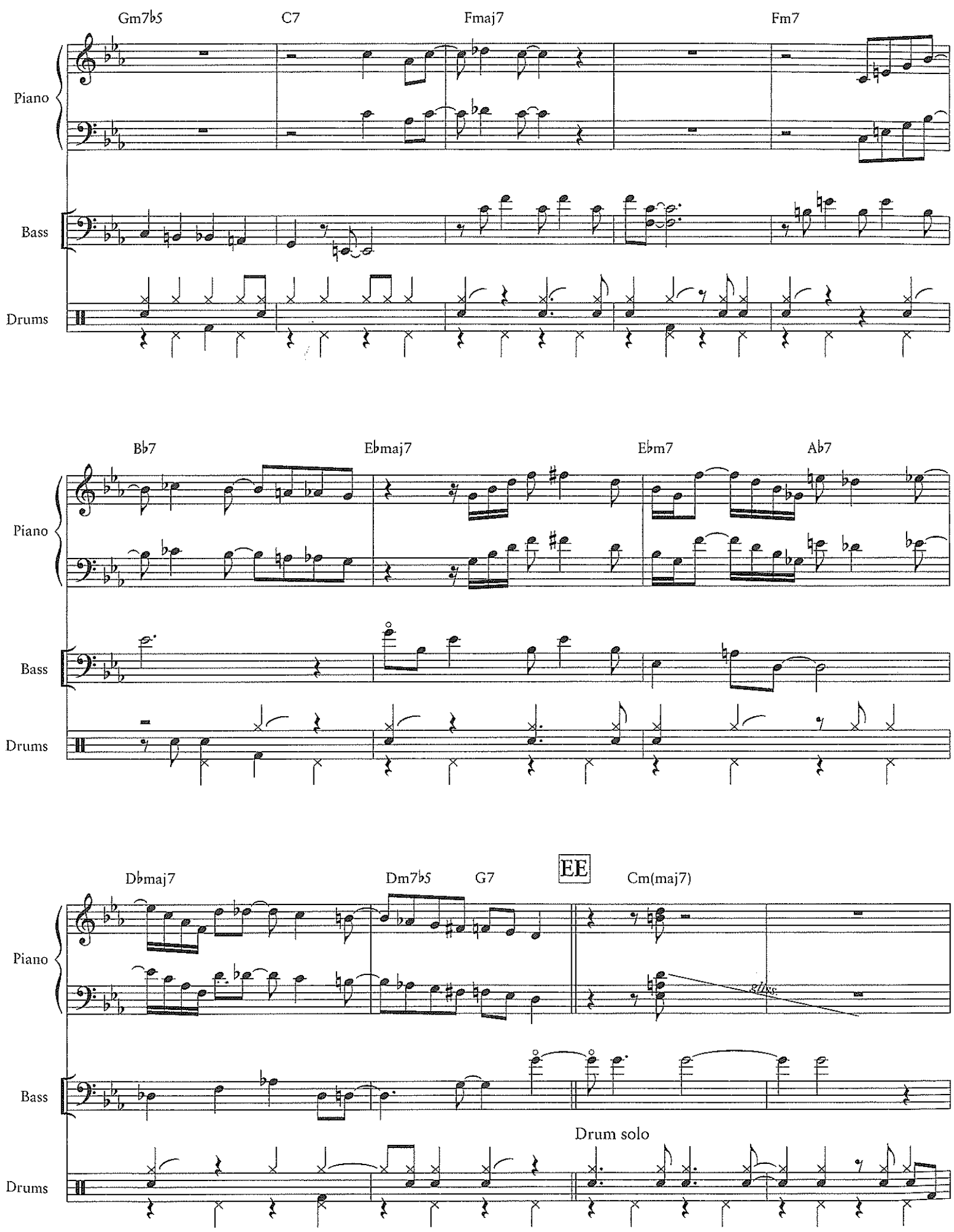

125

106 

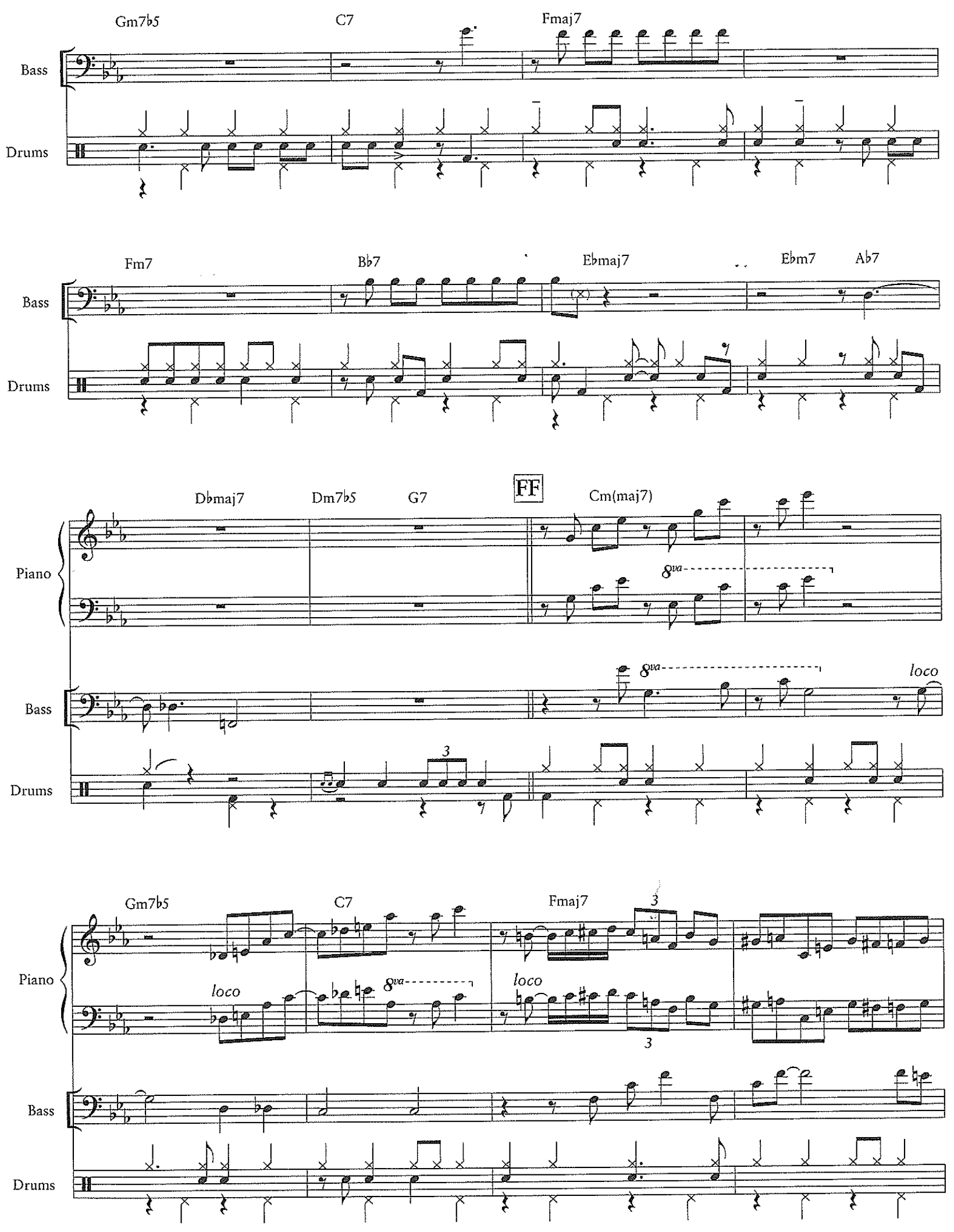

126

107 

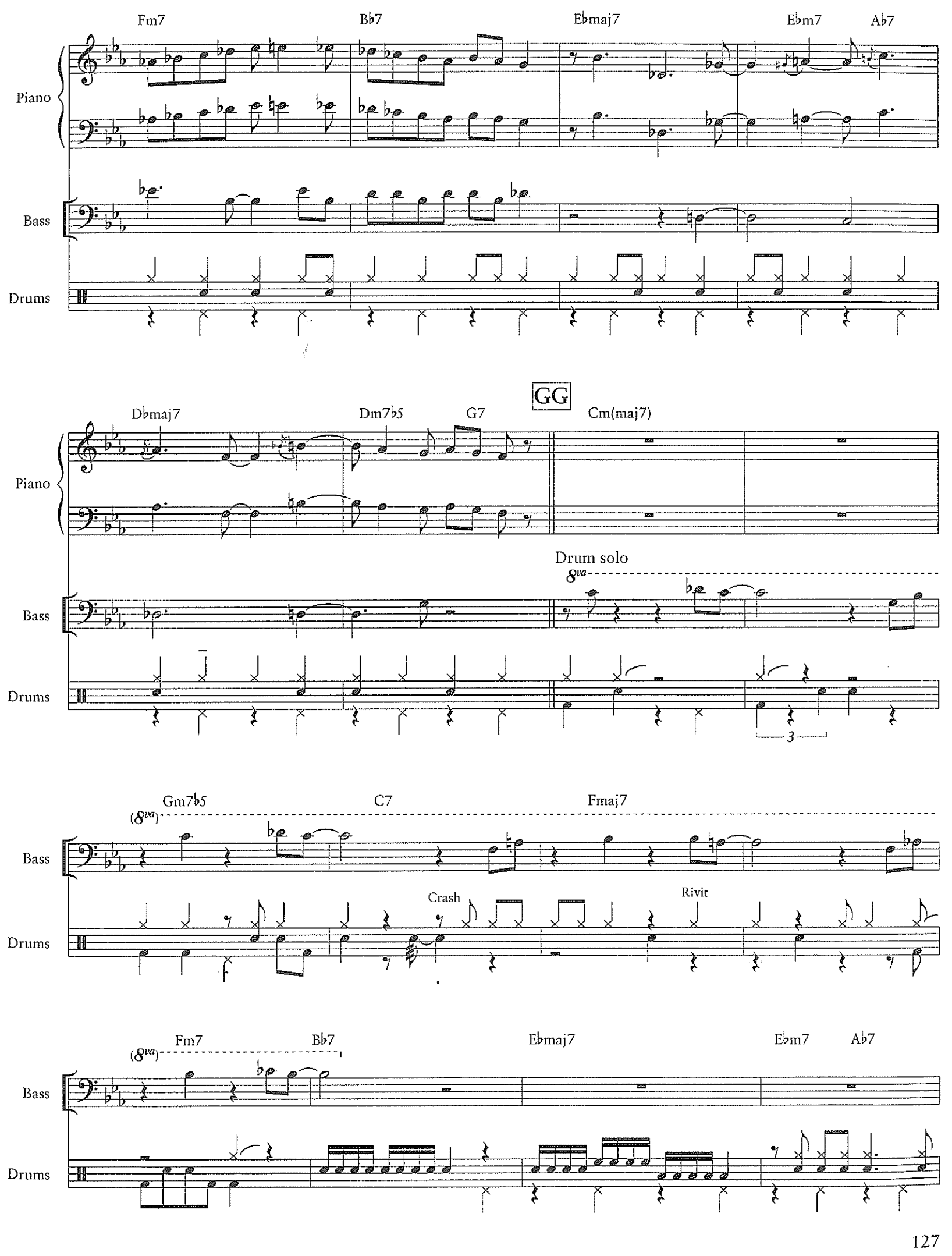

108 

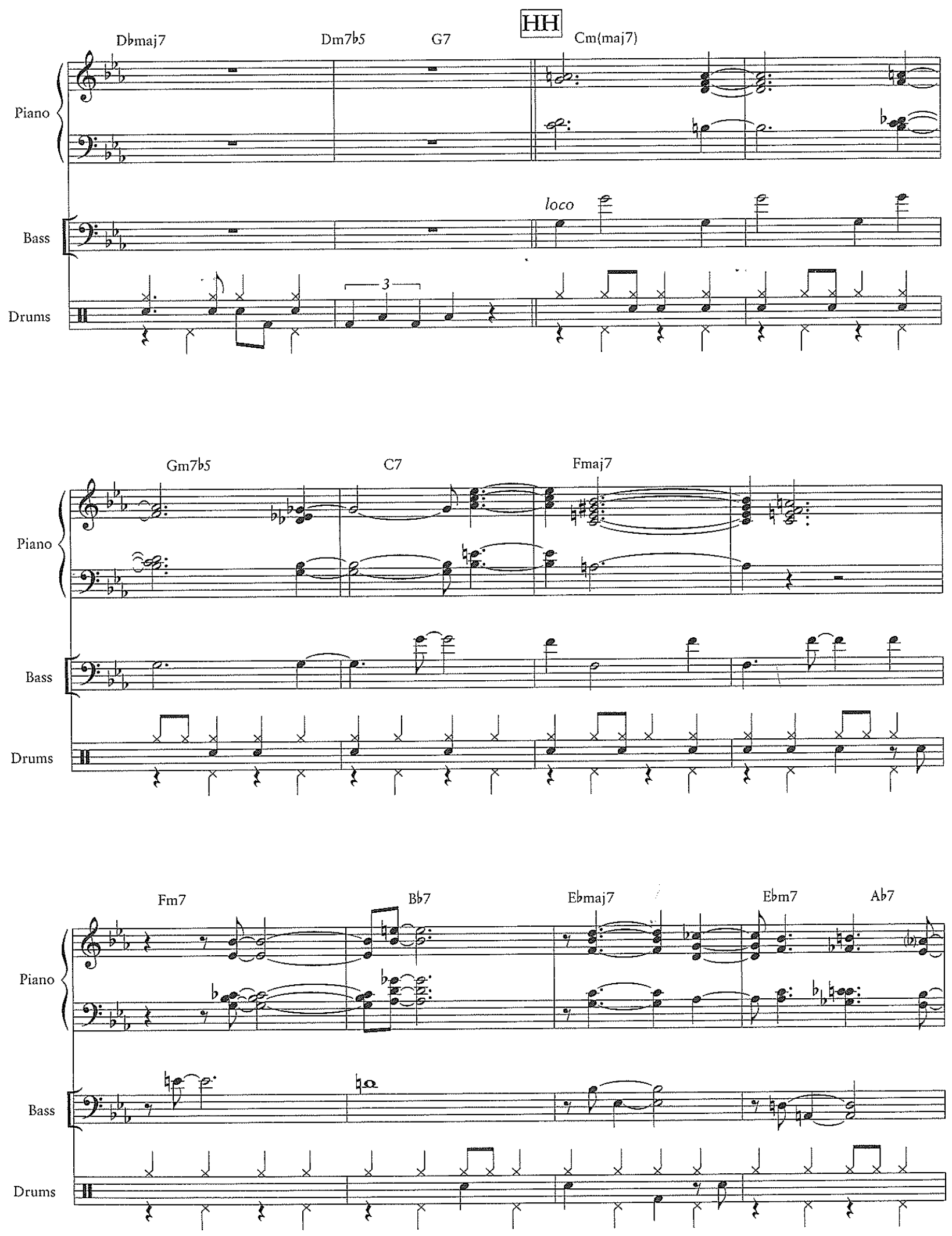

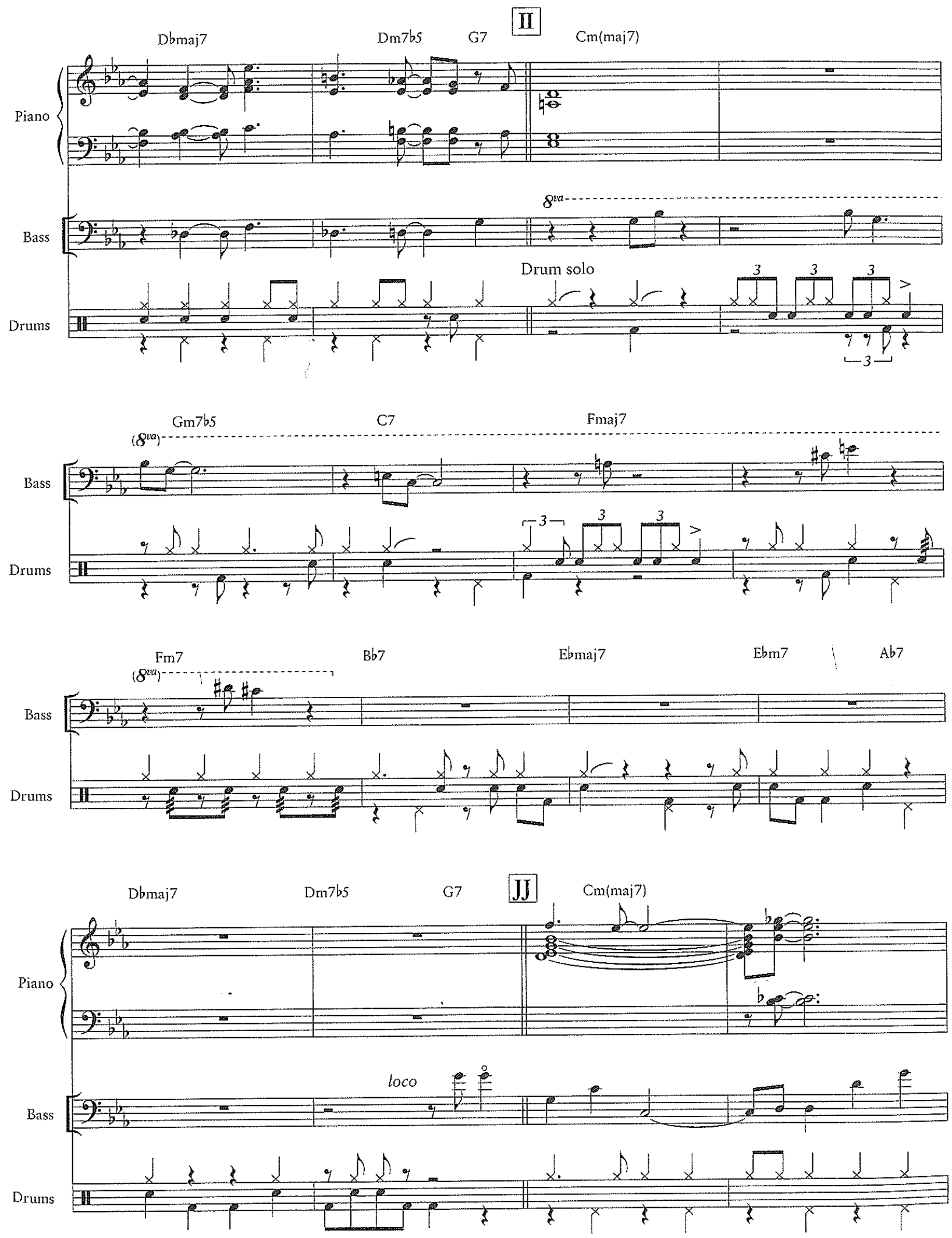

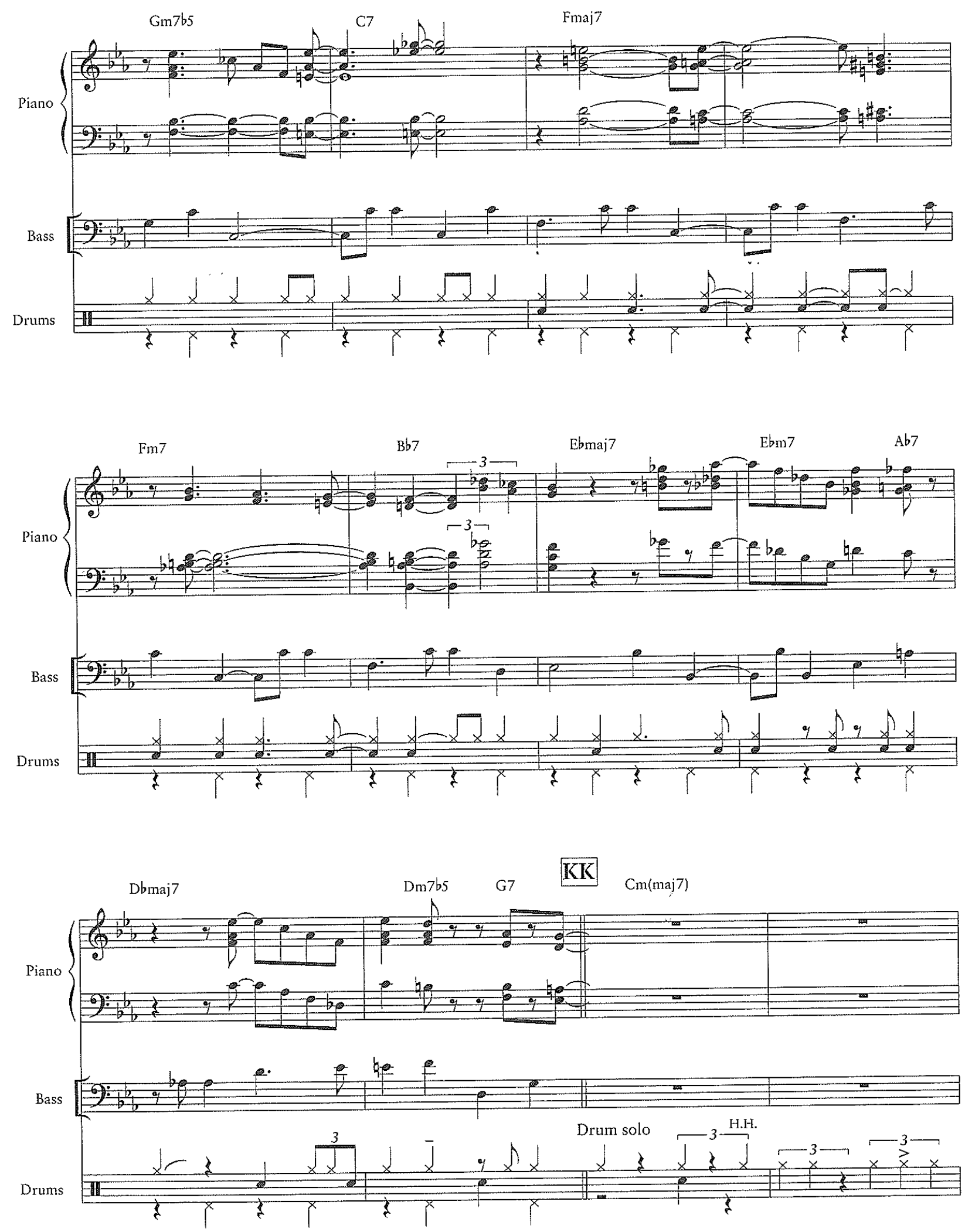

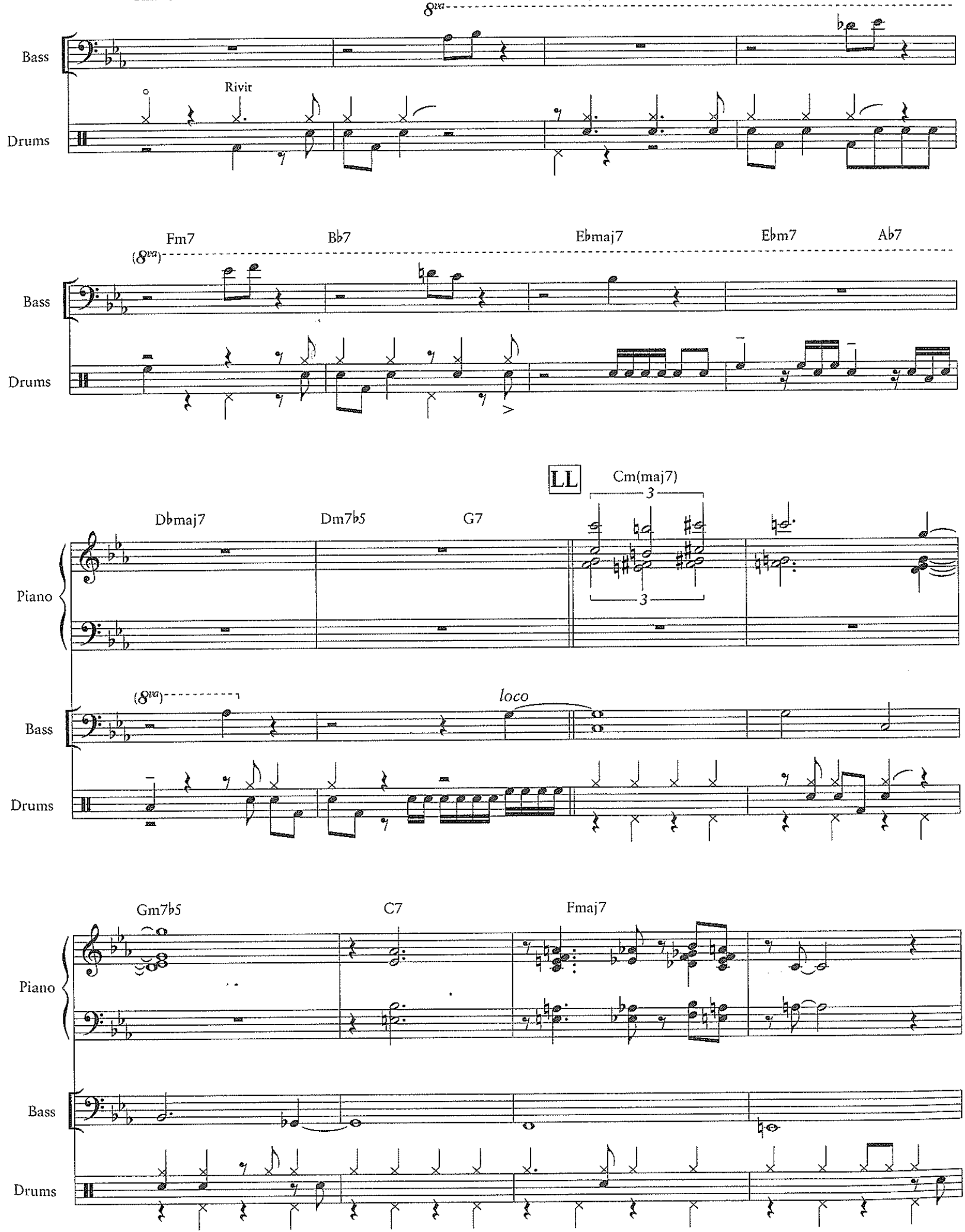

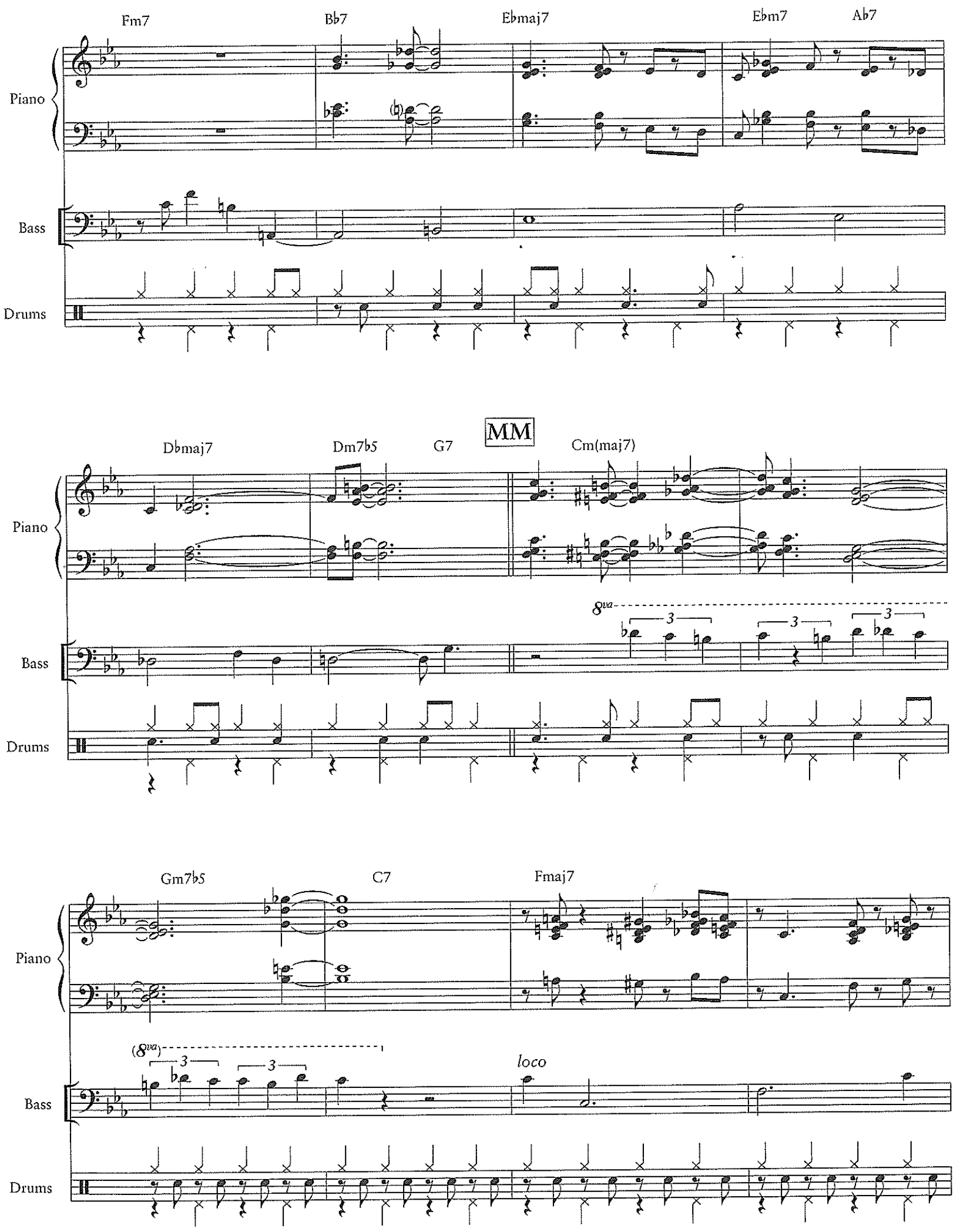

132

113 

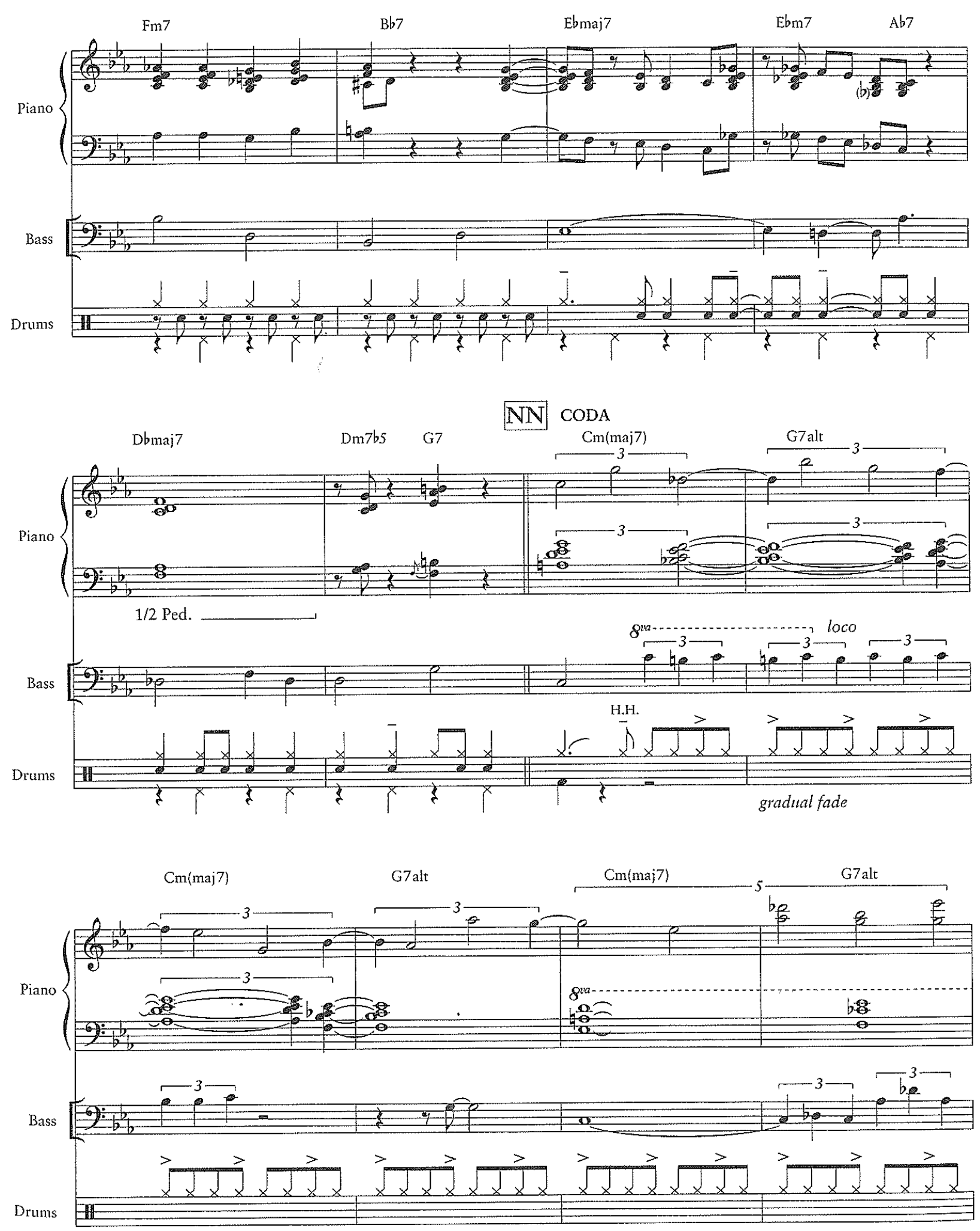

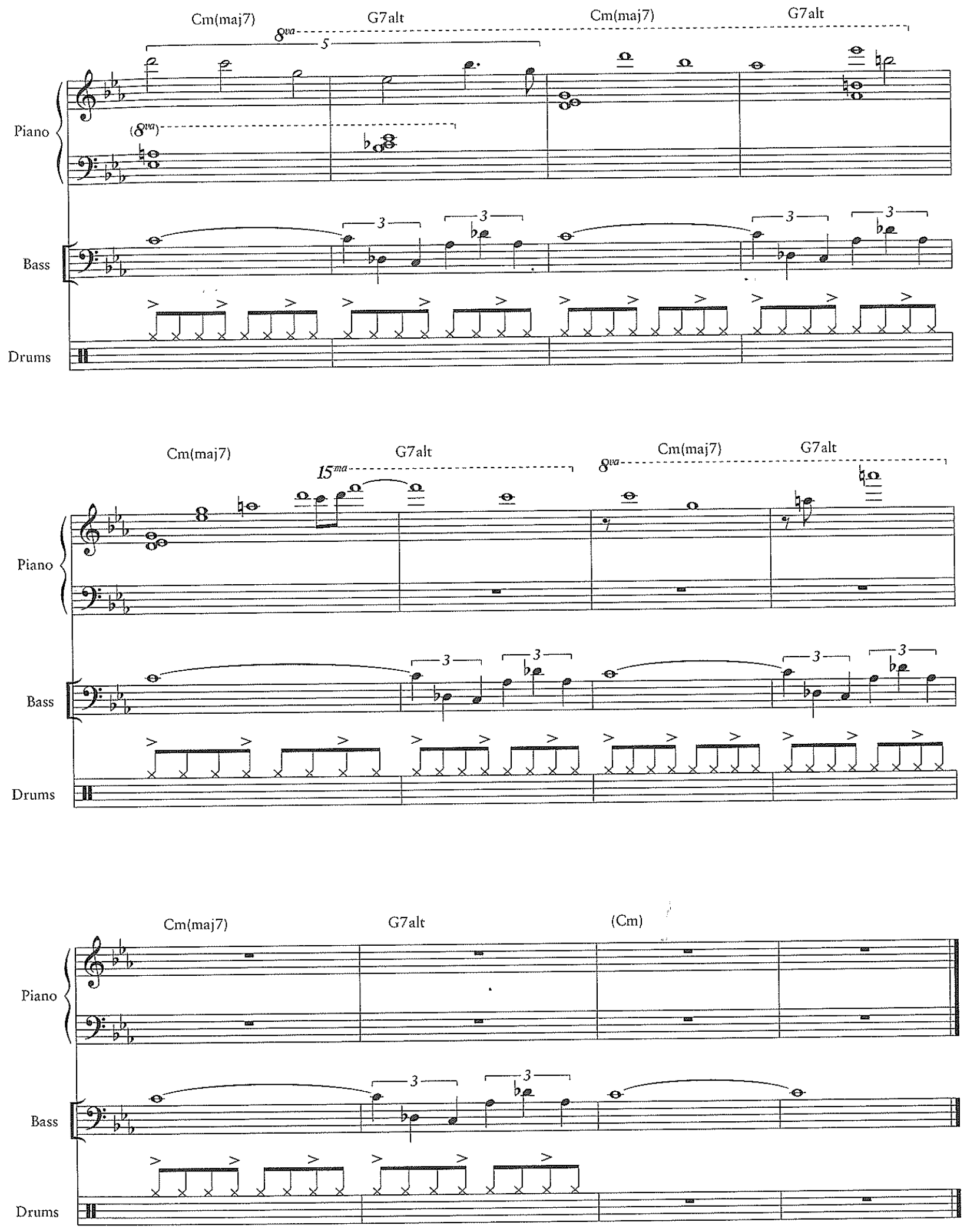
2: Alice In Wonderland - Transcription taken from LeONARd, HaL. The Bill Evans Trio Volume 1. 2003. 


\section{Alice In Wonderland \\ from Walt Disney's ALICE IN WONDERLAND \\ Words by Bob Hilliard \\ Music by Sammy Fain}
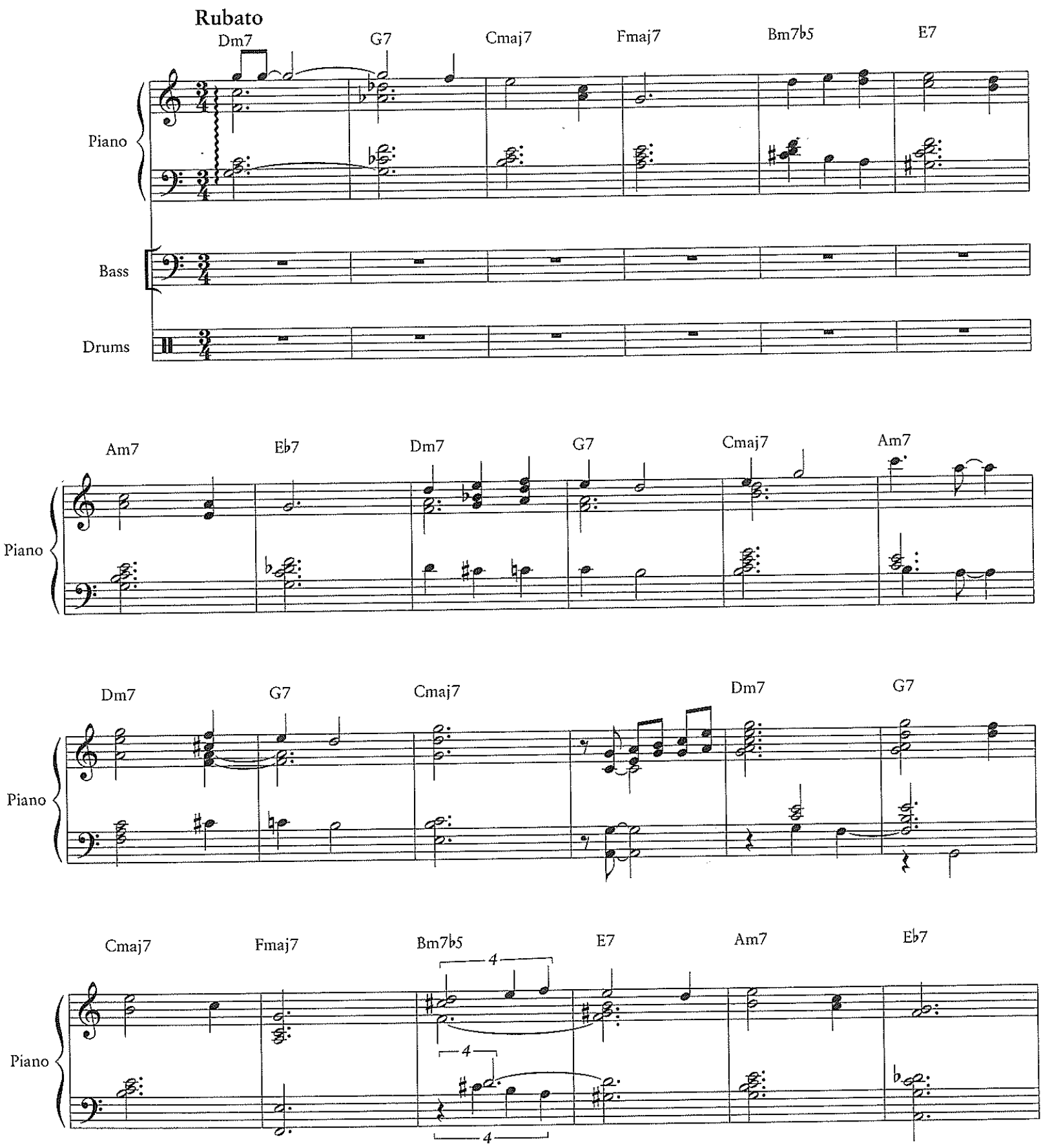

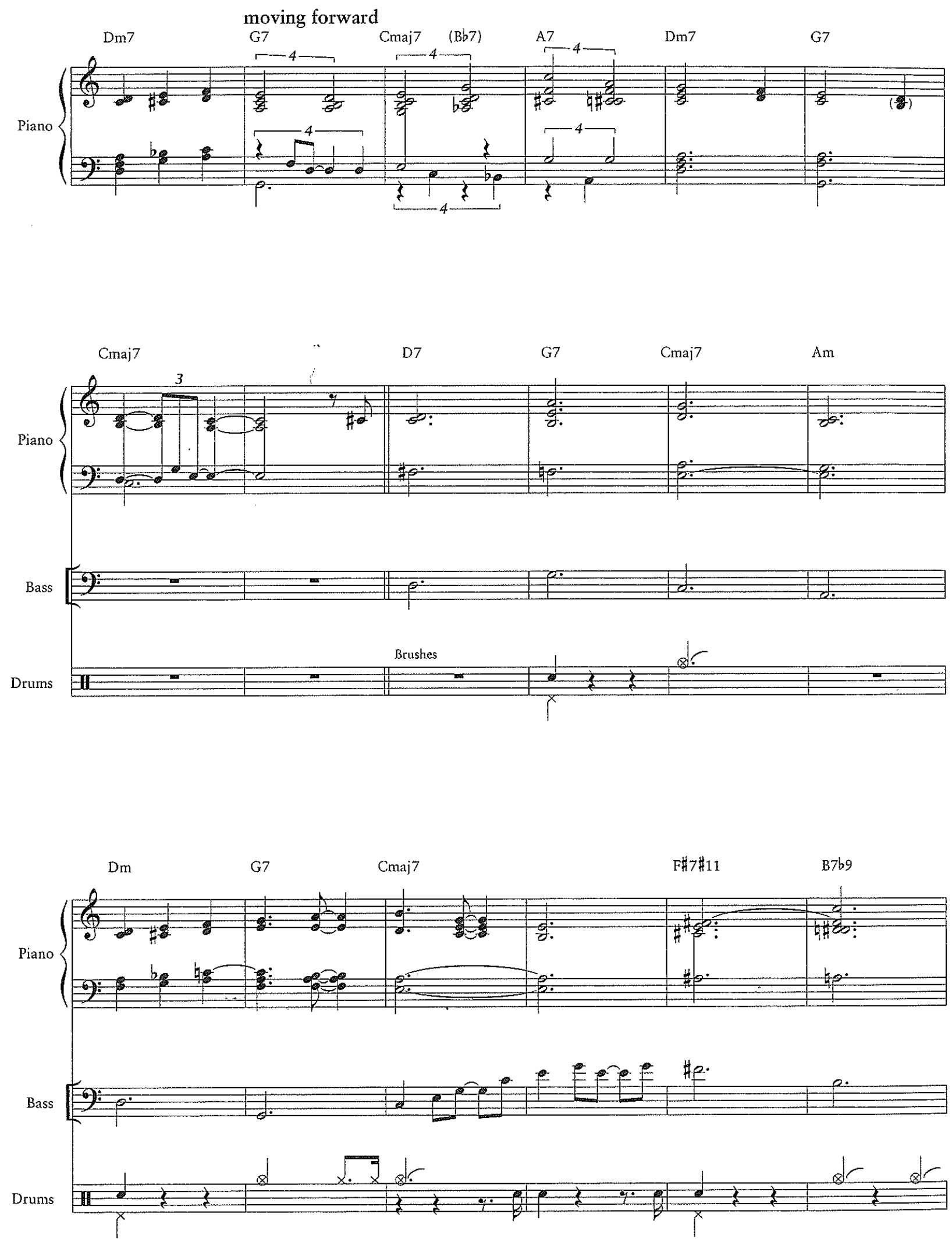

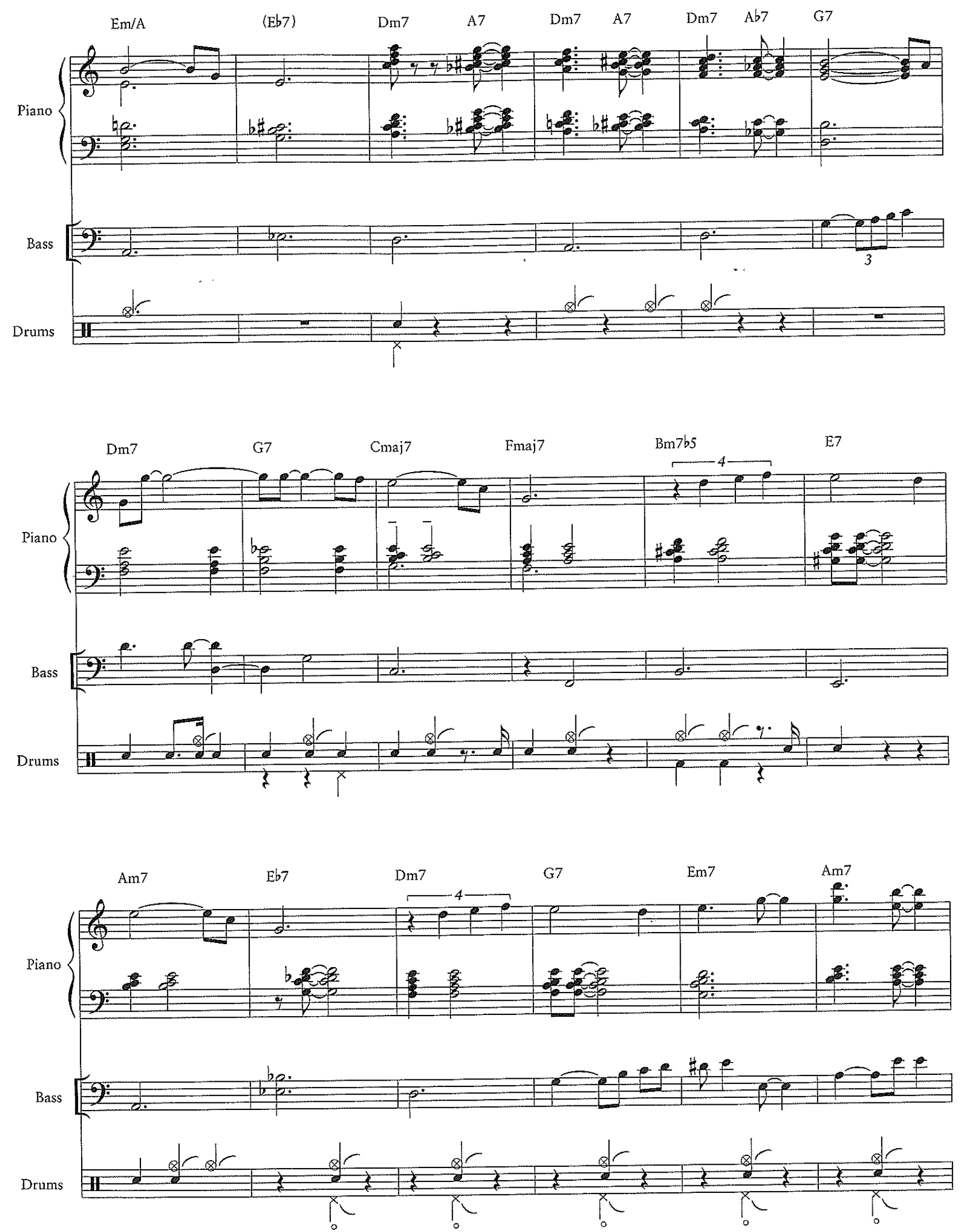


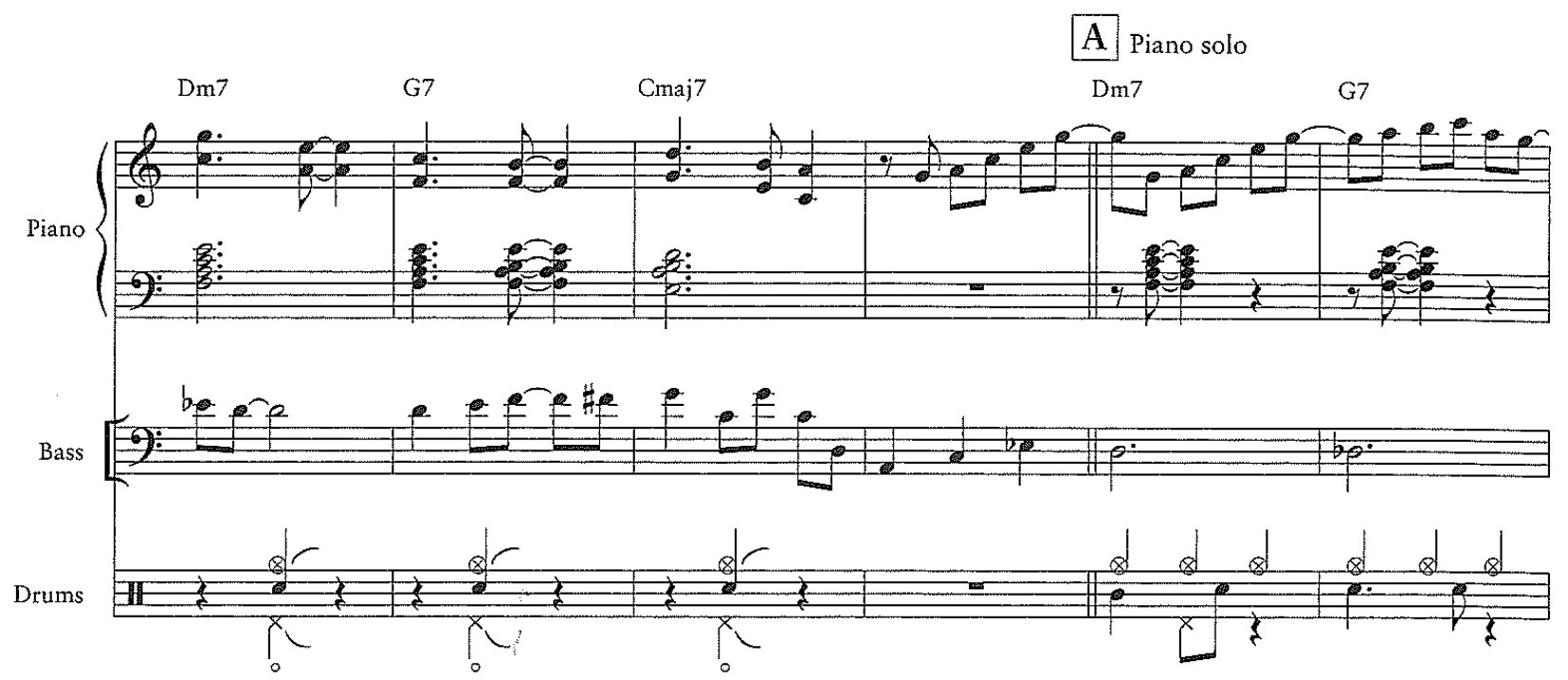

Cmaj7

Fmaj7

Bm7b5

E7alt

Am7

Eb7

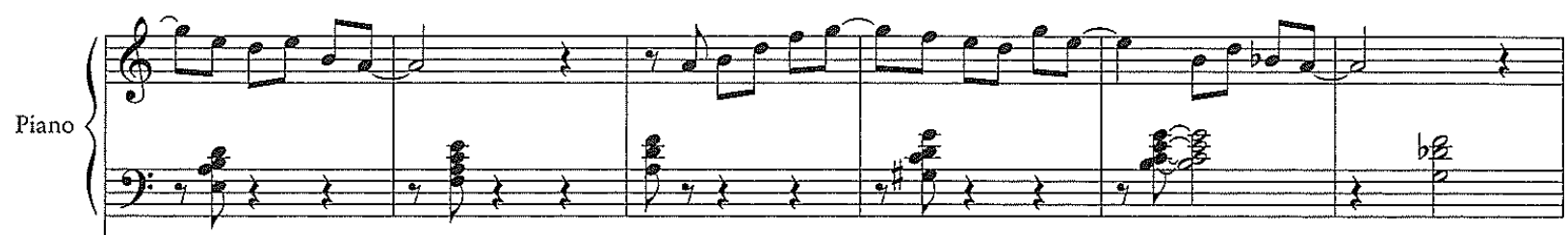

Bass

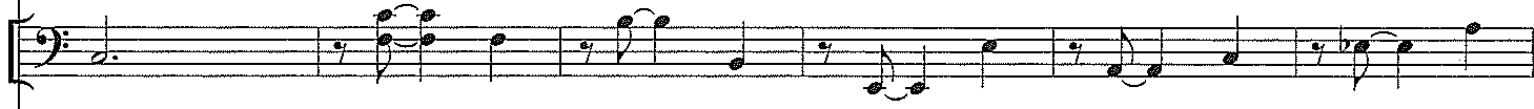

Jrums
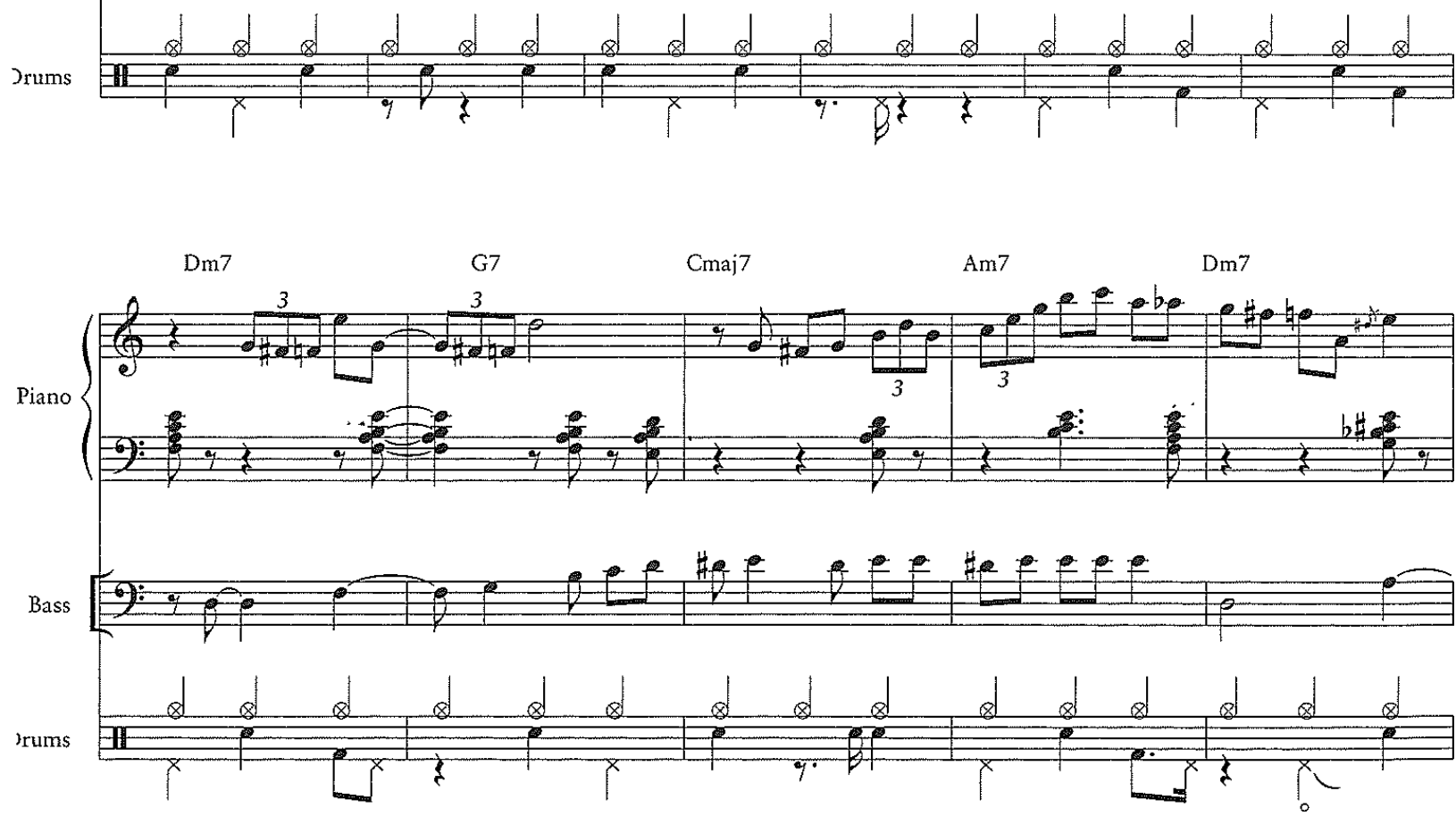

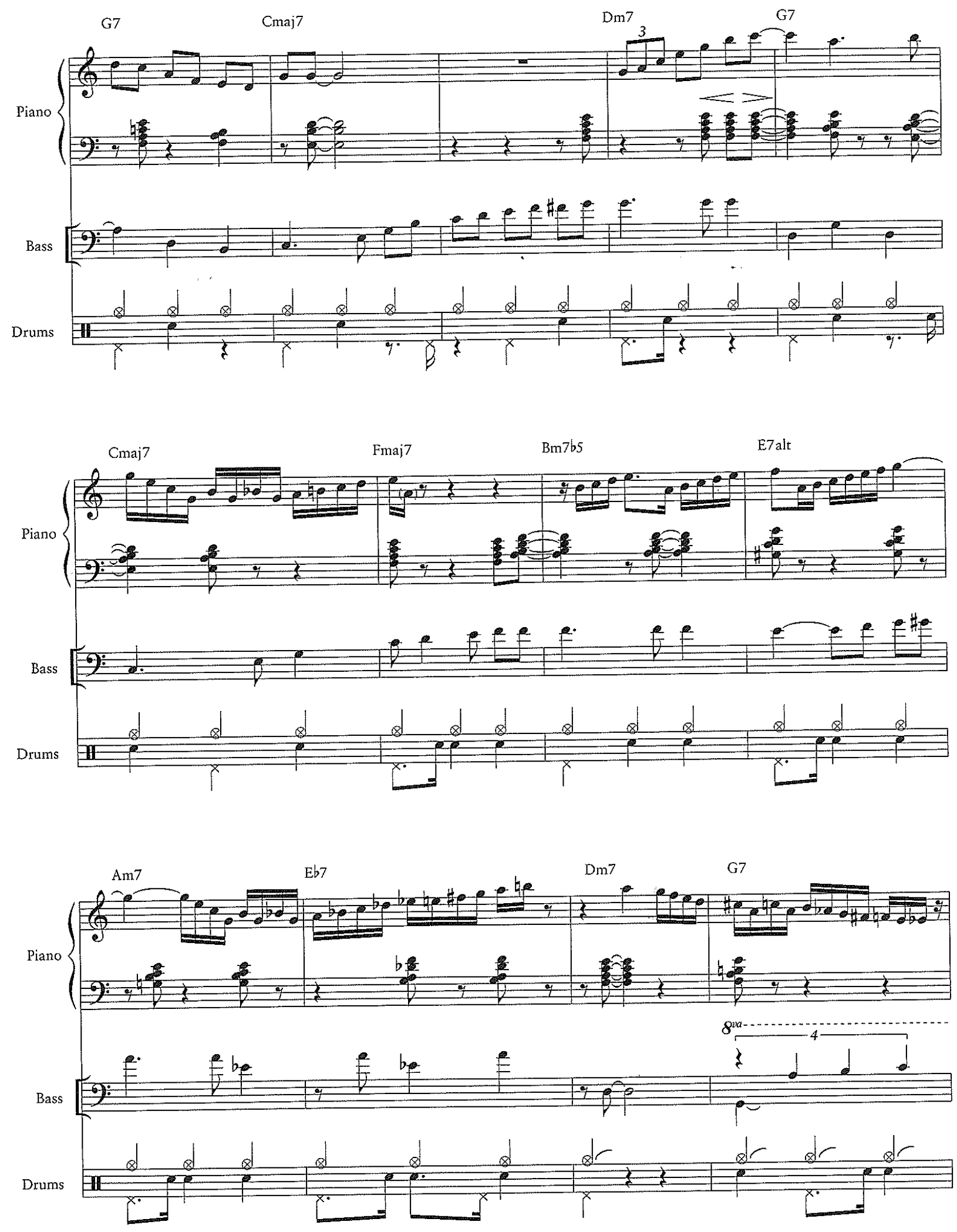

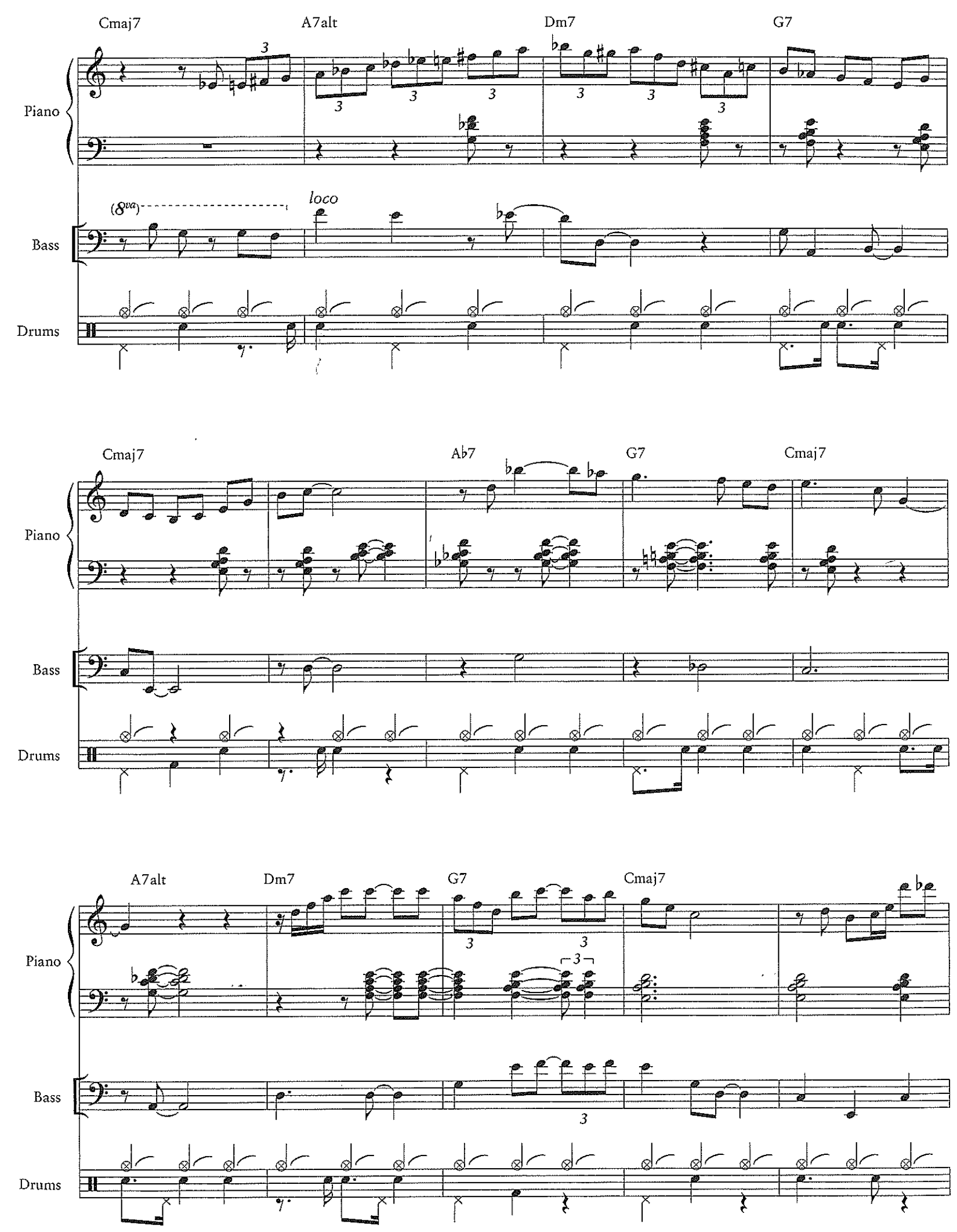

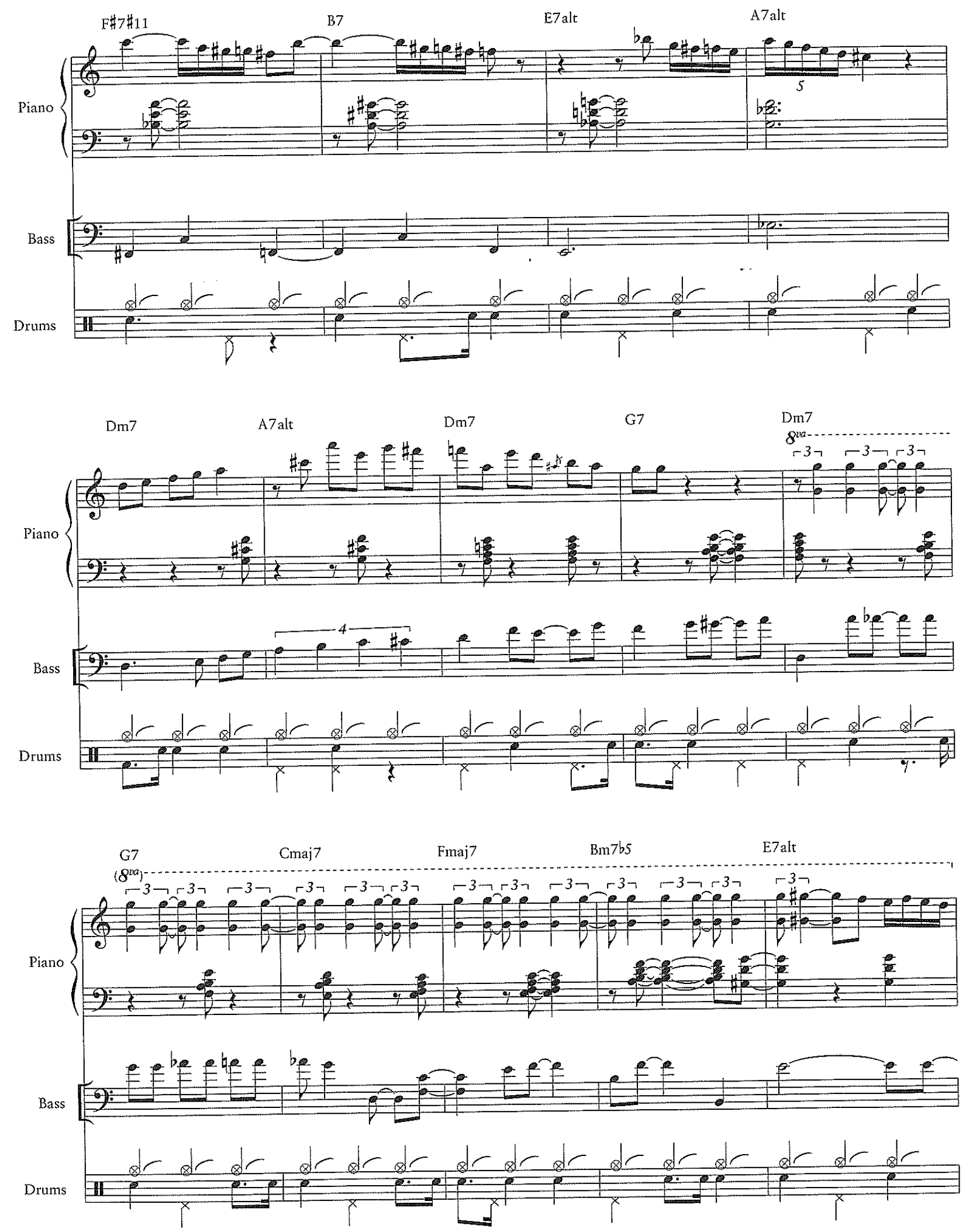

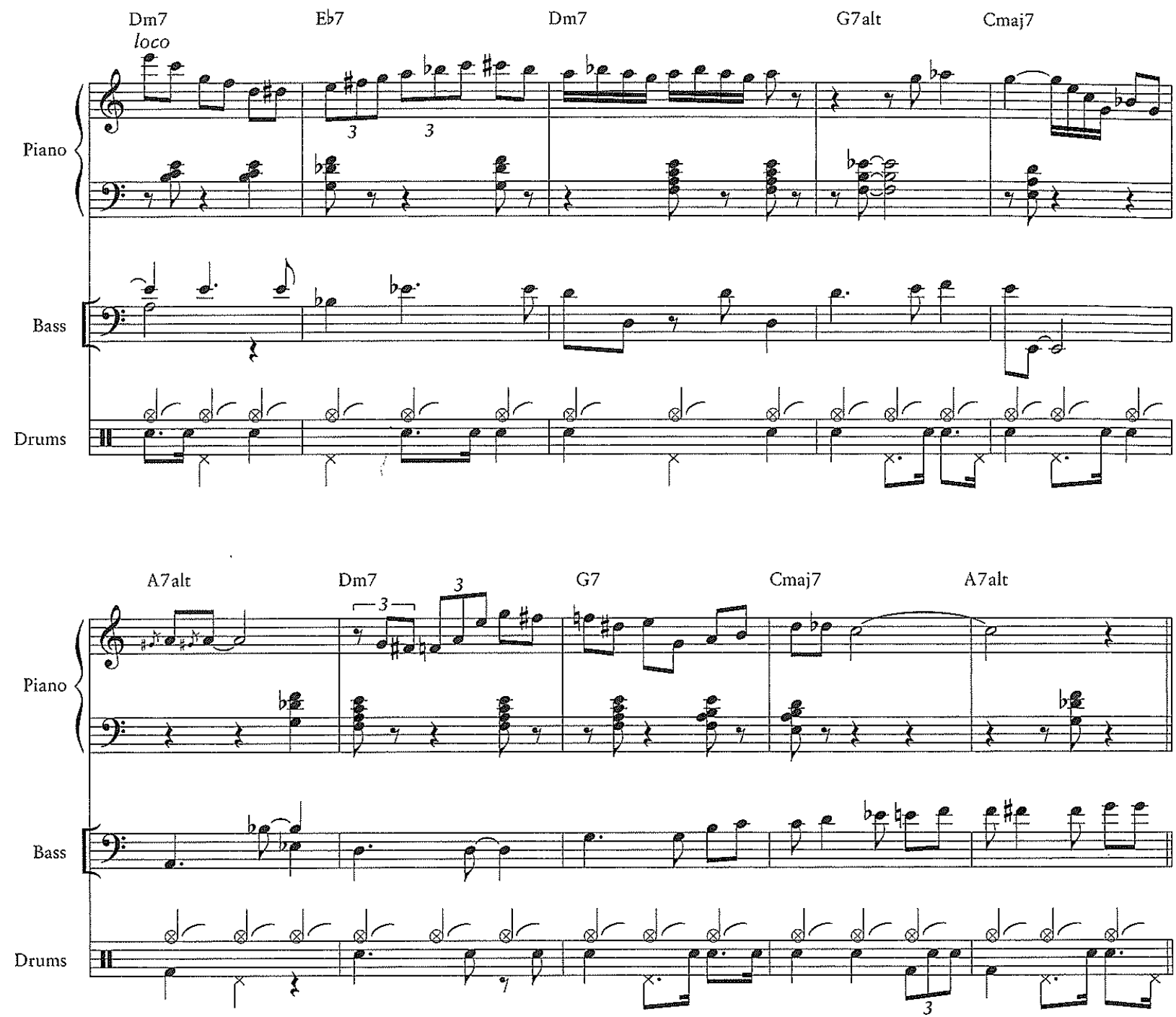

B Dm7

Fmaj7

$\mathrm{Bm}>\mathrm{b} 5$

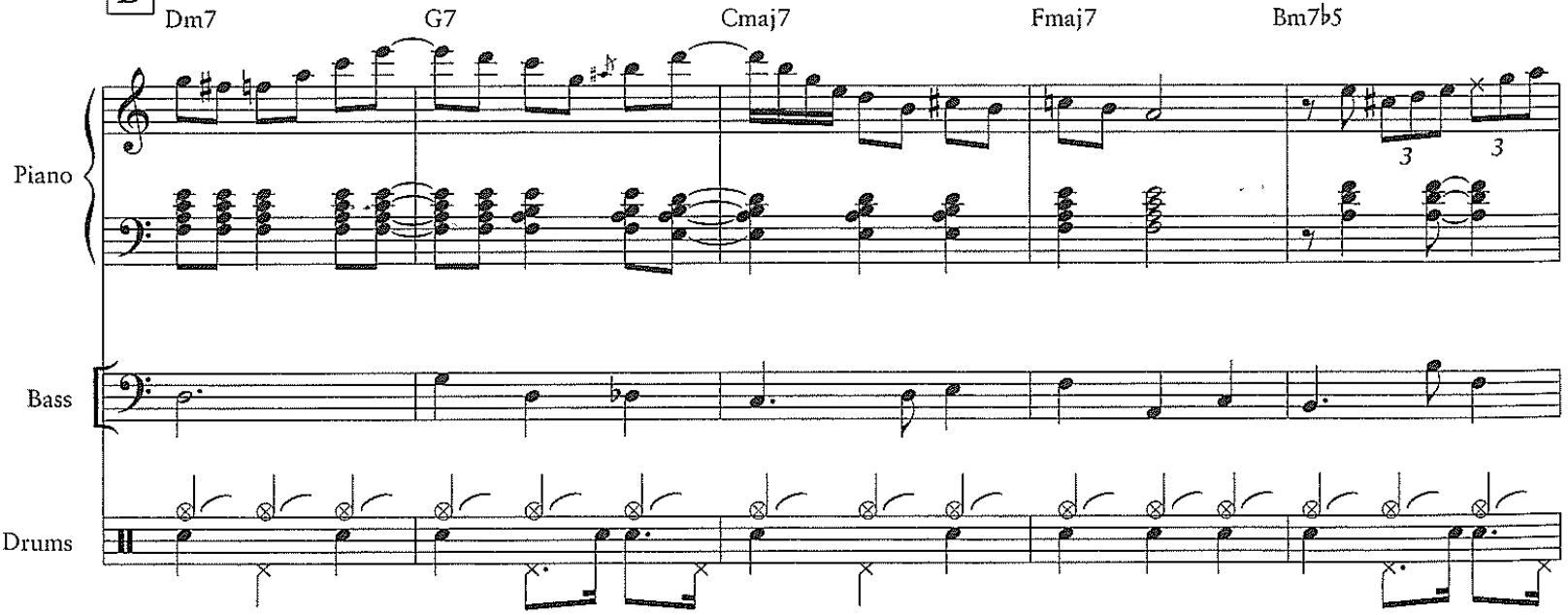



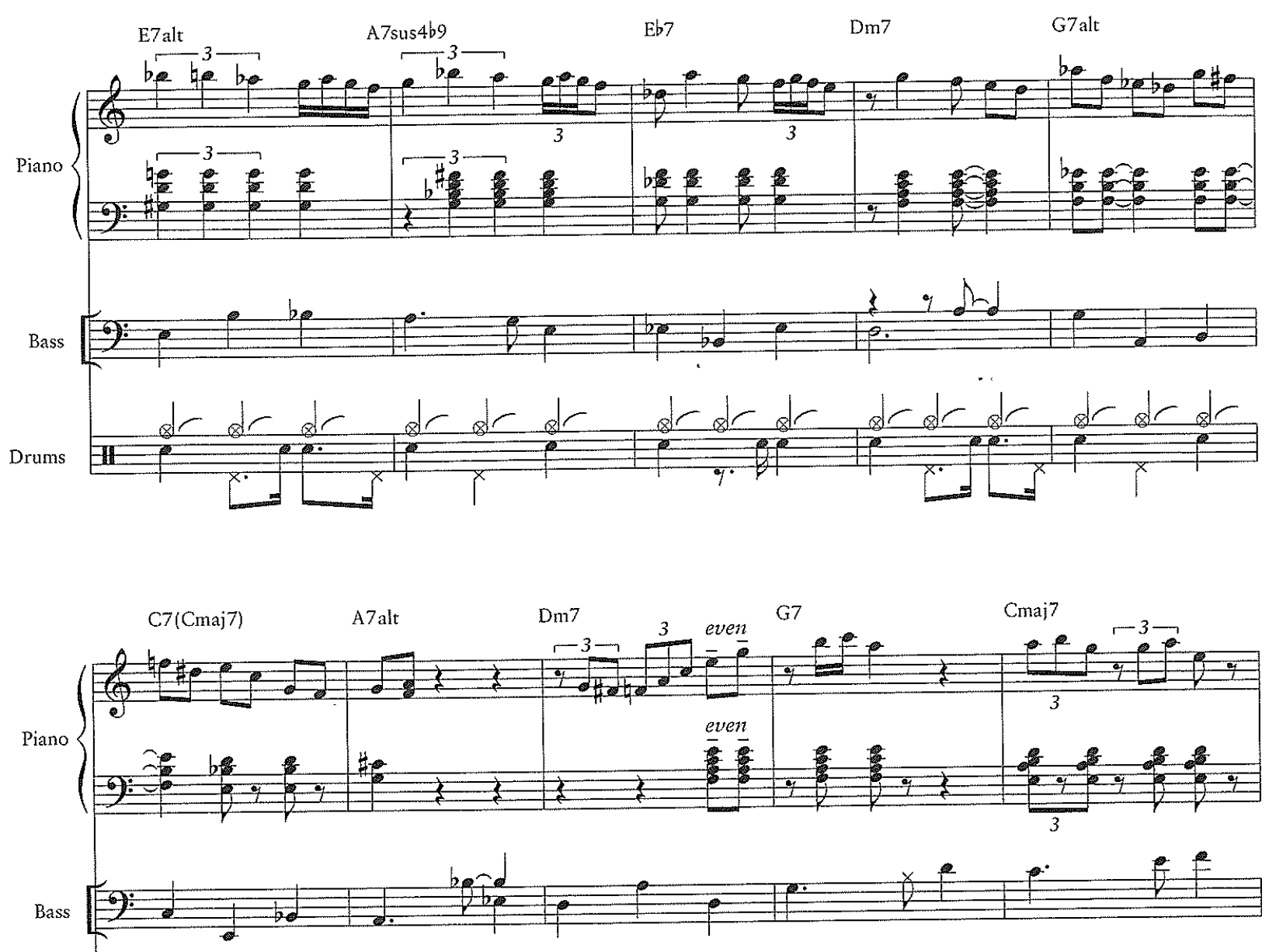

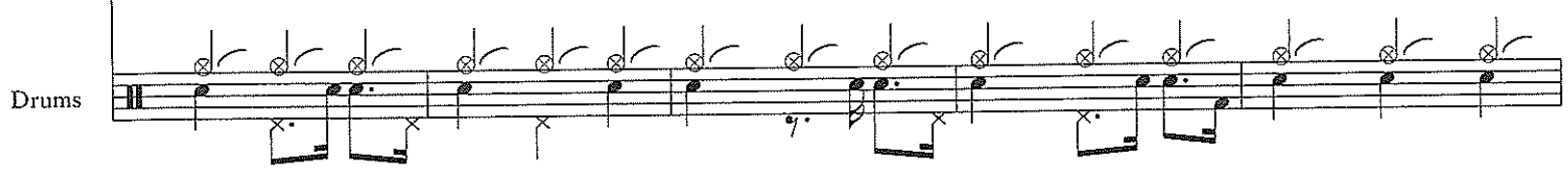
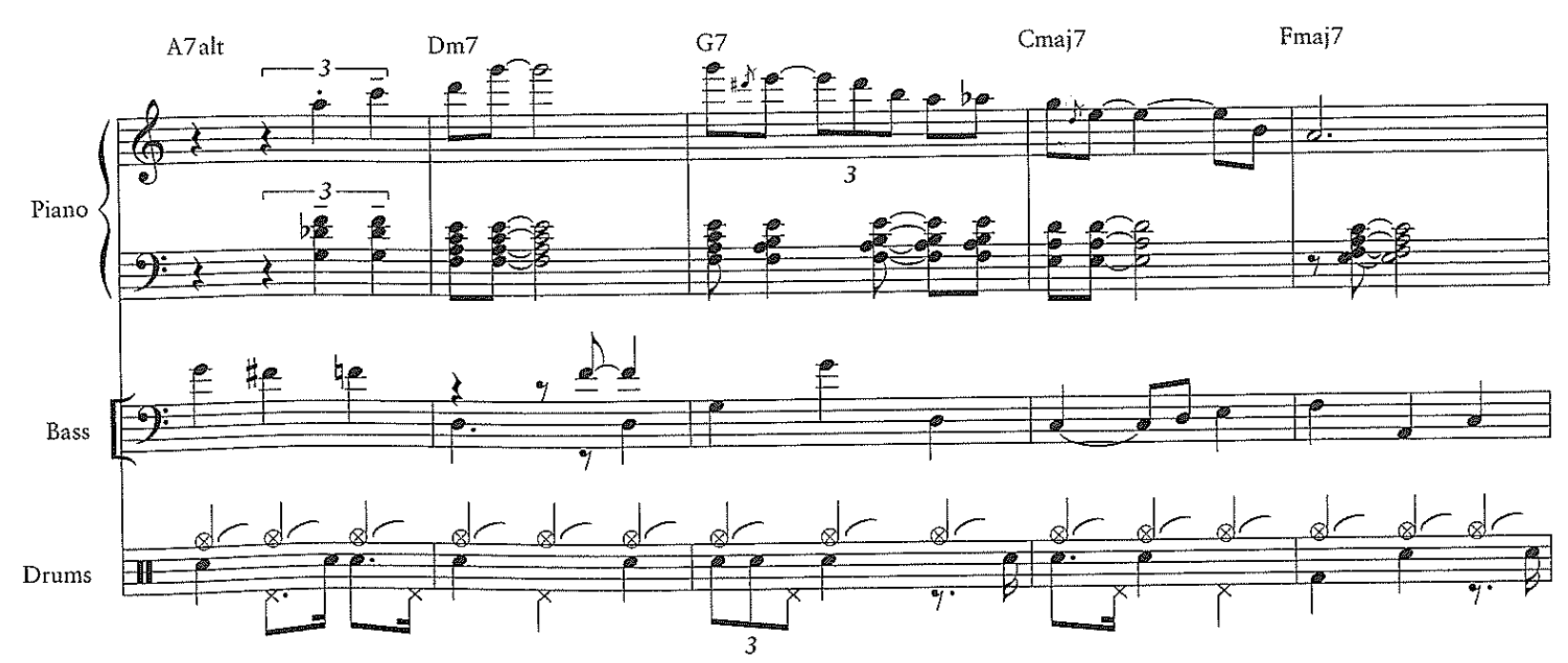

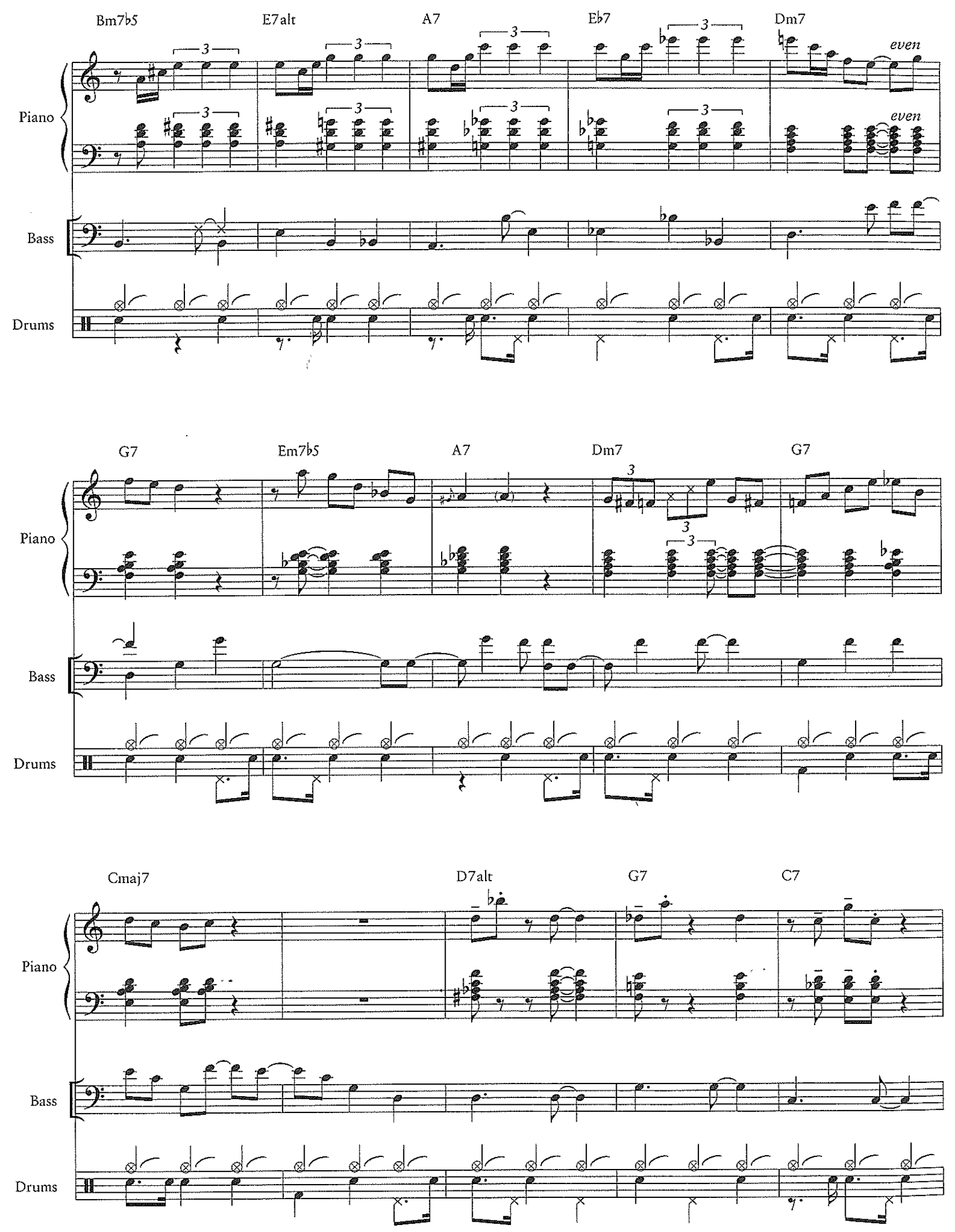

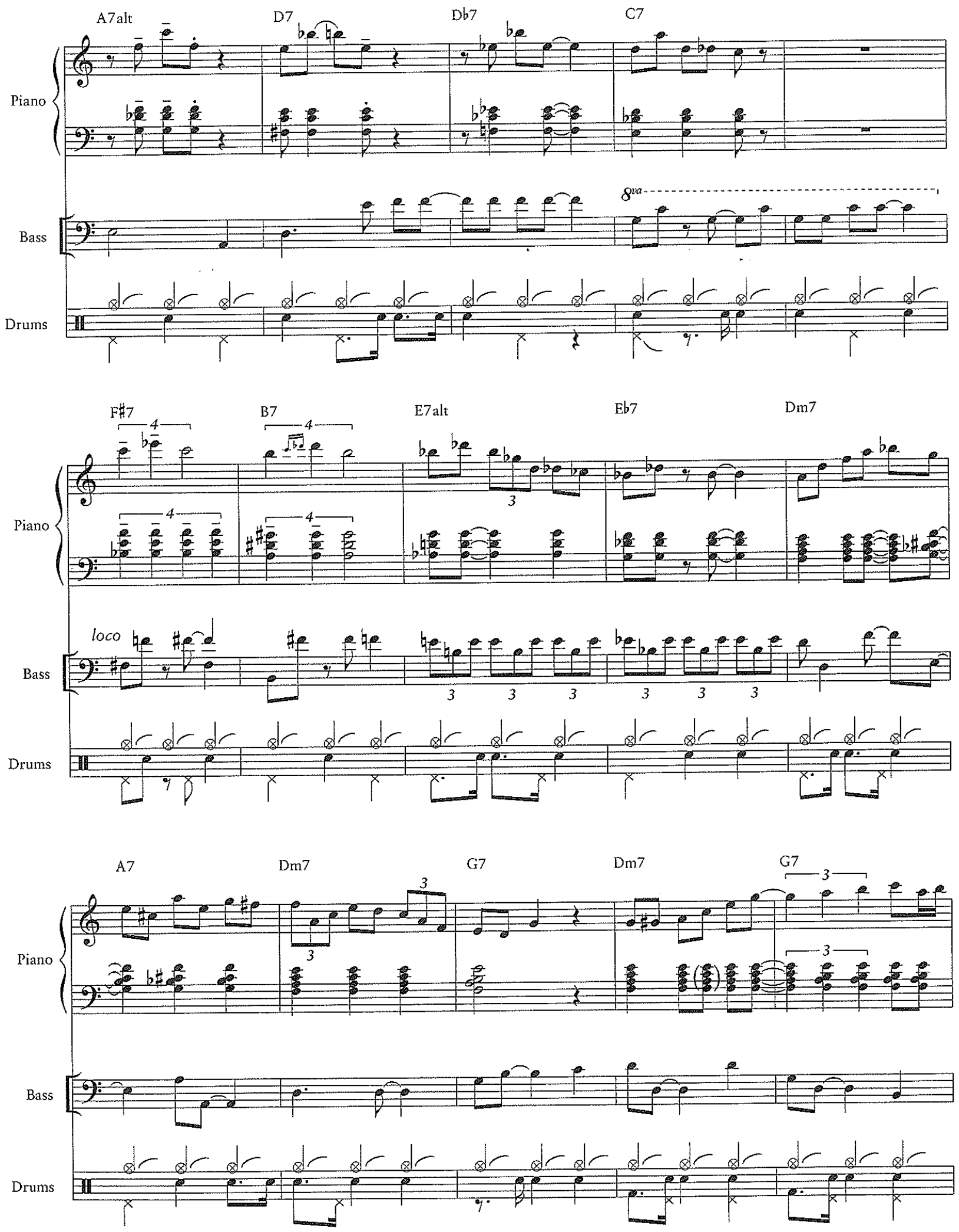

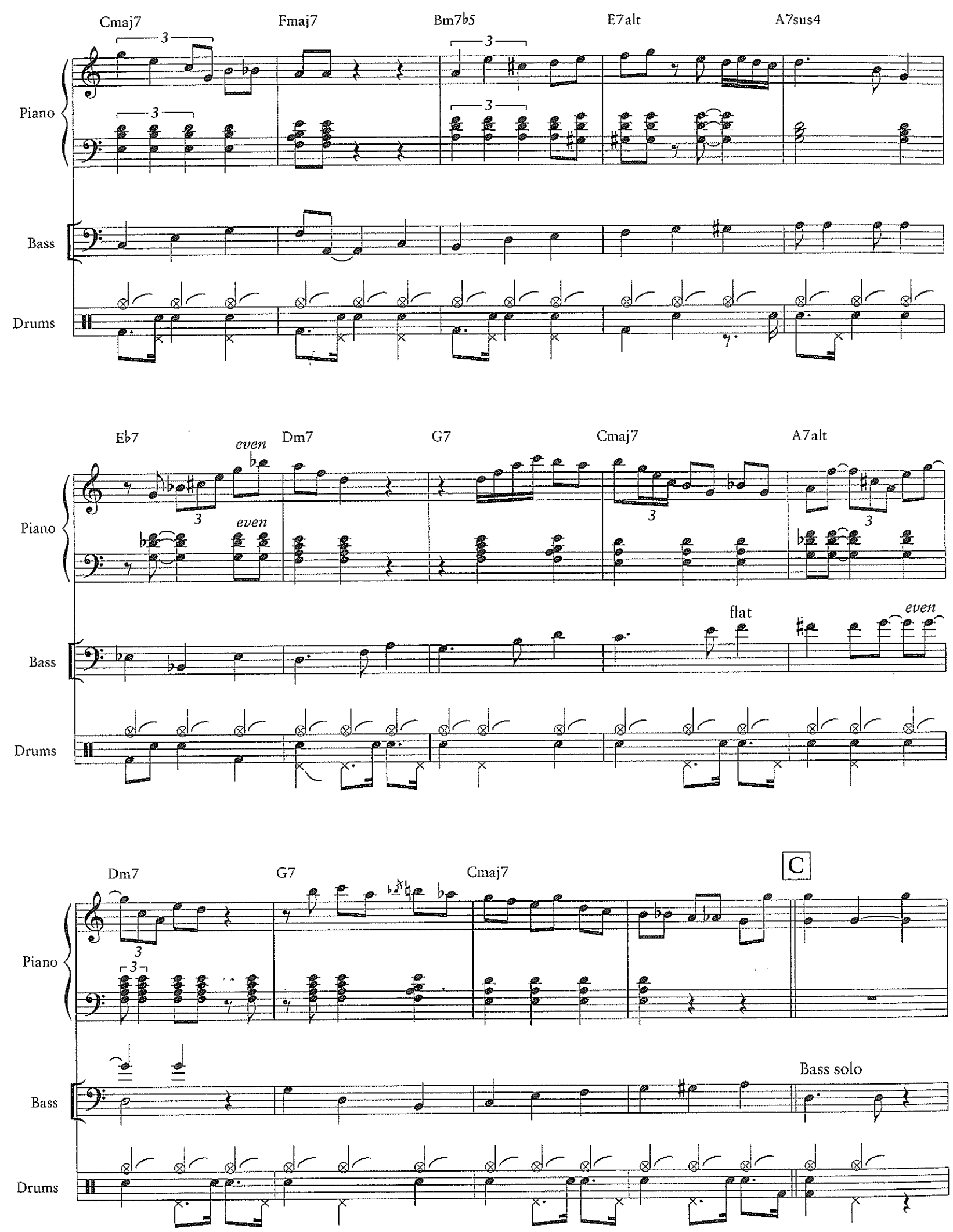

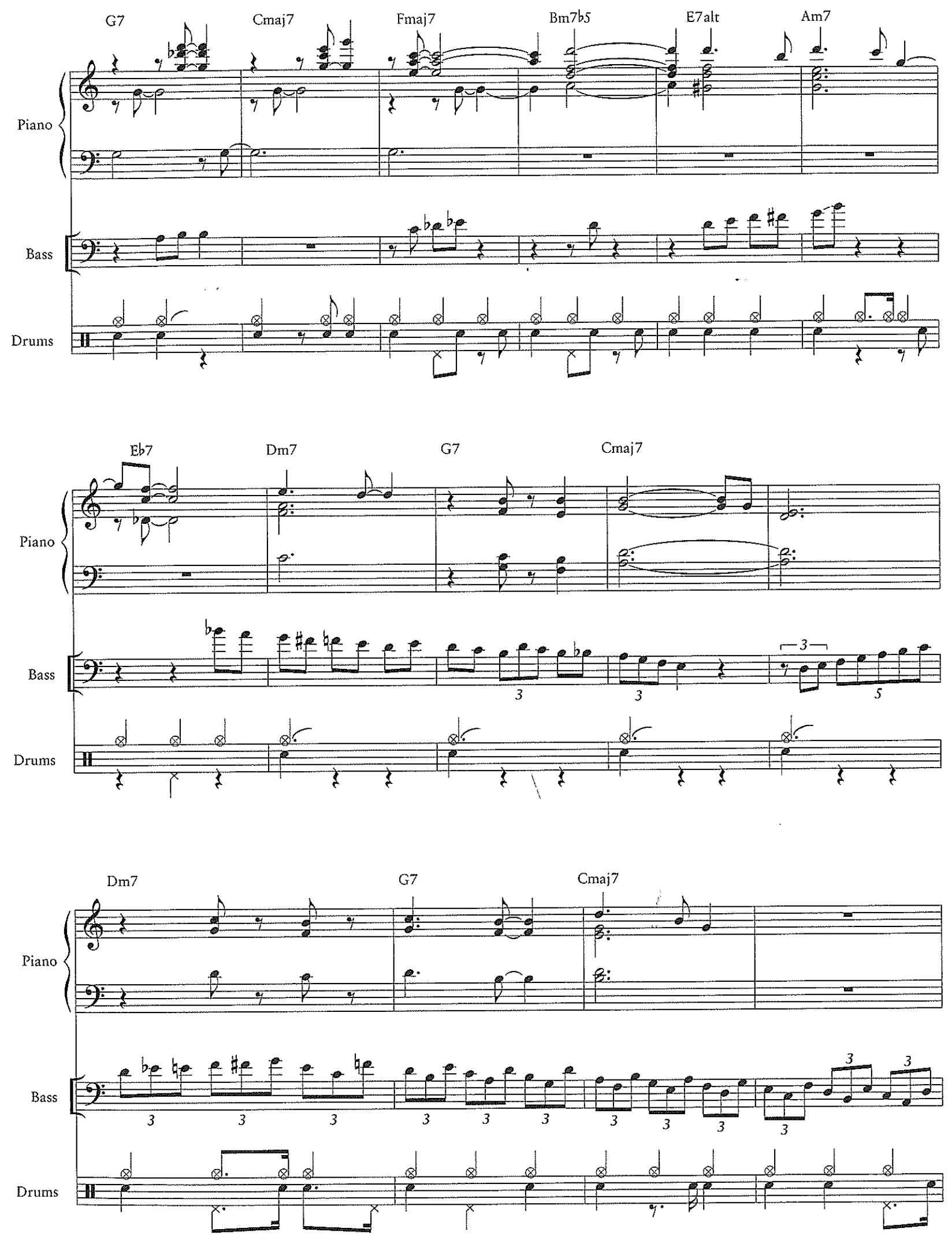

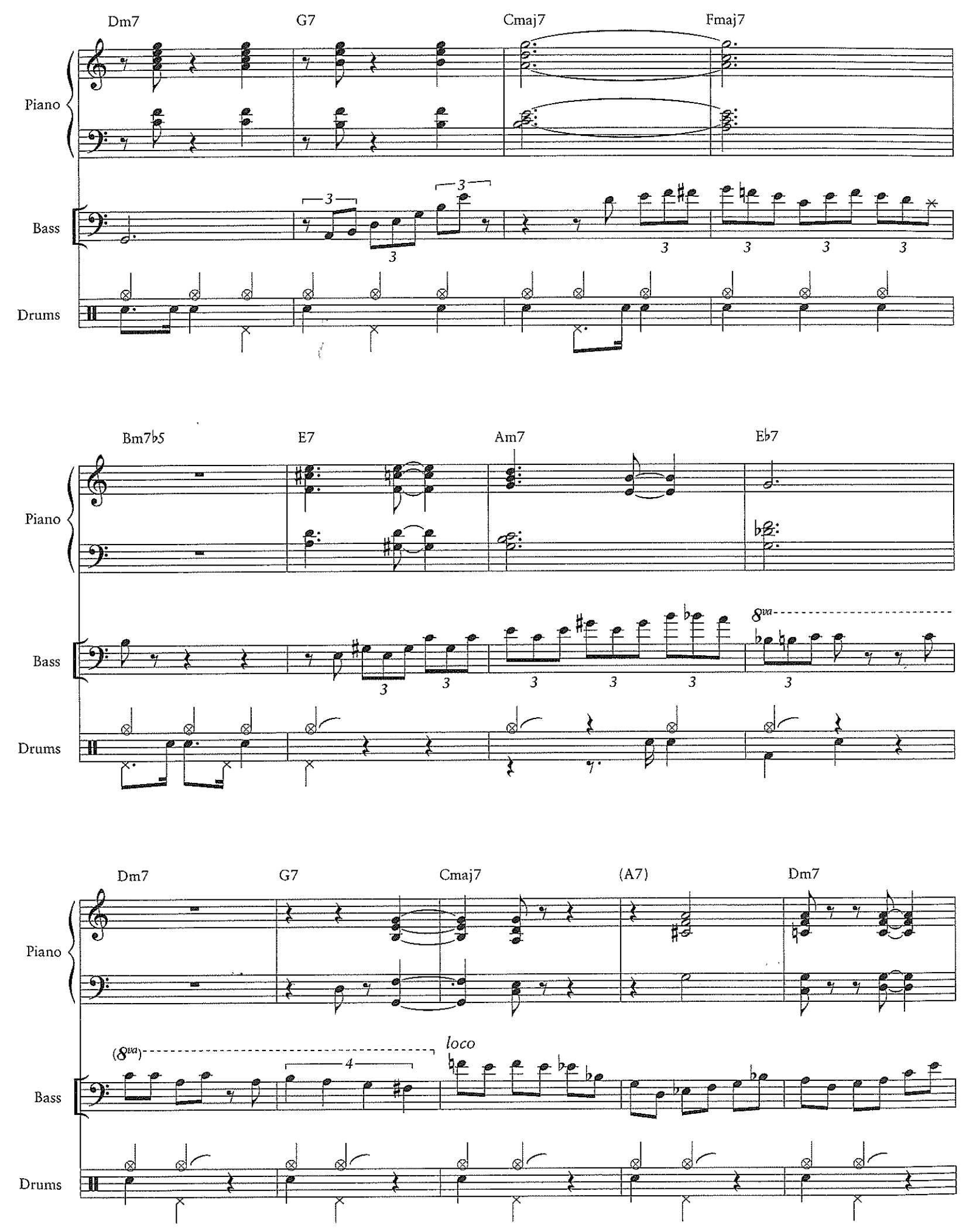

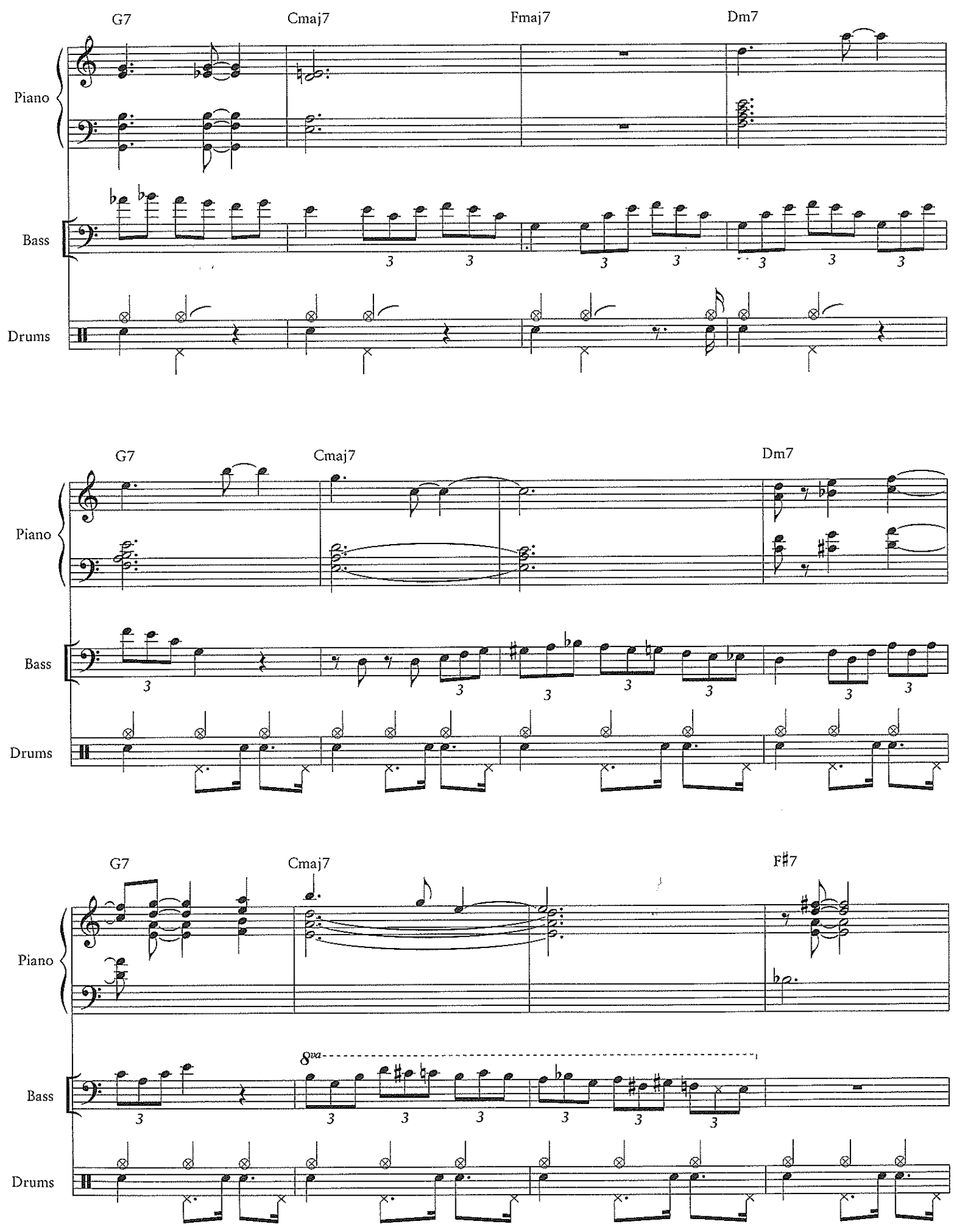

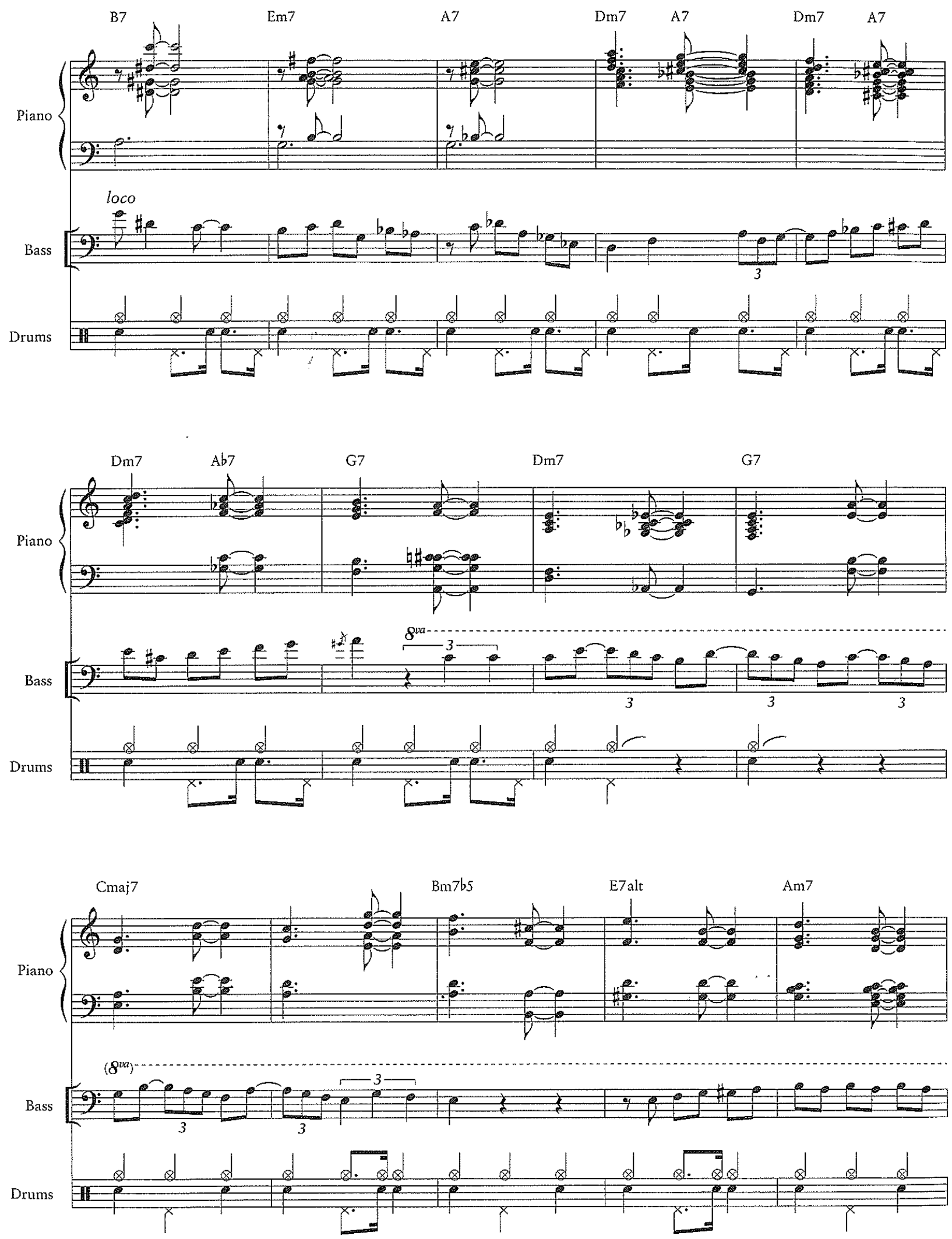

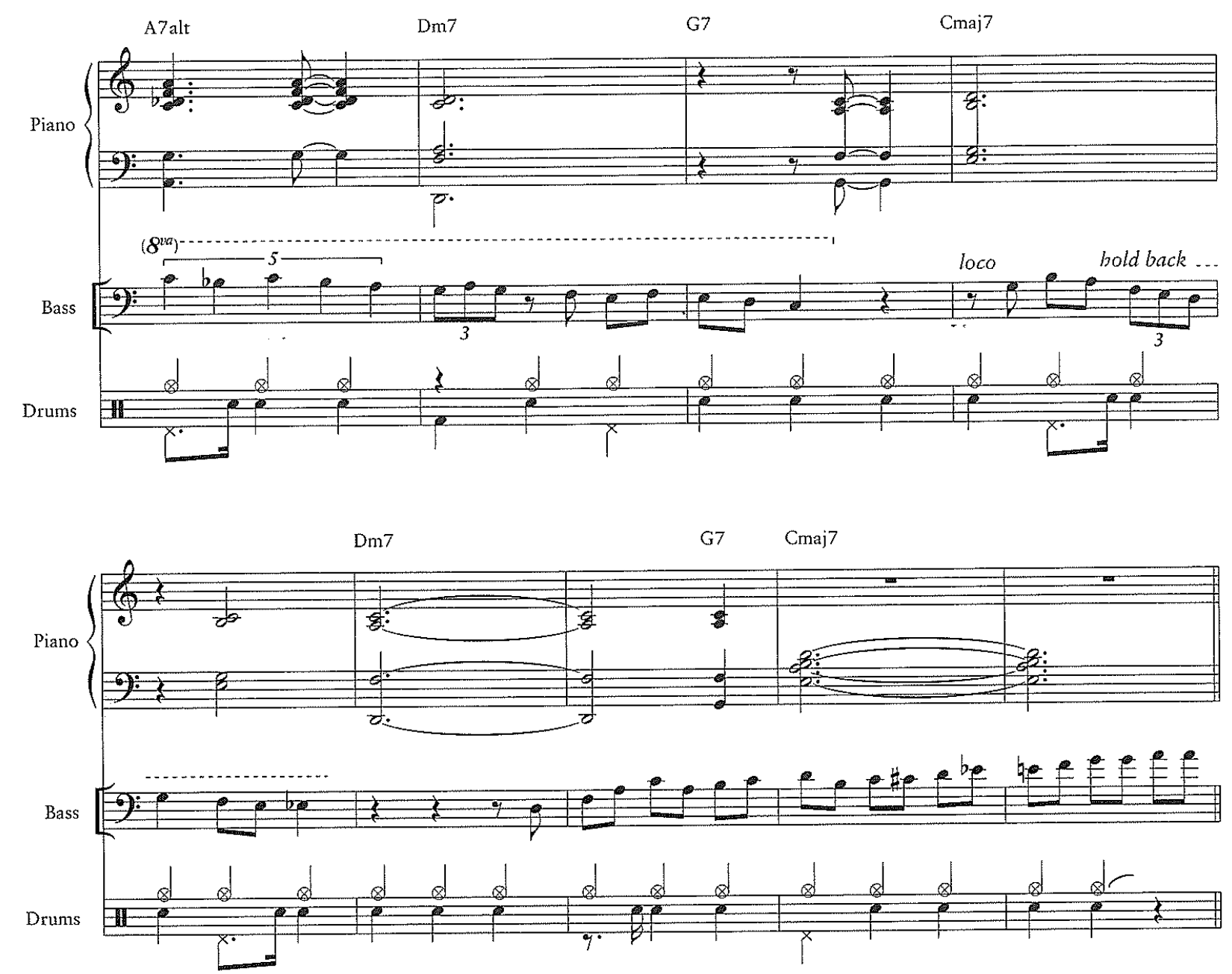

D
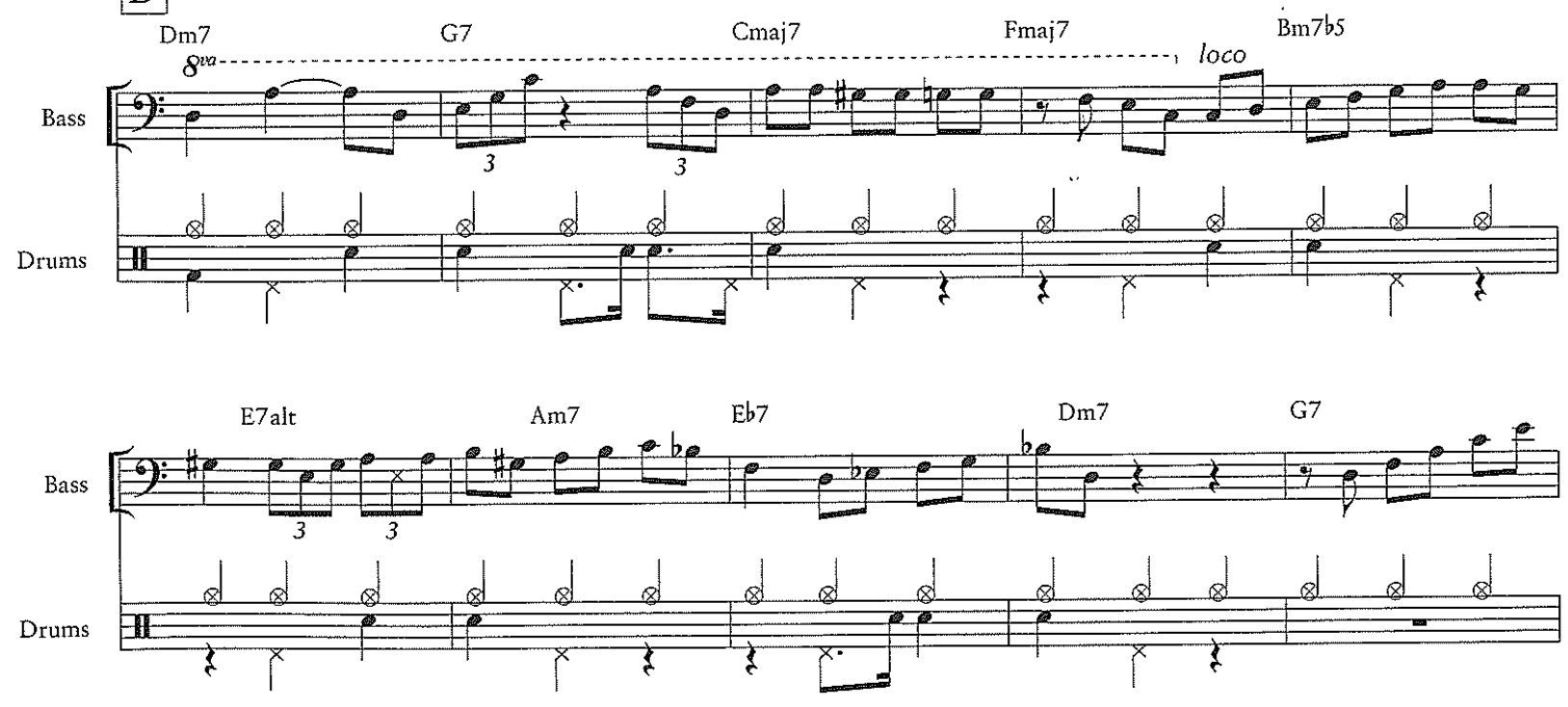

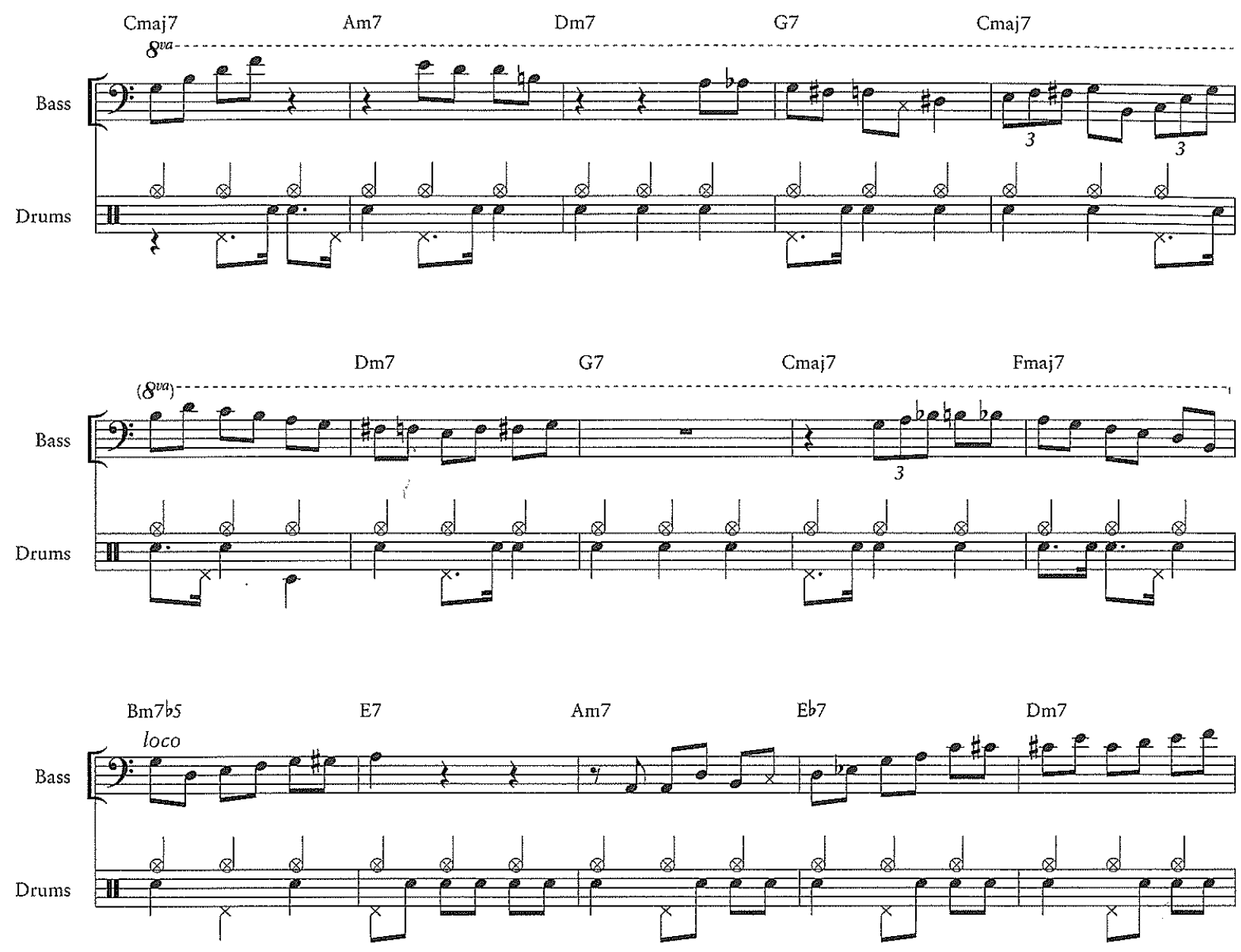

G7

Cmaj7

Dm7

G7

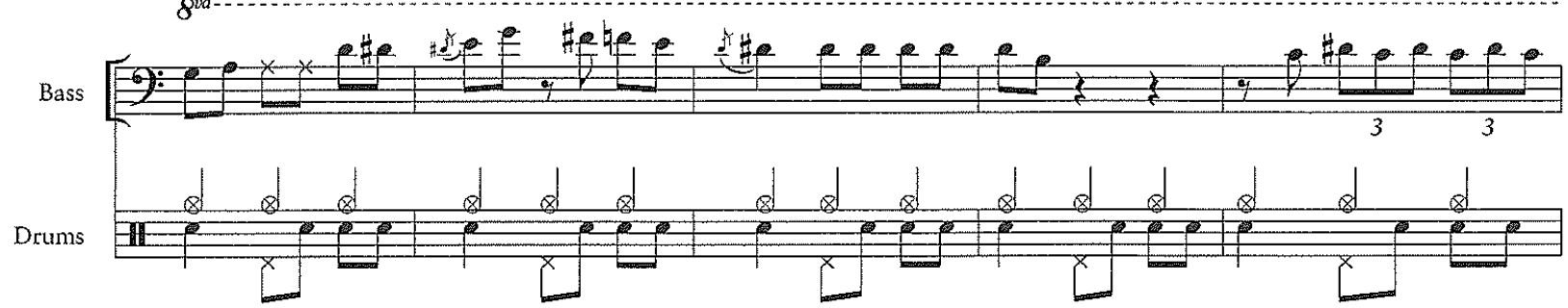

Cmaj7

D7

G7

Cmaj7

$\left(8^{v a}\right)^{-}$

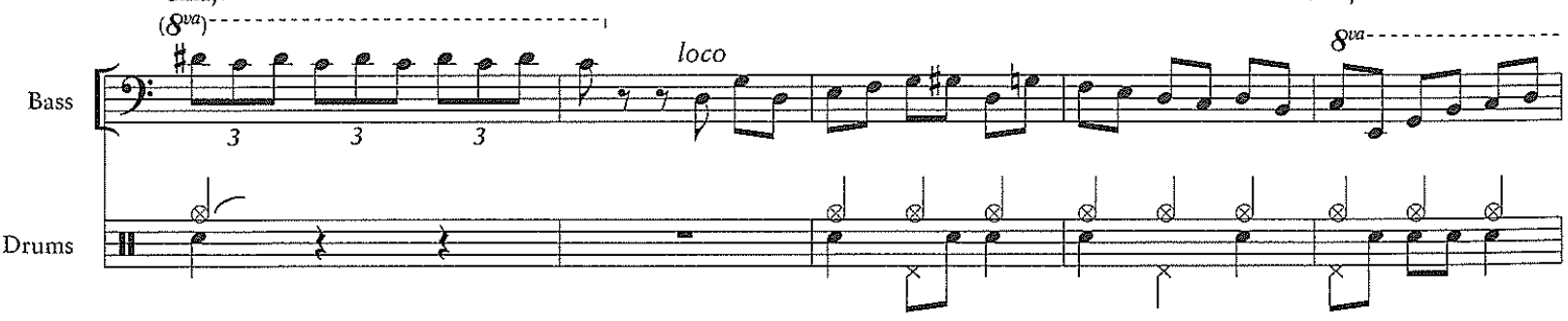



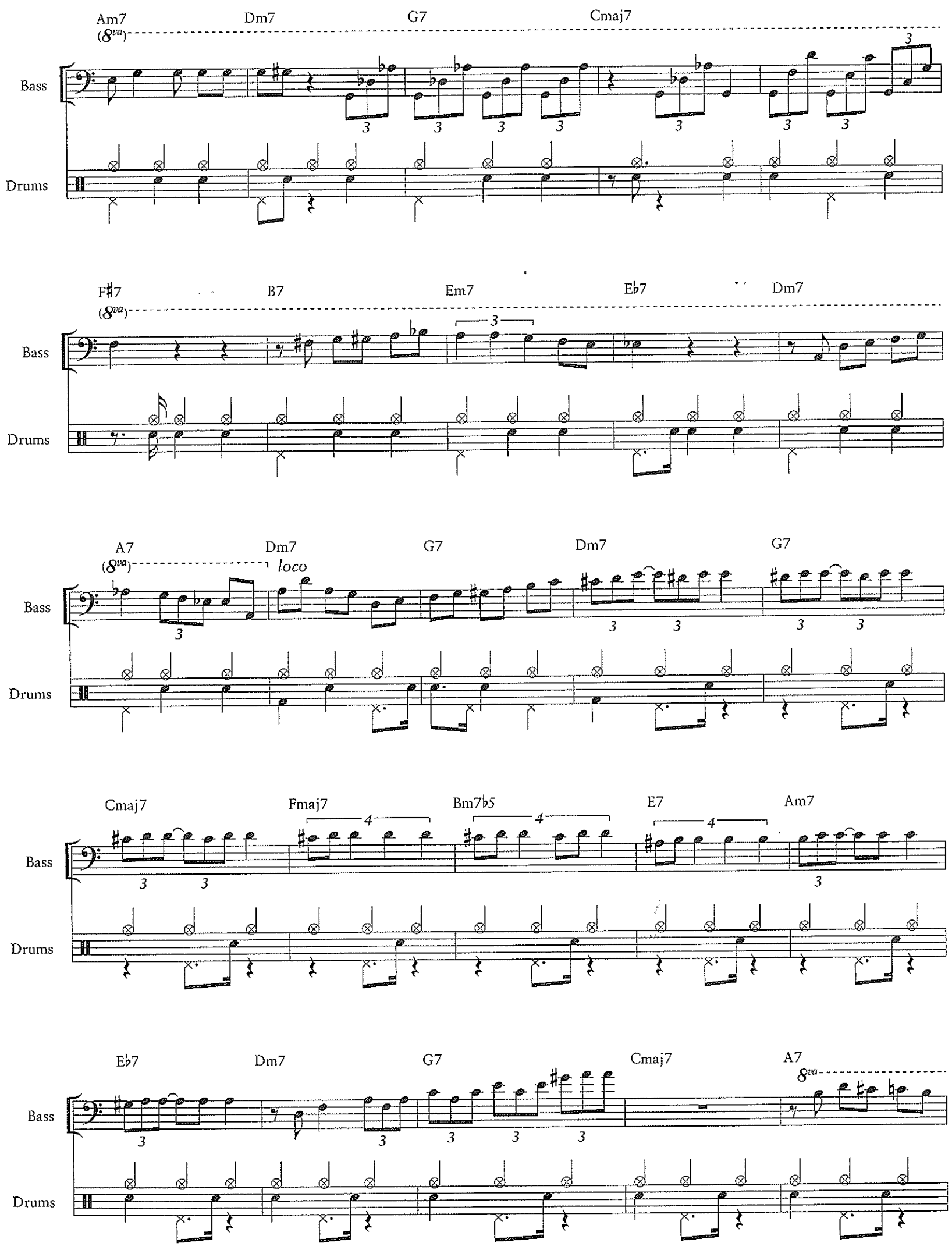

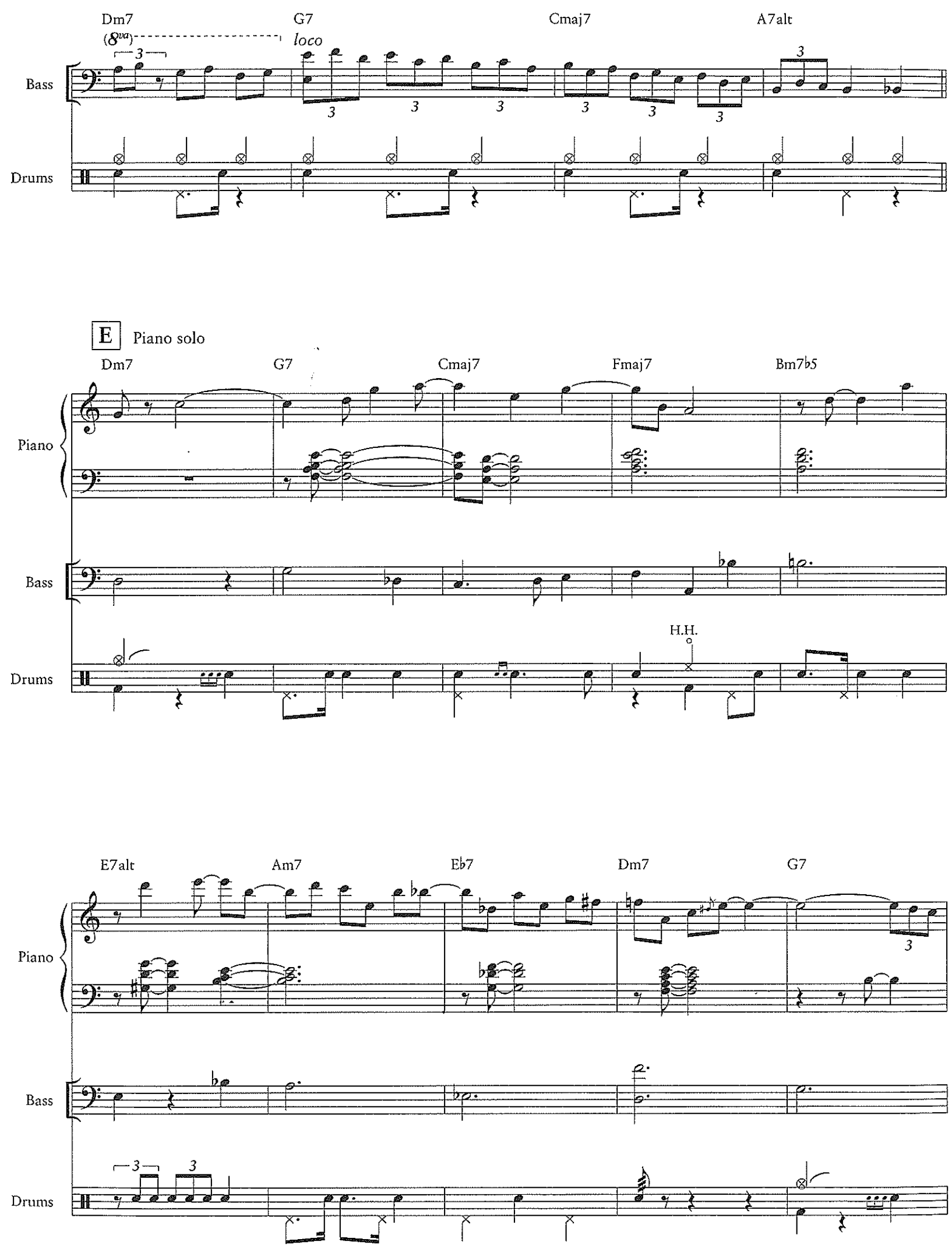

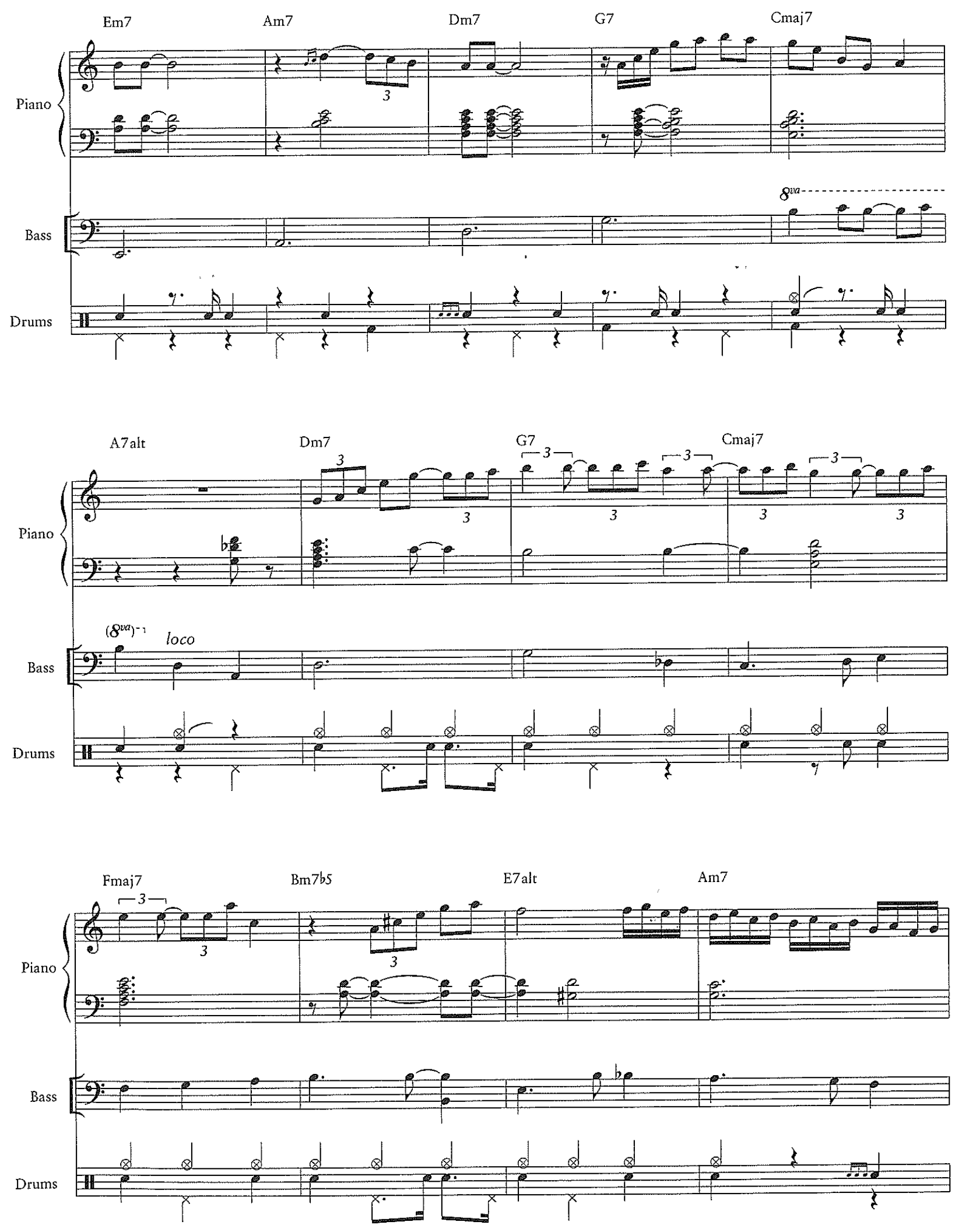
Eb7

Dm7

G7

C7(Cmaj7)
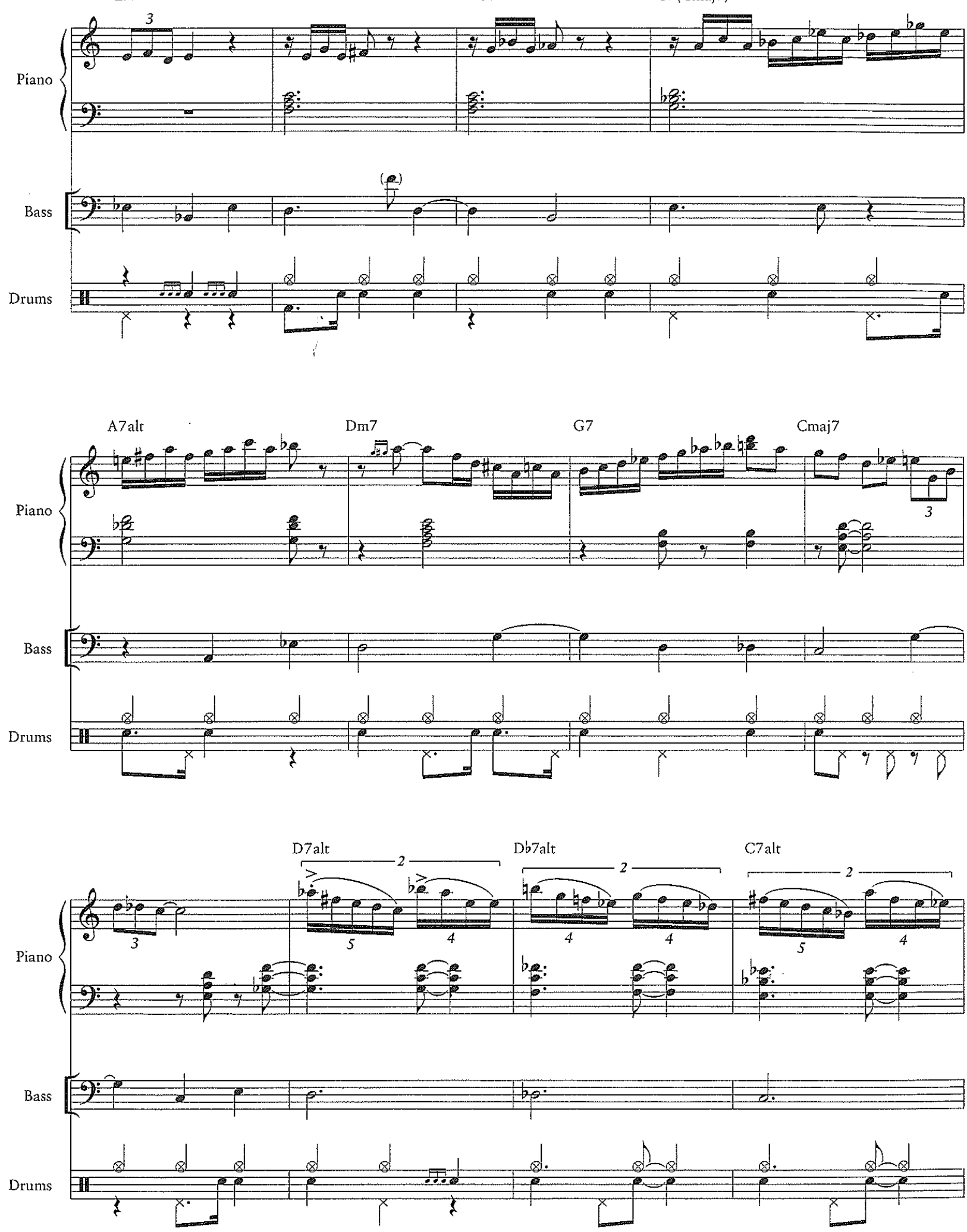

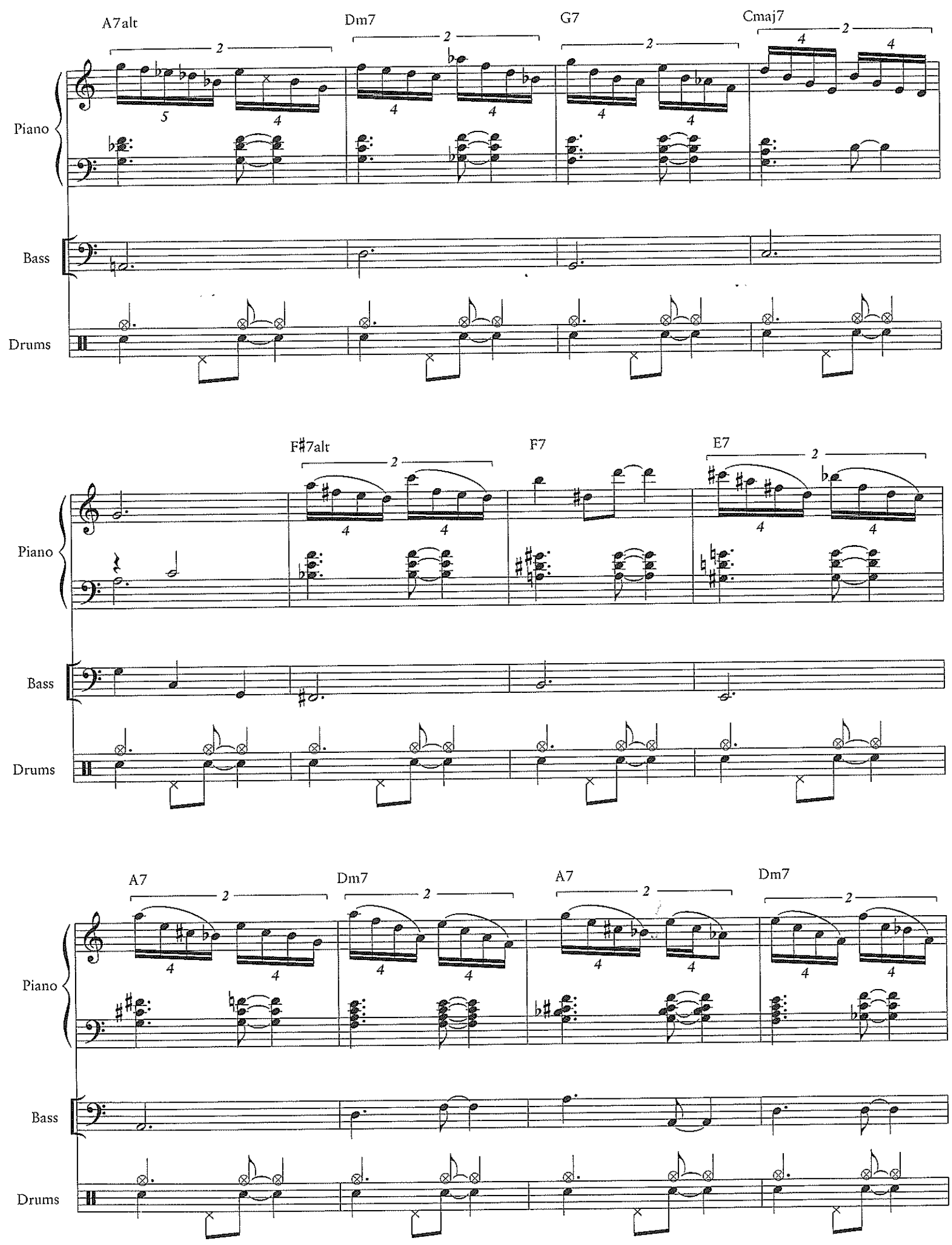

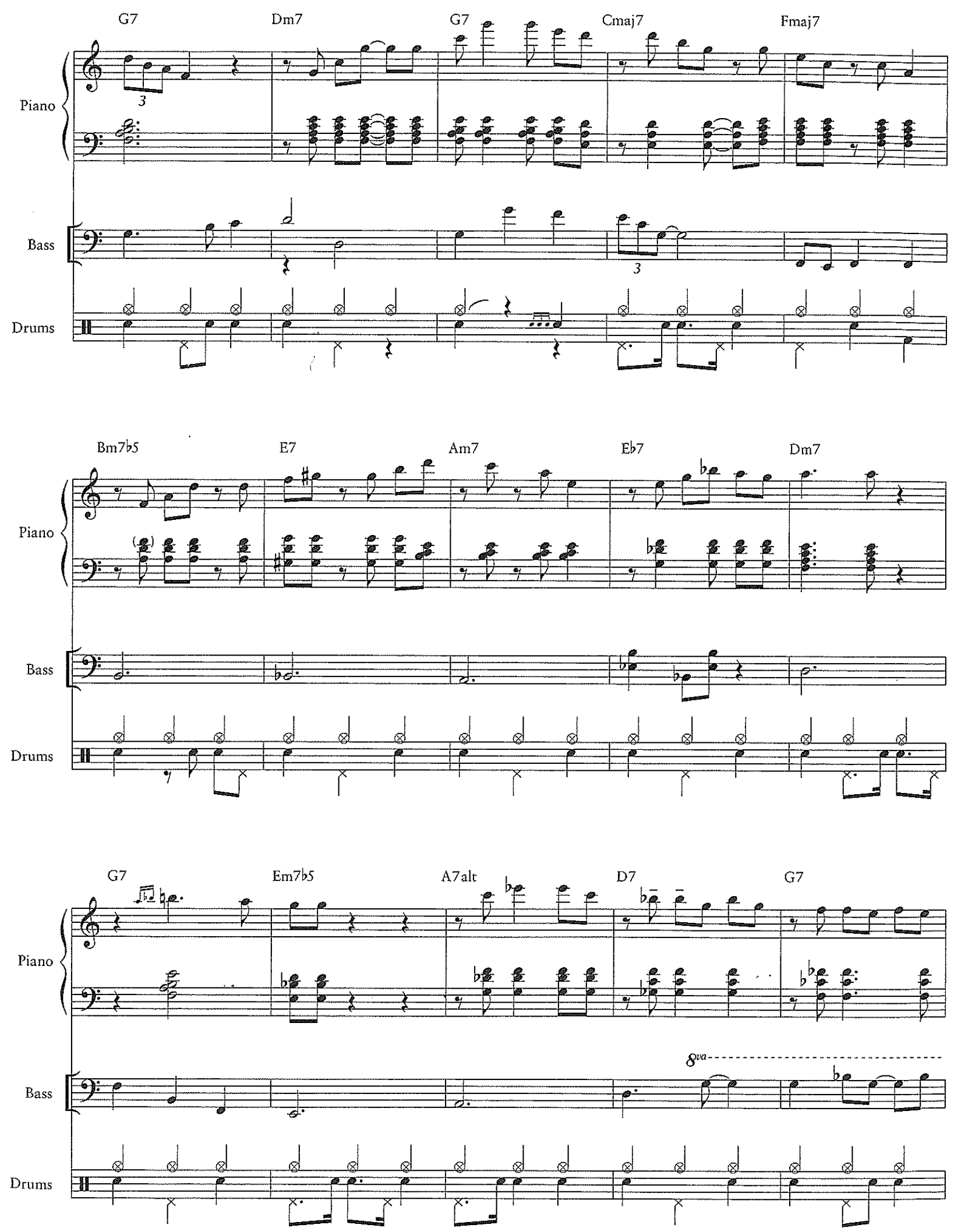

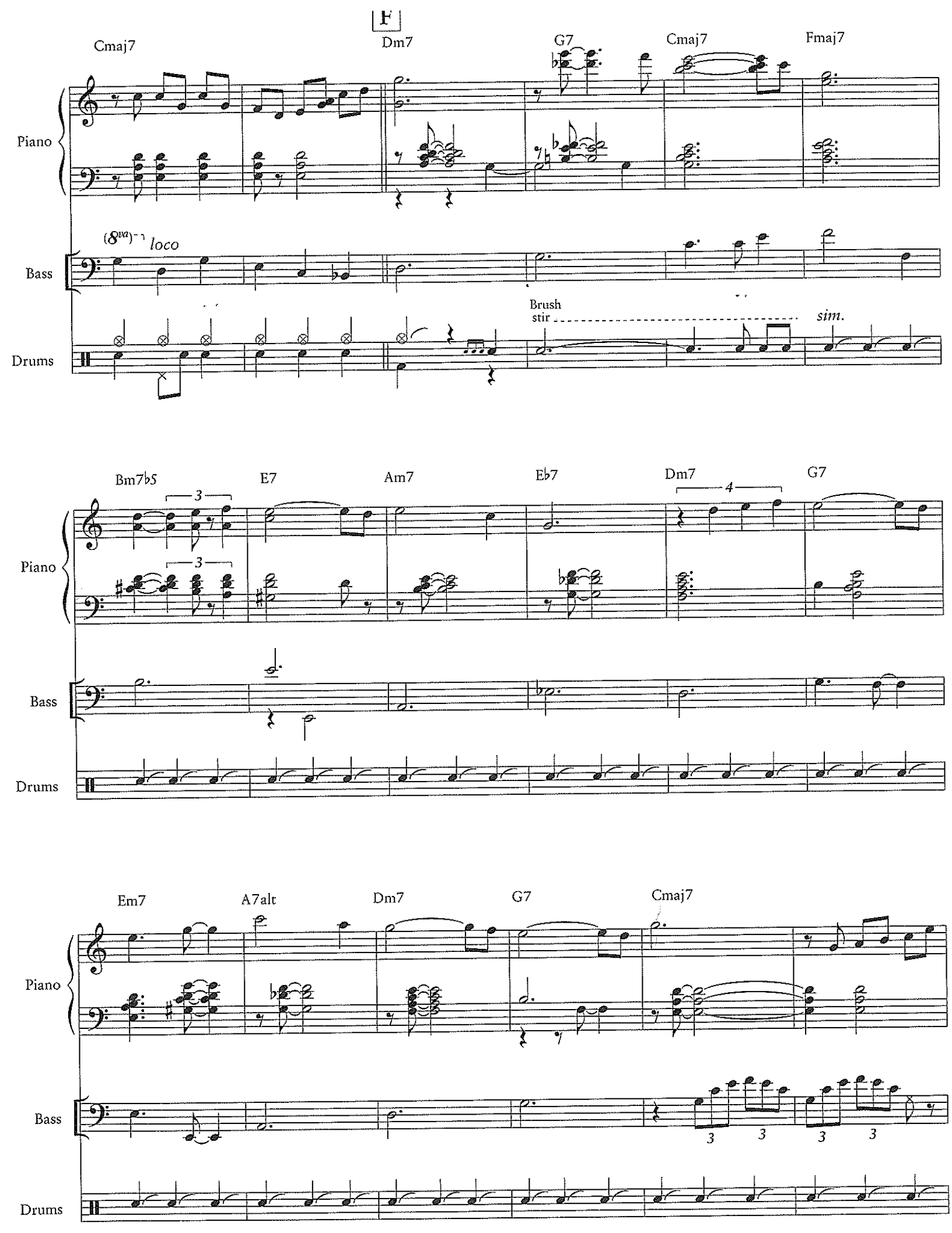

28

142 

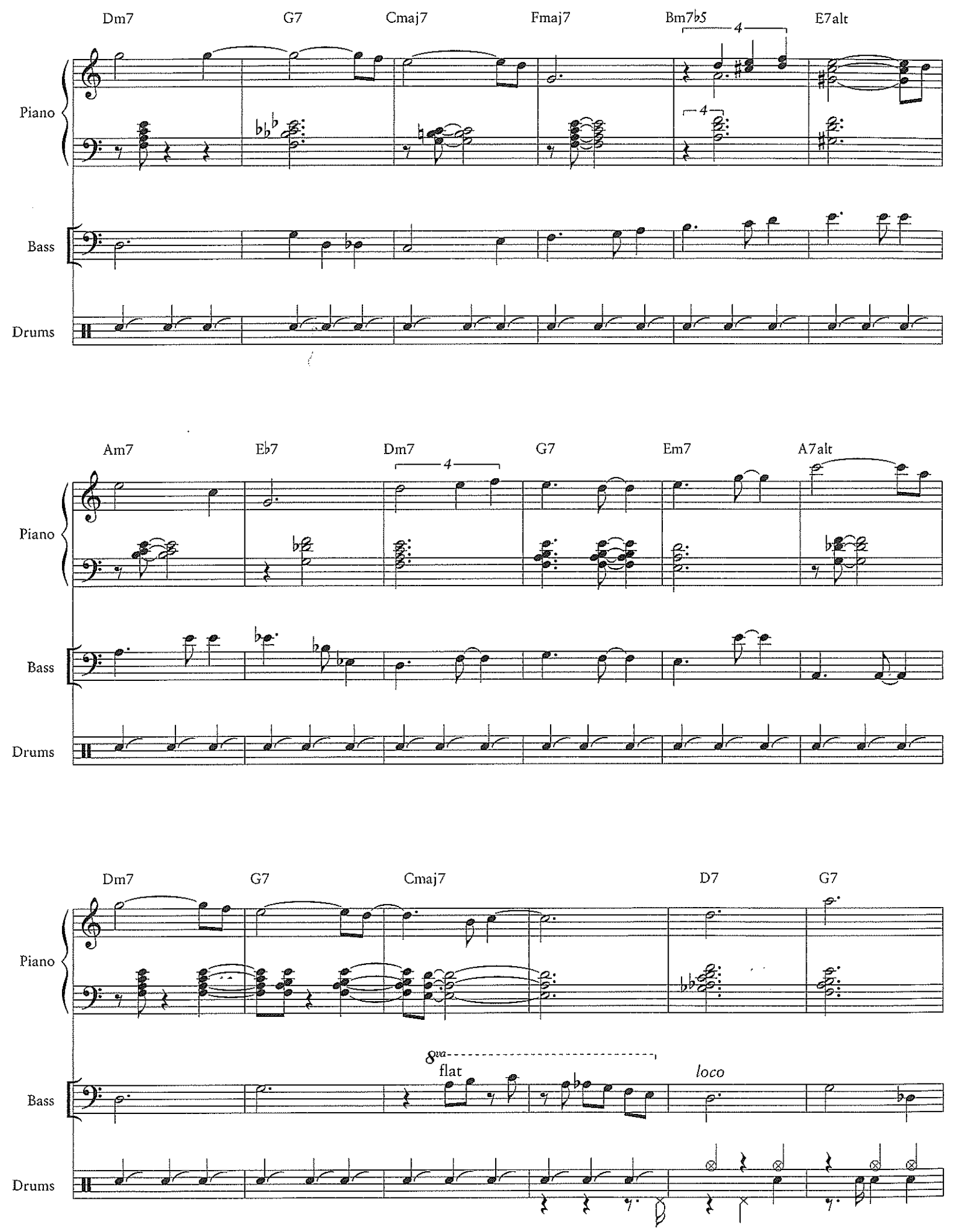

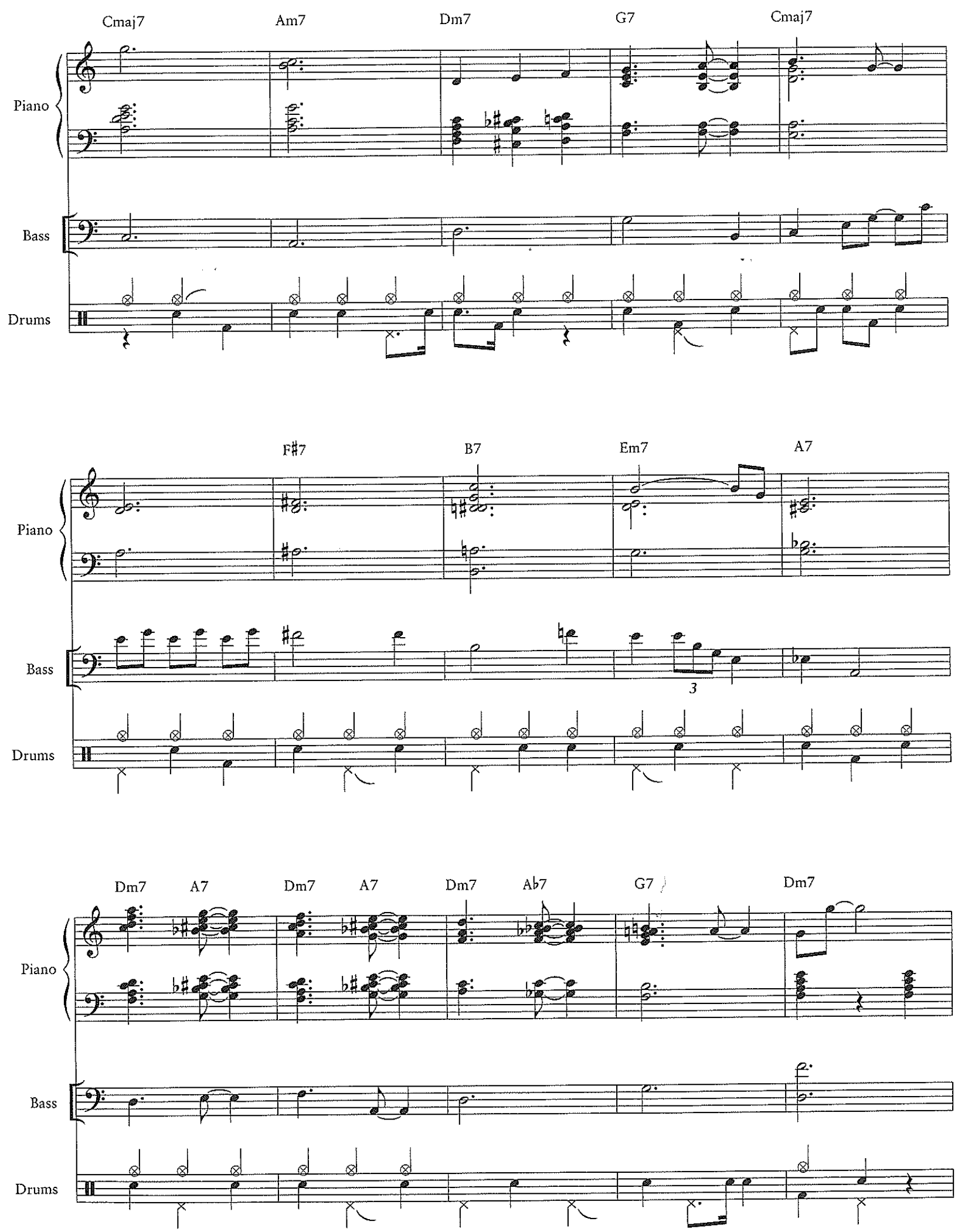

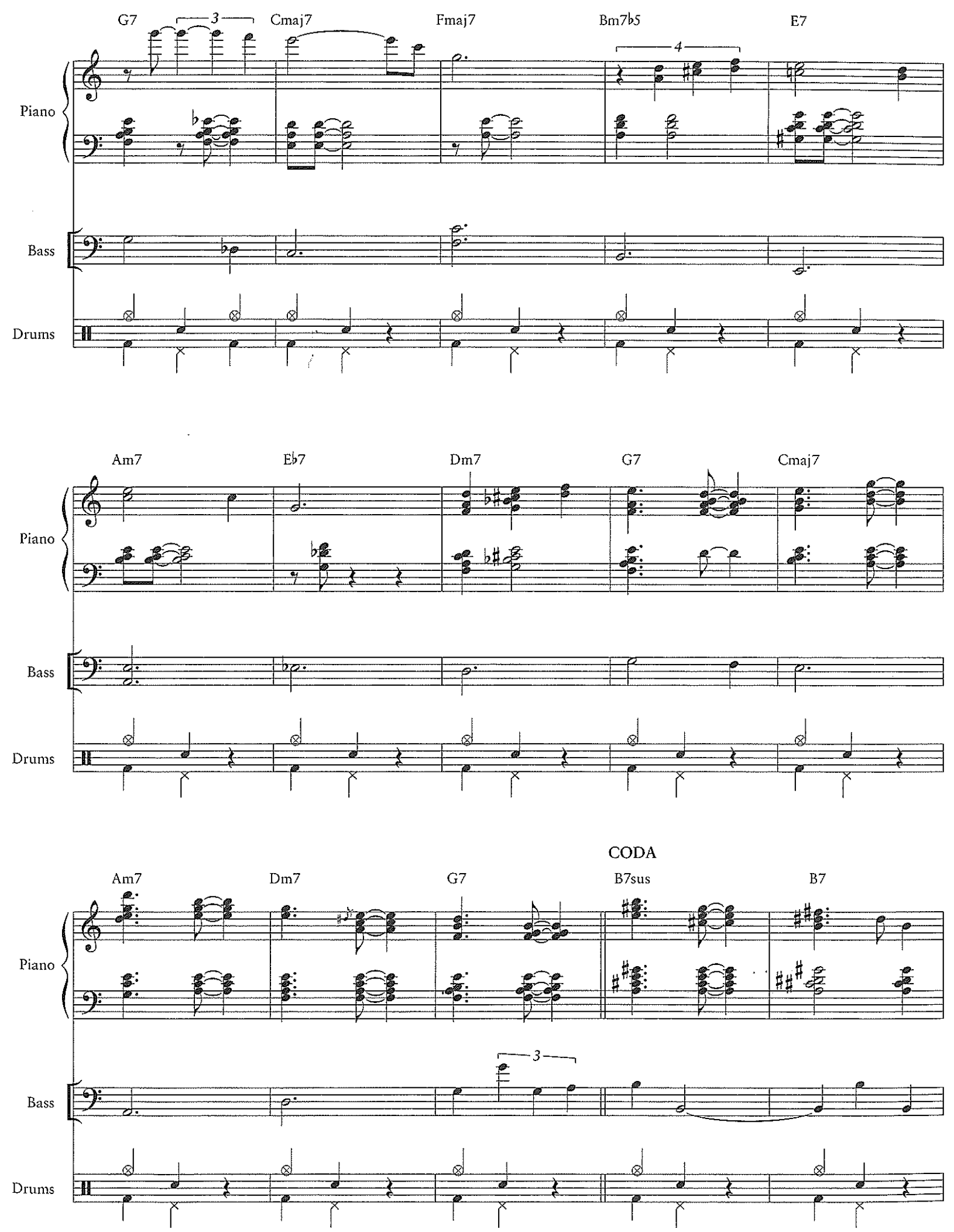

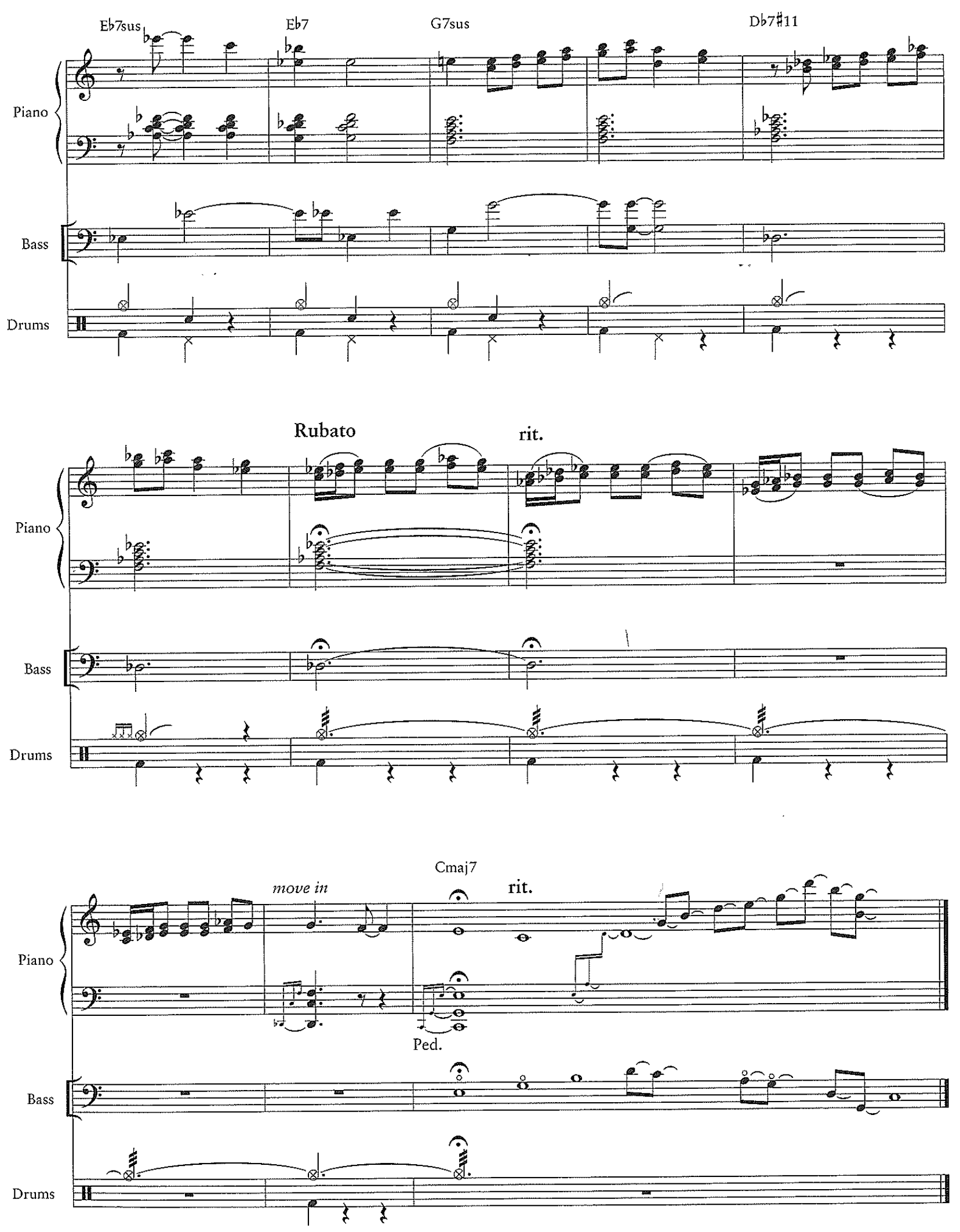
3: Waltz For Debby - Transcription taken from Leonard, Hal. The Bill Evans Trio Volume 1. 2003. 

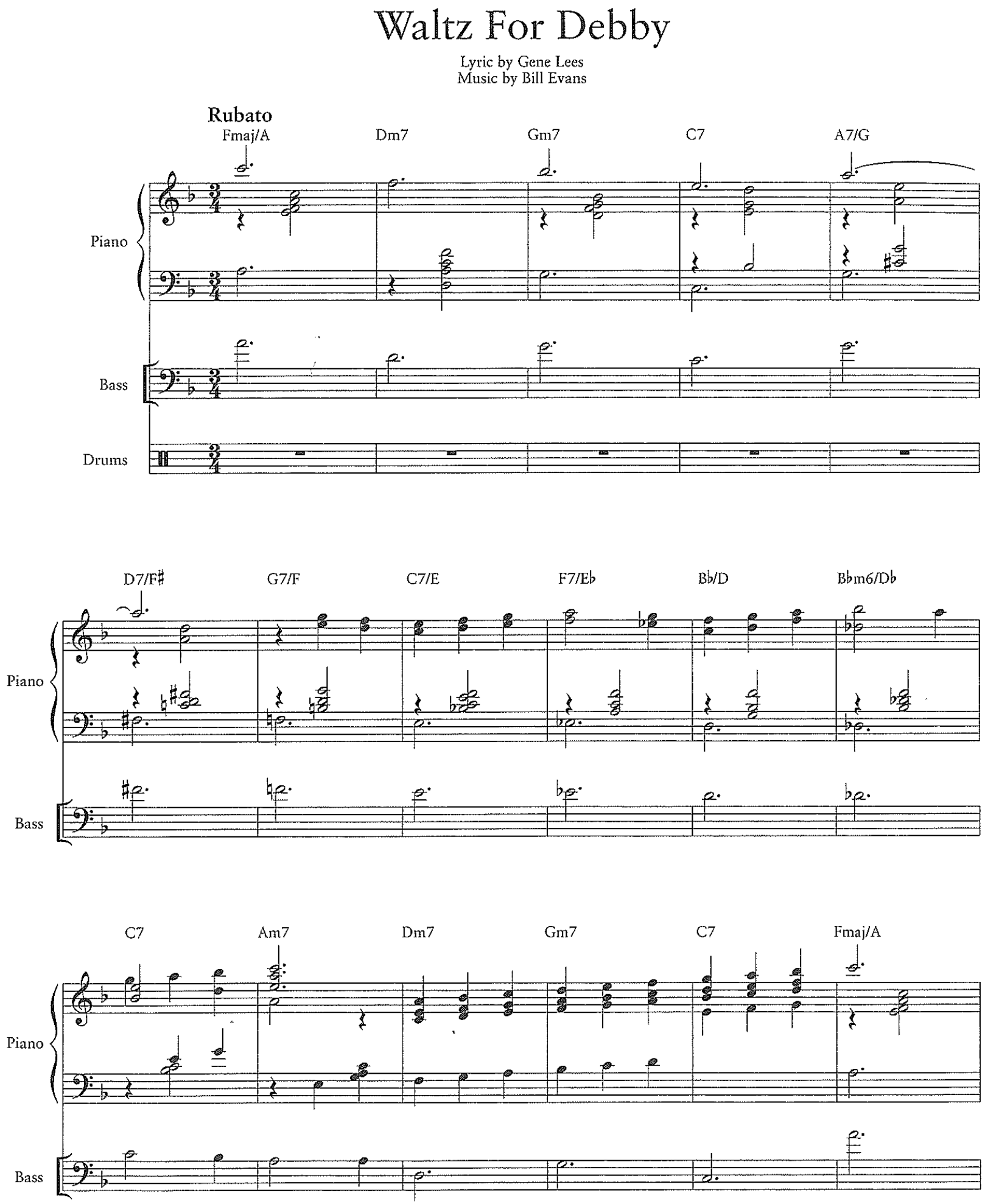

TRO - (C) Copyright 1964 (Renewed), 1965 (Renewed), 1966 (Renewed) Folkways Music Publishers, Inc., New York, NY International Copyright Secured

International Copyright Secured
All Rights Reserved Including Public Performance For Profir

$$
\text { Used by Permission }
$$



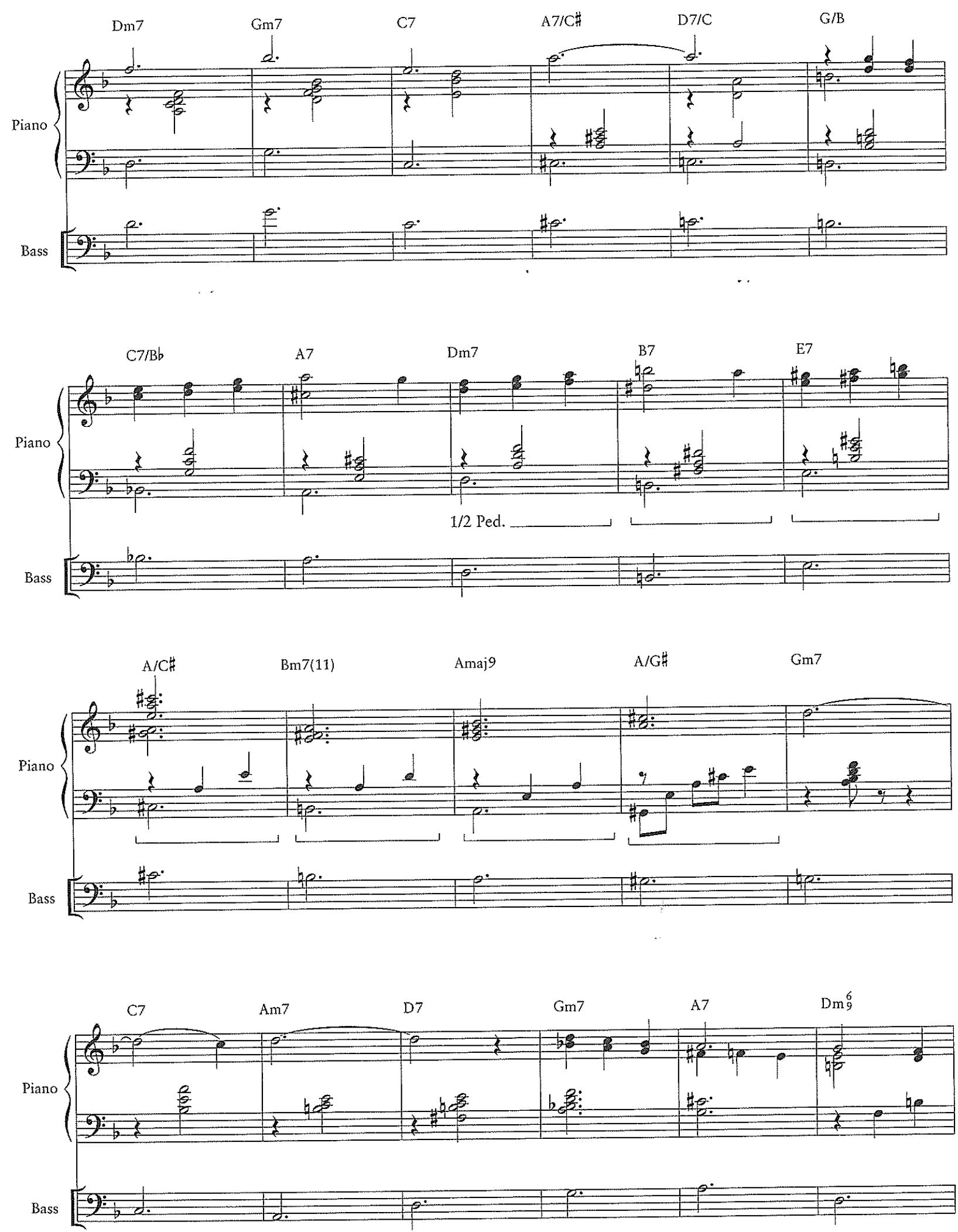

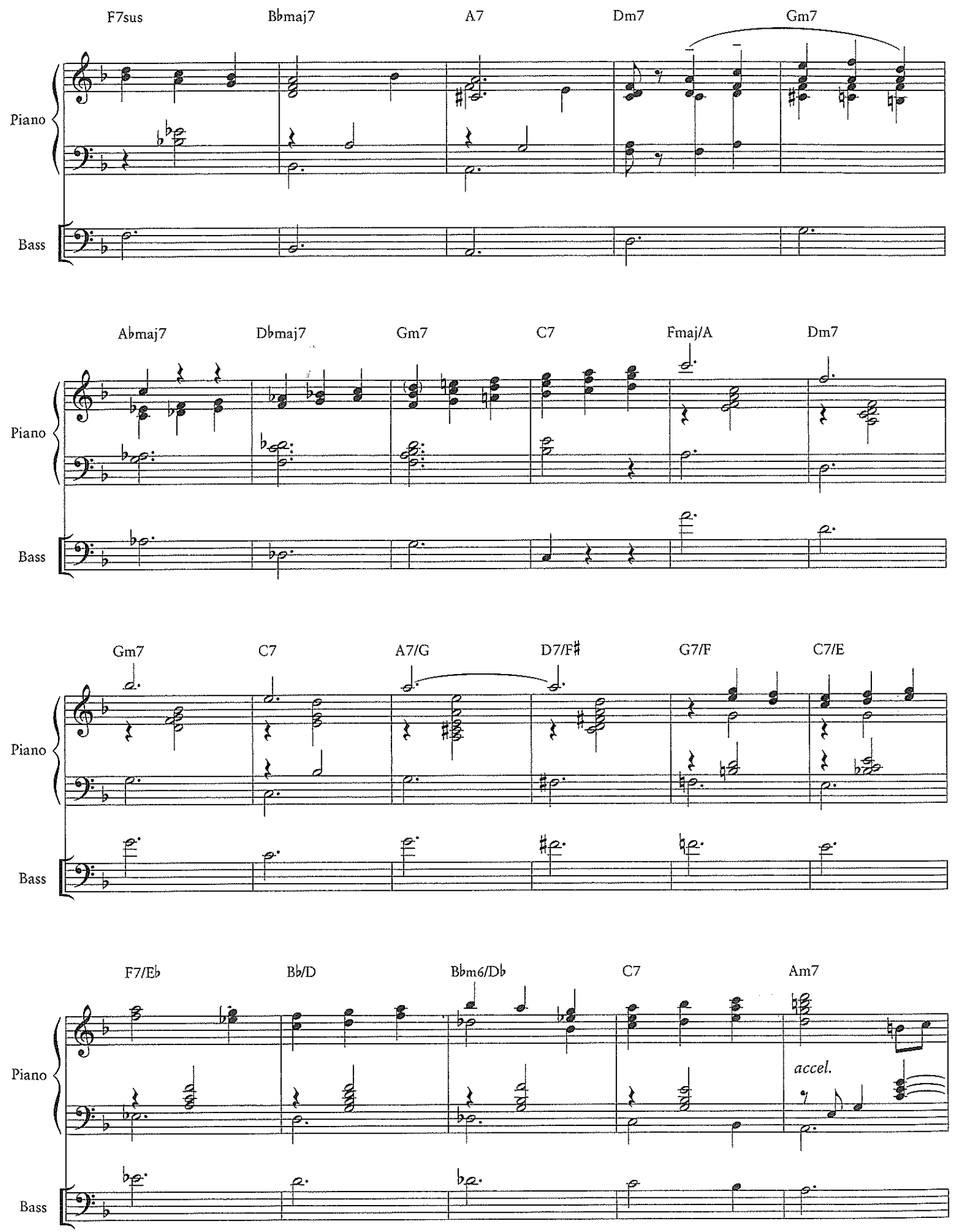

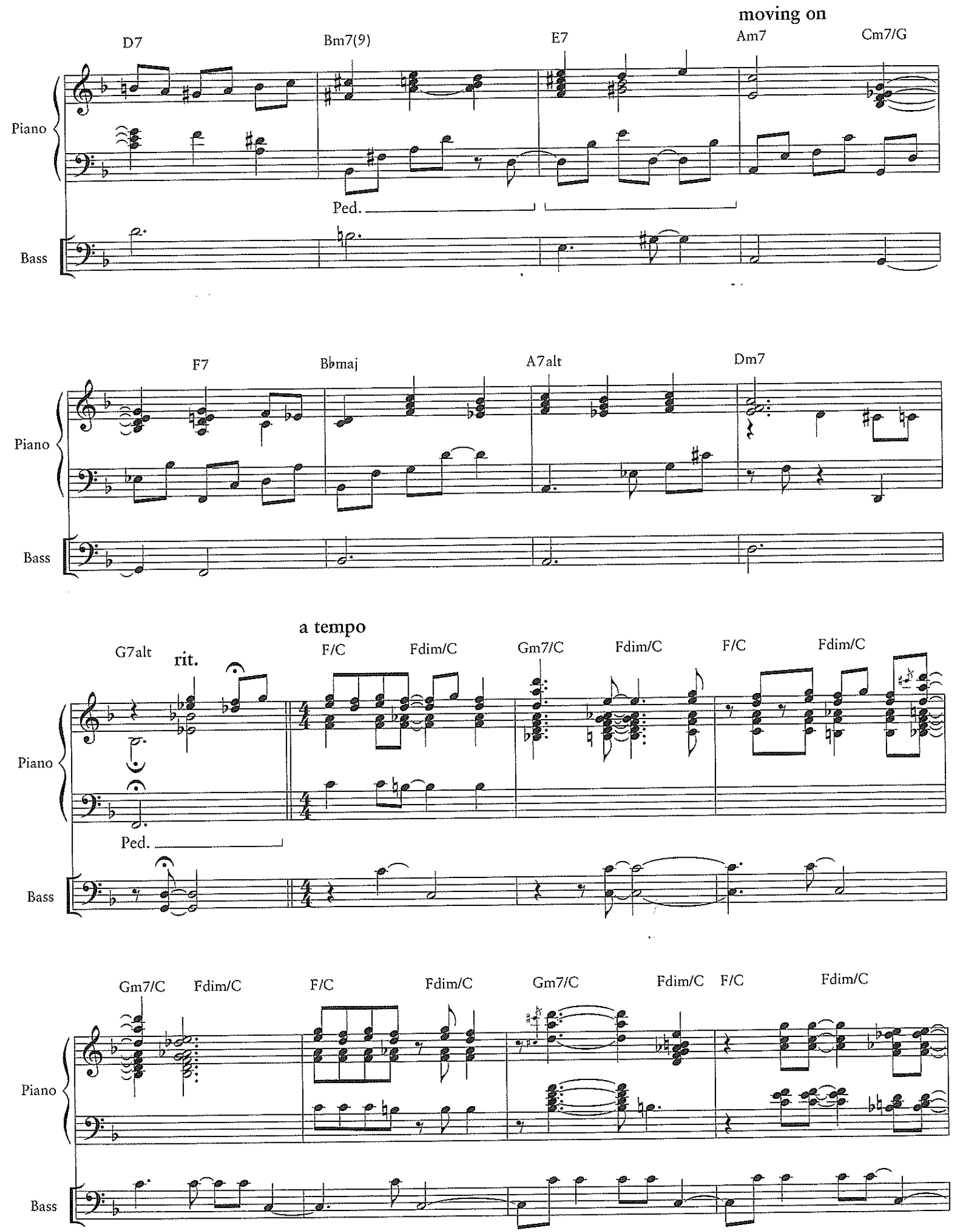

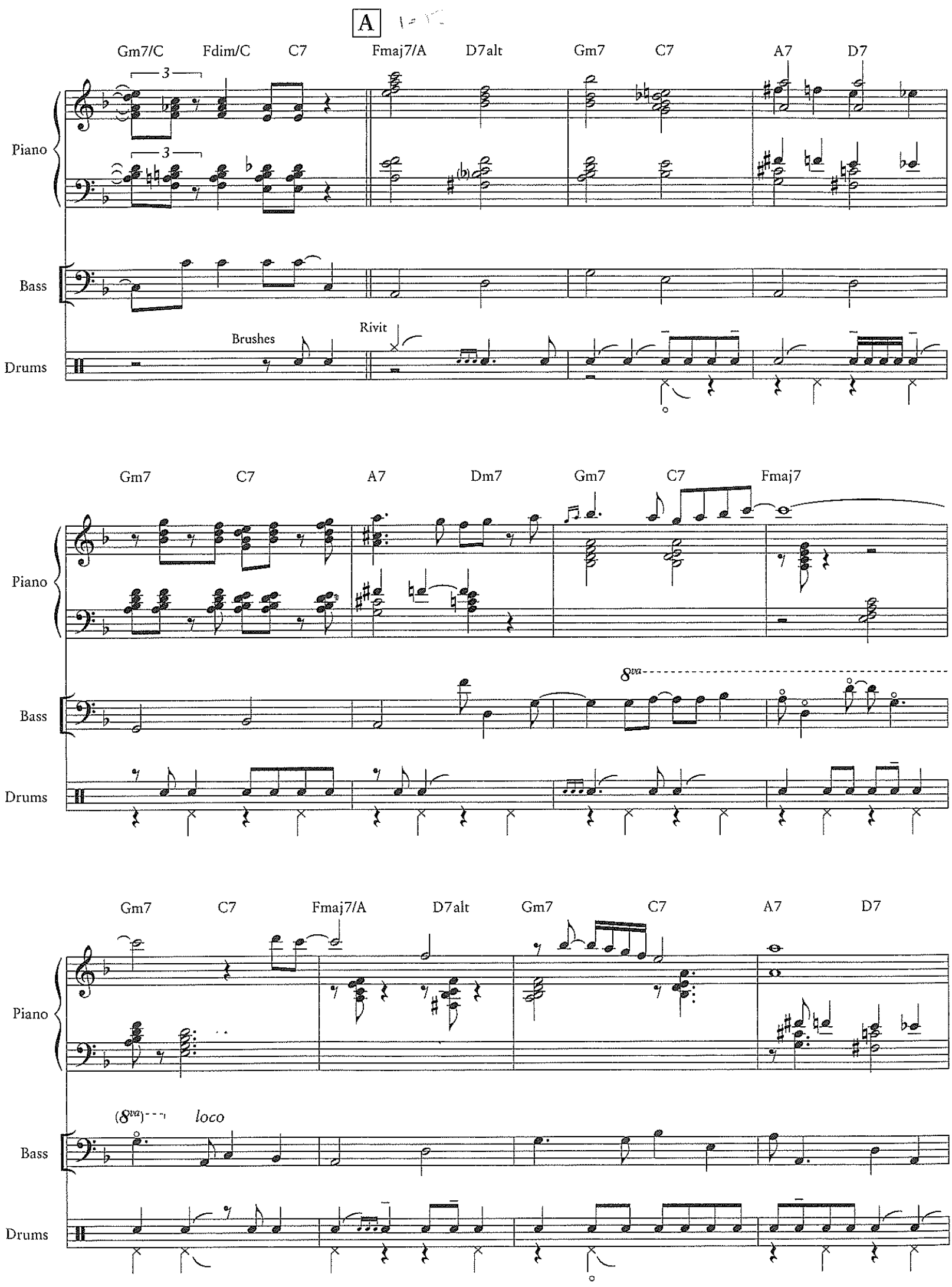


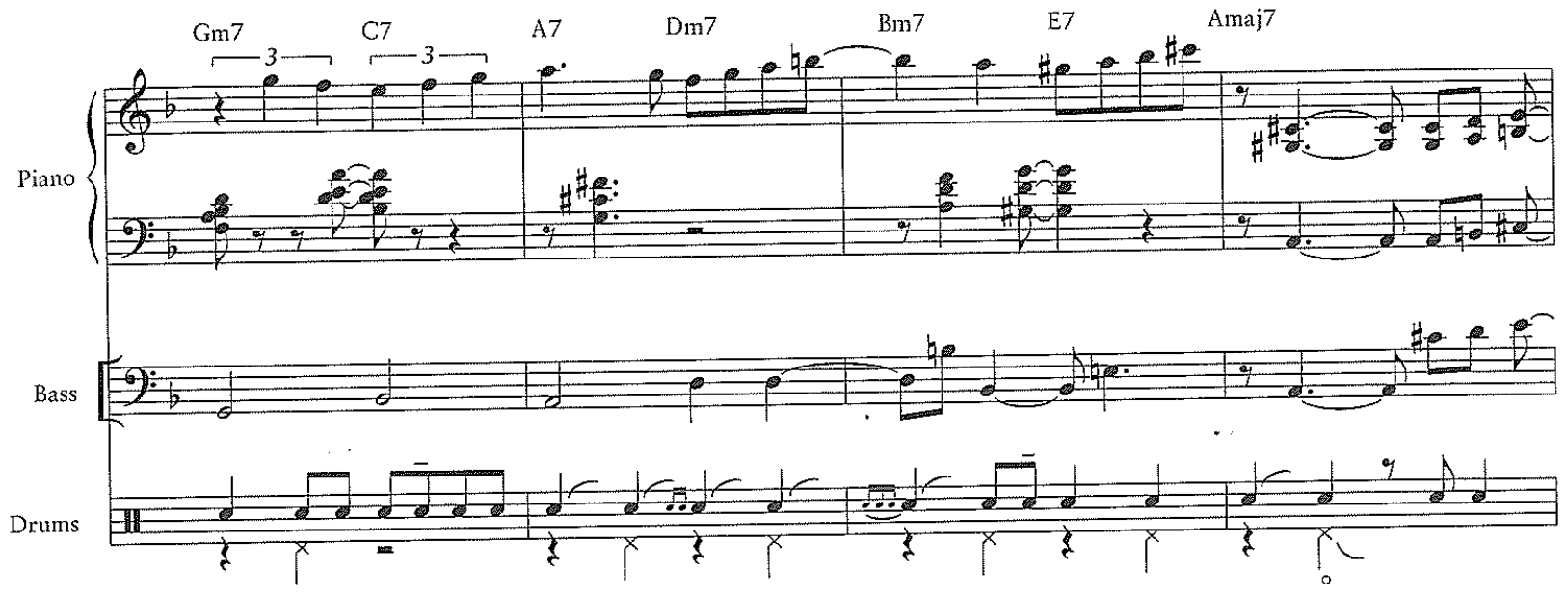

$\begin{array}{llllll}\mathrm{Gm} 7 & \mathrm{C} 7 & \mathrm{Am} 7(11) & \mathrm{D} 7 & \mathrm{Gm} 7 & \mathrm{~A} 7\end{array}$
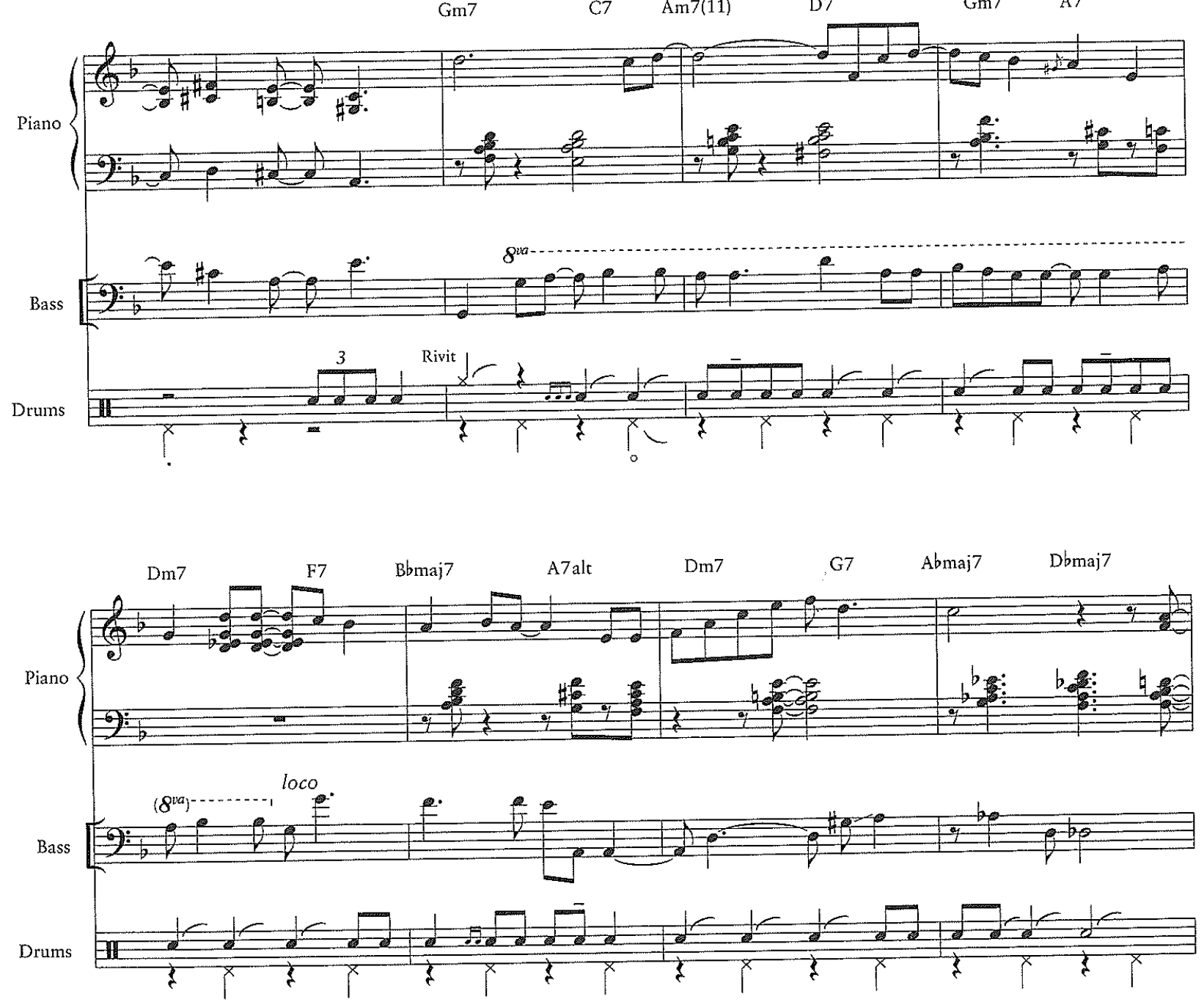

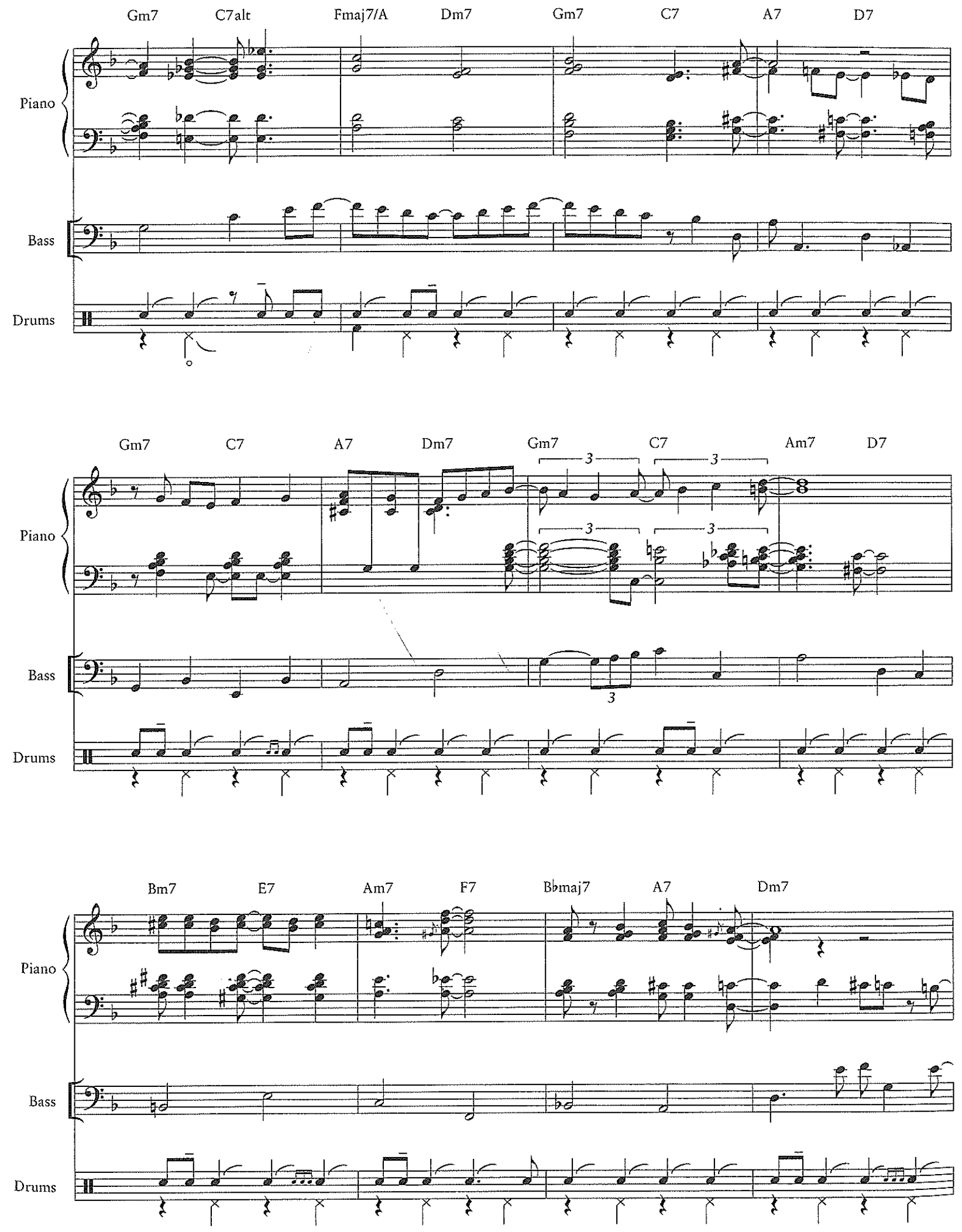


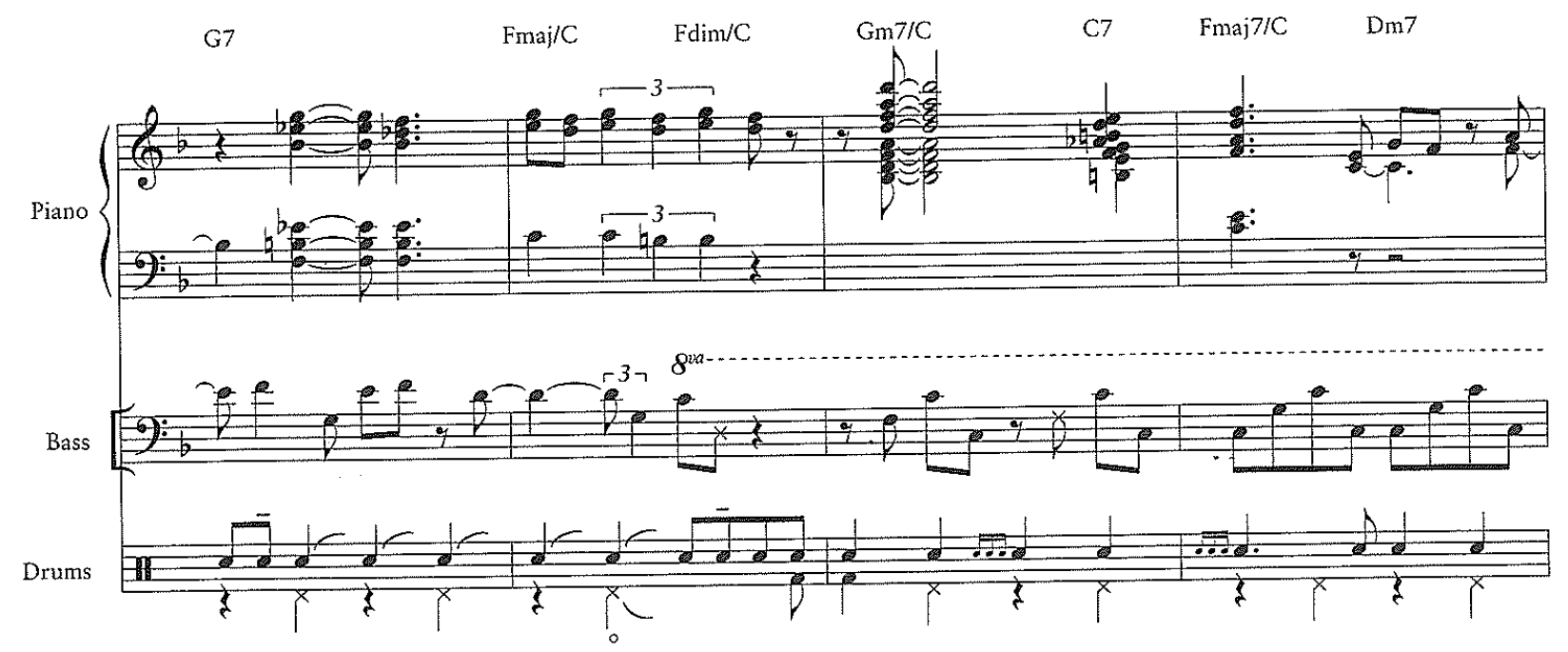

B
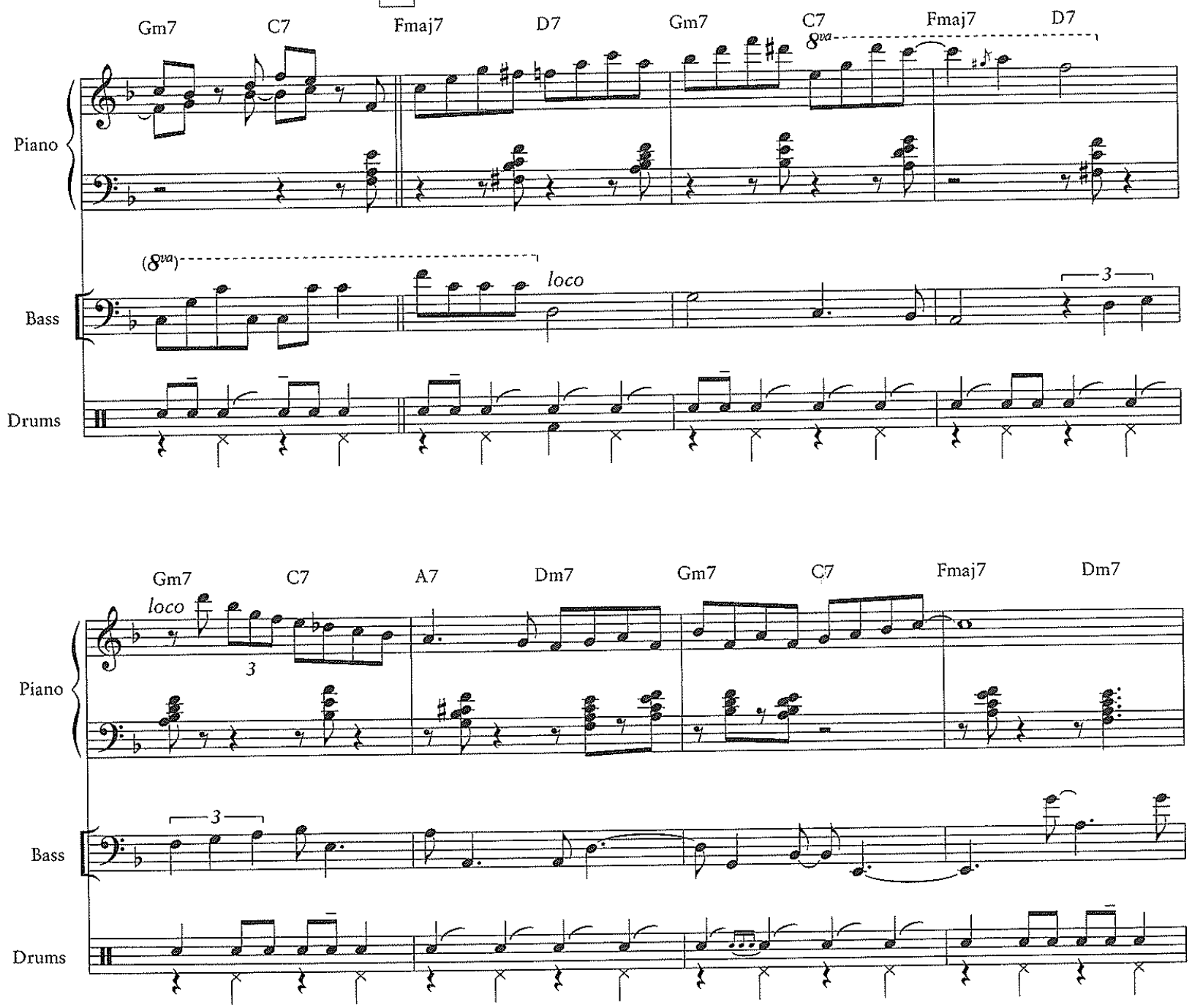

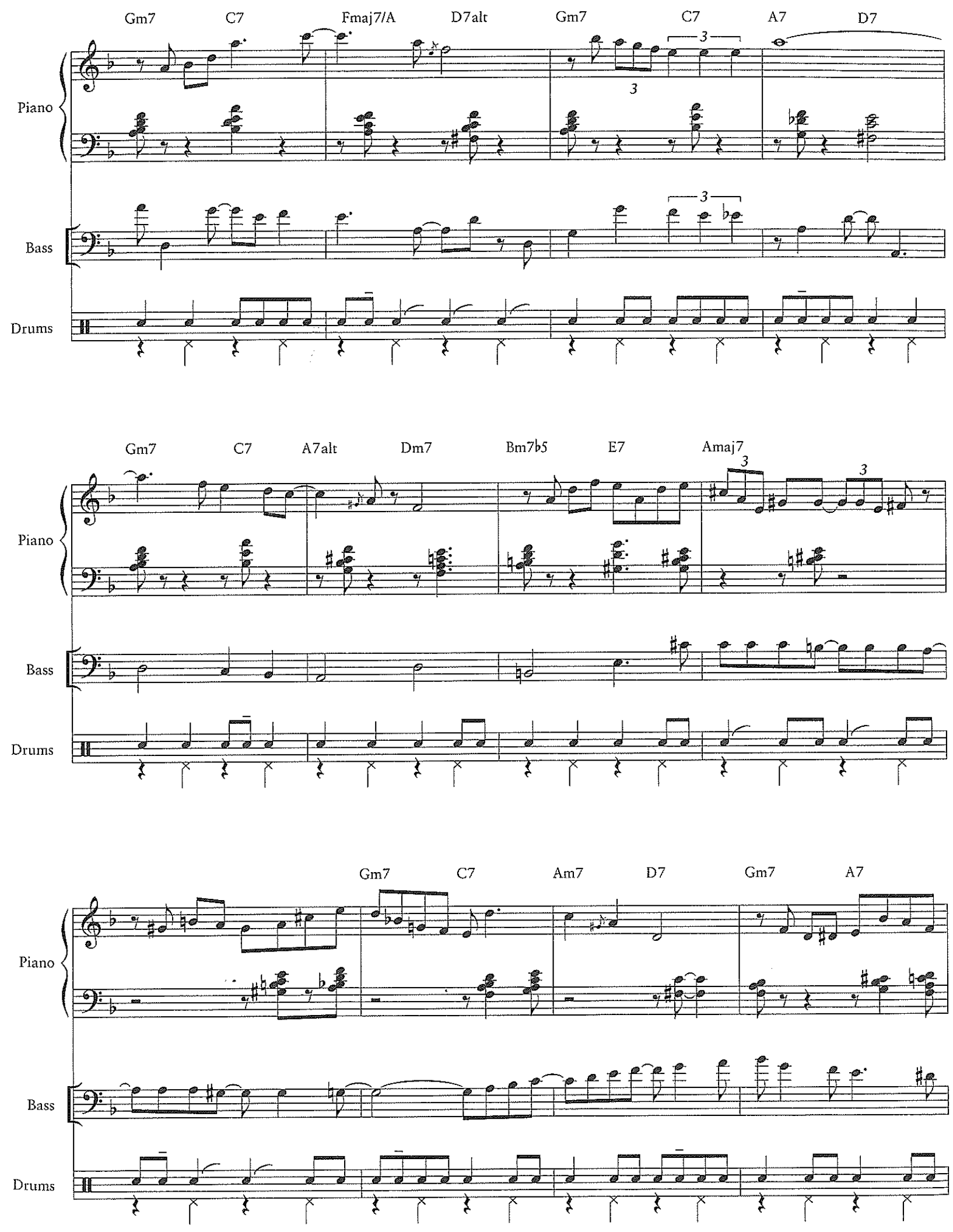

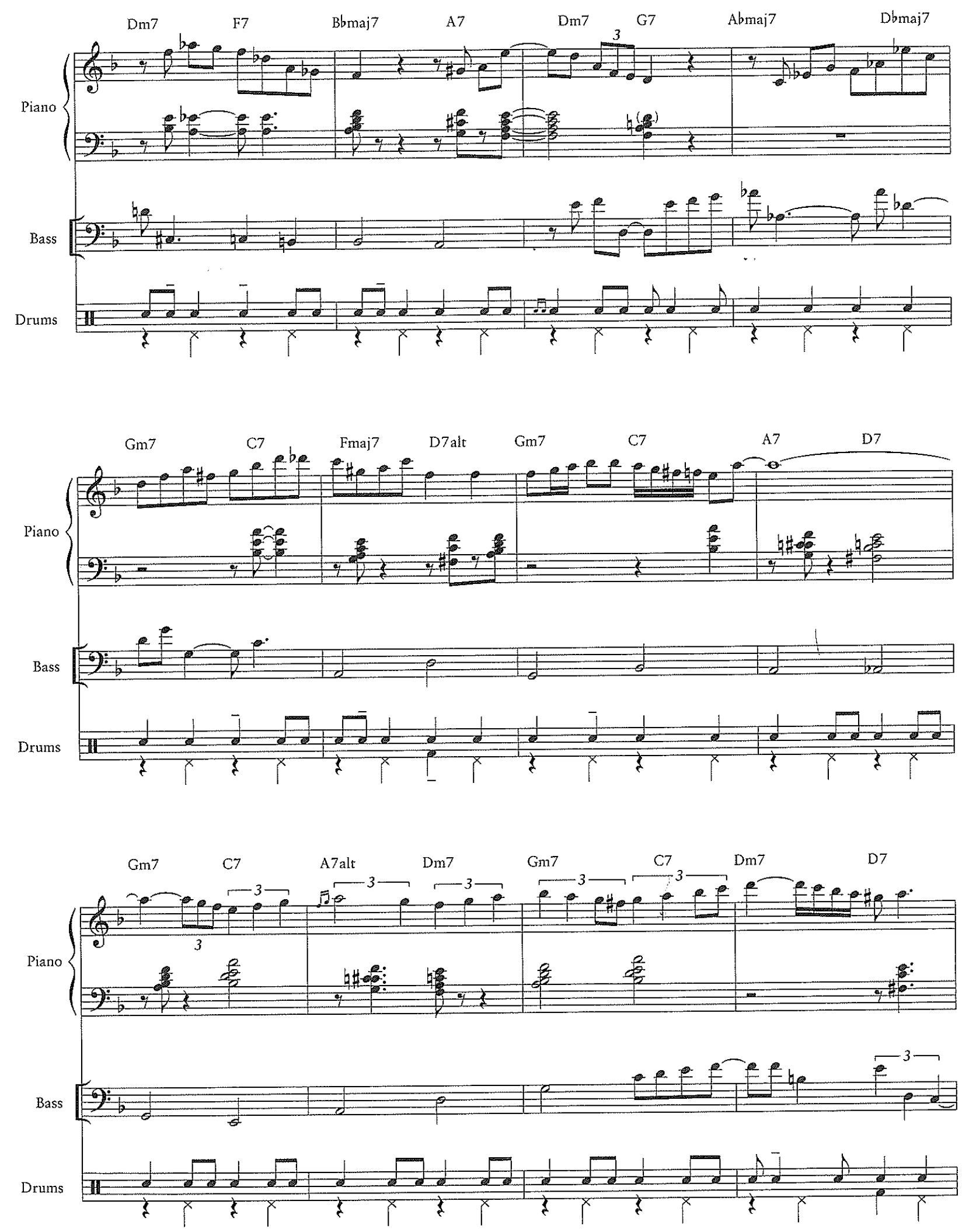

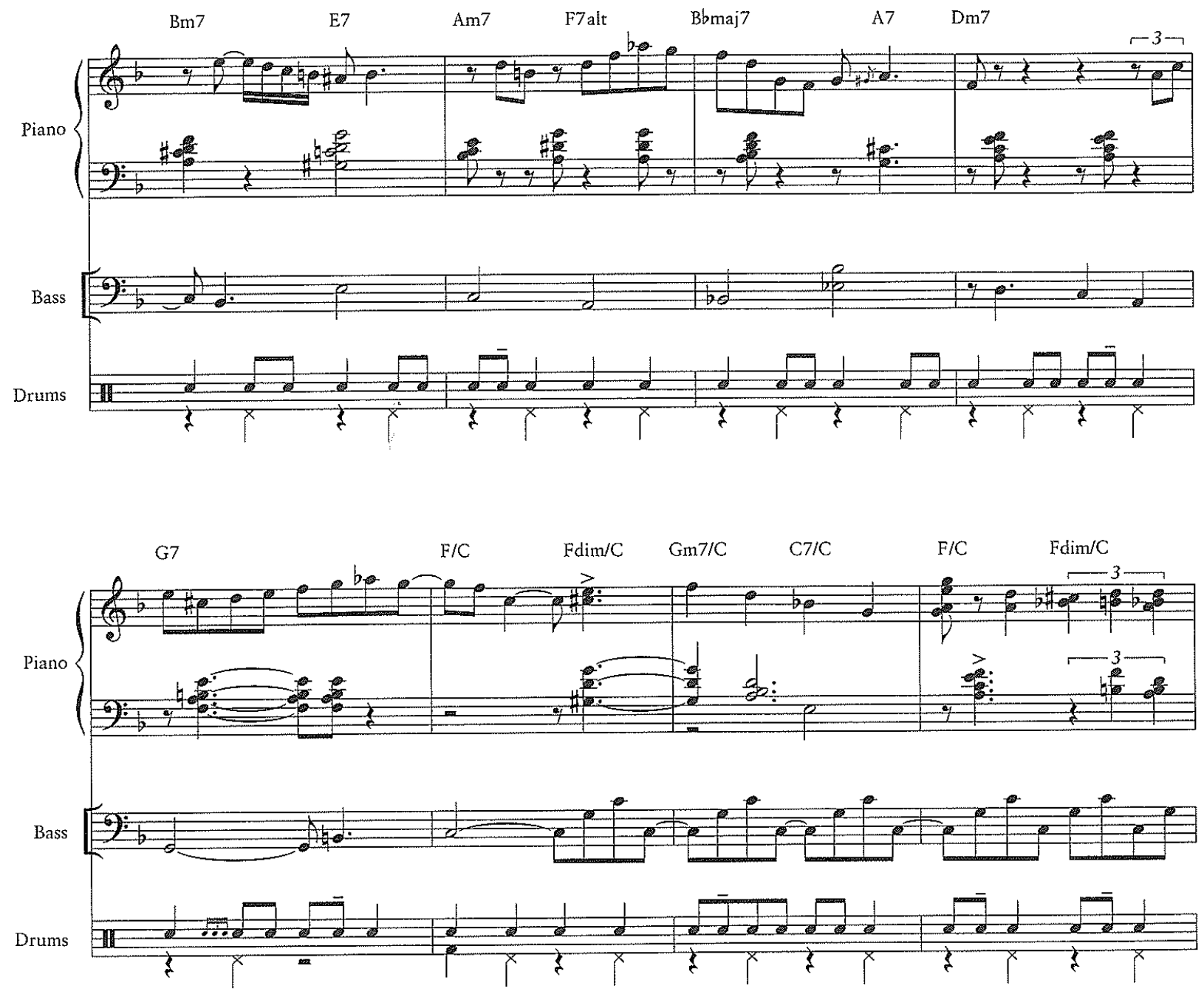

C

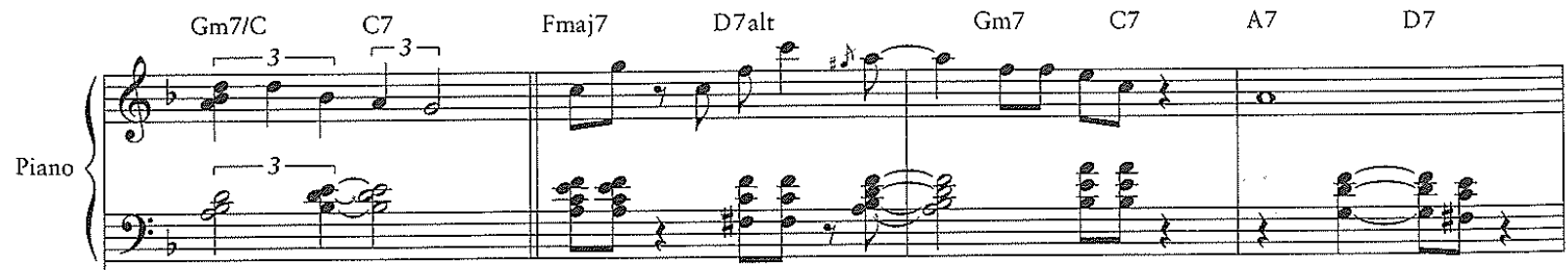

Bass

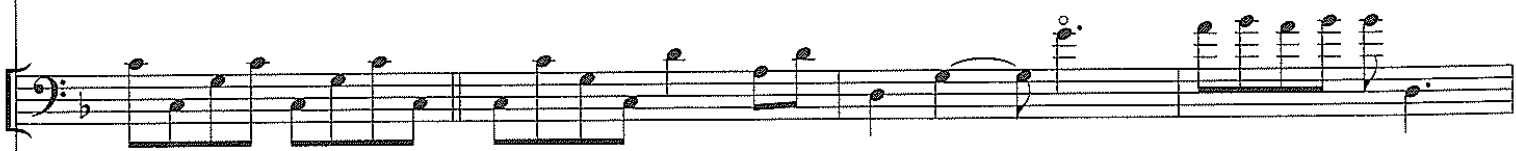

Drums

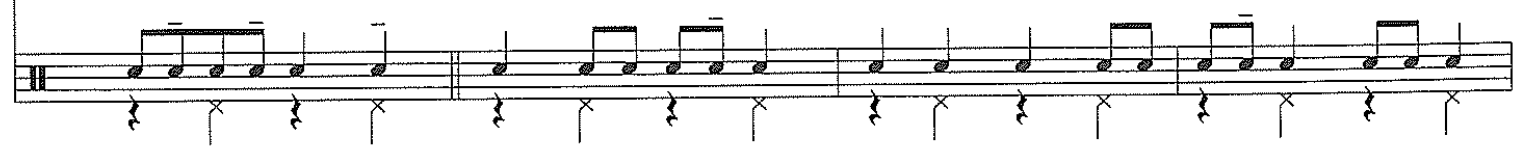



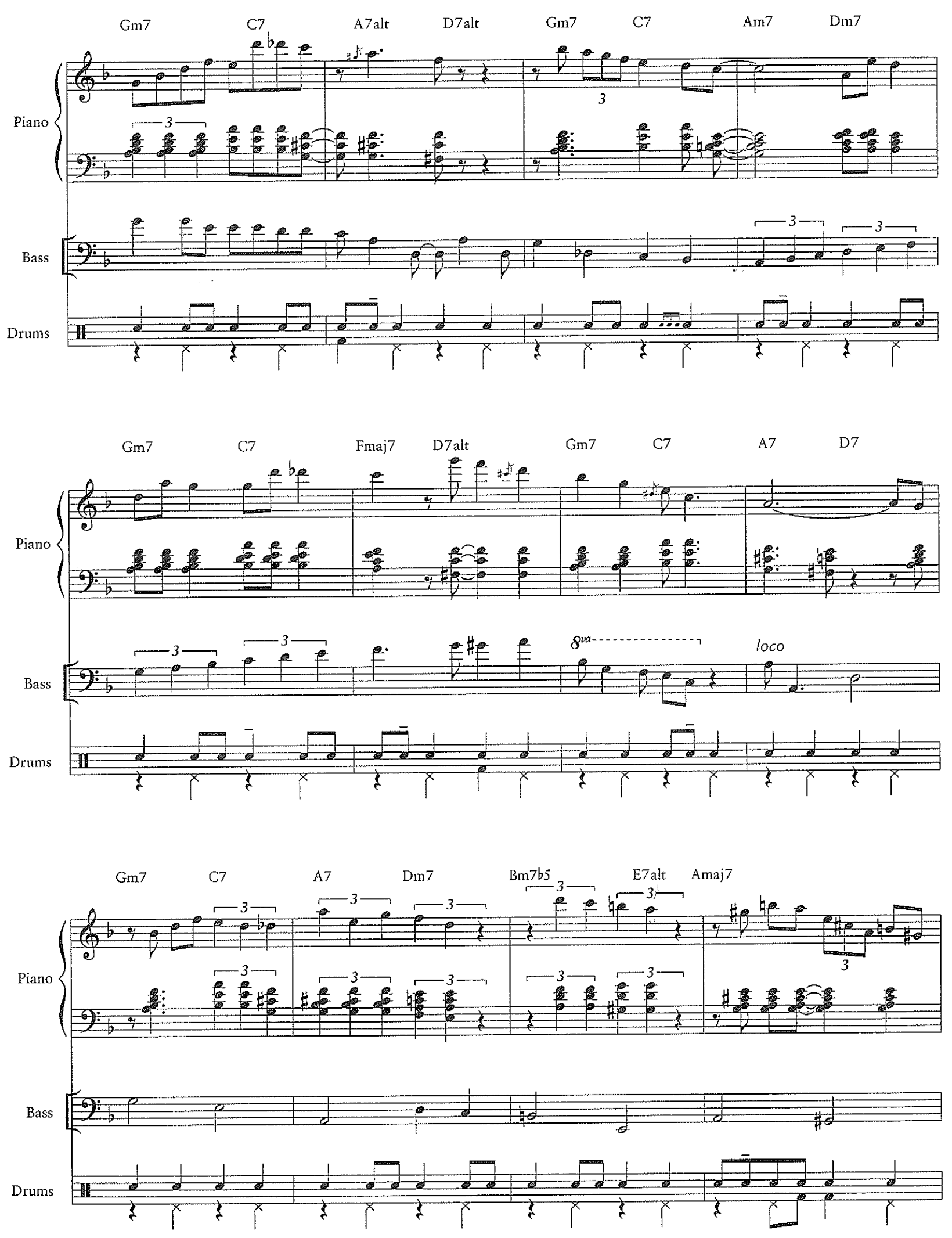

146

159 

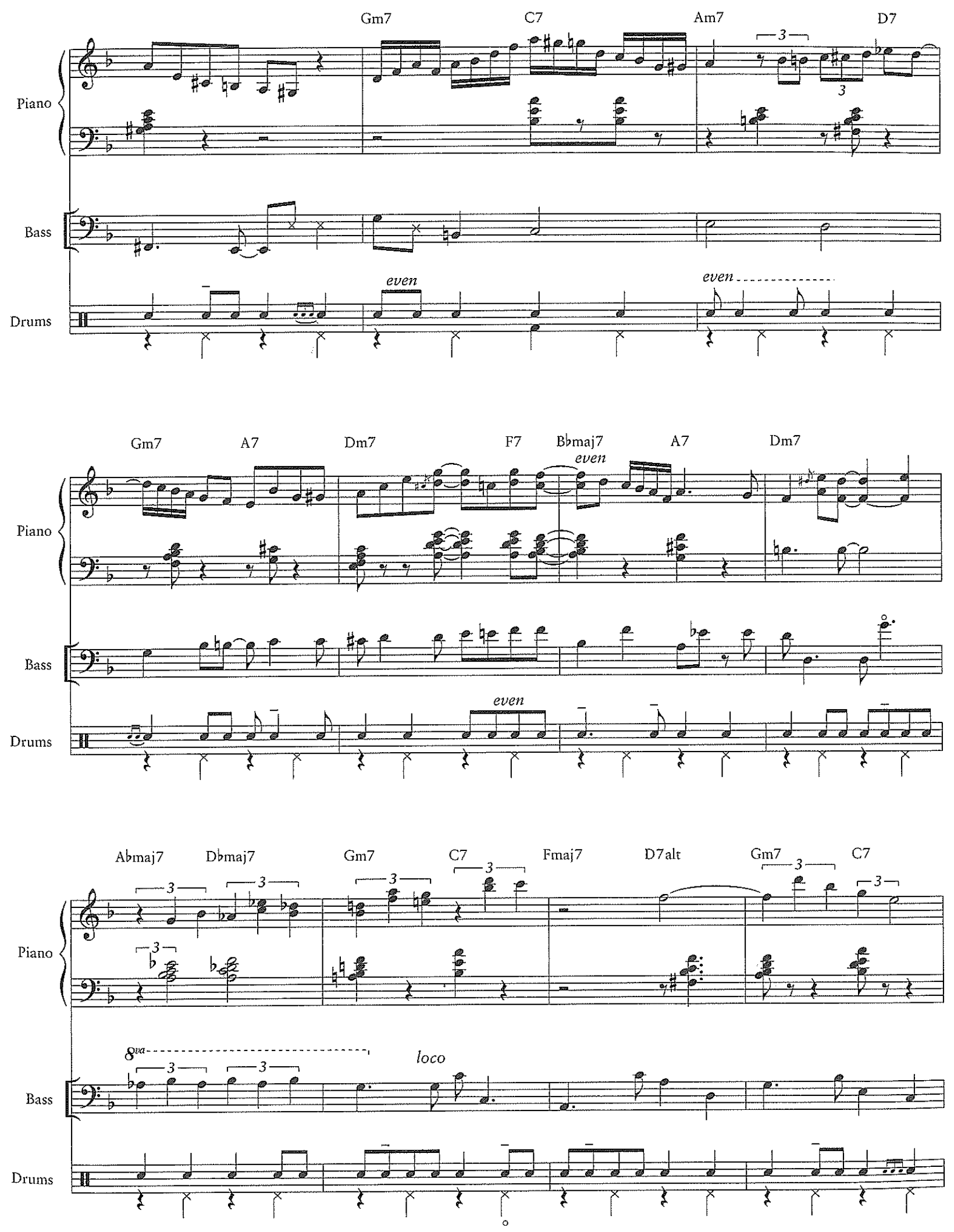

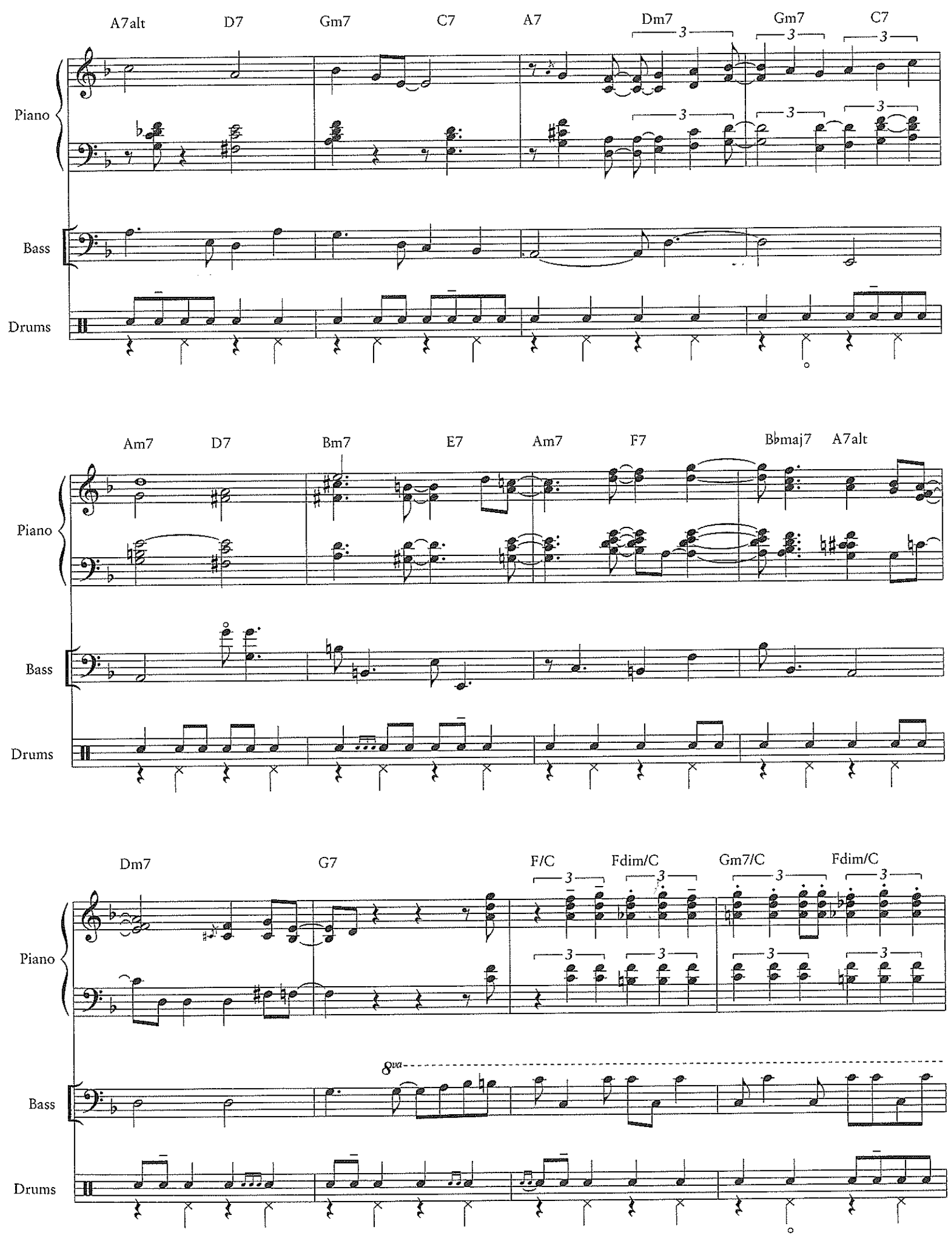

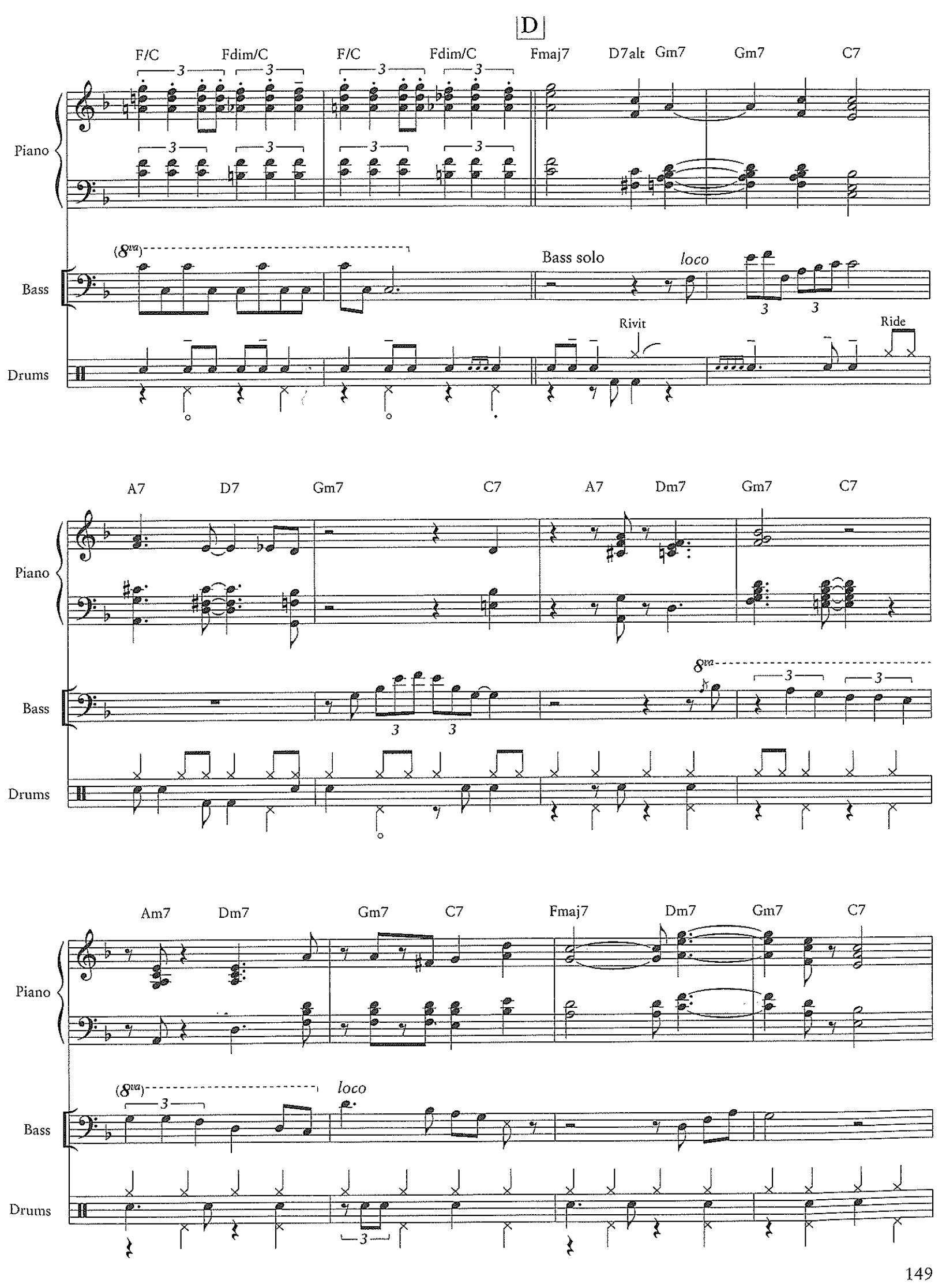

162 

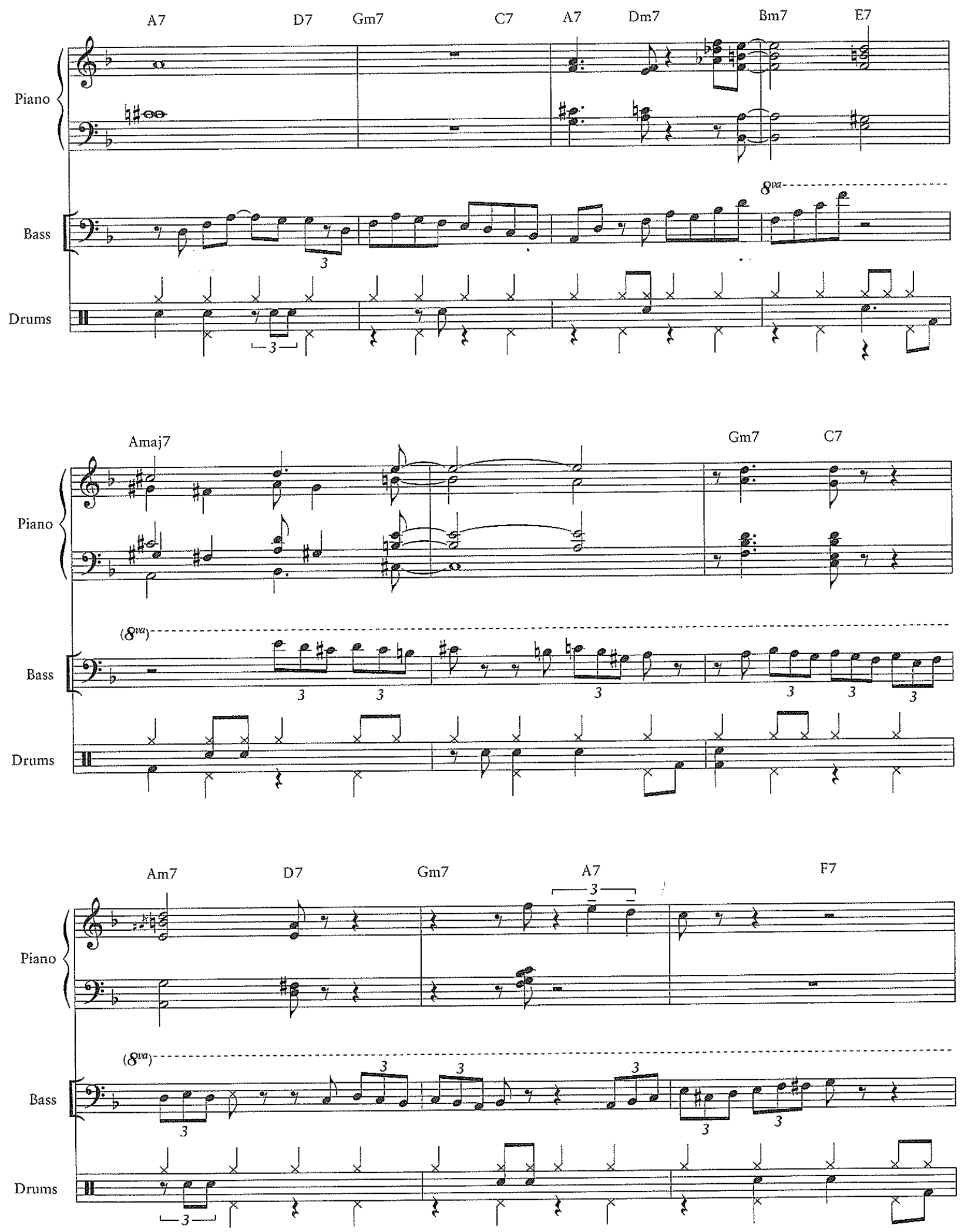

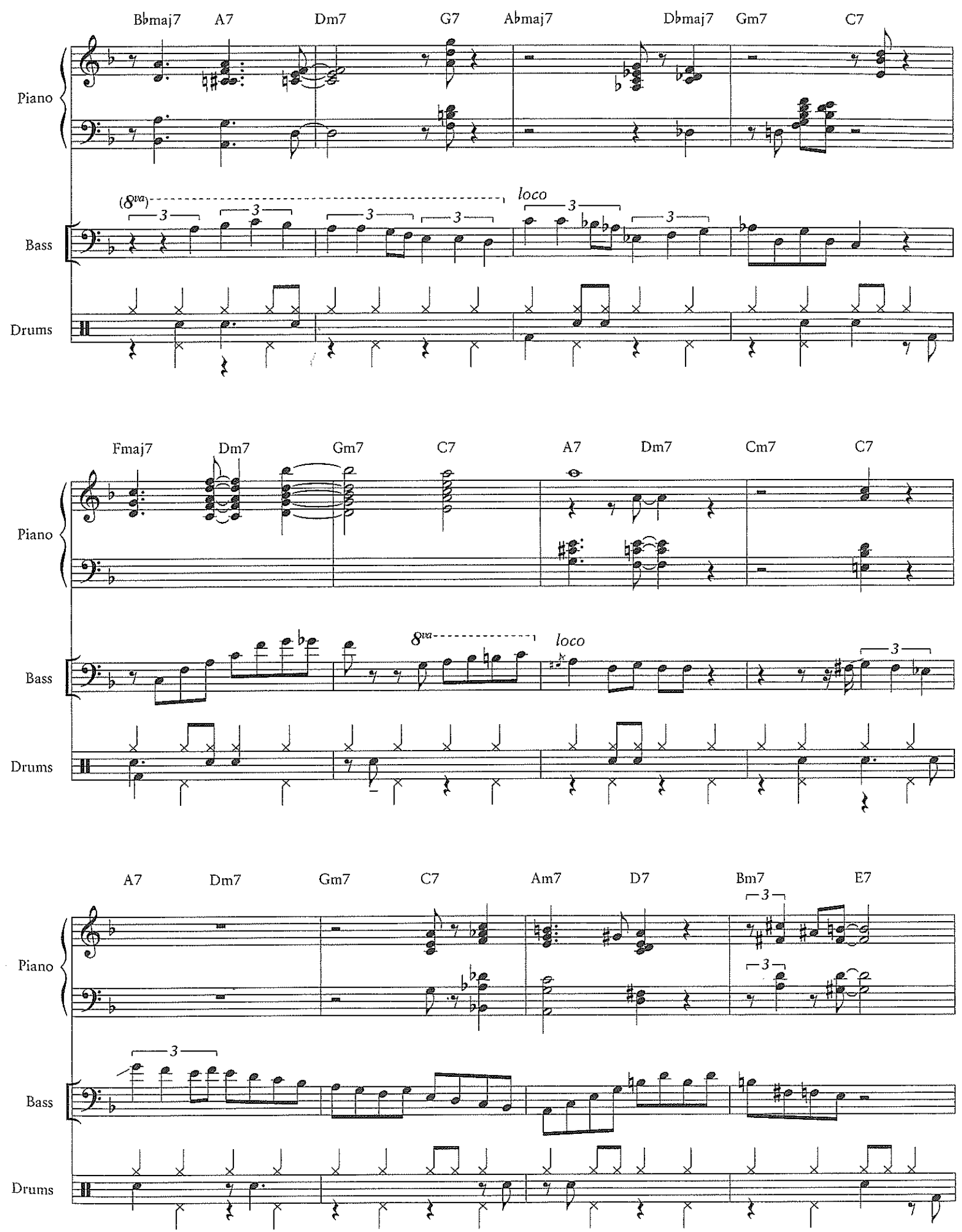

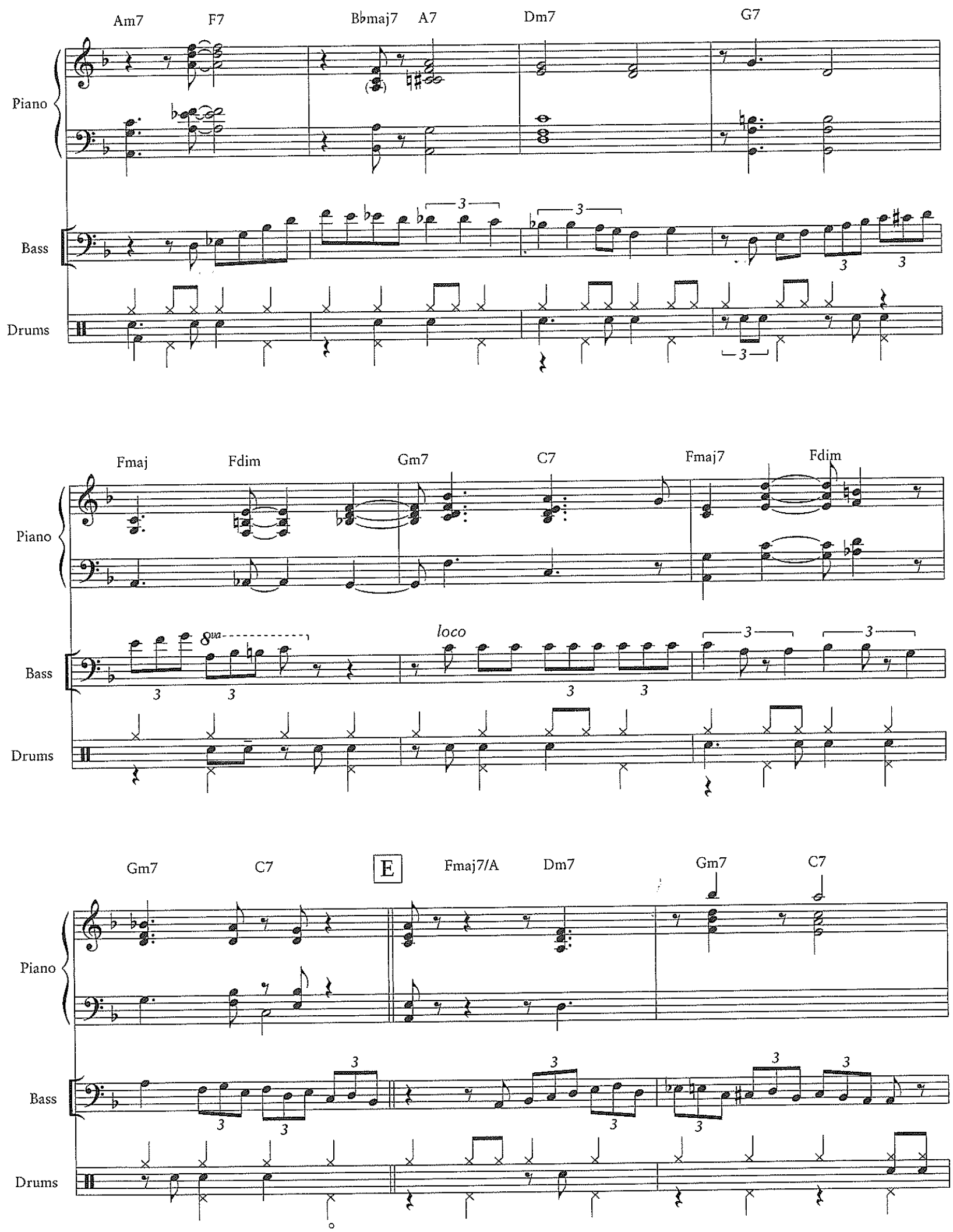

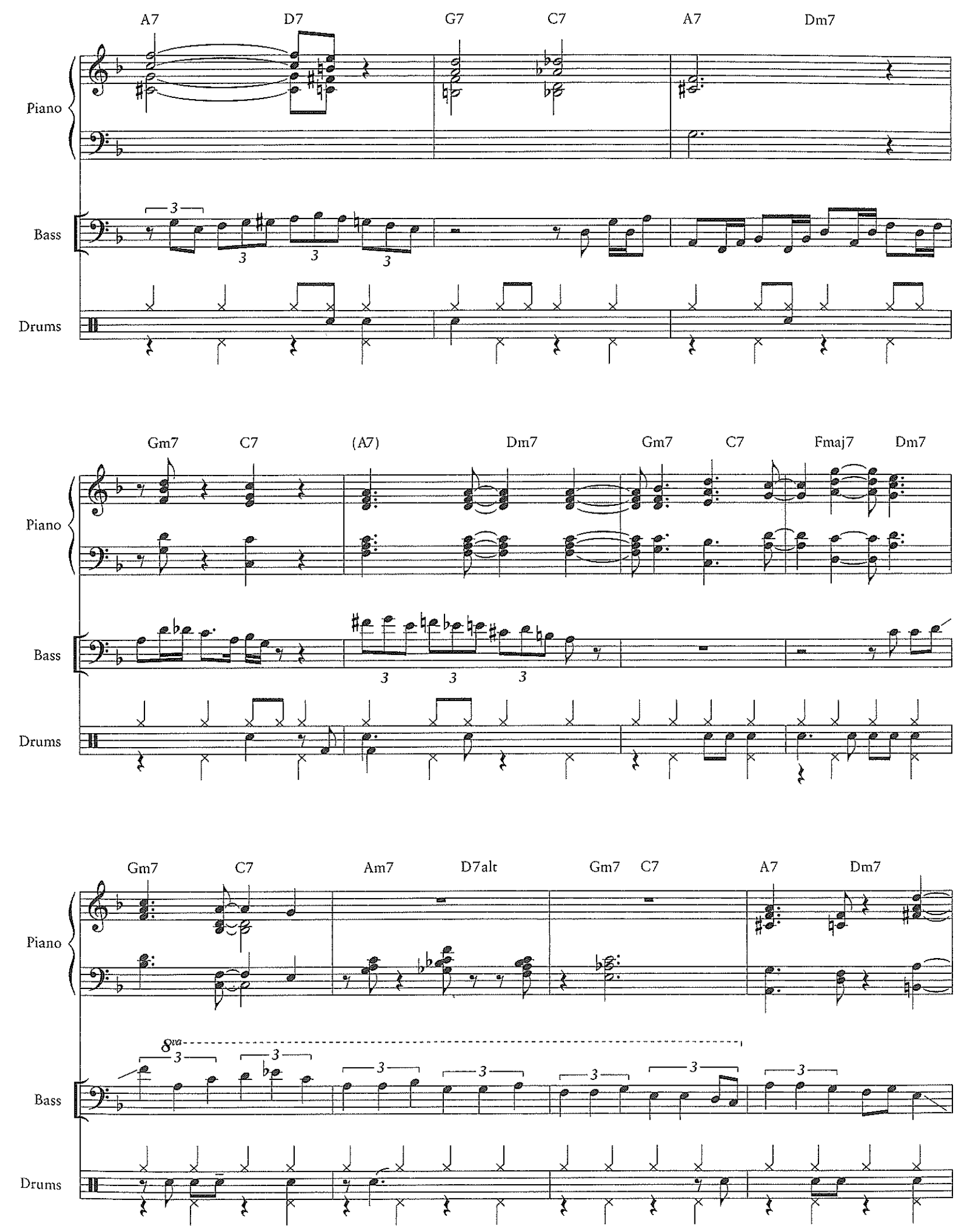

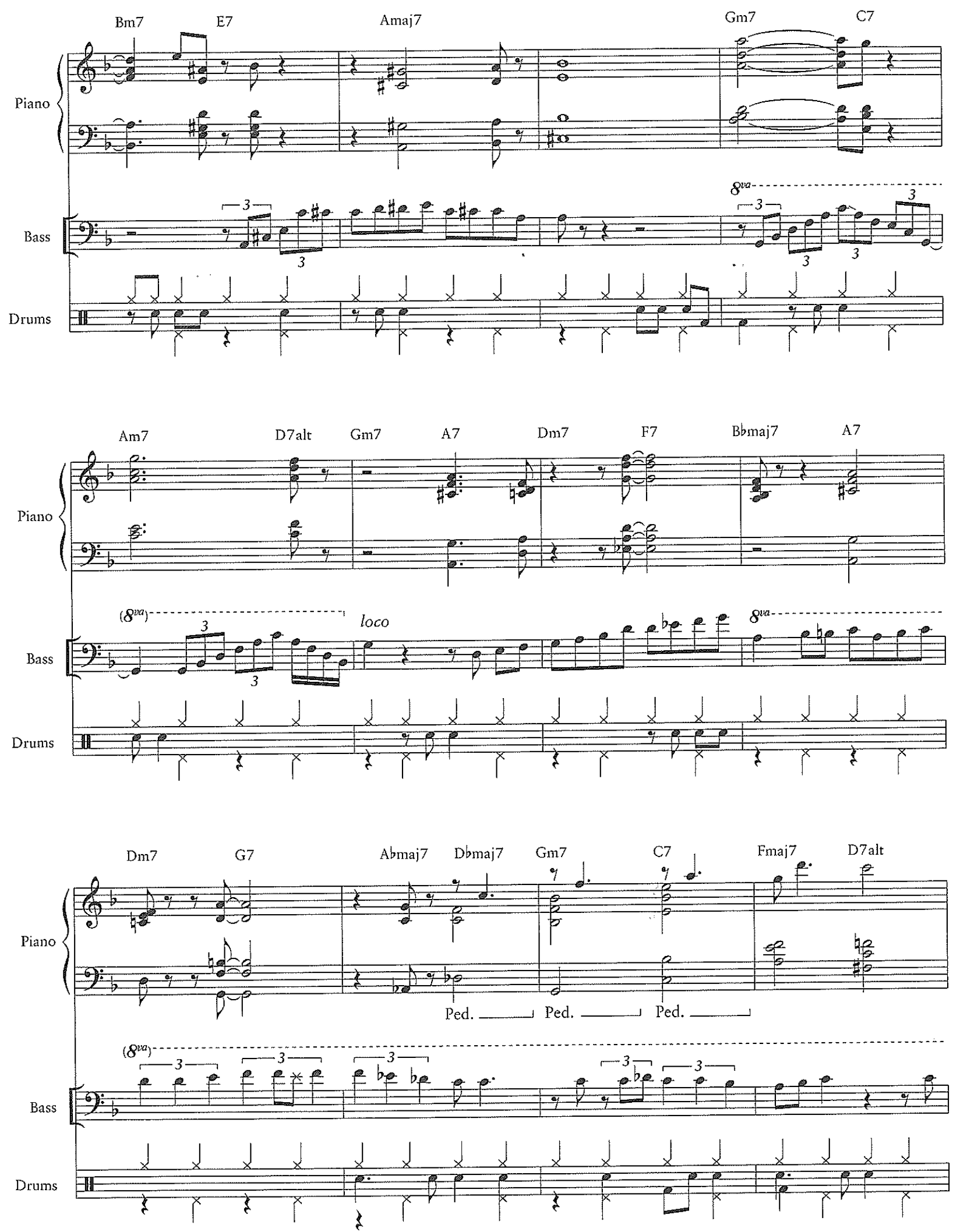

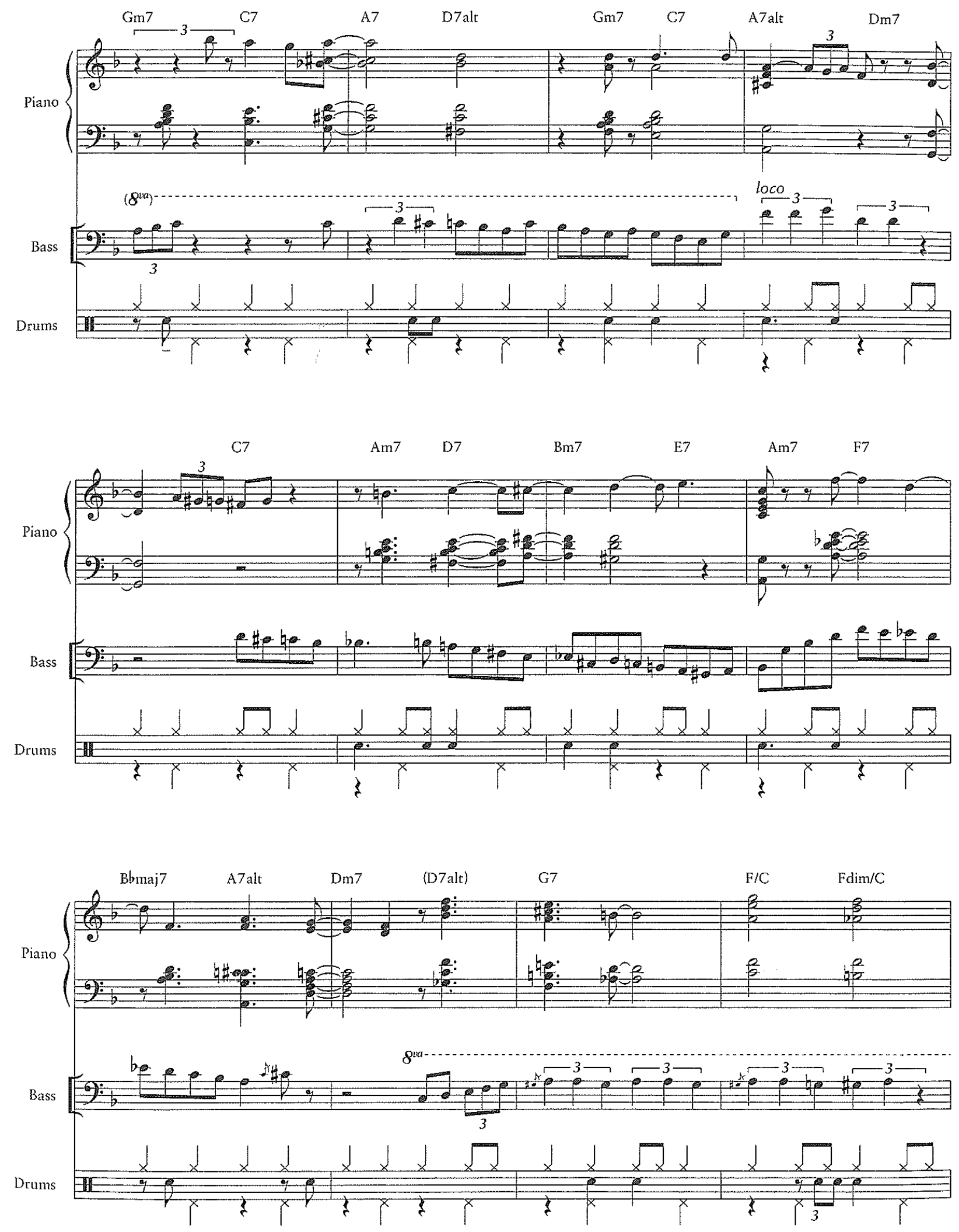

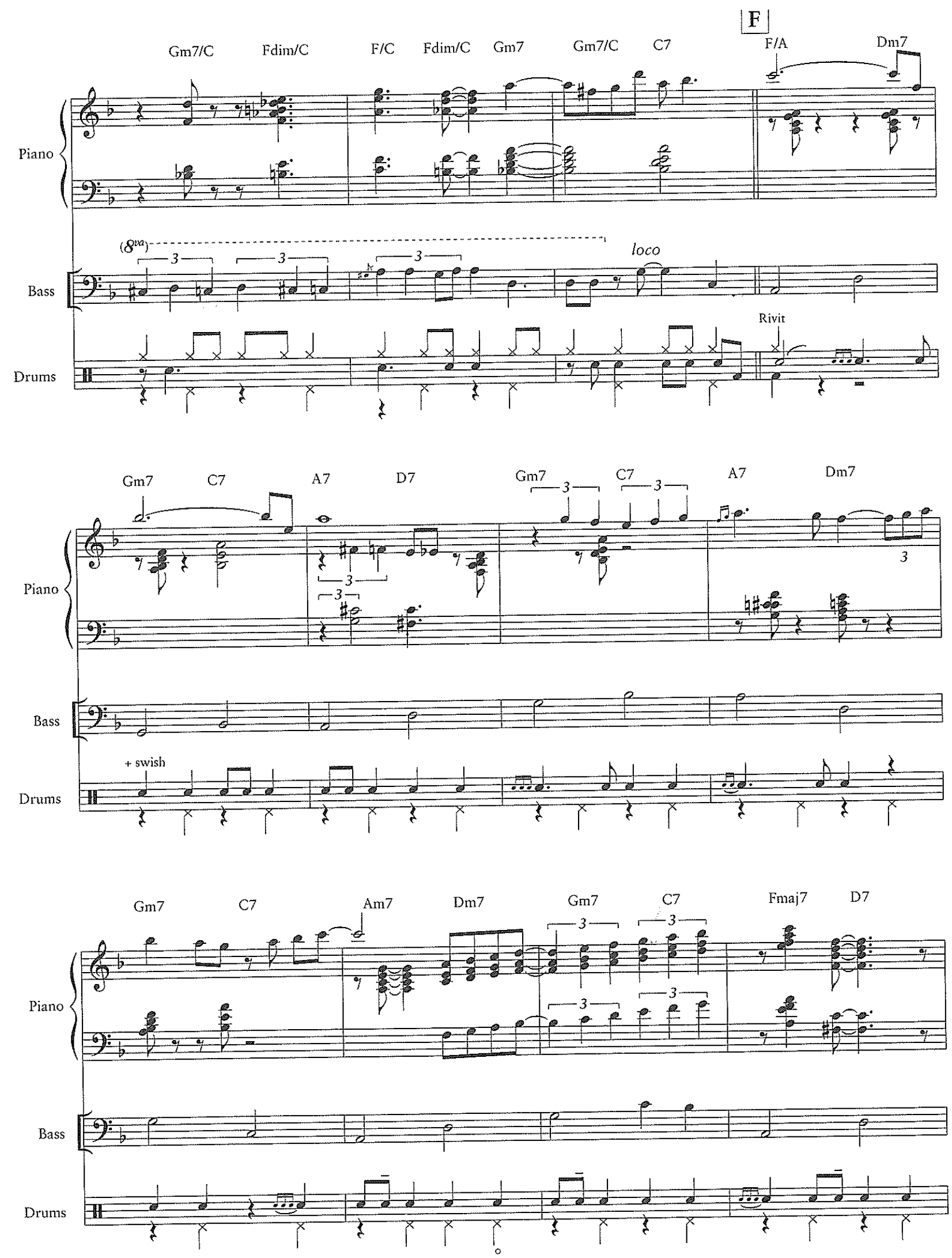


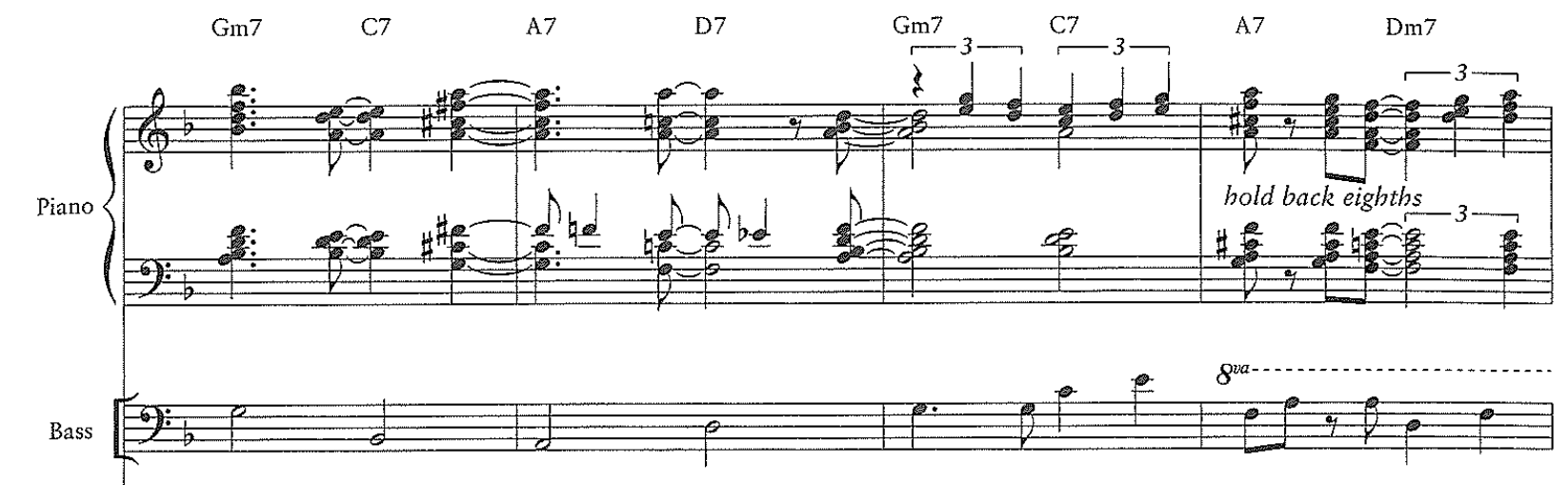

Drums
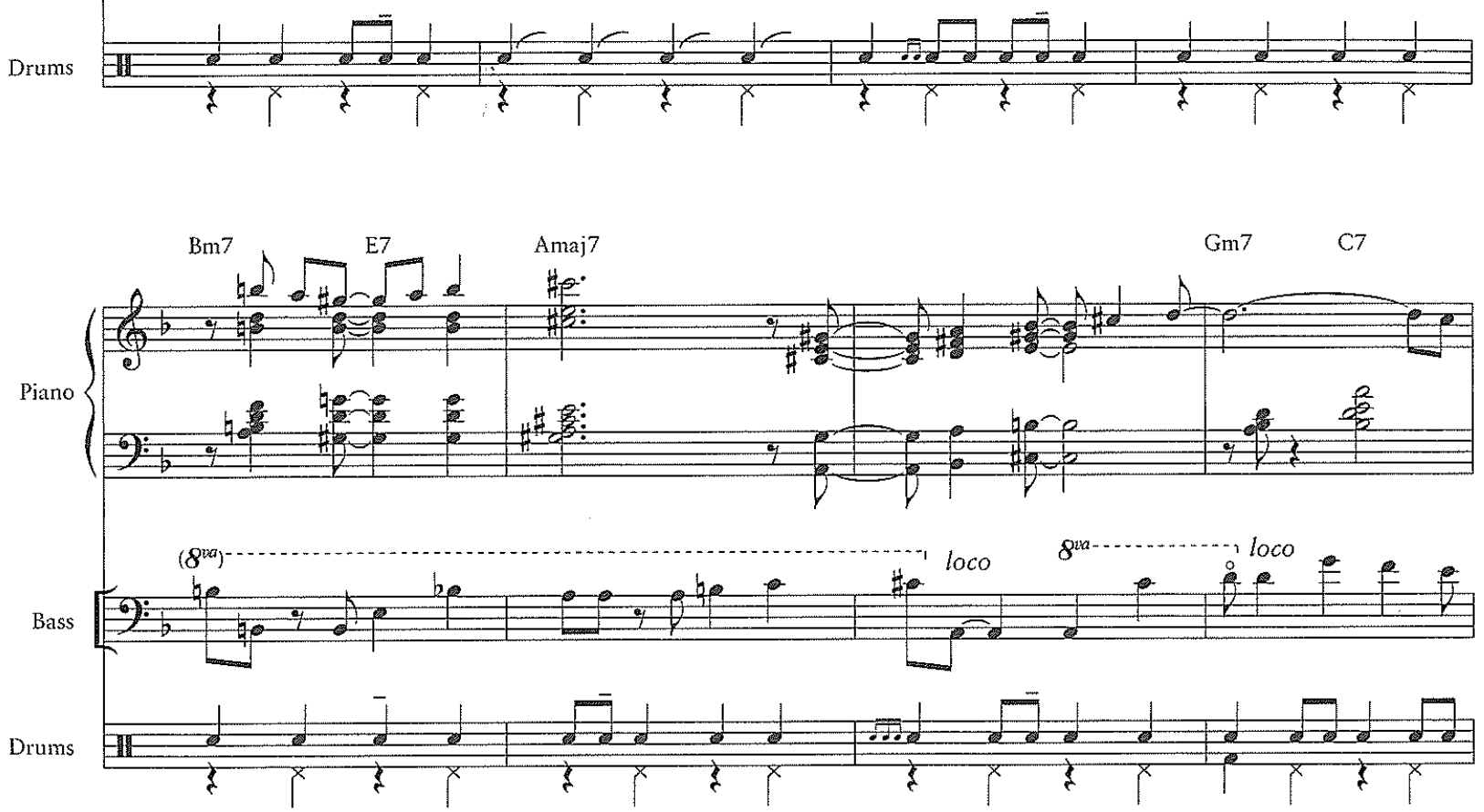

Am7

D7

Gm7

A7

Dm7 F7

pushes forward

Bbmaj7

A7alt

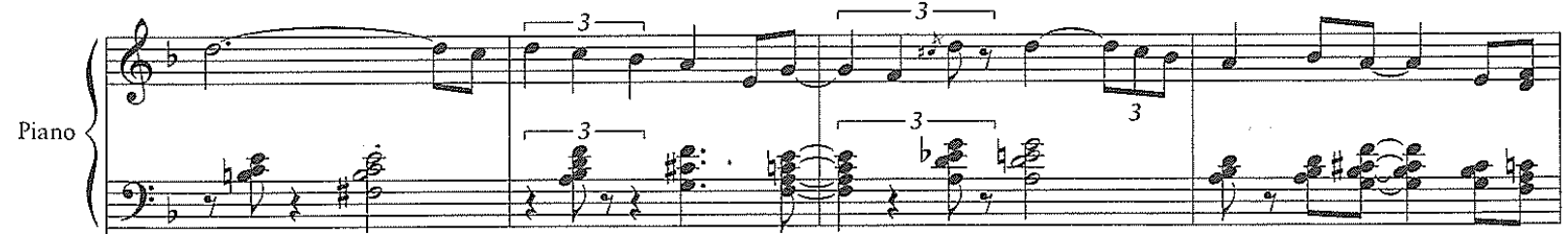

Bass

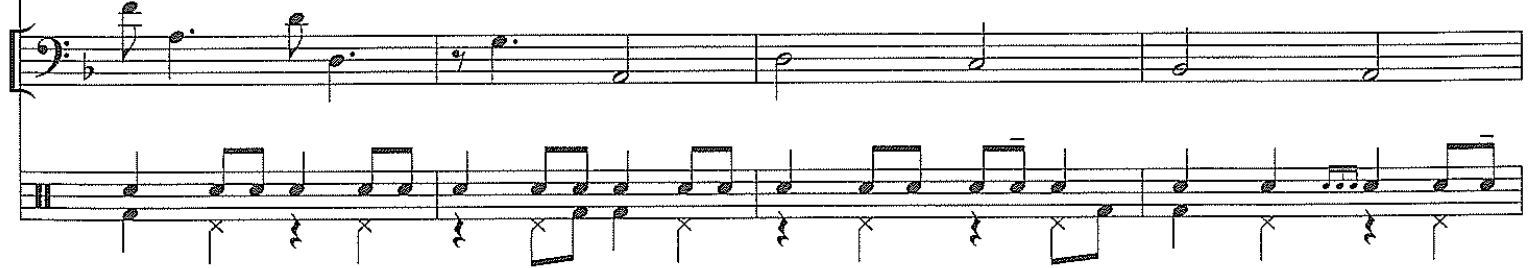



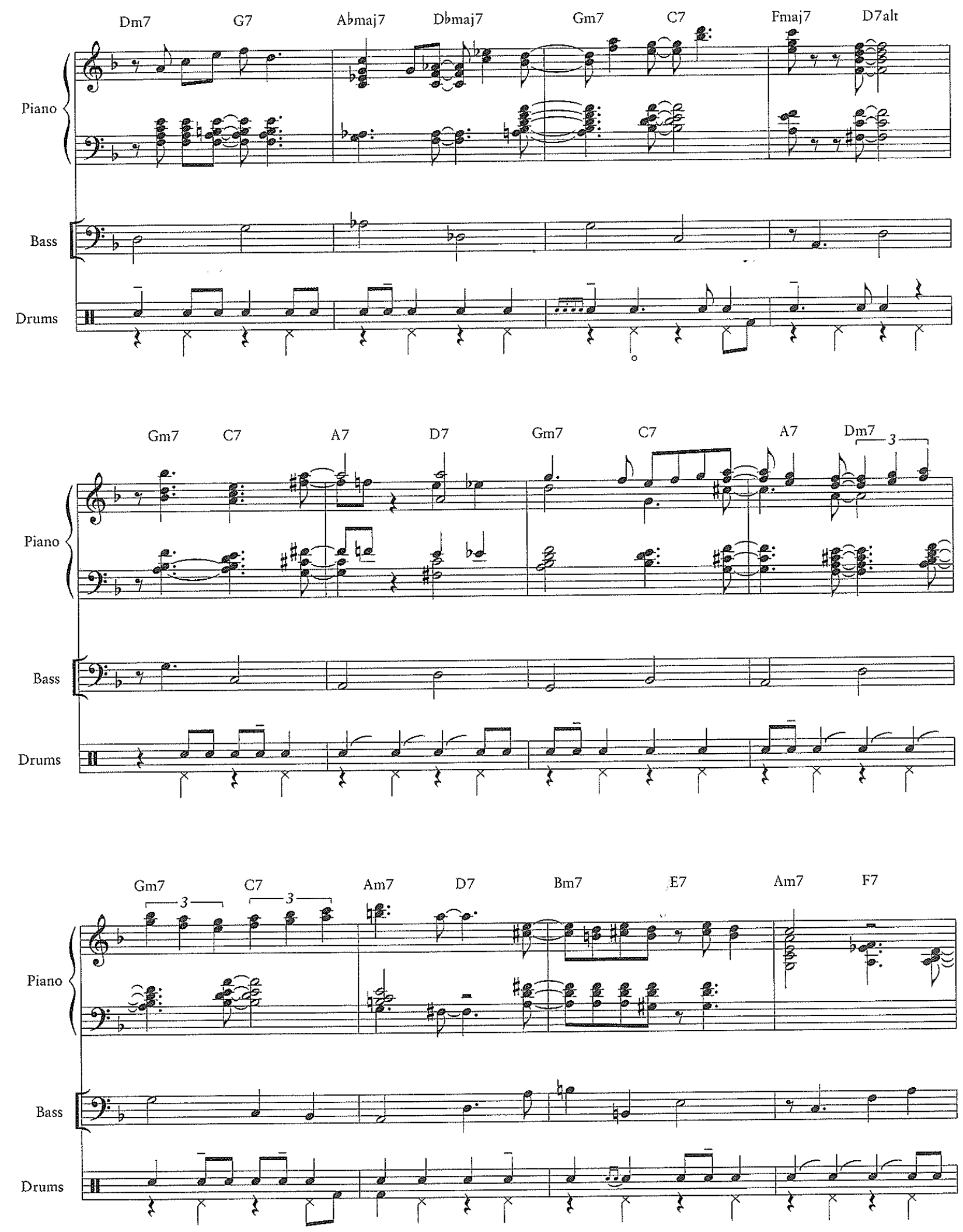

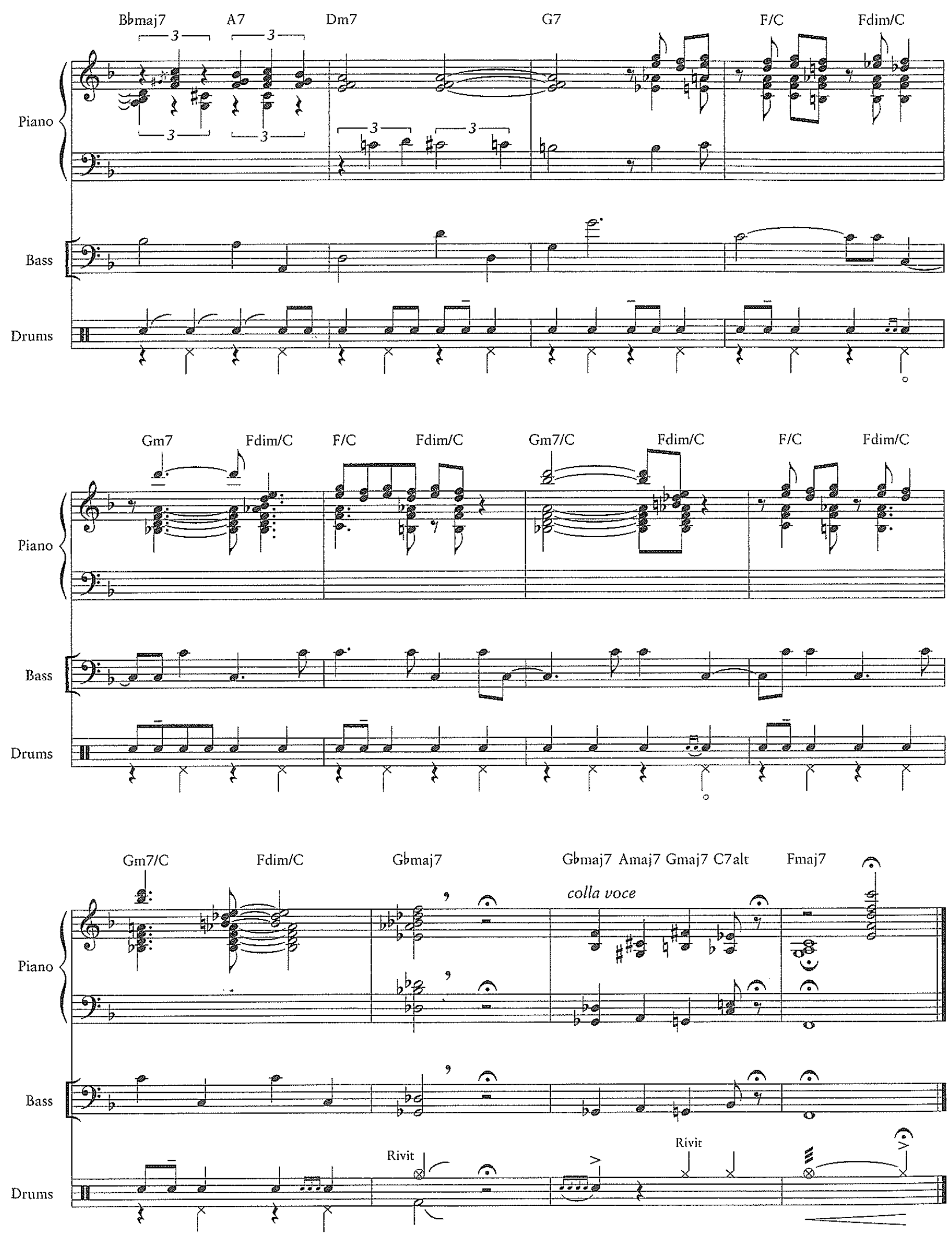
4: Nardis - Transcription taken from Leonard, Hal. The Bill Evans Trio Volume 1. 2003. 


\title{
Nardis
}

\author{
By Miles Davis
}
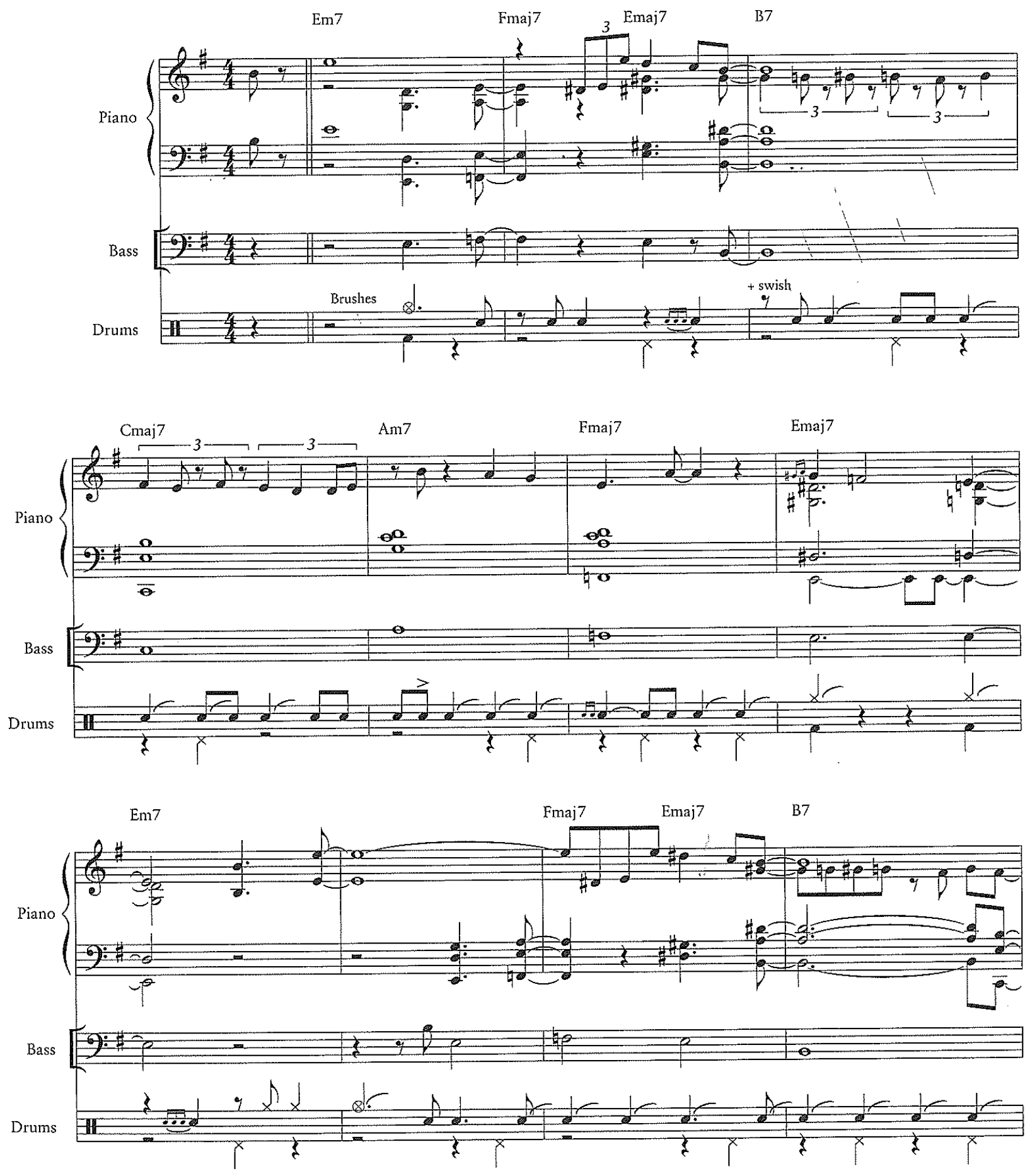

Copyright $(1959$ Jazz Horn Music 

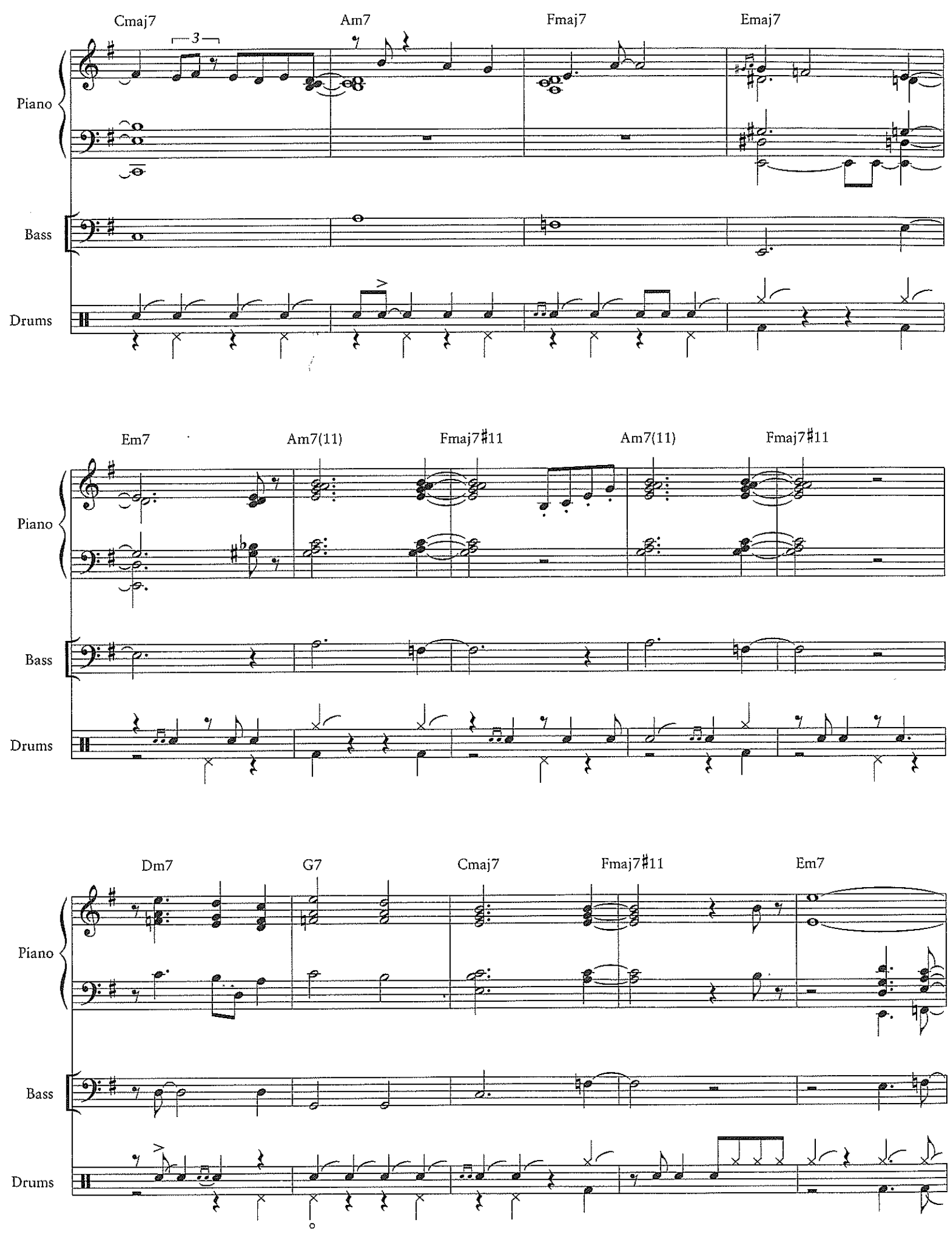

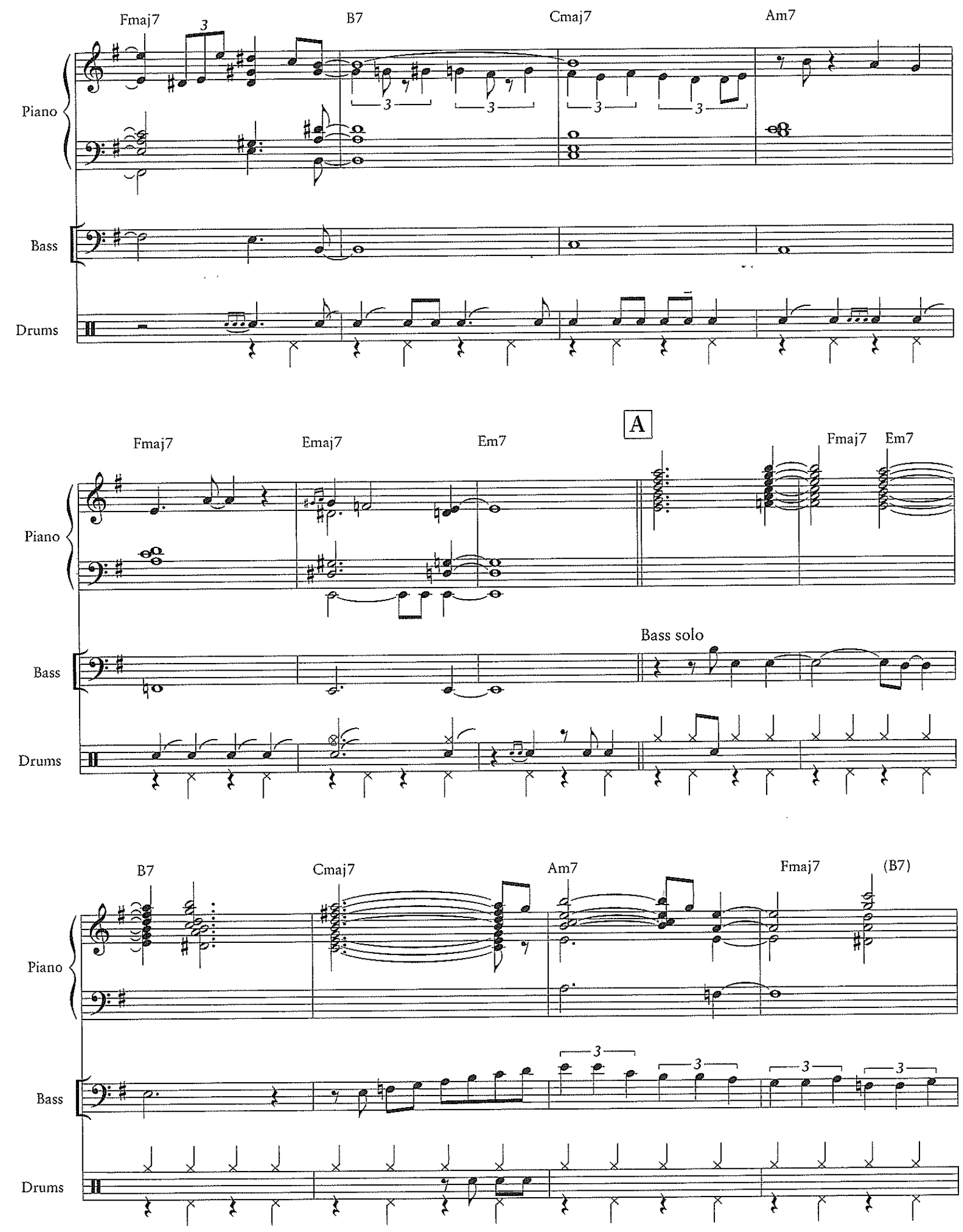

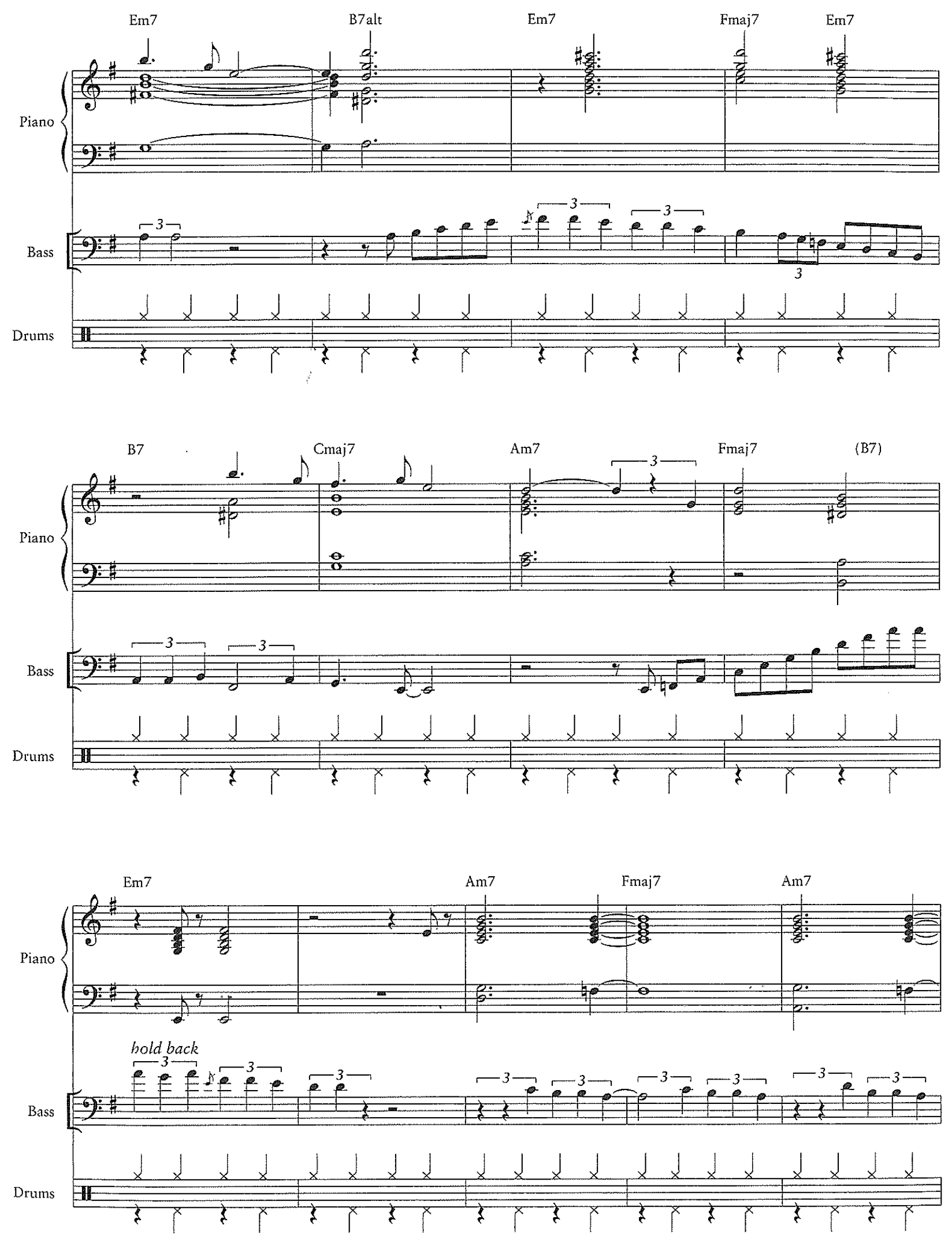

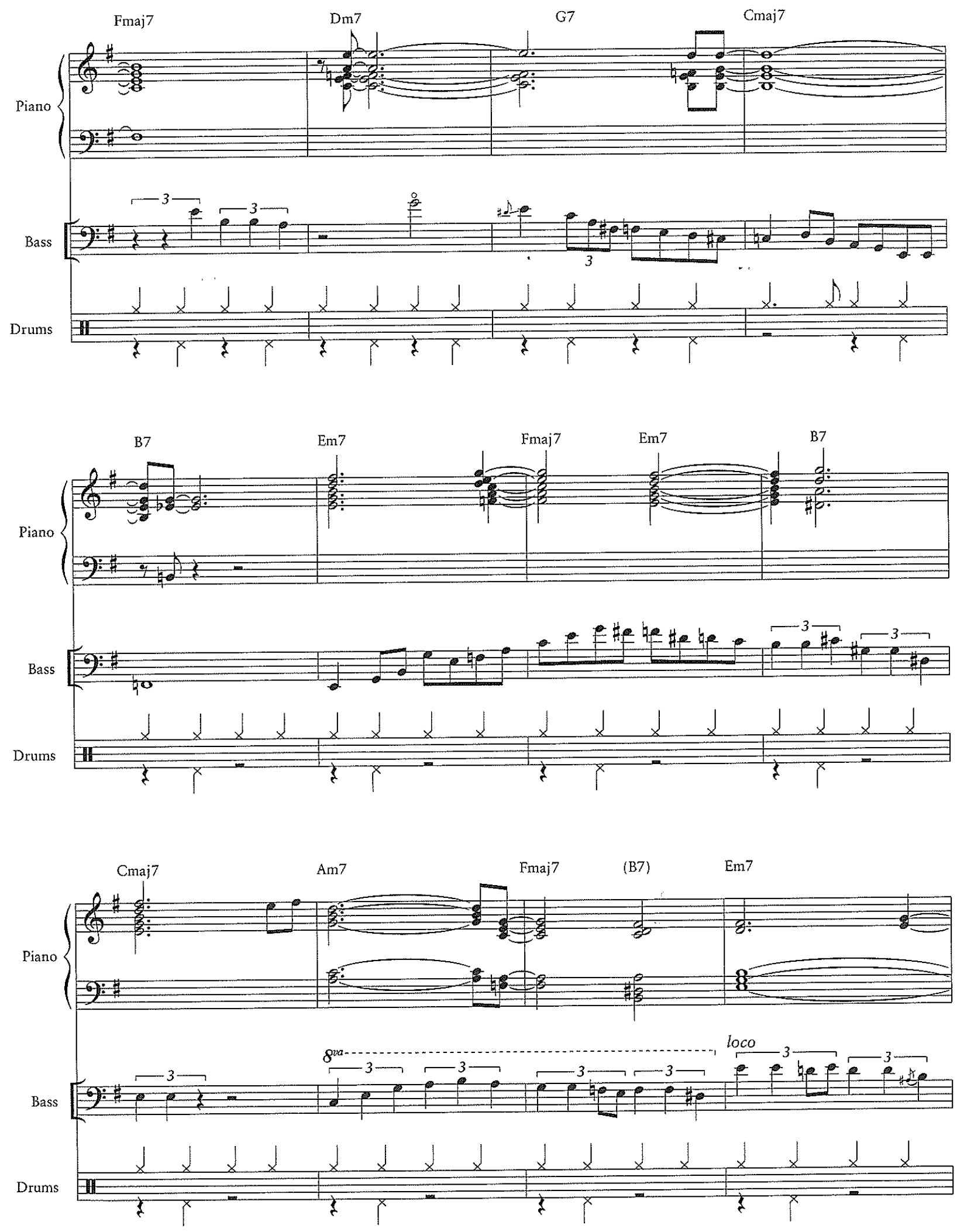
B
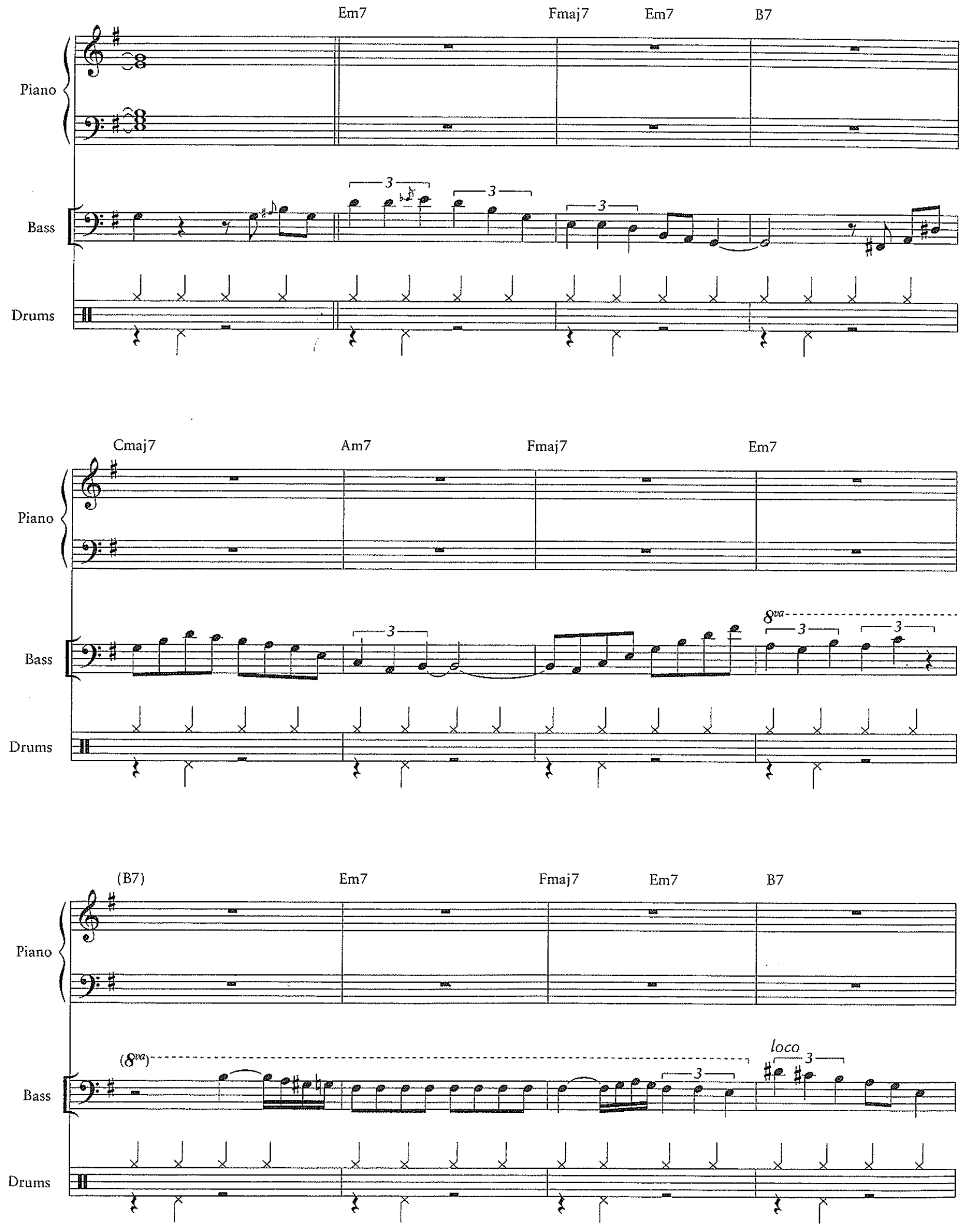

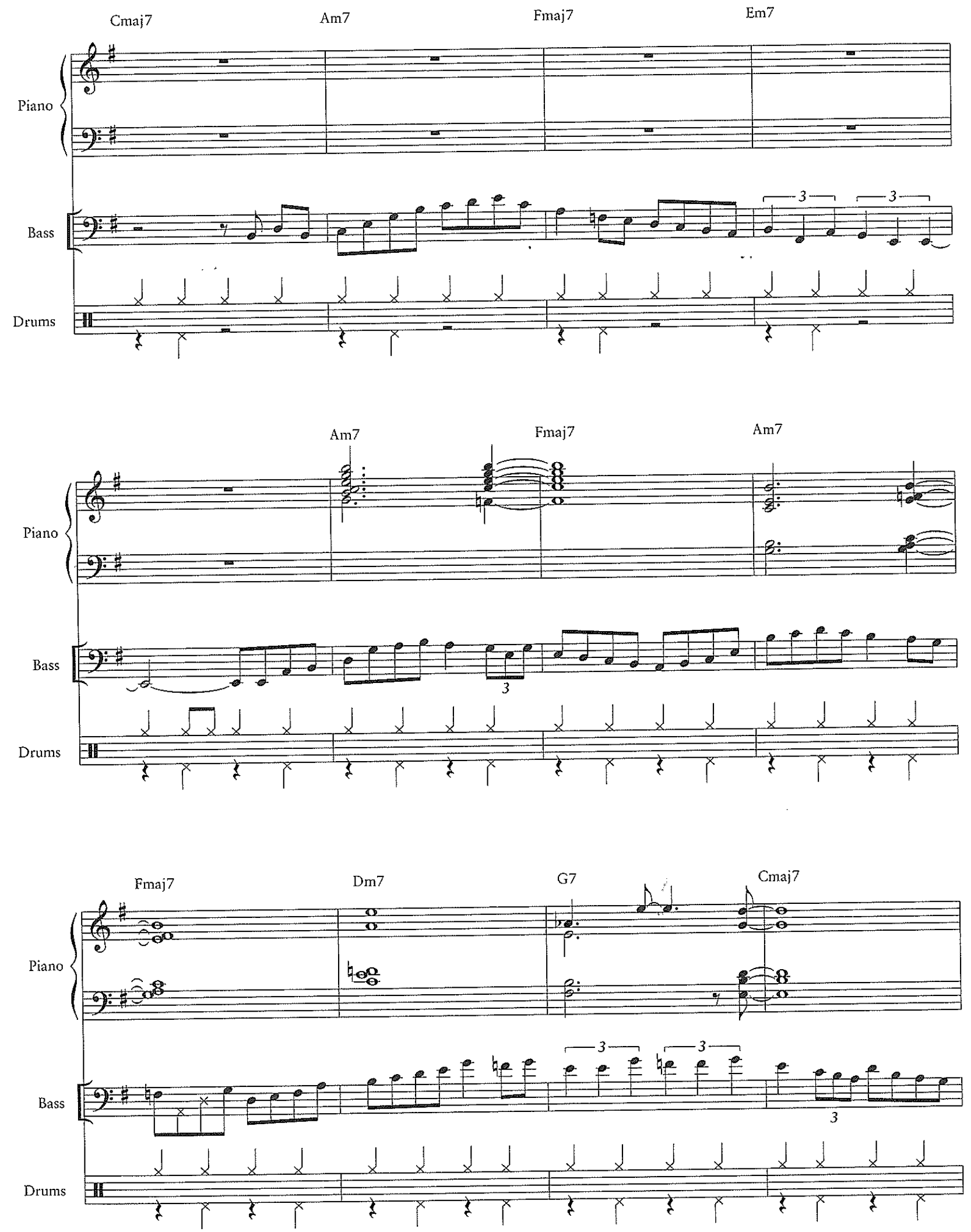

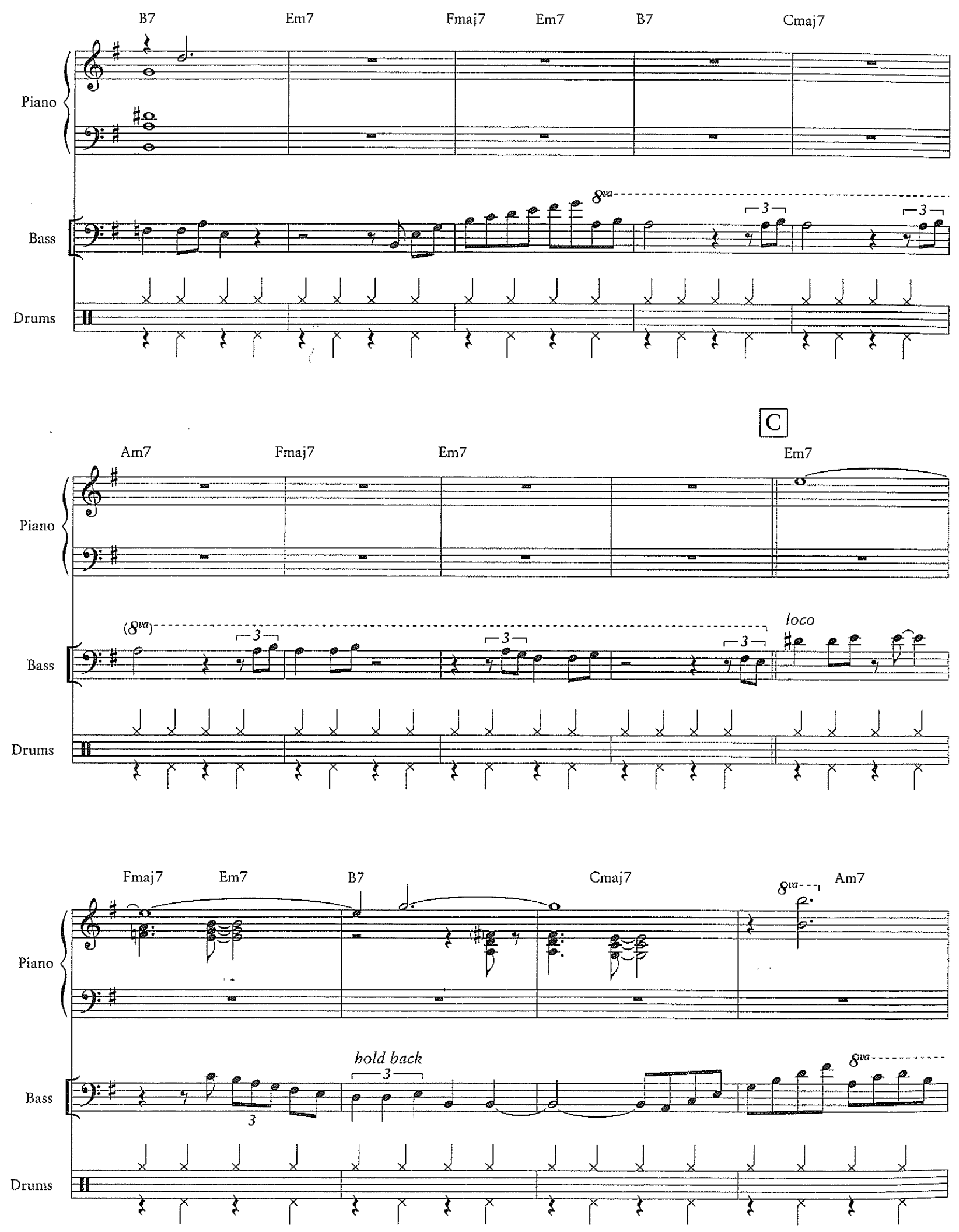

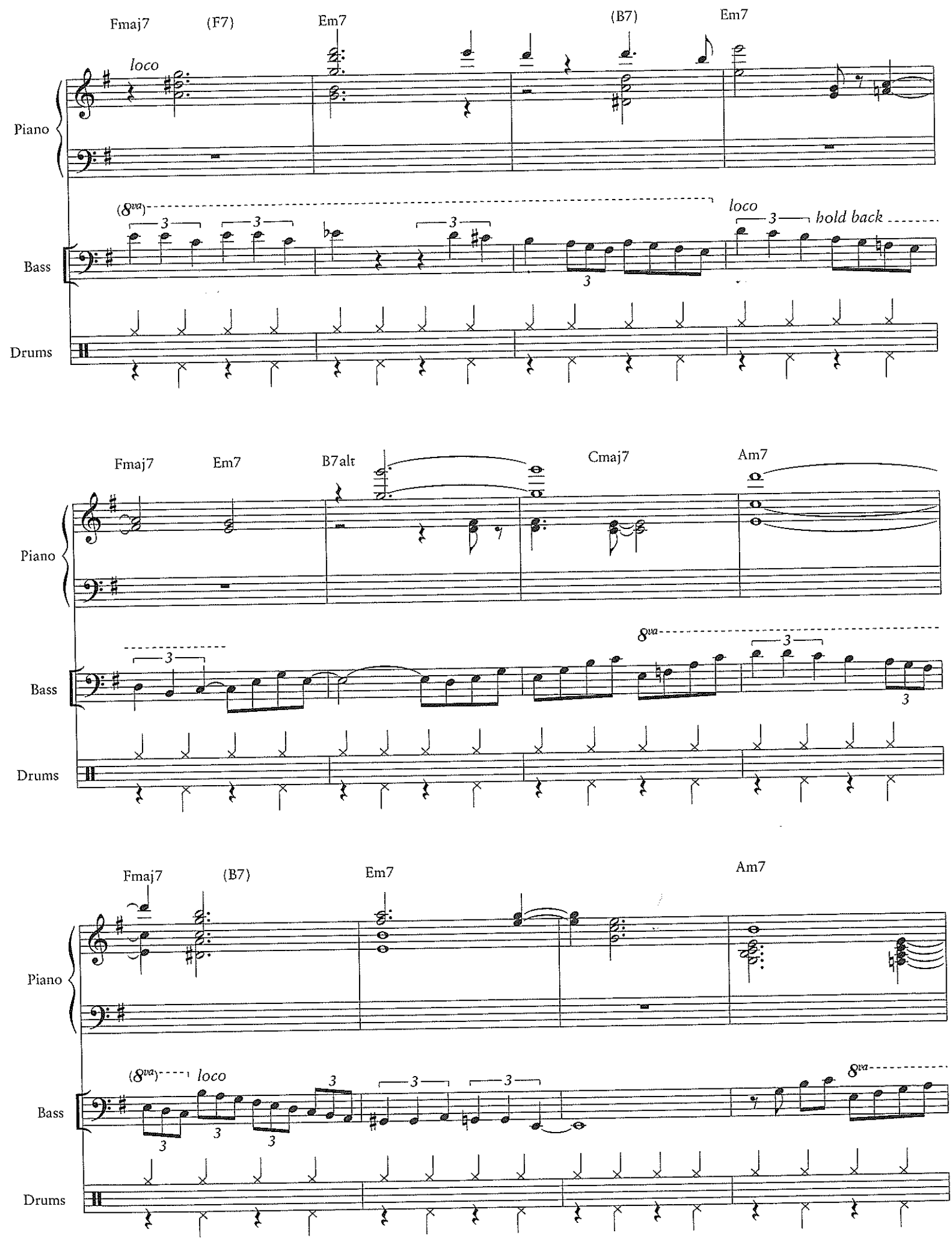

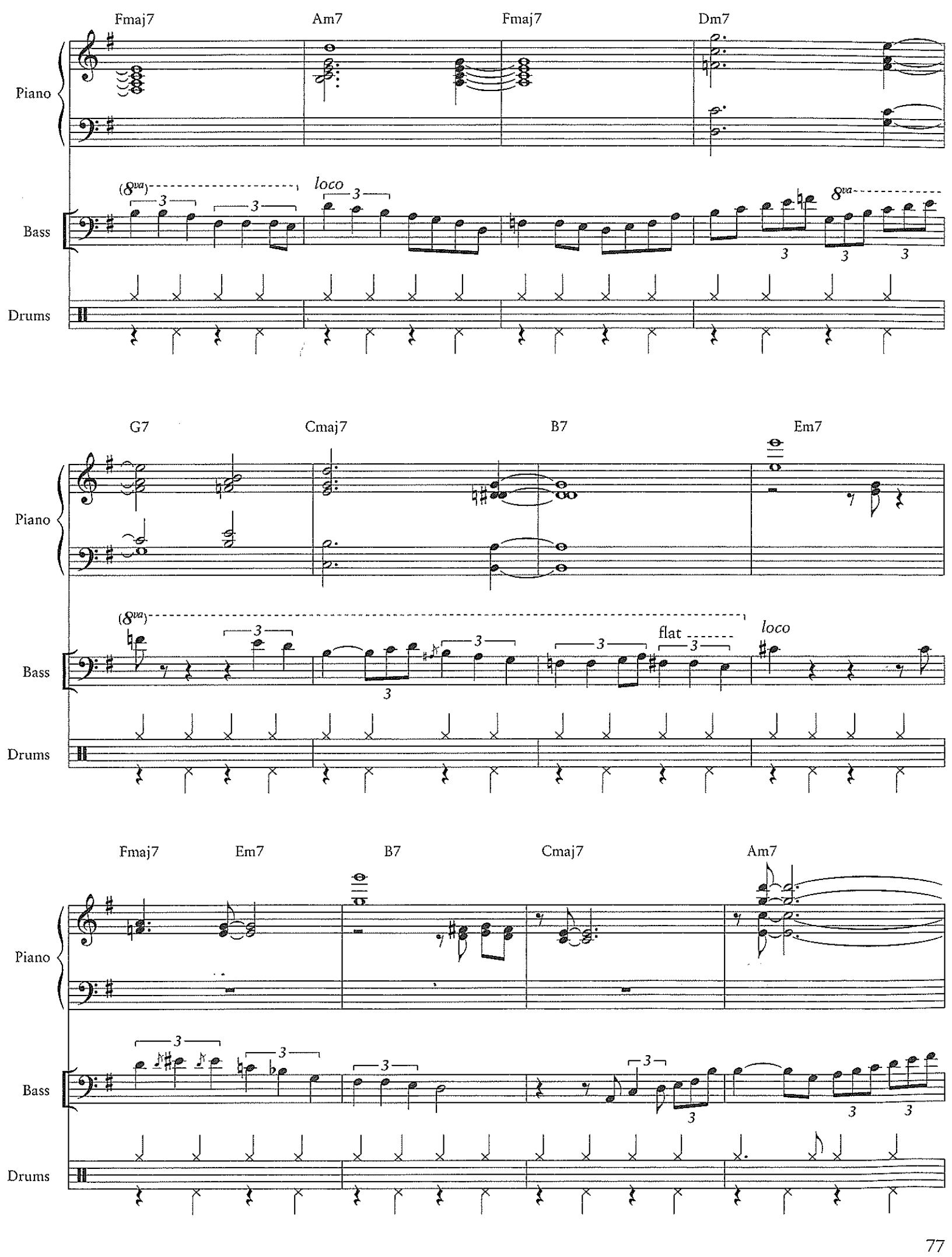

183 

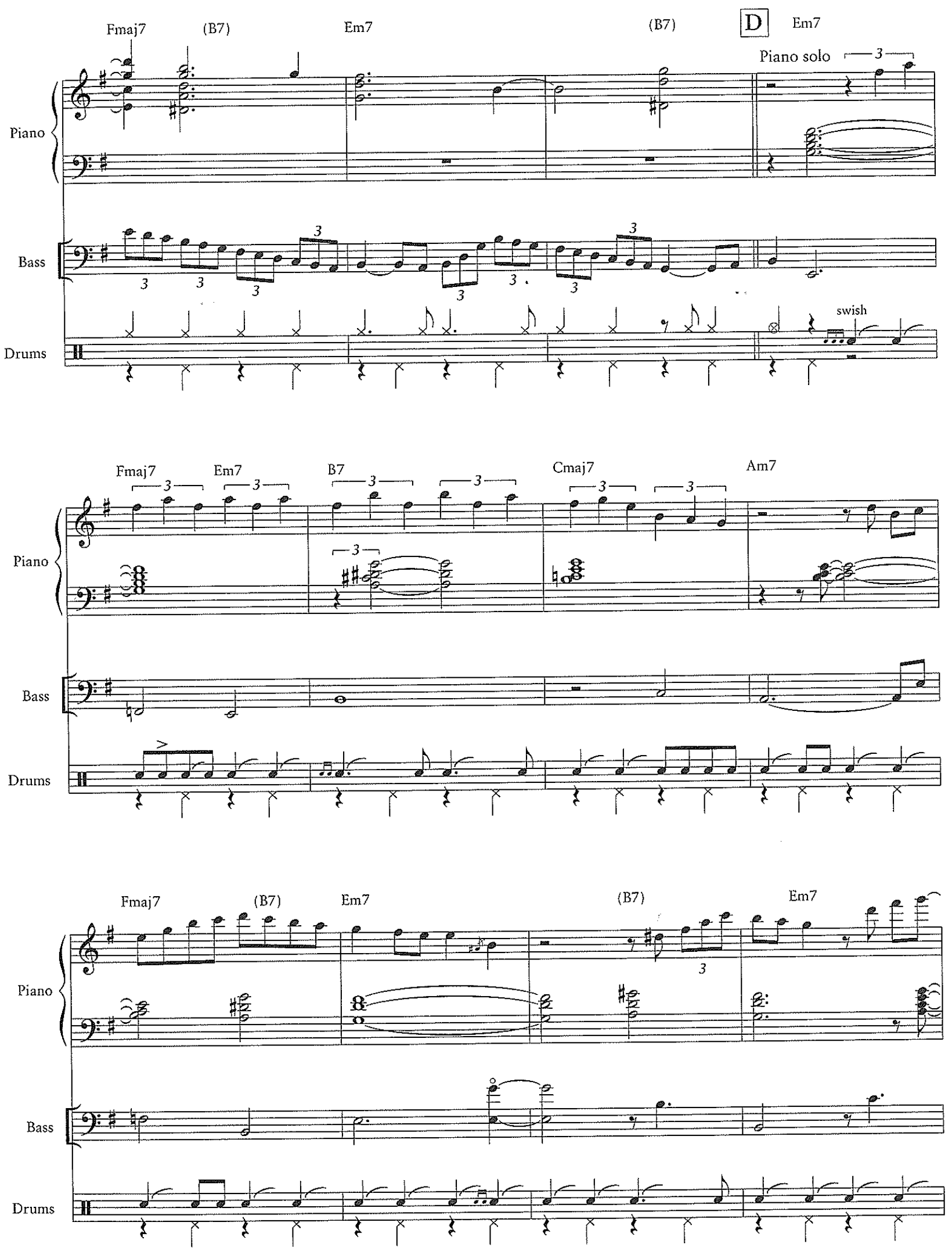

78

184 

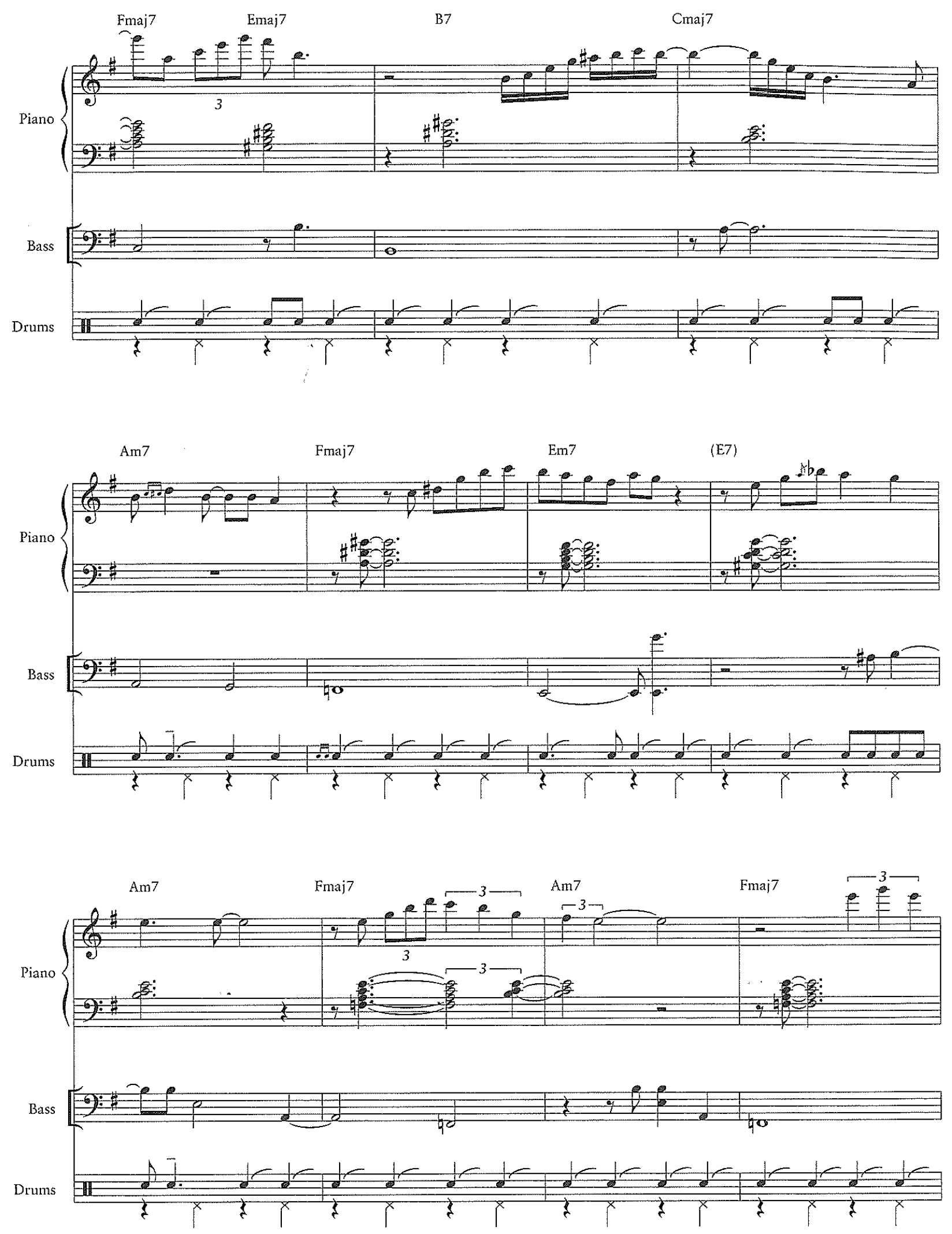

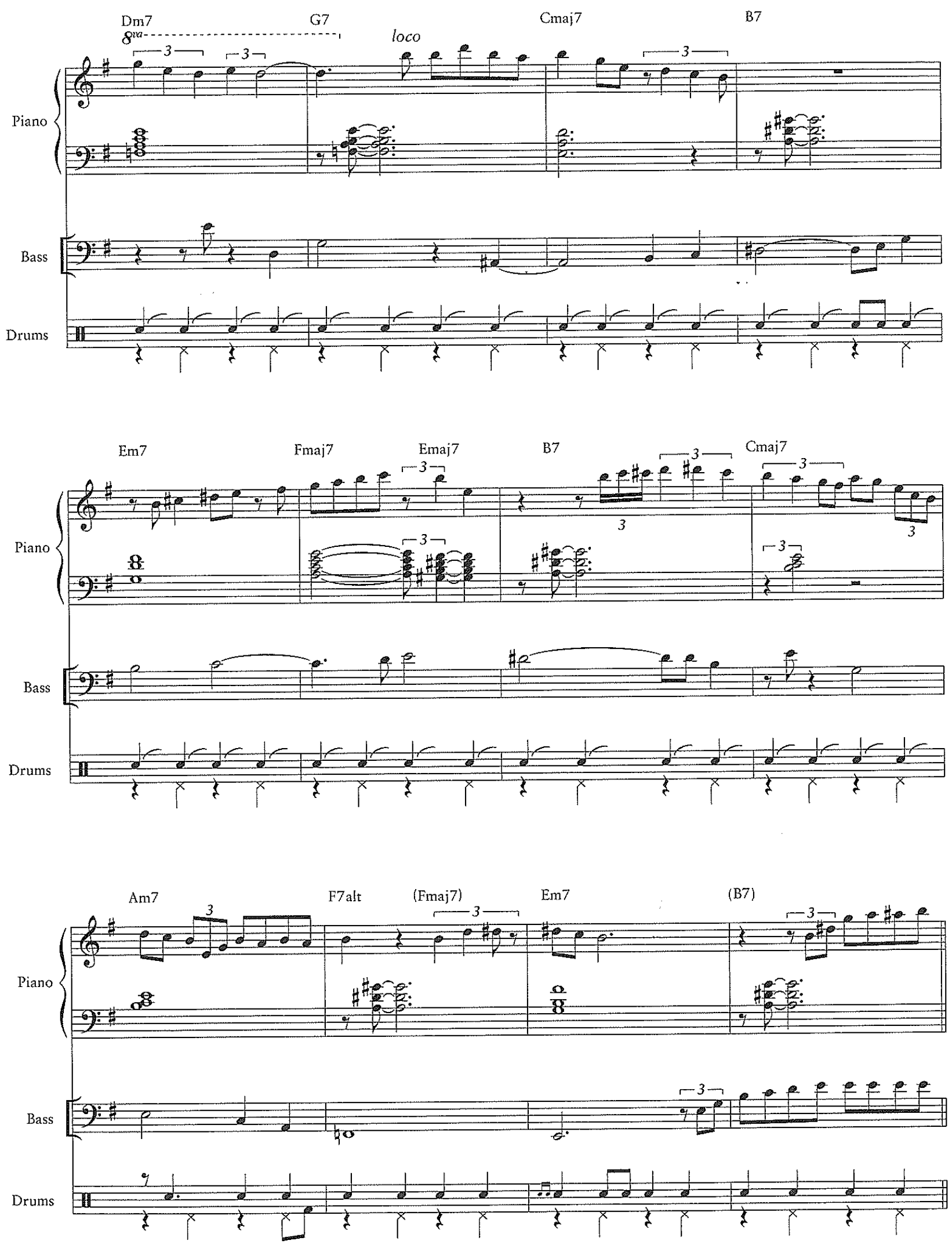

80

186 

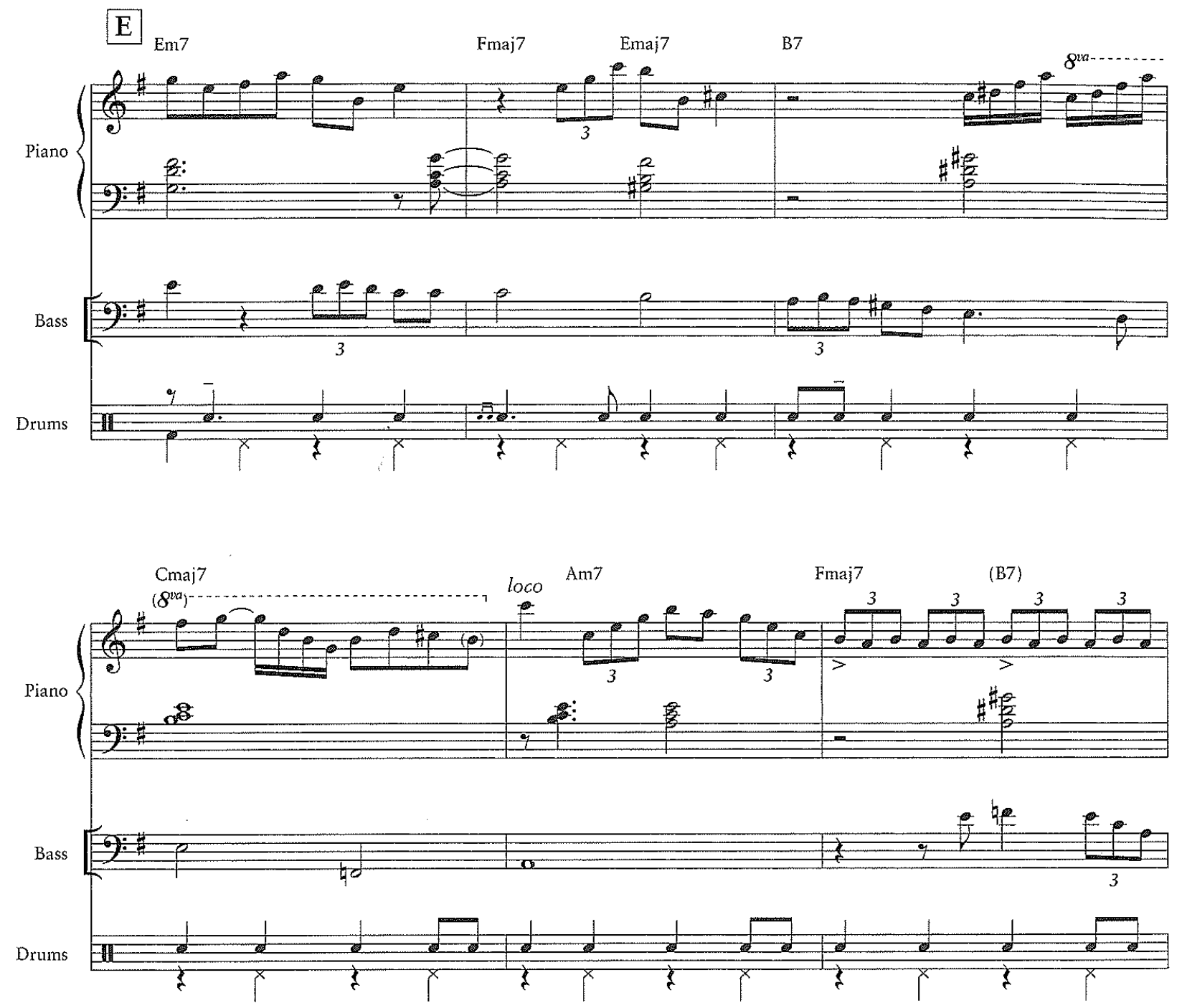

Em

(B7)

Em7

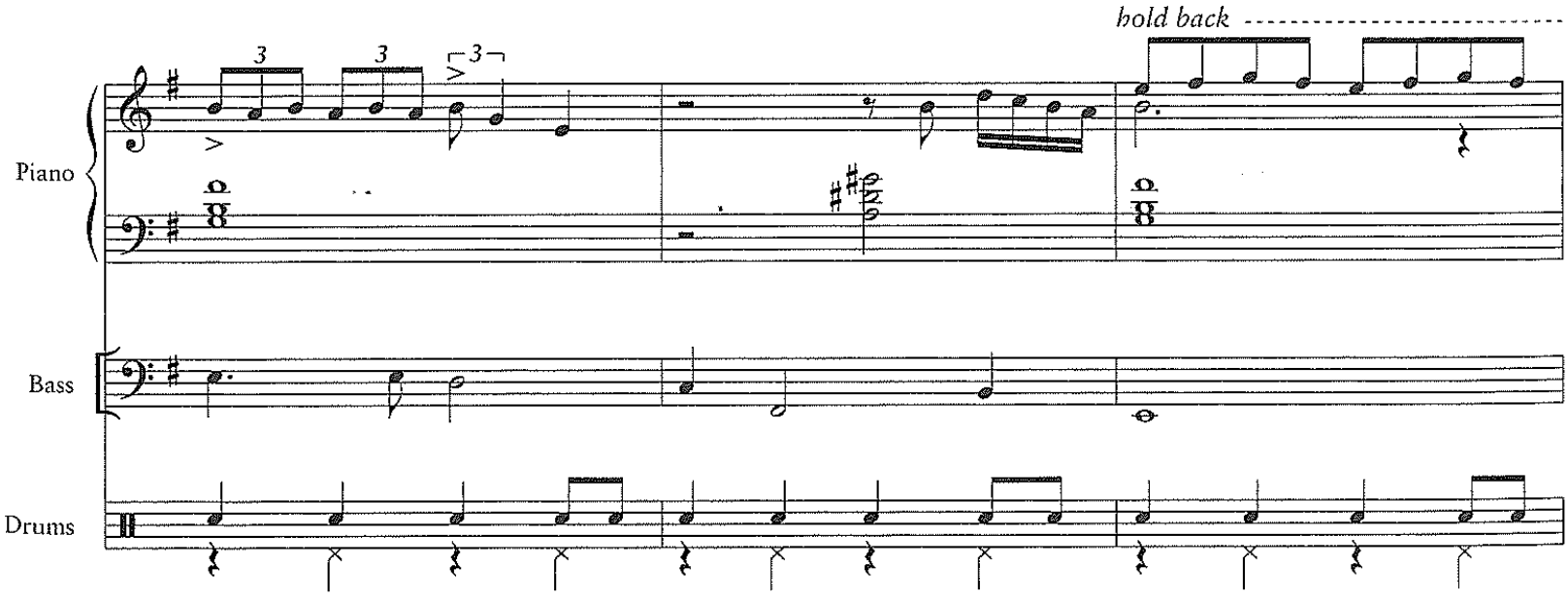



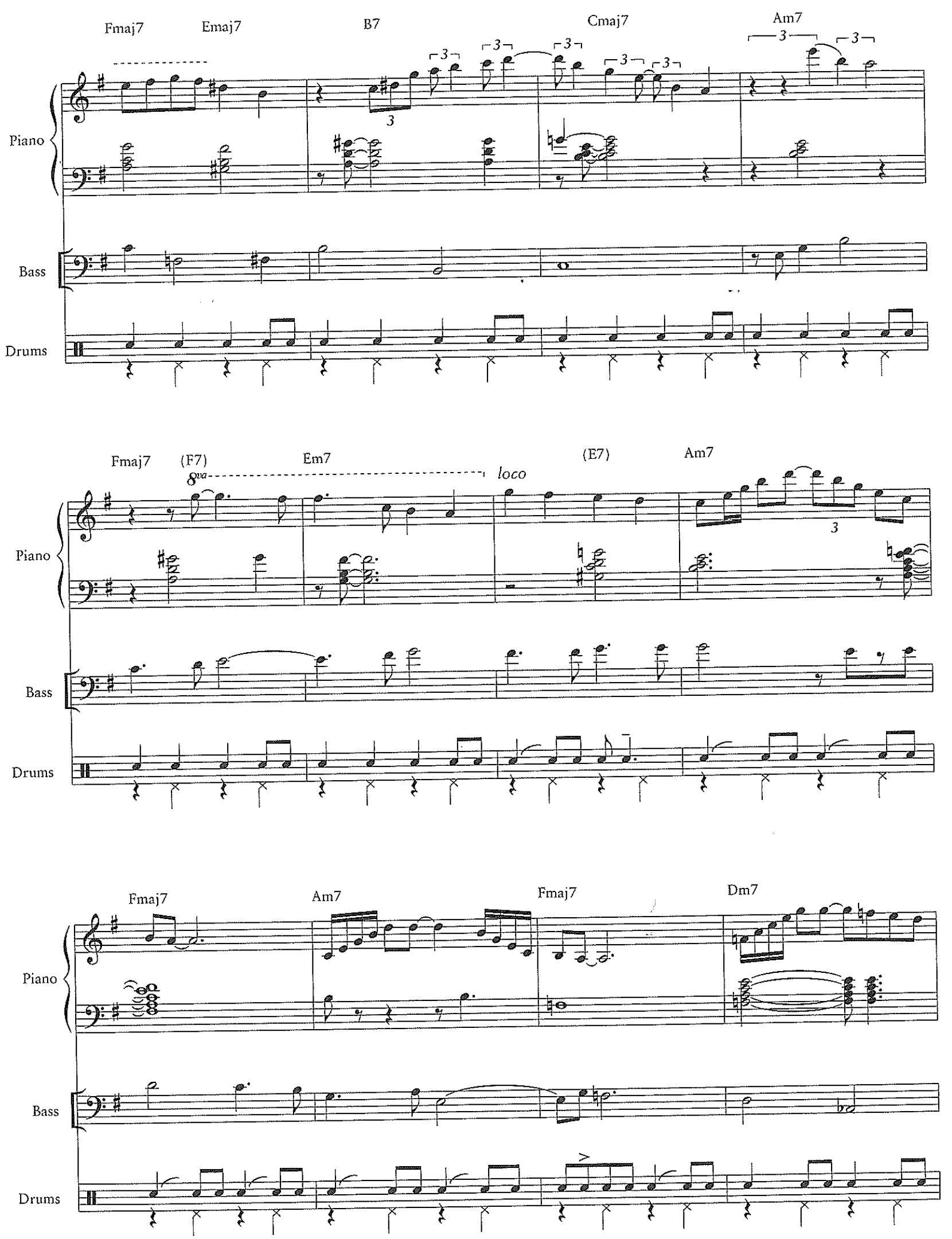

82

188 

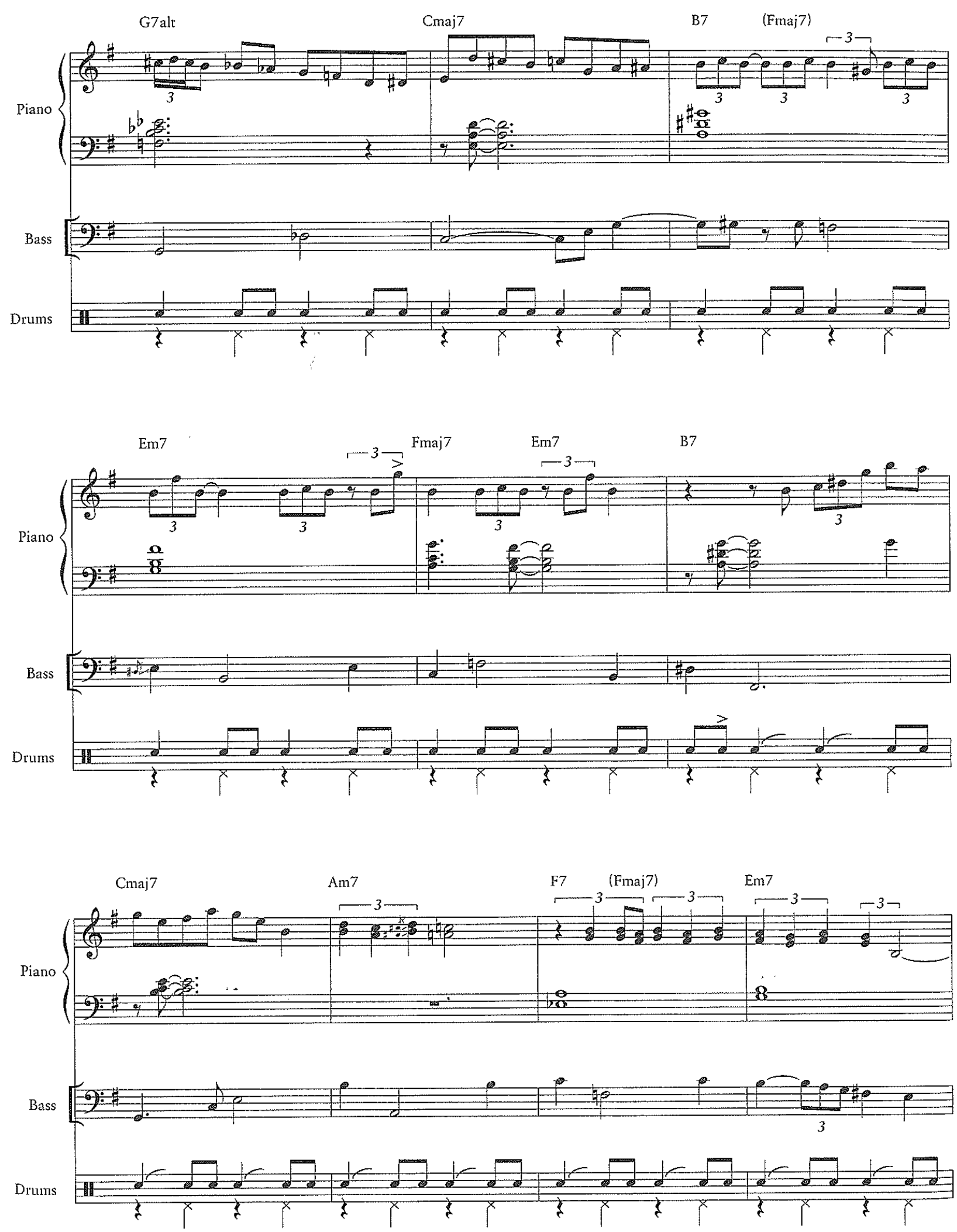
F
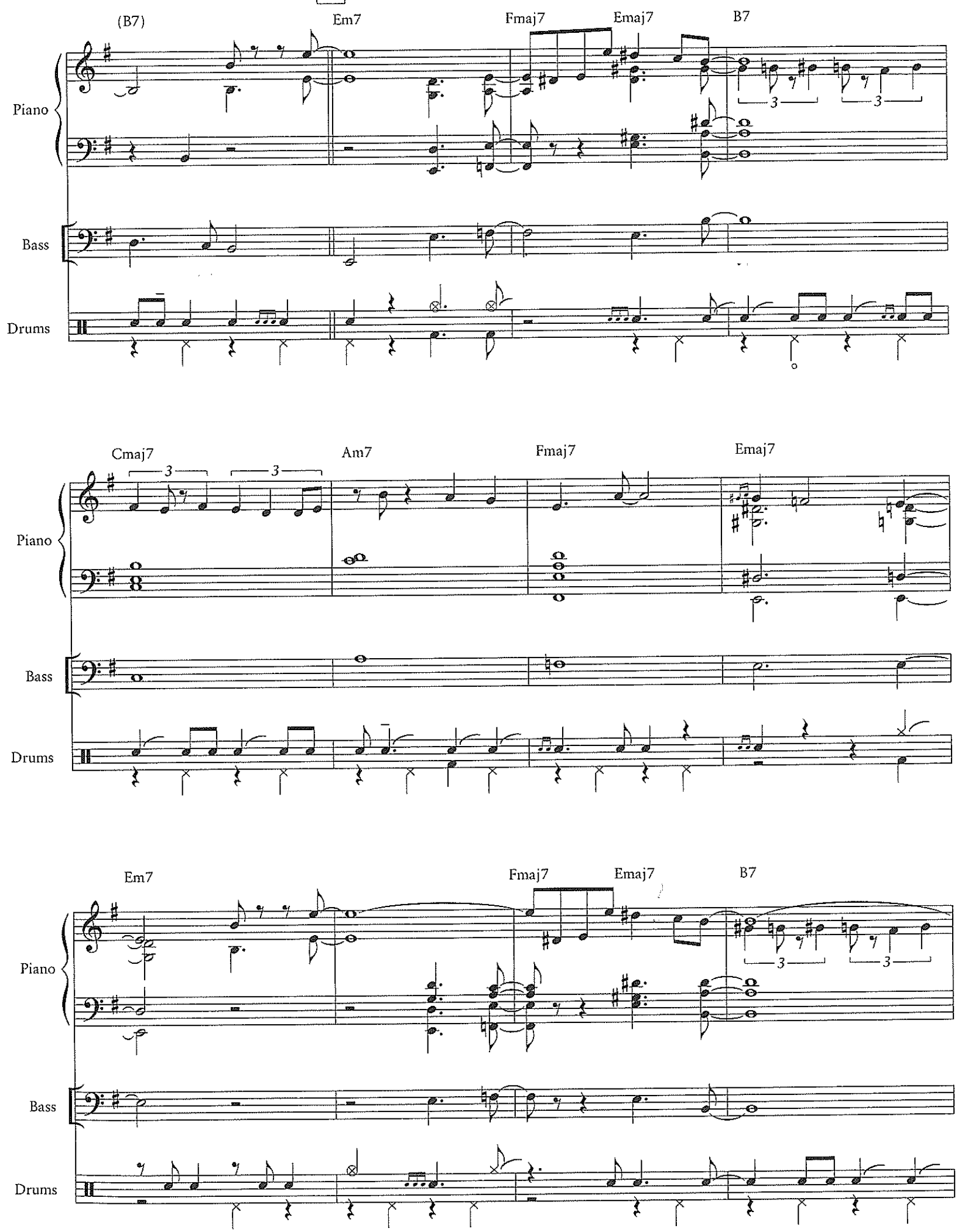

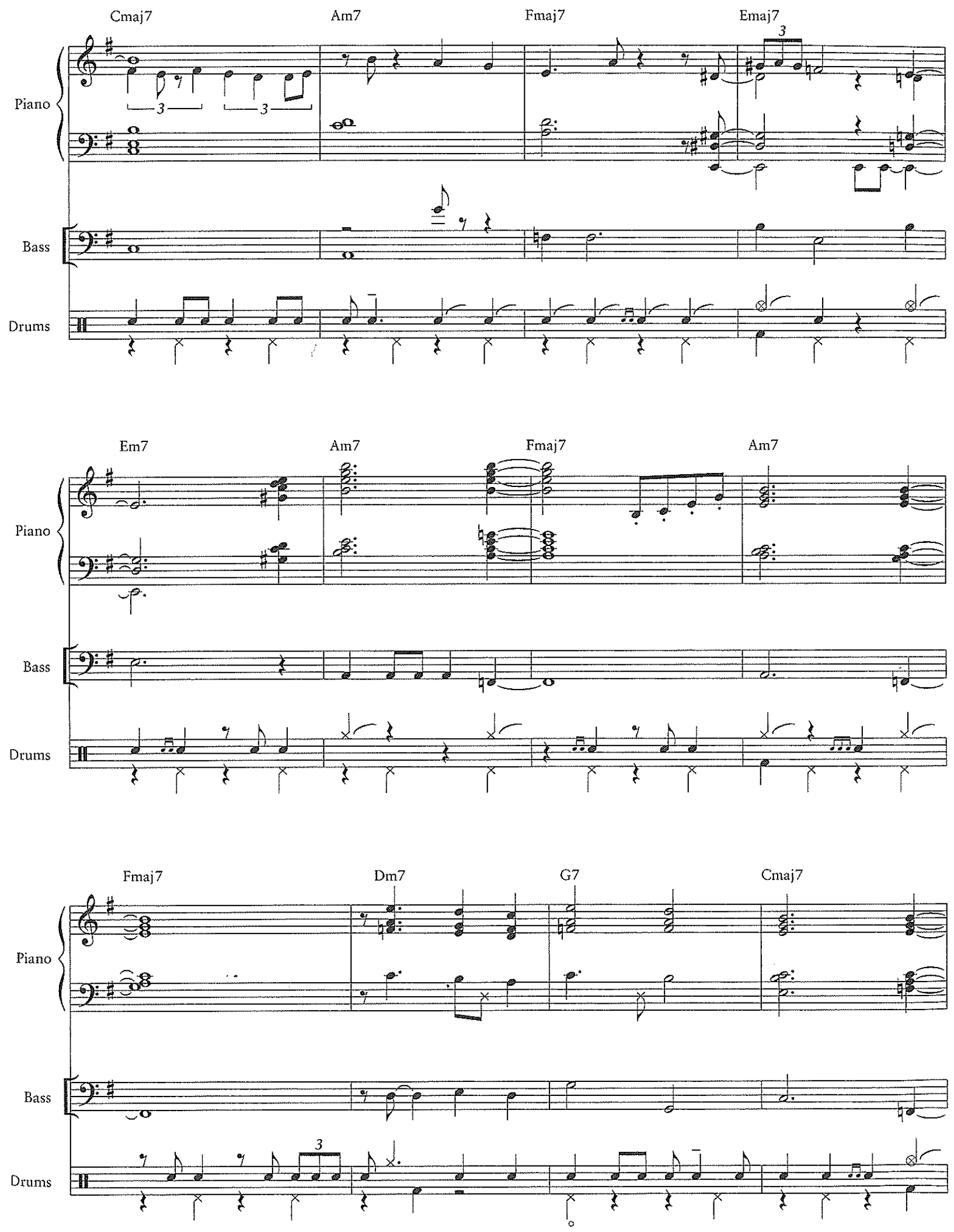

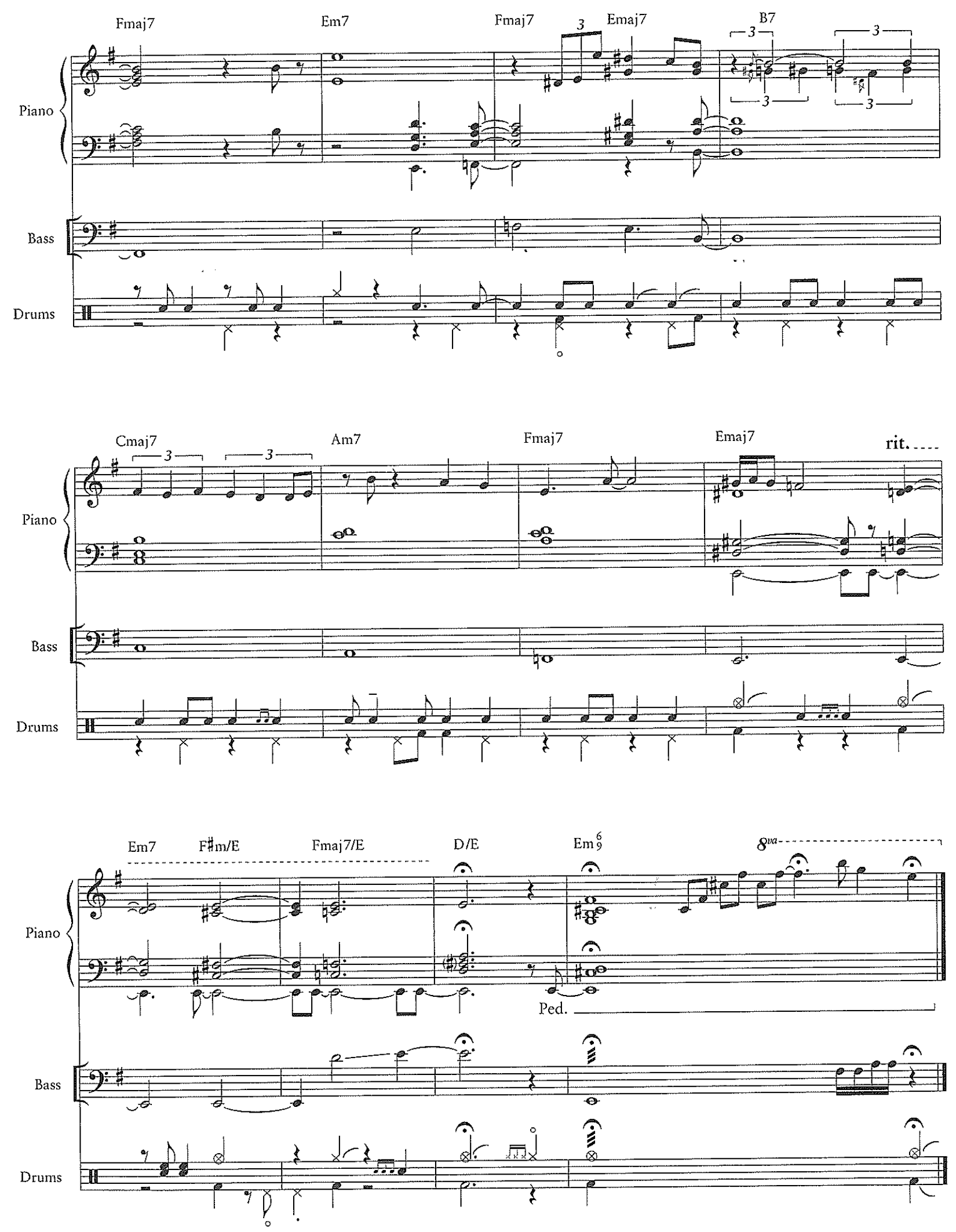

86

192 
5: Gloria's Step - Transcriptions taken from Orpheum Music. GLORIA's STEP IMPROVISATION. 1961. \&

Laird, Adrian. Gloria’s Step(Take 2). 2012. 

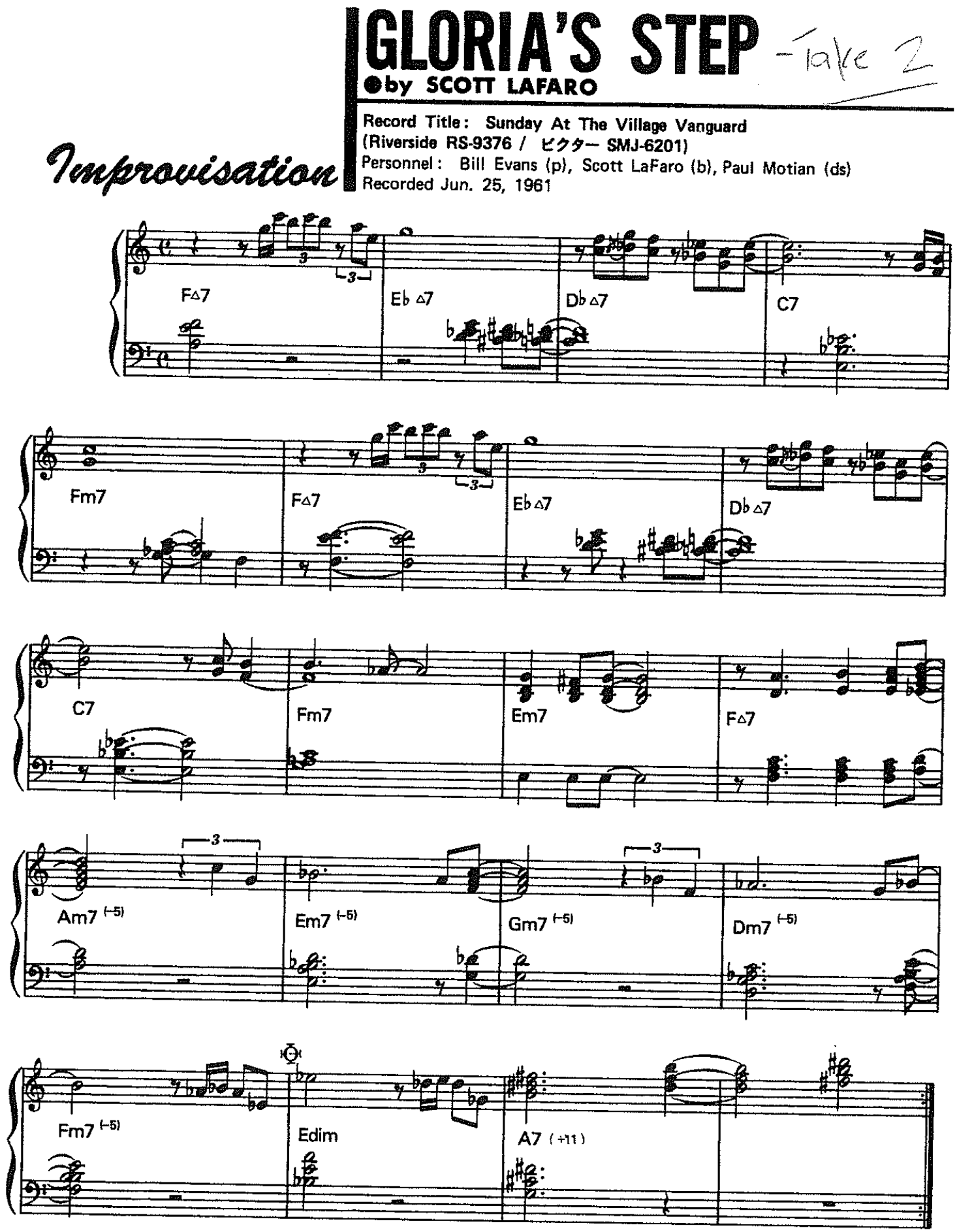

Copyright $@ 1961$ by Orphoum Music.

Rights for Japan assigned to TOSHIBA.EMI MUSIC PUBLISHING CO., LTD. 

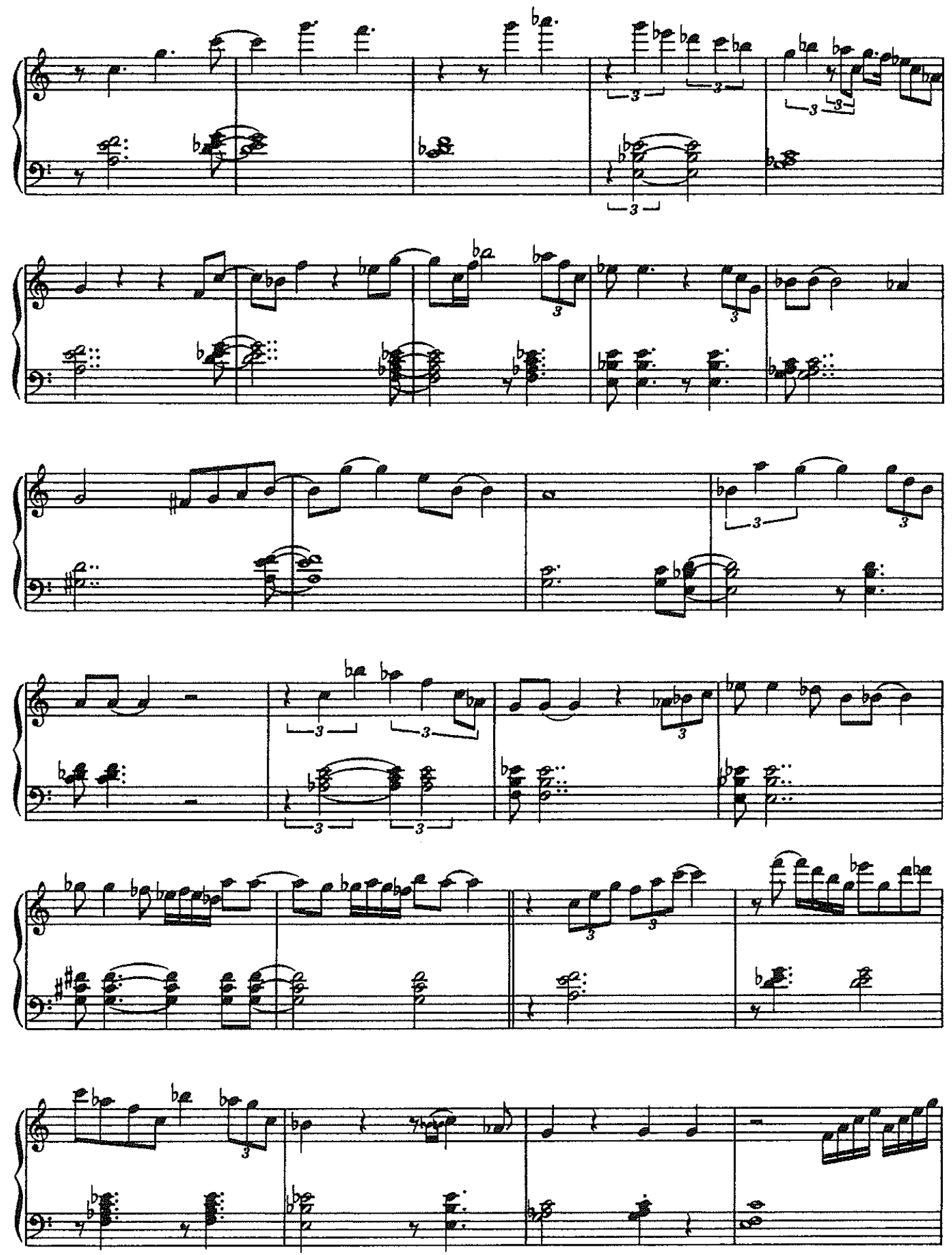

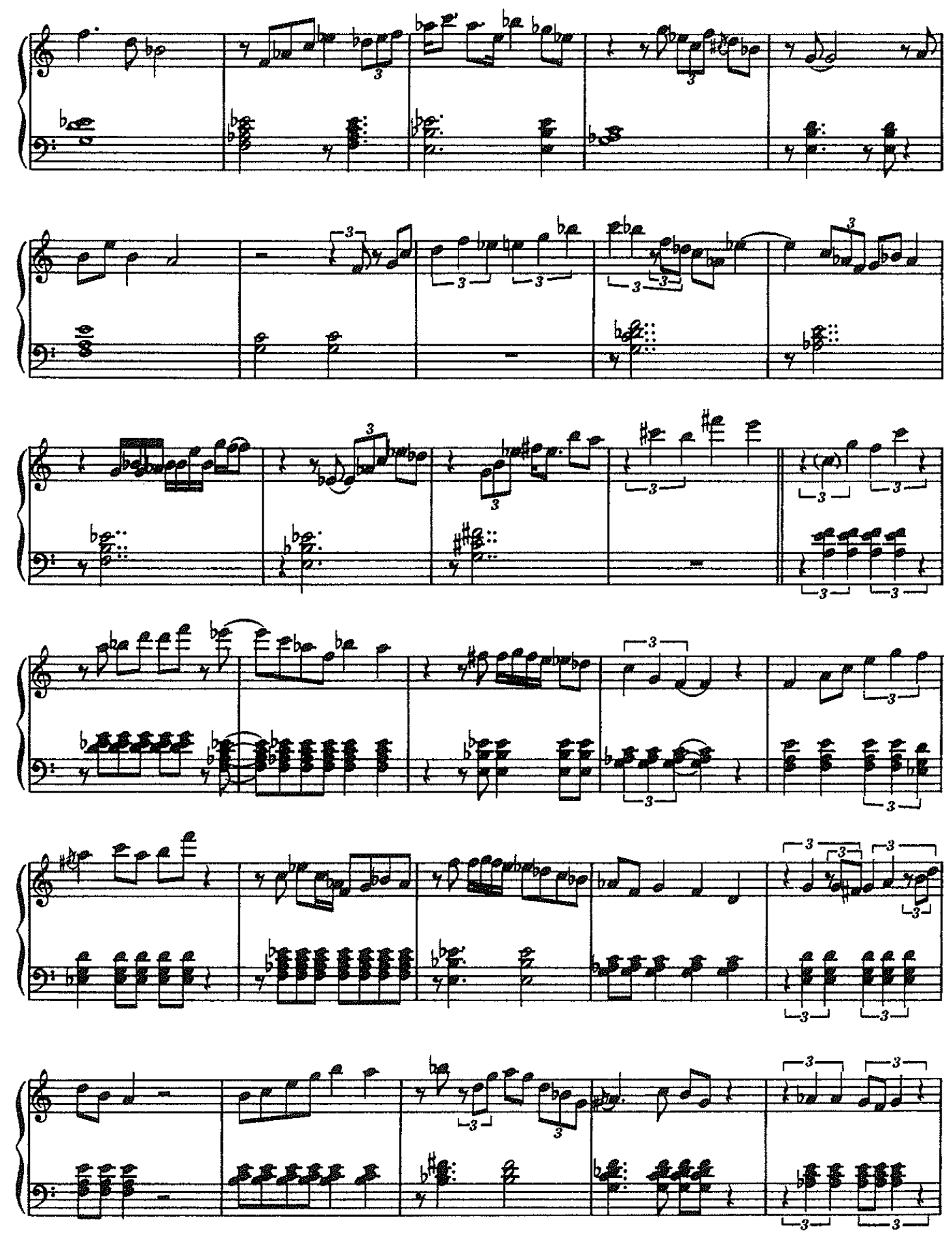

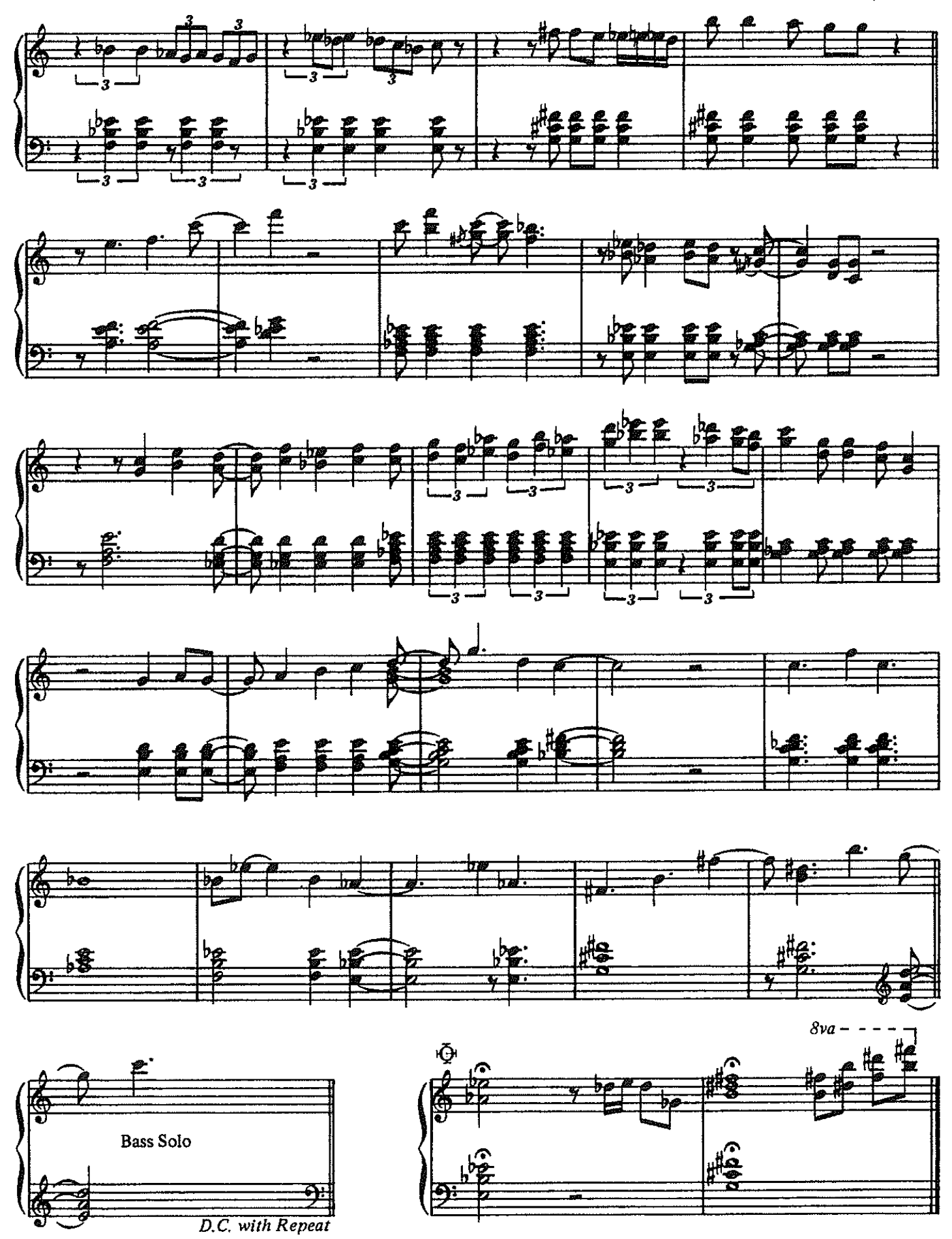
Gloria's Step (Take 2)

As Played by Scott LaFaro on "Sunday at the Village Vanguard" (1961)

. $=160$ Medium Up Swing

Scott LaFaro

$\begin{array}{llllll}F \Delta 7 & E^{b \Delta 7} & 0 \Delta 7 & D^{b \Delta 7} & C^{7}\left(\frac{199}{99}\right. & \text { F-7 }\end{array}$


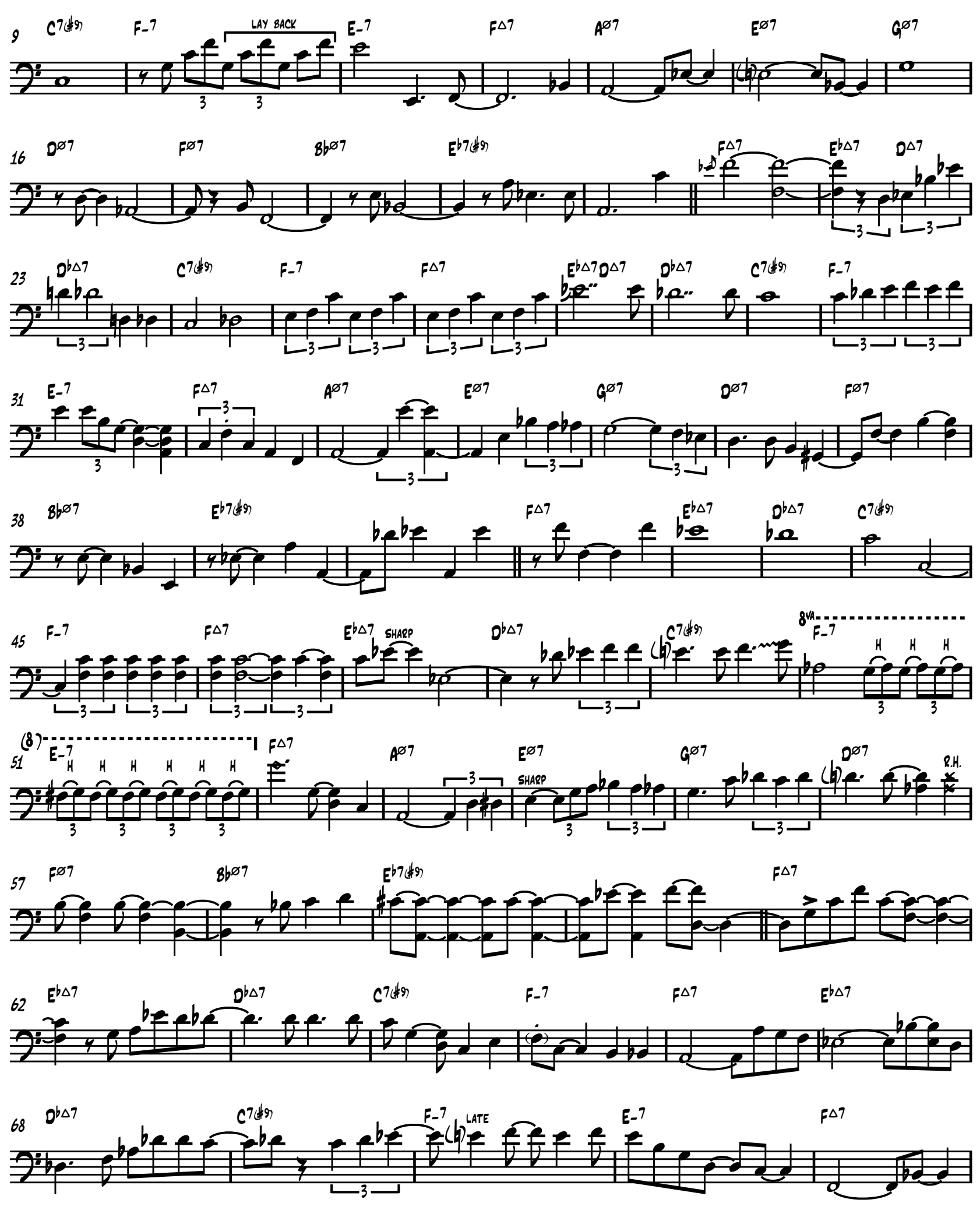

Copyright Adrian Laird $\odot 2012$

198 
2 73 A67 80 RUSHEO

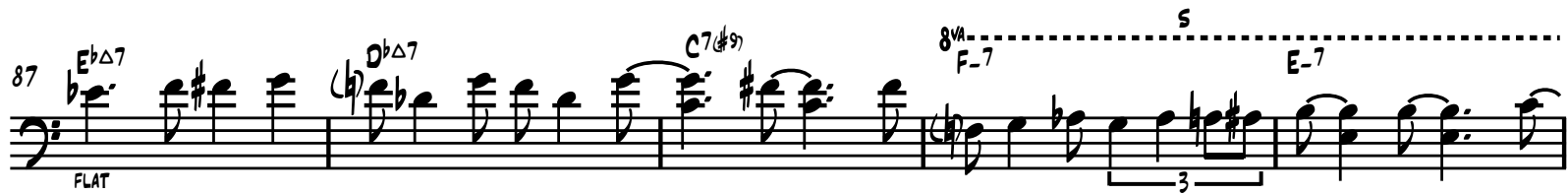
(8) 99 Eb7(\$9) LET RING-_....-1

$105^{F-7}$ 111 SHARP $17^{507}$ (8)

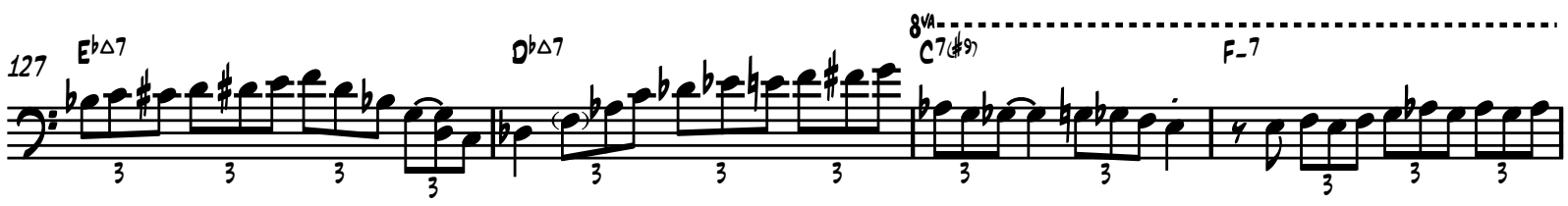

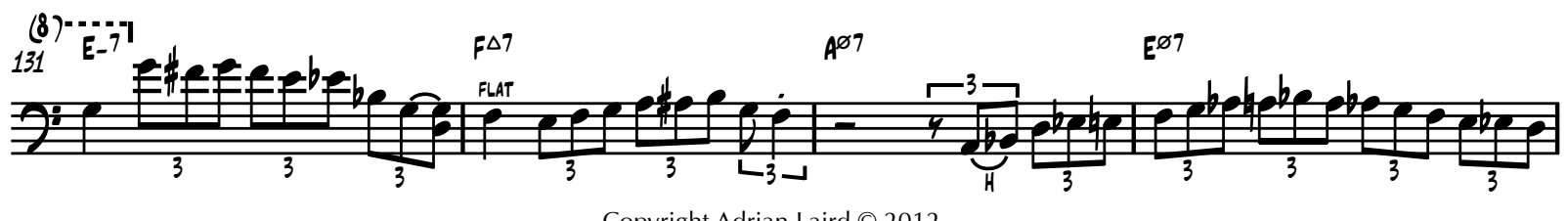




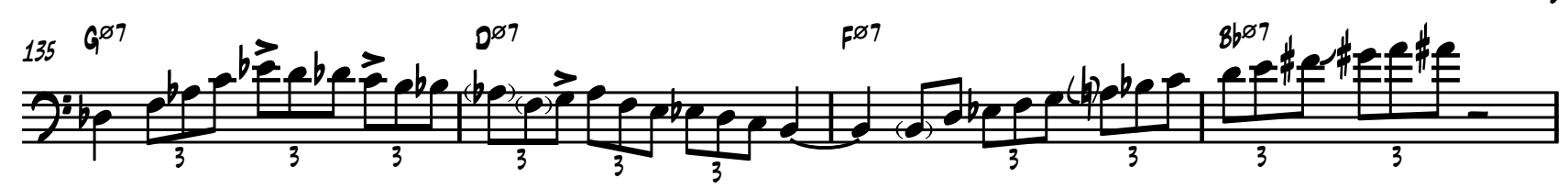

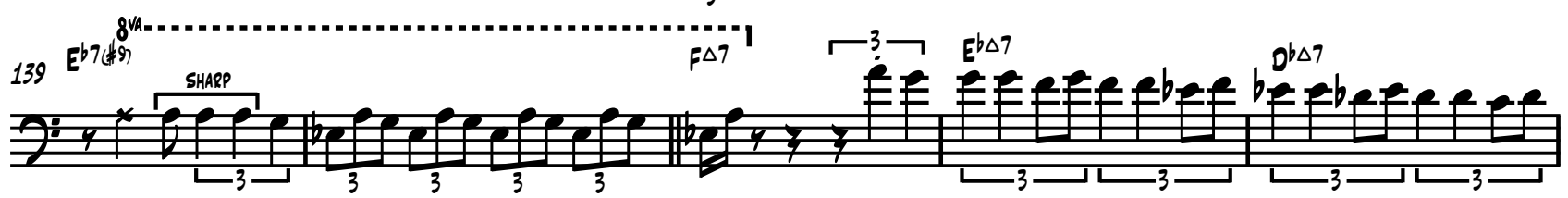
(4)

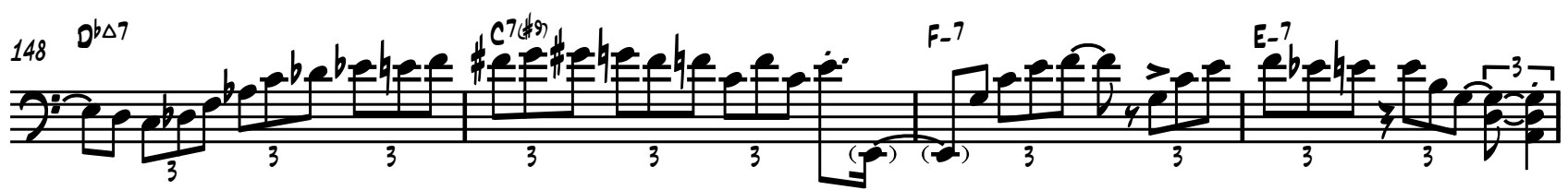
120,

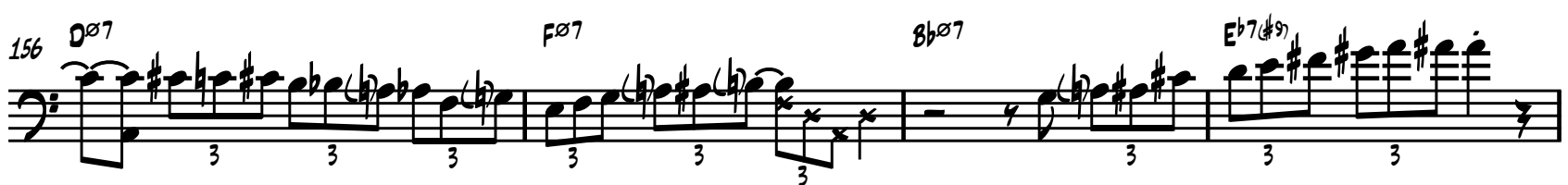
10. 等

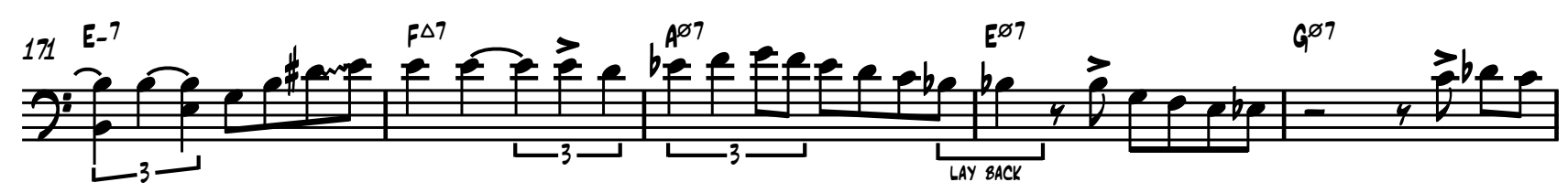

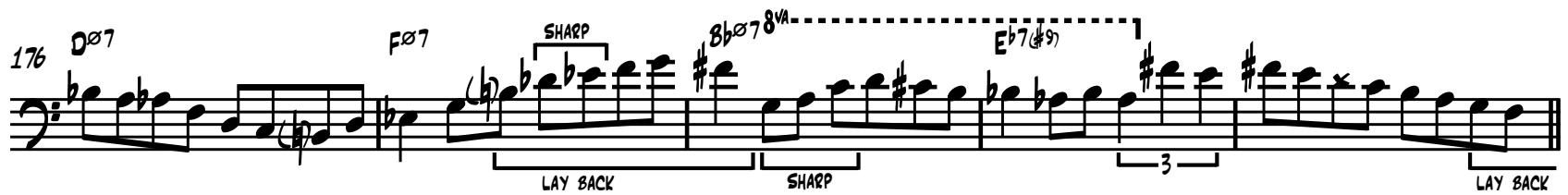
IIt) 


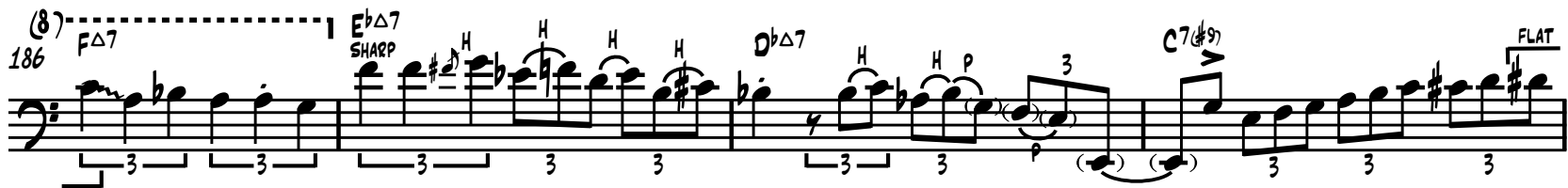
$1900_{3}^{F_{-7}{ }_{\text {LA }}^{8 A C K}{ }_{3}}$ $194{ }_{3}^{\text {EUSHEO }}$ ${ }_{3}^{1988^{8 \mathrm{Ba}}}$ $2044^{C^{749}}$ 211

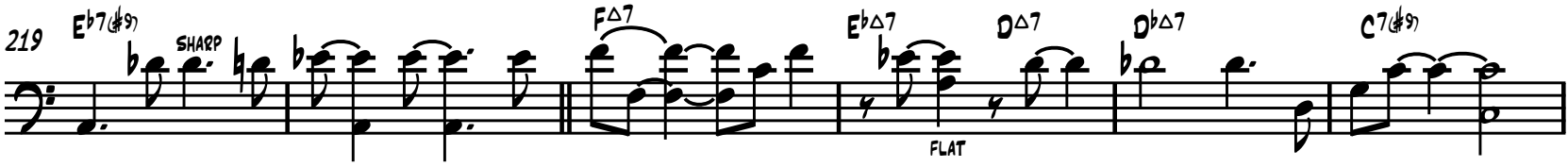
${ }_{225}$ ${ }_{231}^{2-7}$

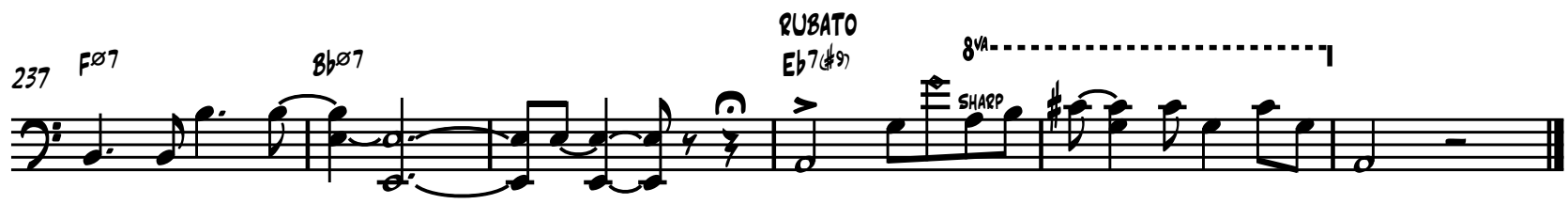




\section{APPENDIX 3 - RECORDINGS}

\section{Recorded at the New Zealand School of Music - March 13th 2014}

\section{DVD TRACKLISTING:}

1 - Alice In Wonderland (Fain/Hilliard)

2 - Gloria's Step (LaFaro)

3 - Up Jumped Spring (Hubbard)

4 - Autumn Leaves (Kosma)

5 - Solar (Davis)

6 - In A Silent Way (Zawinul)

7 - Circle (Davis)

8 - Nefertiti (Shorter)

9 - Nardis (Davis) / In A Silent Way - Reprise (Zawinul)

10 - Jade Visions (LaFaro)

\section{PERSONNEL:}

Anita Schwabe - Piano

Rowan Clark - Bass

Roger Sellers - Drums

with

Alexis French - Trumpet

Christopher Buckland - Tenor Saxophone 
